Aus der Klinik für Nephrologie und Rheumatologie

(Prof. Dr. med. G. A. Müller)

der Medizinischen Fakultät der Universität Göttingen

\title{
Die Rolle des FK506 bei der Expression des BMP- Rezeptors BMPR1A
}

\author{
INAUGURAL - DISSERTATION \\ zur Erlangung des Doktorgrades \\ für Zahnheilkunde \\ der Medizinischen Fakultät der \\ Georg-August-Universität zu Göttingen
}

vorgelegt von

Friederike Klöpper

aus

Hildesheim

Göttingen 2016 
Dekan:

I. Berichterstatter:

II. Berichterstatter:

III. Berichterstatter:

Tag der mündlichen Prüfung:
Prof. Dr. rer. nat. H. K. Kroemer

Prof. Dr. med. M. Zeisberg

PD Dr. Dr. med. A. Neeße

Prof. Dr. med. dent. R. Mausberg

24.04.2017 
Hiermit erkläre ich, die Dissertation mit dem Titel "Die Rolle des FK506 bei der Expression des BMP-Rezeptors BMPR1A" eigenständig angefertigt und keine anderen als die von mir angegebenen Quellen und Hilfsmittel verwendet zu haben.

Göttingen, den .................. 


\section{INHALTSVERZEICHNIS}

INHALTSVERZEICHNIS .1

ABBILDUNGSVERZEICHNIS .. V

TABELLENVERZEICHNIS .VII

ABKÜRZUNGSVERZEICHNIS VIII

1.

EINLEITUNG. 1

1.1 Chronisch progrediente Niereninsuffizenz. 1

1.1.1 Ätiologie der chronischen und terminalen Niereninsuffizienz .......................................... 2

1.1.2 Epidemiologische und sozioökonomische Aspekte ......................................................... 2

1.1.3 Klinischer Verlauf der chronischen Niereninsuffizienz ..................................................... 3

1.1.4 Therapie der chronischen Niereninsuffizienz ................................................................. 4

1.2 Pathophysiologie der chronischen Niereninsuffizienz ................................................... 4

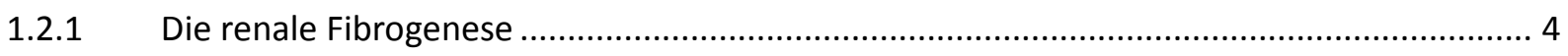

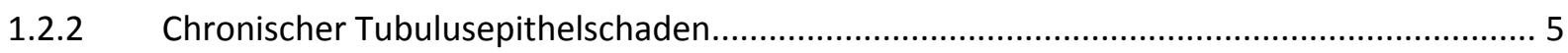

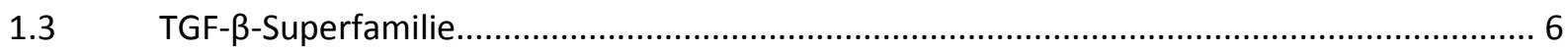

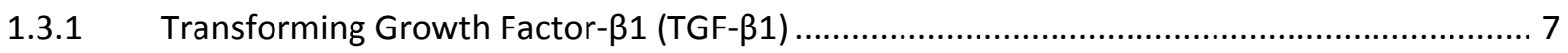

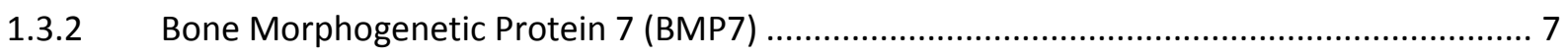

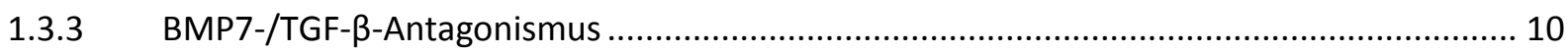

1.3.4 Bone Morphogenetic Protein Receptor 1A (BMPR1A) ................................................ 12

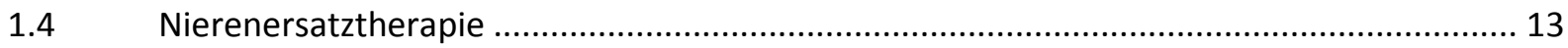

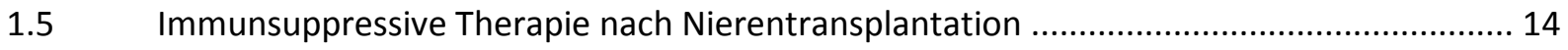

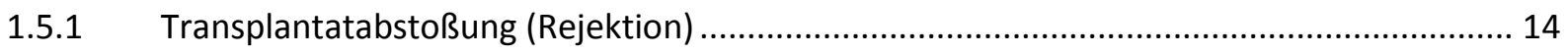

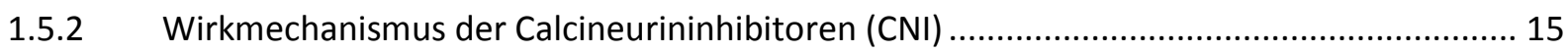

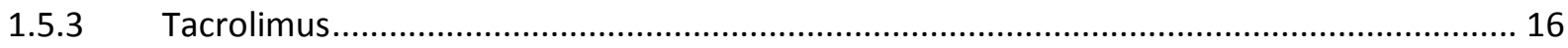

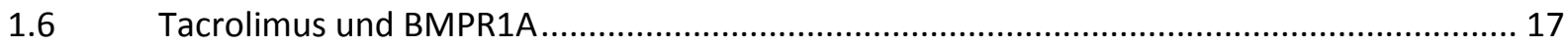

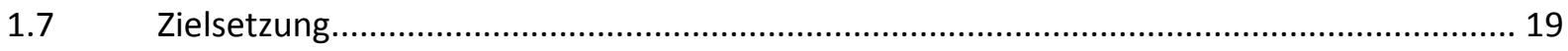

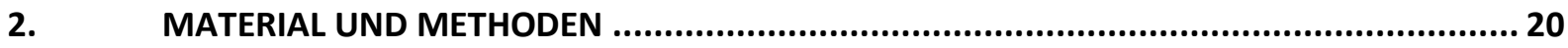




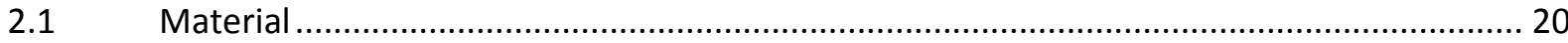

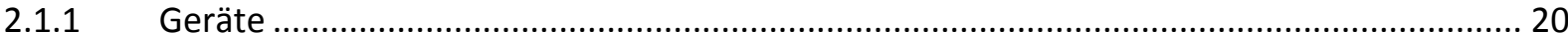

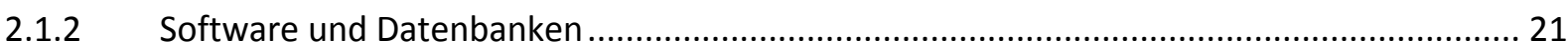

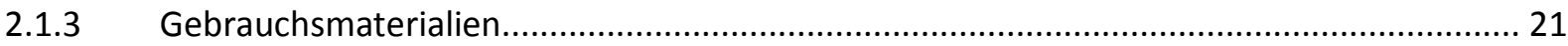

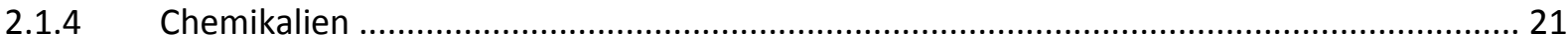

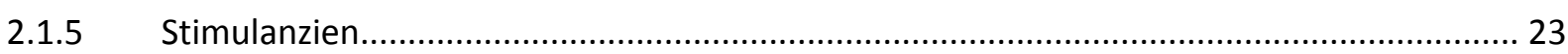

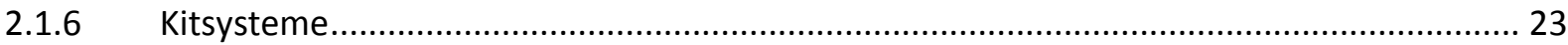

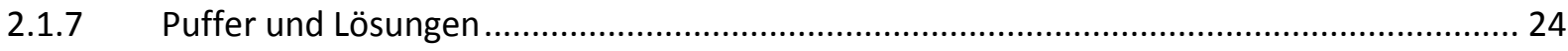

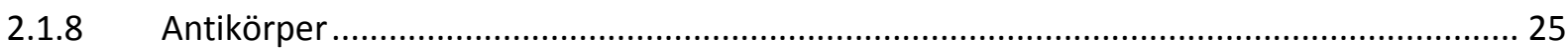

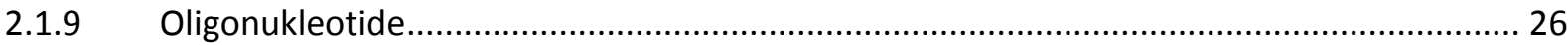

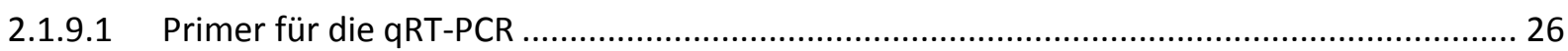

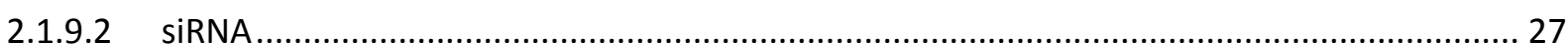

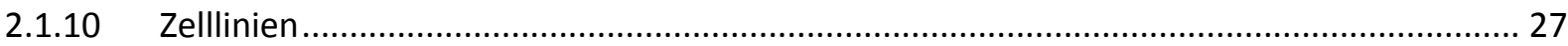

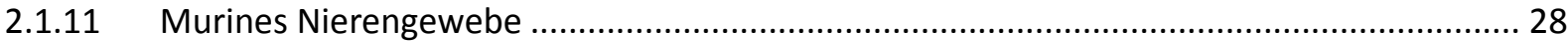

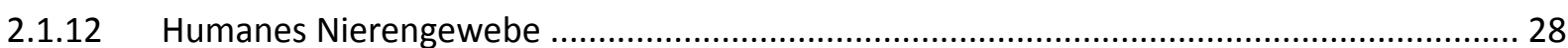

$2.2 \quad$ Methoden

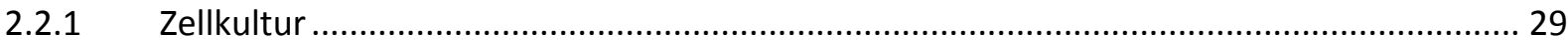

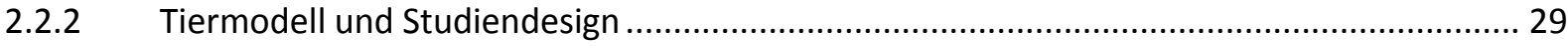

2.2.3 Enzym-gekoppelter Immunadsorptionstest (ELISA) ....................................................... 30

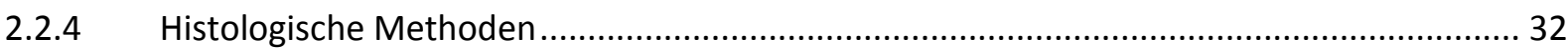

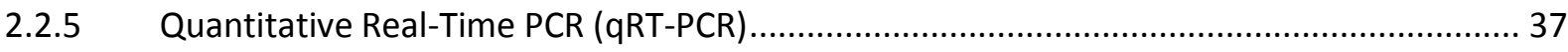

2.2.6 $\quad \mathrm{RT}^{2}$ Profiler ${ }^{\mathrm{TM}}$ PCR-Array Human Transcription Factors ..................................................... 41

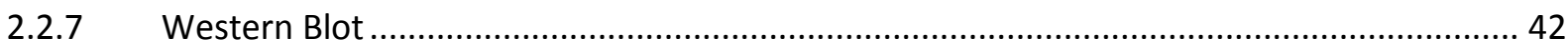

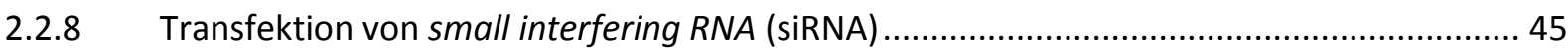

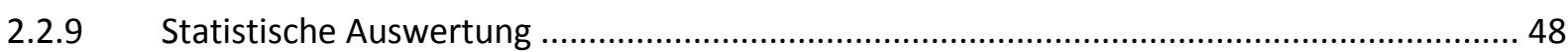

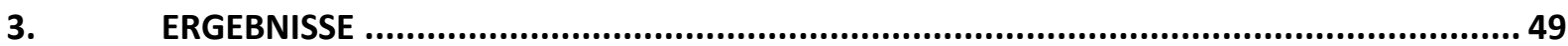

3.1 Induktion des BMP7-Rezeptors BMPR1A nach FK506-Supplementation in vitro................. 49

3.1.1 Selektiv vermehrte Expression des BMPR1A unter FK506-Exposition in HK-2-Zellen.......... 49

3.1.2 Effekt immunsuppressiver Substanzen auf die Regulation der BMP7-Rezeptoren BMPR1B

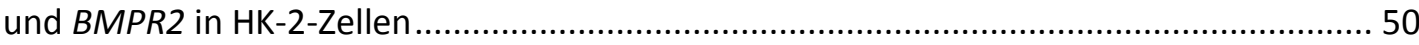

3.2 Spezifische FK506-abhängige Induktion des Bmpr1a in vivo ............................................. 51

3.2.1 Vermehrte Expression des Bmpr1a im Mausmodell der unilateralen Ureterobstruktion ... 51

3.2.2 Verminderte Expression der Bmpr1b- und Bmpr2-Rezeptoren nach unilateraler Ureter-

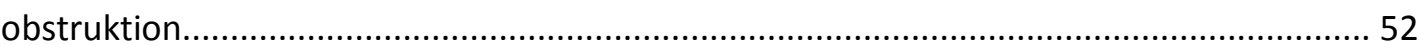

3.2.3 FK506-abhängige Bmpr1a-Induktion in Assoziation mit aktivierter Smad1/5/8-Signaltransduktionskaskade. 
3.2.4 Einfluss der FK506-Exposition auf die Expression des Bmpr1a- und der pSmad1/5/8 Proteine in sham-operierten Nieren

3.3 Milderung der experimentellen renalen Fibrogenese in vivo mittels FK506-assoziierter

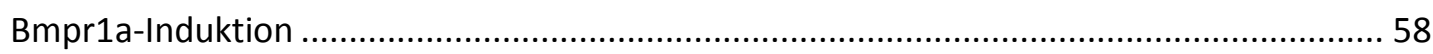

3.3.1 Effekt der FK506-Exposition auf die Histologie scheinoperierter Nieren ............................ 61

3.4 Pikomolarer FK506-Vollblutspiegel in FK506-supplementierten UUO-Mäusen ................... 63

3.5 FK506-vermittelte BMPR1A-Induktion in vitro durch De-novo-Translation unbekannter Transkriptionsfaktoren

3.6 Detektion FK506-induzierter Transkriptionsfaktoren in vitro mittels $\mathrm{RT}^{2}$ Profiler $^{\mathrm{TM}}$ PCR-

Arrays 66

3.7 Validierung der ermittelten Transkriptionsfaktoren in vivo 68

3.8 Induktion des Bmpr1a und der pSmad1/5/8-Proteine unter FK506-Exposition in MCT-

Zellen 69

3.9 Validierung der ermittelten Transkriptionsfaktoren in vitro...... 70

3.10 Spezifisches Gene Silencing der putativen Transkriptionsfaktoren in vitro......................... 71

3.10.1 Effizienz des Gene Silencings in MCT-Zellen ................................................................ 71

3.10.2 Expression des Bmpr1a unter FK506-Exposition nach Gene Silencing in MCT-Zellen.......... 72

3.11 Validierung des Transkriptionsfaktors Arnt in vitro und in vivo ........................................... 73

3.11.1 Vermehrte Expression von Arnt nach FK506-Stimulation in MCT-Zellen ............................ 73

3.11.2 Vermehrte Expression von Arnt nach FK506-Applikation in UUO-Nieren............................ 74

3.12 Validierung der FK506-vermittelten ARNT-, BMRR1A- und pSMAD1/5/8-Induktion in

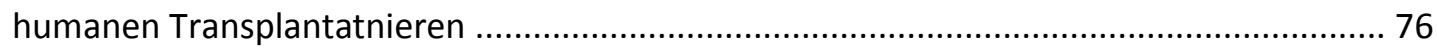

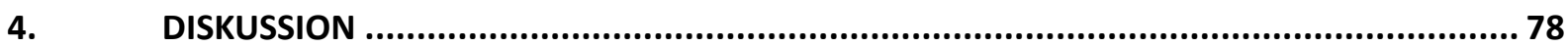

4.1 Quantitative Effektivitätsanalysen unter FK506-Exposition im Nierenparenchym .............. 78

4.1.1 Spezifische Induktion des BMP7-Rezeptors BMPR1A nach FK506-Supplementation........... 78

4.1.2 Milderung der experimentellen renalen Fibrogenese in vivo mittels FK506-assoziierter

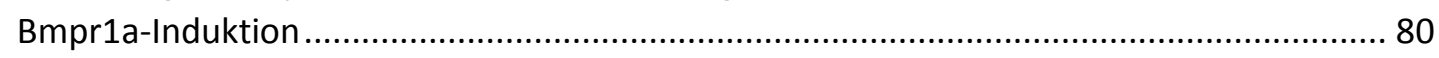

4.1.3 Methodische Differenzen und Limitationen ................................................................ 82

4.2 Charakterisierung molekularer Induktionsmechanismen .................................................. 83

4.2.1 FK506-modulierte BMPR1A-Induktion durch De-novo-Synthese von ARNT ....................... 83

4.2.2 Postulat der transkriptionellen ARNT-Aktivierung durch FK506-Mediation ......................... 85

4.3 Potentielle klinische Relevanz der FK506-vermittelten BMPR1A-Induktion........................ 89 
4.3.1 Übertragbarkeit generierter In-vivo-Resultate in einen klinischen Kontext .....................89

4.3.2 Ausblick und mögliche Therapieoptionen .......................................................... 90

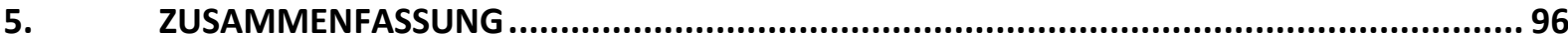

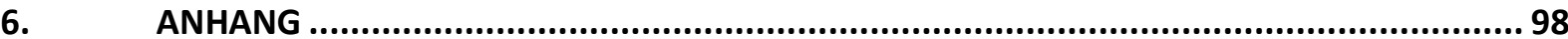

6.1 Genontologie-Analyse mittels webbasierter Datenbanken........................................ 98

6.2 Vollständige unbearbeitete Western Blot-Gele ...................................................... 100

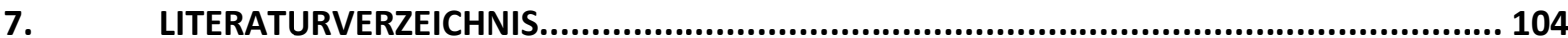




\section{ABBILDUNGSVERZEICHNIS}

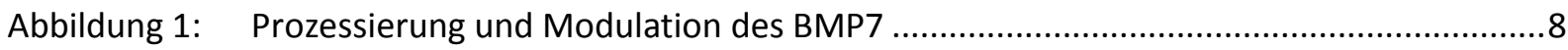

Abbildung 2: Schematische Übersicht antagonisierender Signalwege von BMP7 und TGF- $\beta$......... 11

Abbildung 3: Wirkmechanismus der Calcineurininhibitoren ......................................................... 15

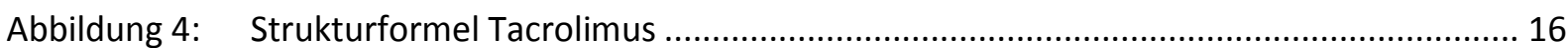

Abbildung 5: BMPR1A-Induktion in Nierentransplantatpatienten unter FK506-Therapie-

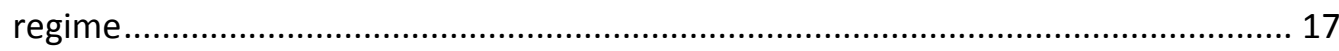

Abbildung 6: $\quad$ RT $^{2}$ Profiler ${ }^{\mathrm{TM}}$ PCR-Array Human Transcription Factors (PAHS-075Z) .......................... 41

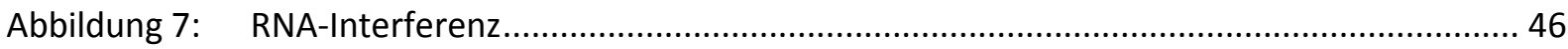

Abbildung 8: Selektiv vermehrte Expression des BMPR1A in vitro unter FK506-Exposition auf Transkriptionsebene.

Abbildung 9: Selektiv vermehrte Expression des BMPR1A in vitro unter FK506-Exposition auf Proteinebene

Abbildung 10: Immunsuppressive Substanzen in vitro ohne Effekt auf die Regulation der BMP7Rezeptoren BMPR1B und BMPR2. 51

Abbildung 11: Spezifische FK506-abhängige Induktion des Bmpr1a in UUO-Nieren 53

Abbildung 12: Assoziation der FK506-abhängigen Bmpr1a-Induktion mit konsekutiv aktivierter Smad1/5/8-Signaltransduktionskaskade in UUO-Nieren

Abbildung 13: FK506-Exposition ohne Einfluss auf die Bmpr1a- und pSmad1/5/8-Expression in sham-Nieren

Abbildung 14: Milderung der experimentellen renalen Fibrogenese mittels FK506-assoziierter Bmpr1a-Induktion im histopathologischen Korrelat der UUO-Niere.

Abbildung 15: Milderung der experimentellen renalen Fibrogenese in vivo durch FK506assoziierte Bmpr1a-Induktion auf Transkriptionsebene.

Abbildung 16: FK506-Exposition ohne Effekt auf die Histologie scheinoperierter Nieren.

Abbildung 17: Pikomolarer FK506-Vollblutspiegel in FK506-supplementierten Versuchstieren

Abbildung 18: FK506-vermittelte BMPR1A-Induktion in vitro basiert auf der De-novoTranslation unbekannter Transkriptionsfaktoren .....

Abbildung 19: Detektion FK506-induzierter Transkriptionsfaktoren in vitro mittels $\mathrm{RT}^{2}$ Profiler $^{\mathrm{TM}}$ PCR-Arrays

Abbildung 20: FK506-modulierte Induktion der Kandidatengene Max und Arnt in UUO-Nieren...... 68

Abbildung 21: Induktion des Bmpr1a und der pSmad1/5/8-Proteine in FK506-supplementierten MCT-Zellen.

Abbildung 22: FK506-modulierte Induktion der putativen Transkriptionsfaktoren in vitro. 
Abbildung 23: Effizienz des Gene Silencings in vitro

Abbildung 24: siRNA-vermitteltes Arnt-Silencing evoziert in vitro die Suppression der Bmpr1aExpression nach initialer FK506-Stimulation

Abbildung 25: Vermehrte Arnt-Expression unter FK506-Exposition in vitro und in vivo im UUOModell.

Abbildung 26: Vermehrte Arnt-Expression unter FK506-Exposition in vivo im UUO-Modell. 75

Abbildung 27: ARNT- und BMPR1A-Induktion mit konsekutiver pSMAD1/5/8-Aktivierung in humanen Transplantatnieren unter FK506-Therapie.

Abbildung 28: (A) FKBP12-Interaktionsnetzwerk (B) FK506-modulierte Gene

Abbildung 29: Hypothetischer BMPR1A-Induktionsmechanismus durch FK506-Mediation .... 88

Abbildung 30: Systembiologische Datenanalyse in humanen Transplantatnieren

Abbildung 31: Inverse Korrelation von BMPR1A und FKBP12/YY1 in verschiedenen Nierenerkrankungen.

Abbildung 32: BMPR1A- und GAPDH-Expression in HK-2-Zellen nach pharmakologischer Präkonditionierung.

Abbildung 33: Expression der Bmp-Rezeptoren und Haushaltsgene in vivo 100

Abbildung 34: pSmad1/5/8- und Gapdh-Expression in vivo 101

Abbildung 35: BMPR1A- und GAPDH-Expression in HK-2-Zellen nach CycloheximidPräinkubation

Abbildung 36: Bmpr1a-, pSmad1/5/8- und Gapdh-Expression in MCT-Zellen nach FK506-Präkonditionierung

Abbildung 37: Bmpr1a- und Gapdh-Expression in MCT-Zellen nach RNAi-basiertem Silencing und FK506-Präkonditionierung.

Abbildung 38: Arnt- und Gapdh-Expression in MCT-Zellen nach FK506-Präkonditionierung ........... 103

Abbildung 39: Arnt- und Gapdh-Expression in vivo 103 


\section{TABELLENVERZEICHNIS}

Tabelle 1: $\quad$ Anwendungsbeispiel zur Nomenklatur von Gensymbolen ......................................... X

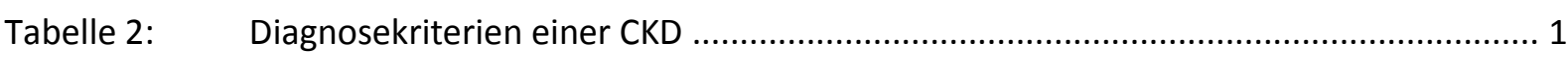

Tabelle 3: Tacrolimus-Zielspiegel nach Nierentransplantation.................................................. 16

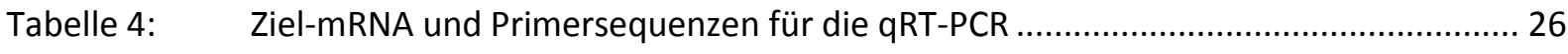

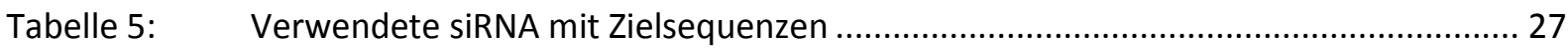

Tabelle 6: Kohorte von Nierentransplantierten mit klinischen und histologischen Charakte-

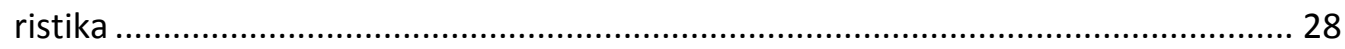

Tabelle 7: $\quad$ Zellkulturmedien und Enzymlösungen der einzelnen Zelllinien.................................. 29

Tabelle 8: $\quad$ Angestrebte FK506-Medikamentendosis pro Maus sowie FK506-Konzentration im Trinkwasser.............................................................................................. 30

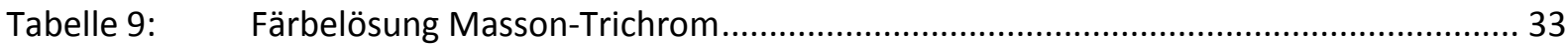

Tabelle 10: Verwendete Antikörper der Immunhistochemie ....................................................... 34

Tabelle 11: Verwendete Antikörper der Immunfluoreszenz in murinen Gewebeproben .............. 35

Tabelle 12: Stimulationsschema von HK-2-Zellen für qRT-PCR und Western Blot ....................... 37

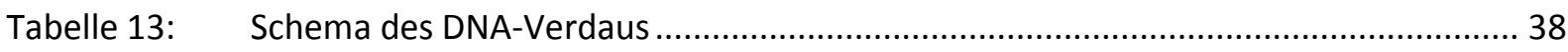

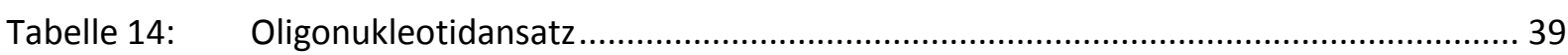

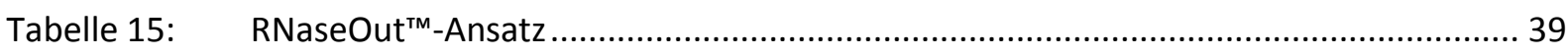

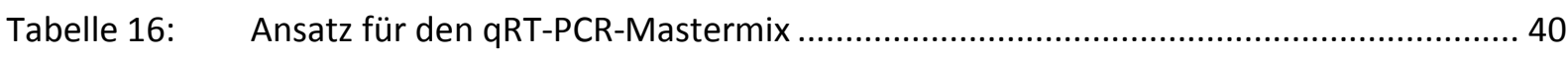

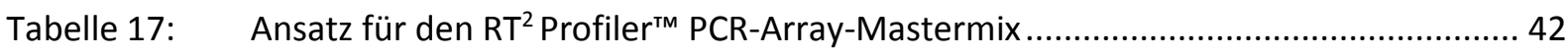

Tabelle 18: Verwendete Antikörper für den Western Blot ............................................................ 45

Tabelle 19: Inverse Korrelation zwischen ARNT und FKBP12/YY1 in humanen

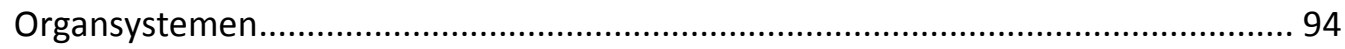

Tabelle 20: GEO-Zugangsdaten und korrespondierende Publikationen...................................... 99 


\section{ABKÜRZUNGSVERZEICHNIS}

Nicht gesondert aufgeführt sind die im deutschen Sprachgebrauch üblichen Standardabkürzungen.

\begin{tabular}{|c|c|c|c|}
\hline ACTA2 & $\begin{array}{l}\text { actin, alpha } 2 \text { smooth muscle, } \\
\text { aorta (Genname von } \alpha \mathrm{SMA} \text { ) }\end{array}$ & $\begin{array}{l}\text { CTFG } \\
\Delta \mathrm{CT} / \Delta \Delta \mathrm{CT}\end{array}$ & $\begin{array}{l}\text { connective tissue growth factor } \\
\text { delta-CT/delta delta-CT }\end{array}$ \\
\hline $\begin{array}{l}\text { ACTB } \\
\text { ACTR }\end{array}$ & $\begin{array}{l}\text { beta-actin } \\
\text { activin A receptor }\end{array}$ & CYP3A4/5 & $\begin{array}{l}\text { cytochrome P450, family } 3, \\
\text { subfamily A, polypeptide } 4 / \text { poly- } \\
\text { peptide } 5\end{array}$ \\
\hline AEC & 3-Amıno-9-ethylcarbazol & DAPI & 4',6-Diamidin-2-phenylindol \\
\hline ALK & activin receptor-like kinase & DGfN & $\begin{array}{l}\text { Deutsche Gesellschaft für } \\
\text { Nephrologie }\end{array}$ \\
\hline $\begin{array}{l}\text { AR } \\
\text { ARNT }\end{array}$ & $\begin{array}{l}\text { androgen receptor } \\
\text { aryl hydrocarbon receptor nuclear }\end{array}$ & DSO & $\begin{array}{l}\text { Deutsche Stiftung Organtrans- } \\
\text { plantation }\end{array}$ \\
\hline$\alpha S M A$ & $\begin{array}{l}\text { translocator } \\
\text { alpha smooth muscle actin } \\
\text { (Genname: ACTA2) }\end{array}$ & $\mathrm{dd}_{2} \mathrm{O}$ & $\begin{array}{l}\text { Deutsche } \\
\text { Transplantationsgesellschaft } \\
\text { bidestilliertes Wasser }\end{array}$ \\
\hline Bis-Tris & $\begin{array}{l}\text { Bis(2-hydroxyethyl)amino- } \\
\text { tris(hydroxymethyl)methan }\end{array}$ & DMEM & $\begin{array}{l}\text { Dulbecco's Modified Eagle's } \\
\text { Medium }\end{array}$ \\
\hline bHLH & basic helix-loop-helix & DMSO & Dimethylsulfoxid \\
\hline $\begin{array}{l}\text { BLAST } \\
\text { BMP7 }\end{array}$ & $\begin{array}{l}\text { Basic Local Alignment Search Tool } \\
\text { bone morphogenetic protein } 7\end{array}$ & DNA & $\begin{array}{l}\text { Desoxyribonukleinsäure } \\
\text { (deoxyribonucleic acid) }\end{array}$ \\
\hline BMPR & $\begin{array}{l}\text { bone morphogenetic protein } \\
\text { receptor } \\
\text { Basenpaare }\end{array}$ & $\begin{array}{l}\text { dNTP } \\
\text { EDTA }\end{array}$ & $\begin{array}{l}\text { Desoxyribonukleosidtriphosphat } \\
\text { Ethylendiamintetraessigsäure } \\
\text { (ethylene diamine tetraacetic acid) }\end{array}$ \\
\hline BSA & $\begin{array}{l}\text { Rinderserumalbumin } \\
\text { (bovine serum albumin) } \\
\text { Grad Celsius }\end{array}$ & ELISA & $\begin{array}{l}\text { Enzym-gekoppelter Immun-- } \\
\text { adsorptionstest (enzyme-linked } \\
\text { immunosorbent assay) }\end{array}$ \\
\hline $\begin{array}{l}\mathrm{C}_{0} \\
\text { CDNA }\end{array}$ & $\begin{array}{l}\text { Talspiegel } \\
\text { komplementäre DNA } \\
\text { (complementary DNA) }\end{array}$ & ELITE & $\begin{array}{l}\text { Efficacy Limiting Toxicity } \\
\text { Elimination } \\
\text { epithelial-mesenchymale }\end{array}$ \\
\hline CEBPB & $\begin{array}{l}\text { CCAAT/enhancer binding protein } \\
(C / E B P) \text {, beta }\end{array}$ & ESRD & $\begin{array}{l}\text { Transition } \\
\text { terminales Nierenversagen }\end{array}$ \\
\hline CKD & $\begin{array}{l}\text { chronisch progrediente Nieren- } \\
\text { insuffizienz (chronic kidney disease) }\end{array}$ & $\mathrm{EtOH}$ & $\begin{array}{l}\text { (end-stage renal disease) } \\
\text { Ethanol }\end{array}$ \\
\hline $\mathrm{CN}$ & Calcineurin & FK506 & Tacrolimus \\
\hline $\begin{array}{l}\text { CNI } \\
\text { COLLAGEN-1A1 }\end{array}$ & $\begin{array}{l}\text { Calcineurininhibitor } \\
\text { collagen type I alpha } 1 \text { chain }\end{array}$ & FKBP & $\begin{array}{l}\text { FK506-Bindeprotein } \\
\text { (FK506-binding protein) }\end{array}$ \\
\hline Co-SMAD & common-mediator SMAD & FSGS & $\begin{array}{l}\text { fokal-segmentale Glomerulo- } \\
\text { sklerose }\end{array}$ \\
\hline CREB1 & $\begin{array}{l}\text { CAMP responsive element binding } \\
\text { protein } 1\end{array}$ & FSP1 & fibroblast-specific protein 1 \\
\hline CsA & Cyclosporin A & GAPDH & $\begin{array}{l}\text { glyceraldehyde-3-phosphate } \\
\text { dehydrogenase }\end{array}$ \\
\hline $\mathrm{Ct}$ & th & GATA3 & GATA binding protein 3 \\
\hline
\end{tabular}




\begin{tabular}{|c|c|c|c|}
\hline GFR & glomeruläre Filtrationsrate & NFW & nukleasefreies Wasser \\
\hline$H-2^{S}$ & MHC Haplotyp H2s & PAI-1 & plasminogen activator inhibitor-1 \\
\hline HE & Hämatoxylin-Eosin & PAS & PER-ARNT-SIM \\
\hline HIF-1 & hypoxia inducible factor 1 & PAS & Perjodsäure-Schiff-Reaktion \\
\hline HK-2 & human kidney-2 & & \\
\hline \multirow[t]{2}{*}{ HOPE } & $\begin{array}{l}\text { Hepes-glutamic acid buffer } \\
\text { mediated Organic solvent }\end{array}$ & PBS & $\begin{array}{l}\text { phosphatgepufferte Kochsalzlösung } \\
\text { (phosphate-buffered saline) }\end{array}$ \\
\hline & Protection Effect & PBS-T & phosphate-buffered saline Tween \\
\hline HPLC & $\begin{array}{l}\text { High Performance Liquid } \\
\text { Chromatography }\end{array}$ & PCR & $\begin{array}{l}\text { Polymerasekettenreaktion } \\
\text { (polymerase chain reaction) }\end{array}$ \\
\hline \multirow[t]{2}{*}{ HRP } & Meerrettichperoxidase & PSMAD & phosphoryliertes SMAD \\
\hline & (horseradish peroxidase) & qRT-PCR & quantitative Real-Time PCR \\
\hline ID & inhibitor of DNA binding & rhBMP7 & rekombinantes humanes BMP7 \\
\hline IL & interleukin & RNA & Ribonukleinsäure (ribonucleic acid) \\
\hline $\lg$ & Immunoglobulin & RNAi & RNA-Interferenz \\
\hline I-SMAD & inhibitorisches SMAD & R-SMAD & regulatorisches SMAD \\
\hline kDa & Kilodalton & scrRNA & nicht-genomische siRNA \\
\hline \multirow[t]{2}{*}{ KDIGO } & Kidney Disease: Improving Global & \multirow{3}{*}{ SDS } & (scrambled siRNA) \\
\hline & Outcomes & & Natriumdodecylsulfat \\
\hline LDS & Lithiumdodecylsulfat & & (sodium dodecyl sulfate) \\
\hline MAX & MYC associated factor $X$ & SiRNA & small interfering $R N A$ \\
\hline MCT & murine tubular epithelial cells & SV40 & Affenvirus 40 (simian virus 40) \\
\hline MET & $\begin{array}{l}\text { mesenchymal-epitheliale } \\
\text { Transition }\end{array}$ & TBS & $\begin{array}{l}\text { Tris-gepufferte Kochsalzlösung } \\
\text { (Tris-buffered saline) }\end{array}$ \\
\hline MMF & Mycophenolat Mofetil & TBS-T & Tris-buffered saline Tween \\
\hline MOPS & $\begin{array}{l}\text { 3-(N-Morpholino) } \\
\text { propansulfonsäure }\end{array}$ & TGF- $\beta 1$ & $\begin{array}{l}\text { transforming growth factor- } 61 \\
\text { (Genname: TGFB1) }\end{array}$ \\
\hline mRNA & Boten-RNA (messenger RNA) & Tris & Tris(hydroxymethyl)- \\
\hline MTS & $\begin{array}{l}\text { Masson-Trichrom-Färbung } \\
\text { (Masson's trichrome stain) }\end{array}$ & TSS & $\begin{array}{l}\text { aminomethan } \\
\text { Transkriptionsstartpunkt }\end{array}$ \\
\hline \multirow[t]{2}{*}{$\mathrm{NCBI}$} & National Center for & & (transcription start site) \\
\hline & Biotechnology Information & USRDS & United States Renal Data System \\
\hline NFAT & nuclear factor of activated T-cells & UUO & unilaterale Ureterobstruktion \\
\hline \multirow[t]{2}{*}{ NF-kB } & nuclear factor of kappa light poly- & YY1 & YIN YANG 1 \\
\hline & peptide gene enhancer in B-cells 1 & ZO-1 & zonula occludens-1 \\
\hline
\end{tabular}

Weitere Abkürzungen sind an entsprechender Stelle im Text aufgeführt. 


\section{Nomenklatur von Gensymbolen}

Die Nomenklatur von Gensymbolen entspricht den international festgelegten Konventionen (Wain et al. 2002).

$\rightarrow$ Bezeichnung humaner Gene/mRNA: in Großbuchstaben, Kursivsetzung

$\rightarrow$ Bezeichnung muriner Gene/mRNA: mit Großbuchstaben beginnend, gefolgt von Kleinbuchstaben

$\rightarrow$ Genprodukte/Proteine:

Groß- und Kleinschreibung erfolgt nach denselben Richtlinien ihrer kodierenden Gene, keine Kursivsetzung

Tabelle 1: Anwendungsbeispiel zur Nomenklatur von Gensymbolen

\begin{tabular}{c|c|c}
\hline Spezies & Gensymbol & Proteinsymbol \\
\hline \hline Homo sapiens & BMPR1A & BMPR1A \\
\hline Mus musculus & Bmpr1a & Bmpr1a \\
\hline
\end{tabular}




\section{EINLEITUNG}

\subsection{Chronisch progrediente Niereninsuffizenz}

Die chronisch progrediente Niereninsuffizienz (chronic kidney disease, CKD) korreliert mit einem fortschreitenden Funktionsverlust des Organs, dessen Filtrations- und Eliminationsaufgaben im Falle eines vollständigen Nierenversagens mittels Dialyse oder allogener Transplantation ersetzt werden müssen. Eine Früherkennung ist entscheidend für die Progression der Erkrankung, wird jedoch durch einen zunächst asymptomatischen Krankheitsverlauf und den bisherigen Mangel an etablierten Biomarkern, die eine Diagnose ungeachtet bestehender Grunderkrankungen ermöglichen, erschwert. Weiterhin fehlen derzeit kausale Therapiestrategien, die zur Restitution destruierter Organstrukturen beitragen.

Die CKD ist allgemein definiert als eine über mindestens drei Monate andauernde strukturelle oder funktionelle Anomalie der Niere bei bereits bestehender gesundheitlicher Beeinträchtigung des Patienten. Diese von der KDIGO (Kidney Disease: Improving Global Outcomes) im Jahr 2012 modifizierte Praxisleitlinie basiert dabei auf der Diagnose eines für einen Nierenschaden relevanten Markers oder einer auf unter $60 \mathrm{ml} / \mathrm{min}$ pro $1,73 \mathrm{~m}^{2}$ Körperoberfläche reduzierten glomerulären Filtrationsrate (siehe Tabelle 2).

Tabelle 2: Diagnosekriterien einer CKD

Ein/mehrere Marker positiv oder reduzierte GFR (modifiziert nach KDIGO CKD Work Group 2013, Seite 5).

Albuminurie (Albumin/Kreatin-Verhältnis $\geq 30 \mathrm{mg} / \mathrm{g} ; \geq 3 \mathrm{mg} / \mathrm{mmol}$

Marker eines Nierenschadens

Abnormitäten im Urinsediment

(einer oder mehrere positiv)

Elektrolyt- und andere Störungen infolge tubulärer Schädigung

Pathologische Anomalien, histologisch verifizierbar

strukturelle Unregelmäßigkeiten innerhalb bildgebender Verfahren

Zustand nach Nierentransplantation

Glomeruläre Filtrationsrate (GFR) GFR $<60 \mathrm{ml} / \mathrm{min} / 1,73 \mathrm{~m}^{2}$ (GFR-Kategorien G3a - G5)

Des Weiteren formulierte die KDIGO in Abhängigkeit von der Ätiologie der jeweiligen Nierenerkrankung (CGause) sowie unter Einbezug der Nierenparameter GFR (G1 - G5) und Albuminurie (A1 - A3) das deutlich präzisierte CGA-Klassifizierungsschema, auf dessen Grundlage eine ursachenspezifische Therapie fokussiert, vor allem aber eine umfangreiche Risikostratifizierung vorgenommen werden kann. Die über den Kalkulationsalgorithmus CKD-EPI (CKD-Epidemiology Collaboration) geschätzte GFR (estimated GFR, eGFR) optimiert zudem die in nunmehr sechs Stufen differenzierte GFR-Kategorie, wobei deren Level G5 mit einer eGFR unter $15 \mathrm{ml} / \mathrm{min} / 1,73 \mathrm{~m}^{2}$ weiterhin den Zustand des terminalen Nierenversagens (end-stage renal disease, ESRD) mit der Notwendigkeit zur Nierenersatztherapie bezeichnet (KDIGO CKD Work Group 2013). 


\subsection{1 Ätiologie der chronischen und terminalen Niereninsuffizienz}

Chronische Nierenerkrankungen gewinnen im Zuge des weltweiten demographischen und globalen Wandels, nicht zuletzt aber aufgrund der kontinuierlichen Progression der dem westlichen Lebensstil geschuldeten Volksleiden Diabetes mellitus, Hypertonie und Übergewicht immer mehr an Brisanz.

Als Hauptursache der chronischen und terminalen Niereninsuffizienz in den Industrienationen gilt das Vorliegen eines Diabetes mellitus Typ I und II, welcher bei rund 30 bis $40 \%$ der Betroffenen eine sogenannte diabetische Nephropathie induziert (Whaley-Connell et al. 2009). Prognosen zufolge dürfte insbesondere die ansteigende Prävalenz der Diabetiker mit voraussichtlich 439 Millionen involvierten Patienten bis ins Jahr 2030 unweigerlich den globalen Wachstumstrend der CKD begünstigen (Jha et al. 2013). Die aufgrund eines diagnostizierten arteriellen Hypertonus bedingte hypertensive Nephropathie führte allein in Deutschland im Jahr 2006 in 24 \% der Fälle zum terminalen Nierenversagen und stellt hierzulande wie auch in den USA den zweithäufigsten Risikofaktor einer Nierenersatztherapie dar (Frei und Schober-Halstenberg 2008, Bakris und Ritz 2009, USRDS 2013 Annual Data Report). Deutlich kausal hängt ferner die überalternde Gesellschaftsstruktur mit dem Beginn der chronischen Nierenersatztherapie zusammen: In Deutschland stieg der Altersmedian der inzidenten Patienten in den Jahren 1996 bis 2006 von 63 auf 70 Jahre, sodass rund $69 \%$ der Betroffenen bei Aufnahme einer Behandlung 65 Jahre und älter waren (Frei und SchoberHalstenberg 2008). Primäre Nierenerkrankungen hingegen wie Glomerulo- und interstitielle Nephritiden oder Zystennieren spielen für das Entstehen einer terminalen Niereninsuffizienz eine vergleichsweise untergeordnete Rolle (Frei und Schober-Halstenberg 2008).

\subsubsection{Epidemiologische und sozioökonomische Aspekte}

Basierend auf den statistischen Erhebungen des fortlaufenden Forschungsprogramms NHANES (National Health and Nutrition Examination Survey) beziffert der USRDS (United States Renal Data System) Annual Data Report 2013 die aktuelle CKD-Prävalenz in den Vereinigten Staaten für den Untersuchungszeitraum 2005 bis 2010 auf $14 \%$ der Gesamtbevölkerung. In der Population terminal nierenkranker Patienten bedingt die Verdopplung von Inzidenz und Prävalenz in den Jahren 1990 bis 2005 einen dramatischen Anstieg auf rund 430.000 Dialysepatienten sowie 190.000 Nierentransplantierte am Stichtag 31.12.2011 (USRDS 2013 Annual Data Report, St Peter 2007). Vergleichbare Daten gehen in Deutschland aus dem Jahresbericht 2006 des Bundesverbands QuaSi-Niere hervor, demzufolge 70.000 dialysepflichtige sowie 24.000 transplantierte Personen im Rahmen einer Nierenersatztherapie behandelt wurden. Innerhalb der letzten 10 Jahre lässt sich daraus ein jährlicher Prävalenz- und Inzidenzanstieg therapeutischer Maßnahmen infolge eines Nierenversagens von etwa 4 bis $5 \%$ konstatieren (Frei und Schober-Halstenberg 2008). Weltweit wird die Prävalenz der chronisch Nierenkranken auf einen Anteil von 8 bis $16 \%$ der Gesamtbevölkerung geschätzt (Jha et al. 2013) bei einer für das Jahr 2010 prognostizierten Anzahl von zwei Millionen terminal niereninsuffizienter Patienten (Lysaght 2002).

Vor diesem Hintergrund gewinnen insbesondere sozioökonomische sowie gesundheitspolitische Aspekte an Bedeutung. So veranschlagt die staatliche Krankenversicherung des amerikanischen Gesundheitssystems Medicare im Jahr 2011 allein für die Nierenersatztherapie Ausgaben in Höhe von 34,3 Milliarden Dollar (USRDS 2013 Annual Data Report). Laut der Deutschen Gesellschaft für Nephrologie (DGfN) belaufen sich die Kosten eines Dialysepatienten in Deutschland auf etwa 40.000 Euro 
pro Jahr, woraus sich für die gesetzlichen Krankenversicherungen eine geschätzte Auslage für ambulante Dialysebehandlungen von rund zwei Milliarden Euro jährlich ergibt und somit allein zwei Drittel des für die Nierenersatztherapie kumulierten Gesamtbetrages ausmacht (DGfN 2014, Potthoff et al. 2012, Nebel 2003). Für den operativen Eingriff einer Nierentransplantation wird eine Summe zwischen 50.000 bis 65.000 Euro kalkuliert. Bei funktionsfähigem Transplantat unterschreiten die jährlichen Nachsorgekosten mit 6.000 bis 12.500 Euro pro Patient allerdings bereits im zweiten Jahr postoperativ die durchschnittliche Vergütungshöhe der Dialyse (Kleophas und Reichel 2007, DGfN 2014).

Die sich zu den anfallenden Kosten der Nierenersatztherapie addierenden Aufwendungen für mildere CKDStadien befördern die immensen Belastungen der weltweiten Gesundheitssysteme und bekräftigen die Notwendigkeit zur Etablierung präventiver Therapiekonzepte.

\subsubsection{Klinischer Verlauf der chronischen Niereninsuffizienz}

Eine diagnostizierte chronische Niereninsuffizienz erhöht substantiell Morbidität und Mortalität des betroffenen Patienten und bedingt ein entsprechend sensibles Screening zur Abschätzung ihrer Erstmanifestation und Progression. Prognostisch relevante Risikovariablen stellen dabei die Ursache der CKD, das Vorliegen bzw. der Grad einer GFR- und Albuminurie-Kategorie sowie zusätzliche Komorbiditäten dar. Ferner gelten u. a. Alter, Geschlecht, Ethnizität, arterielle Hypertonie, Adipositas, kardiovaskuläre Erkrankungen ebenso wie der Abusus von Nikotin und nephrotoxischen Substanzen als valide Prädiktoren eines fortschreitenden Nierenfunktionsverlustes (KDIGO CKD Work Group 2013). Da eine klinisch manifeste Symptomatik sich häufig erst in späten CKD-Stadien äußert, erfolgt die Diagnose oft nur zufällig im Rahmen von Routineuntersuchungen (Methven und MacGregor 2009).

Die renale Minderfunktion der Niere induziert Störungen des Elektrolyt- und Säure-Basen-Haushaltes und verursacht infolge der sich ausweitenden Salz-und Wasserretention Ödeme in den unteren Extremitäten, im Zustand der Urämie auch in der Lunge. Die unzureichende Wahrnehmung endokriner Aufgaben führt aufgrund der defizitären Erythropoetin- und Calcitriolsynthese zur renalen Anämie und, im Zusammenspiel mit dem sekundären Hyperparathyreoidismus, zur renalen Osteodystrophie. Überdies verstärken arteriosklerotische Ablagerungen im Gefäßsystem der Niere die Deregulierung der Volumenhomöostase, in deren Folge sich ein arterieller Hypertonus auch sekundär entwickeln kann (Keller und Geberth 2010). Die zunehmend dekompensierte Retention harnpflichtiger Substanzen intensiviert sich mit dem Eintreten von Oligo- bzw. Anurie im Terminalstadium der Niereninsuffizienz und resultiert angesichts akkumulierender Urämietoxine im Blut des Patienten in einer endogenen Intoxikation. Als weitere schwerwiegende Komplikationen seien nephrogene Koagulopathien, Perikarditis, urämische Enzephalopathien, periphere Neuropathien sowie gastrointestinale und dermatologische Symptome zu nennen (Keller und Geberth 2010, Vanholder et al. 2008). Von besonderer prognostischer Relevanz ist die Manifestation kardiovaskulärer Erkrankungen, die als eigenständiges Ereignis oder infolge toxisch bedingter Organschäden im Kontext eines terminalen Nierenversagens auftreten und die häufigste Todesursache der ESRD darstellen (Levin 2003, Vanholder et al. 2008). 


\subsubsection{Therapie der chronischen Niereninsuffizienz}

Therapieoptionen der chronischen Niereninsuffizienz implizieren die Behandlung einer diagnostizierten Grunderkrankung, die Restriktion nephrotoxischer Substanzen sowie die Reduktion bestehender Progressionsfaktoren. Vordergründig wird dabei die Normalisierung des systemischen Blutdrucks auf $\leq 140 / 90 \mathrm{mmHg}$ bzw. bei bestehender Proteinurie von $\geq 30 \mathrm{mg} / \mathrm{Tag}$ auf $\leq 130 / 80 \mathrm{mmHg}$ fokussiert, wobei gemäß der aktuellen klinischen Praxisleitlinie der KDIGO die Applikation von Inhibitoren des AngiotensinConverting-Enzyms oder von Angiotensin-Rezeptorantagonisten empfohlen wird (KDIGO CKD Work Group 2013). Über die Unterdrückung des proliferativen Peptidhormons Angiotensin II vermitteln die beiden Antihypertensiva - neben der Senkung des intraglomerulären Drucks - antiproteinurische und damit zusätzlich nephroprotektive Wirksamkeit (Keller und Geberth 2010). Weitere allgemeine Maßnahmen umfassen eine moderate Proteinzufuhr, eine natrium-, kalium- und phosphatarme Diät sowie die Einstellung eines im Normbereich liegenden Body-Mass-Index (KDIGO CKD Work Group 2013).

Zwar können diese Optionen einen wesentlichen Beitrag zur Remission der Erkrankung leisten, jedoch keinesfalls gänzlich den progredienten Nierenfunktionsverlust unterbinden oder gar eine Restitution der zunehmenden Organdestruktion vermitteln (Turgut et al. 2010). Somit steht derzeit keine kausale Therapie in der klinischen Nephrologie zur Verfügung, welche den chronisch progredienten Nierenfunktionsverlust gänzlich aufhalten kann.

\subsection{Pathophysiologie der chronischen Niereninsuffizienz}

\subsubsection{Die renale Fibrogenese}

Das morphologische Korrelat der chronisch progredienten Niereninsuffizienz ist insgesamt durch das kombinierte Auftreten der tubulointerstitiellen Fibrose mit einhergehender Tubulusatrophie (IFTA), der Rarefizierung peritubulärer Kapillaren sowie einer fokal-segmentalen Glomerulosklerose (FSGS) gekennzeichnet (Boor et al. 2010, Bröcker et al. 2010). Letztlich korrelieren gemäß der von Bohle bereits in den 1960er-Jahren aufgrund morphometrischer Analysen postulierten Theorie jedoch der Grad des interstitiellen Fibrosierungsprozesses und die Abnahme der Nierenfunktion signifikant miteinander (Bohle et al. 1977, Bohle et al. 1987), wohingegen sich primär glomeruläre Veränderungen prognostisch deutlich besser darstellen (Bohle et al. 1992). Dabei zeichnet die IFTA als gemeinsame Endstrecke pathogenetisch äußerst verschiedenartiger Nierenerkrankungen ein relativ uniformes Bild und ist die Folge eines fehlregulierten Reparaturmechanismus, der die natürliche Homöostase zwischen Matrixsynthese und -degradation außer Kraft setzt (Bröcker et al. 2010). Stattdessen wird ein arbiträrer Vernarbungsprozess, die sogenannte renale Fibrogenese, initiiert (Kuncio et al. 1991, Strutz und Neilson 2003), der initial in Analogie zur physiologischen Organheilung erfolgt und, wie im Tiermodell bereits belegt, eine restitutio ad integrum zulässt (Eddy 1996).

Zunächst setzen tubuläre Epithelzellen eine Reihe von Chemokinen und Wachstumsfaktoren frei, woraufhin mononukleäre Leukozyten, vorzugsweise T-Lymphozyten und Monozyten bzw. Makrophagen, Mastzellen sowie dendritische Zellen in das Interstitium migrieren und wiederum über die Induktion inflammatorischer Zytokine u. a. dem TNF- $\alpha$ (tumor necrosis factor- $\alpha$ ), dem TGF- $\beta 1$ (transforming growth factor- 61 ), dem FGF-2 (fibroblast growth factor 2) sowie verschiedener Interleukine einen weiteren profibrotischen 
Stimulus liefern (Holdsworth und Summers 2008, John und Nelson 2007, Müller et al. 1992, Strutz und Neilson 1994, Strutz und Neilson 2003). Die kontinuierlich sezernierten Zytokine aus infiltrierten Entzündungs- und residenten Tubuluszellen evozieren in ihrer Komplexität die Aktivierung und Proliferation interstitieller Fibroblasten. Dies führt zur gesteigerten Synthese extrazellulärer Matrix (EZM) bei gleichzeitig reduziertem Matrixabbau, in dessen Konsequenz es zur massiven Deposition von EZM-Komponenten kommt (Jones et al. 1992, Strutz und Neilson 2003). Die sich reduzierende Leukozyteninfiltration bedingt zwar die Auflösung des primären Inflammationsprozesses, die Aktivierung der Fibroblasten, Hauptmediatoren der renalen Fibrogenese, bleibt jedoch angesichts der anhaltenden Zytokinsekretion des Tubulusepithels fortbestehen bzw. intensiviert sich infolge autokriner Proliferationsmechanismen von Fibroblasten und Myofibroblasten (Müller et al. 2000, Strutz und Neilson 2003). Die im exzessiven Ausmaß voranschreitende Ablagerung von Matrixproteinen in Verbindung mit der progredienten Schädigung tubulärer Epithelzellen und peritubulärer Kapillaren resultiert letztlich im Verlust von Organarchitektur und -funktion (Ng et al. 1998, Strutz und Neilson 2003, Müller et al. 2000).

\subsubsection{Chronischer Tubulusepithelschaden}

Die Rolle tubuloepithelialer Zellen während der renalen Fibrose wird im Wesentlichen durch den Verlust ihrer Regenerationsfähigkeit bestimmt. Dabei implizieren die zunächst protektiven, mit Progredienz der Erkrankung jedoch zunehmend maladaptiven Mechanismen den Arrest im Zellzyklus, Veränderungen im intrazellulären Zellmetabolismus sowie eine Aktivierung der Autophagozytose (Kang HM et al. 2015, Li L et al. 2010, Li L et al. 2014, Yang L et al. 2010).

Im Hinblick auf die Generierung von Fibroblasten wurde ferner das Phänomen der epithelialmesenchymalen Transition (EMT), eines Dedifferenzierungsprozesses, in dessen Verlauf adulte renale Tubuluszellen innerhalb eines pathogenen Milieus transformieren und einen zunehmend spindelförmigen Phänotyp ähnlich mesenchymalen Zellen entwickeln (Greenburg und Hay 1982, Liu 2004, Zuk et al. 1989), als wesentlich angenommen. LeBleu et al. gelang es allerdings, mittels fate mapping-Methoden im murinen Tubulusepithel, gekoppelt an genetische Reporter zum Tracking mesenchymaler Zellen, den Anteil der Myofibroblasten, die nach Durchlaufen eines vollständigen Transitionsprozesses originären Tubuluszellen entstammten, auf $5 \%$ zu quantifizieren (LeBleu et al. 2013). Insbesondere die Hypothese, Epithelzellen könnten sich nach Degradation der Basalmembran mit einhergehendem Verlust ihrer apikal-basalen Polarität aus ihrem tubuloepithelialen Zellverband lösen und frei migrieren, wird inzwischen kontrovers diskutiert und festigte Zweifel an der Existenz der EMT in vivo (Humphreys et al. 2010, Kriz et al. 2011, Li L et al. 2010, Zeisberg M und Duffield 2010). Statt einer kompletten phänotypischen Konversion definiert sich die EMT indes durch die Entstehung eines hybriden, koexprimierenden und somit profibrotischen Zelltypus. Dabei bedingt die EMT die kontinuierliche Herunterregulation epithelialer Adhäsionsmoleküle wie E-Cadherin, ZO-1 (zonula occludens-1) und Cytokeratin zugunsten der mesenchymalen Markerproteine Vimentin, aSMA ( $\alpha$-smooth muscle actin), FSP1 (fibroblast-specific protein 1) und Kollagen vom Typ I (Collagen-1) (Lovisa et al. 2015, Strutz 1995, Zeisberg M und Neilson 2009). Darüber hinaus korreliert die Transdifferenzierung neben der rein morphologischen Alteration mit funktionellen Einbußen des Tubulusepithels, die wiederum durch die Depletion einiger spezifischer Transportergene ausgelöst werden. Parallel induziert die EMT selbst Zellzyklus-arretierende Signale und beeinträchtigt somit physiologische 
Reparatur- und Regenerationsmechanismen. Weiterhin verstärkt sich mit der pathogenen Modifizierung des zellulären Sekretoms der Fibrosierungs- und Inflammationsprozess und nachfolgend die Rekrutierung des Immunsystems (Lovisa et al. 2015, Grande et al. 2015).

Letztlich beeinflussen sich die skizzierten Abläufe wechselseitig und evozieren somit das Fortbestehen eines exazerbierenden Circulus vitiosus. Die Suppression des EMT-Programms könnte daher ein vielversprechendes therapeutisches Konzept zur Protektion chronischer Schäden im Nierenparenchym darstellen (Lovisa et al. 2015).

\section{$1.3 \quad$ TGF- $\beta$-Superfamilie}

Dysbalancen von Wachstumsfaktoren leisten wesentliche Beiträge zur Entstehung der renalen Fibrogenese. In diesem Kontext ist die Superfamilie des transforming growth factor- 6 (TGF- $\beta$ ), ein Zusammenschluss strukturell ähnlicher Regulationsproteine, deren Namensgebung auf seinen Prototyp TGF- $\beta 1$ als erstes isoliertes Mitglied zurückzuführen ist, zu nennen (Massagué 1990). Im Rahmen der Organogenese beeinflussen die jeweiligen Mitglieder über Proliferation, Differenzierung und Apoptose verschiedenster Zelltypen die Strukturierungs- und Spezifikationsmechanismen einzelner Gewebe und modulieren darüber hinaus skelettales sowie neuronales Wachstum. Im adulten Organismus sorgen sie während der Wundheilung und Geweberegeneration für die Kontinuität der Gewebshomöostase und sind überdies Regulatoren des Immunsystems (Chang H et al. 2002, Ducy und Karsenty 2000, Herpin et al. 2004, Li MO et al. 2006, Massagué 2000). Allein in Vertebraten gehören der Ordnung der TGF- $\beta$-Superfamilie mittlerweile über 30 identifizierte Zytokine an, zu denen die Isoformen des TGF- $\beta$, bone morphogenetic proteins (BMPs), inhibin, activin, growth differentiation factors (GDFs) wie nodal und lefty sowie das anti-Muellerian hormone (AMH) zählen (Gordon und Blobe 2008).

Signale an der Zielzelle werden bei den Mitgliedern der TGF- $\beta$-Superfamilie im Wesentlichen durch zwei Rezeptorklassen transduziert. Charakteristische Strukturmerkmale der bislang identifizierten, etwa 500 Aminosäuren umfassenden, sieben Typ I- und fünf Typ II-Rezeptoren stellen eine kurze extrazelluläre $\mathrm{N}$-terminale Bindungsdomäne, eine transmembranäre Region sowie eine intrazelluläre C-terminale Serin/Threonin-Kinasedomäne dar (Shi und Massagué 2003). Die Bindung des dimeren Liganden führt zur Rekrutierung eines meist heterotetrameren Komplexes aus je zwei Typ I- und zwei Typ II-Rezeptoren und induziert über die daraufhin eintretende Konformationsänderung der intrazellulären Serin/Threonin-Kinase des Typ II-Rezeptors die Phosphorylierung der spezifischen glycin- und serinreichen Domäne (GS-Box) des Typ I-Rezeptors. Der anschließend aktivierte Typ I-Rezeptor initiiert durch die Phosphorylierung regulatorischer SMAD-Proteine (R-SMAD) eine intrazelluläre Signalkaskade, in deren Verlauf es zur Interaktion mit dem common-mediator SMAD4 (Co-SMAD) kommt. Die inhibitorischen SMAD-Proteine (I-SMAD) SMAD6 und 7 hingegen agieren in Blockadefunktion (Attisano und Wrana 2002, Shi und Massagué 2003, Yamashita et al. 1994). Determinanten für die Spezifität des jeweiligen Signalweges stellen korrespondierende Loop-Segmente des Typ I-Rezeptors sowie der R-SMAD-Proteine dar (Feng XH und Derynck 1997, Lo et al. 1998). 


\subsubsection{Transforming Growth Factor- $\beta 1$ (TGF- $\beta 1)$}

Bereits 1980 entdeckten Roberts et al. die Fähigkeit der transforming growth factors (TGFs), murinen Fibroblasten aus isolierten Geweben in vitro als Wachstumsstimulanz zu dienen (Roberts et al. 1980). Bisher konnte der Subtyp TGF- $\beta$ in einer Vielzahl von Organen wie der Niere, Leber, Herz oder Lunge als das zentrale Schlüsselzytokin pathologischer Fibrosierungsprozesse identifiziert werden (Border und Noble 1994). In diesem Zusammenhang kommt von seinen drei im humanen Organismus existierenden Isoformen TGF- $\beta 1,-\beta 2$ und $-\beta 3$ insbesondere der aktivierten Variante des TGF- $\beta 1$ eine herausragende Rolle zu: Zum einen forciert der Faktor eine fortschreitende Deposition interstitieller und mesangialer Matrixkomponenten, indem er residente Fibroblasten und Mesangiumzellen zur verstärkten Produktion von Kollagen, Fibronectin und Proteoglykanen stimuliert. Andererseits verhindert TGF- $\beta 1$ über die Induktion des Proteaseinhibitors PAl-1 (plasminogen activator inhibitor-1) bei gleichzeitiger Suppression extrazellulärer Proteasen die Degradation der Matrixproteine (Border et al. 1990, Peters et al. 1998, Strutz et al. 2001). Ferner gilt das TGF- $\beta 1$ als autonomer Mediator sukzessiver Transdifferenzierungsmechanismen in tubulären Epithelzellen, währenddessen sie mesenchymale Charakteristika entwickeln und in die Front EZM-produzierender Fibroblasten involviert werden (Liu 2006).

Neben dem Vorgang der EMT gilt die TGF- $\beta$-induzierte Apoptose in Podozyten, im tubulären Epithel sowie in der glomerulären und peritubulären Mikrovaskulatur als der grundlegende zelluläre Pathomechanismus fortschreitender Nierenerkrankungen. Daraus resultierende Geschehnisse wie Podozytendepletion, tubuläre Atrophie und Verlust der Kapillaren addieren sich zu den eingangs genannten Effekten und münden nach voranschreitender Glomerulosklerose und tubulointerstitieller Fibrose letztlich im Untergang der Nephrone (Böttinger und Bitzer 2002). Die dargestellten Zusammenhänge konnten auch im Rahmen zahlreicher tierexperimenteller Studien nachvollzogen werden. Kopp et al. erzielten beispielsweise in transgenen Mäusen infolge erhöhter systemischer Tgf- $\beta 1$-Plasmakonzentrationen Nierenschäden in Form einer tubulointerstitiellen Fibrose, atrophierter Tubuli und glomerulärer Abnormitäten (Kopp et al. 1996). Das TGF- $\beta$ transduziert seine Effekte über die Bindung des Typ II-Rezeptors T $\beta R I$, woraufhin die Komplexierung des Typ I-Rezeptors TRRI (ALK5) eintritt und somit die anschließende Phosphorylierung der intrazellulären R-SMADs SMAD2/3 ermöglicht. Diese formieren einen Komplex mit SMAD4, das in den Zellkern transloziert und nach DNA-Bindung die Transkription TGF- $\beta$-assoziierter Gene moduliert (Heldin et al. 1997, Rahimi und Leof 2007, Shi und Massagué 2003).

\subsubsection{Bone Morphogenetic Protein 7 (BMP7)}

In den 1960er Jahren wurde das körpereigene BMP7 (bone morphogenetic protein 7) aufgrund seiner Eigenschaft, die ektope Knorpel- und Knochenformation zu induzieren, entdeckt und daraufhin mit dem ursprünglichen Terminus osteogenic protein-1 (OP-1) bezeichnet (Urist 1965). Die strukturelle Charakterisierung des Polypeptids mittels Sequenzanalysen erlaubte schließlich die Zuordnung zur TGF- $\beta$ Superfamilie und führte zu seiner Umbenennung (Celeste et al. 1990, Ozkaynak et al. 1990, Wozney et al. 1988).

Zur Synthese der biologisch aktiven Form des BMP7 erfolgt nach Translation des aus 431 Aminosäuren bestehenden Präpropeptids seine Dimerisierung sowie die anschließende proteolytische Abspaltung von Signalsequenz und Prodomäne. Das prozessierte mature BMP7 liegt daraufhin als Homodimer mit einem 
kalkulierten Molekulargewicht von $36 \mathrm{kDa}$ vor, dessen beiden glykosylierten Untereinheiten je 139 Aminosäuren umfassen, etwa $16 \mathrm{kDa}$ schwer und über Disulfidbrücken gekoppelt sind (siehe Abbildung 1 (A)) (Celeste et al. 1990, Sampath et al. 1992, Zeisberg M 2006).

Zur Übermittlung seiner Signale kann das BMP7 mit den drei membranständigen Typ II-Rezeptoren BMPR2, ACTRII, ACTRIIB sowie den Typ I-Rezeptoren ACTRI (ALK2), BMPR1A (ALK3) und BMPR1B (ALK6) interagieren (Kawabata et al. 1998, ten Dijke et al. 1994, Yamashita et al. 1996).

Nach erfolgter Rezeptorbindung des homodimeren Liganden formiert sich ein stabiler Rezeptorkomplex und induziert über die Phosphorylierung der zytoplasmatischen rezeptorregulierten Proteine SMAD1/5/8 zu pSMAD1/5/8 die Aktivierung der intrinsischen SMAD-Signalkaskade. Die phosphorylierten R-SMADs komplexieren nun mit dem SMAD4, das nach Translokation in den Zellkern die Expression seiner Zielgene reguliert (Derynck et al. 1998, Tamaki et al. 1998). In Bezug auf die Interaktionen zwischen dem BMP7 und seinen spezifischen Rezeptoren fungieren die extrazellulären Moleküle NOG (noggin), USAG1 (uterine sensitization-associated gene-1) und GREM1 (gremlin 1) als Inhibitoren, während das kielin/chordinlike protein (KCP) die biologische Aktivität des BMP7 über die Intensivierung der Rezeptorbindung stabilisiert (siehe Abbildung 1 (B)) (Bechtel und Zeisberg M 2009).

A

PRÄPROTEIN
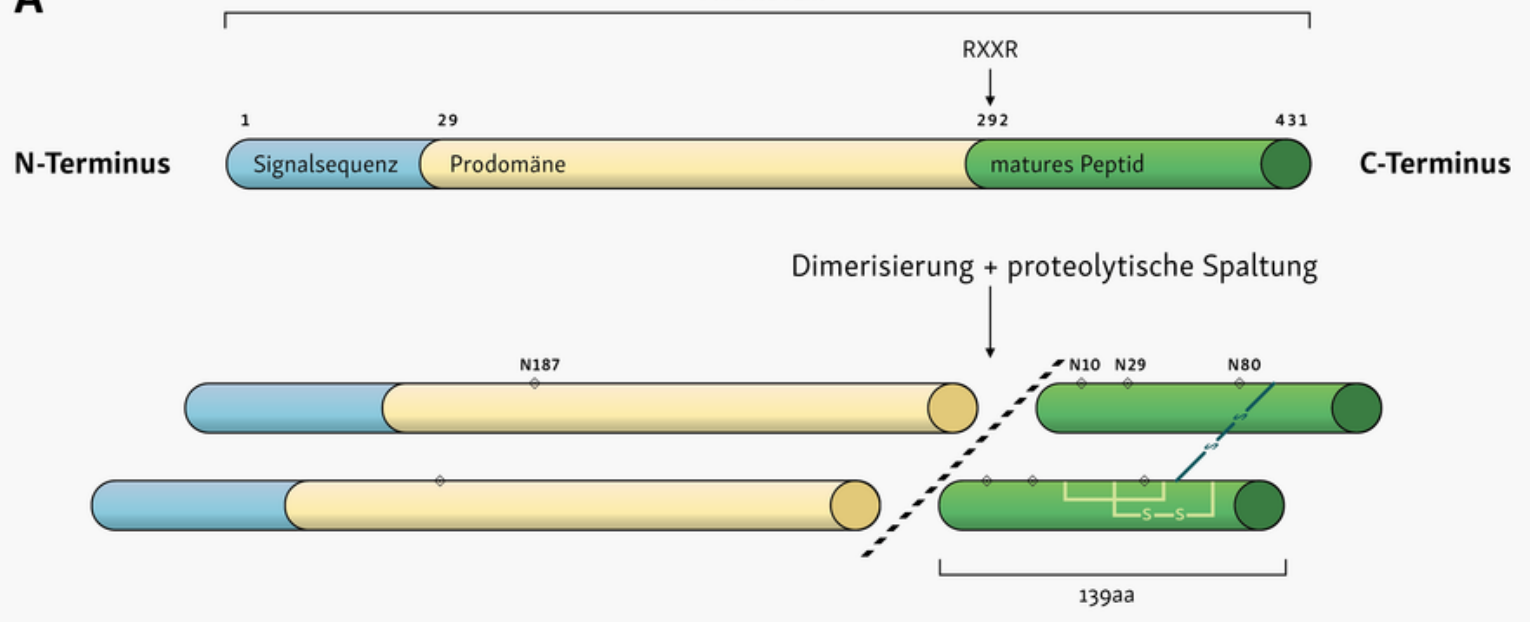

B

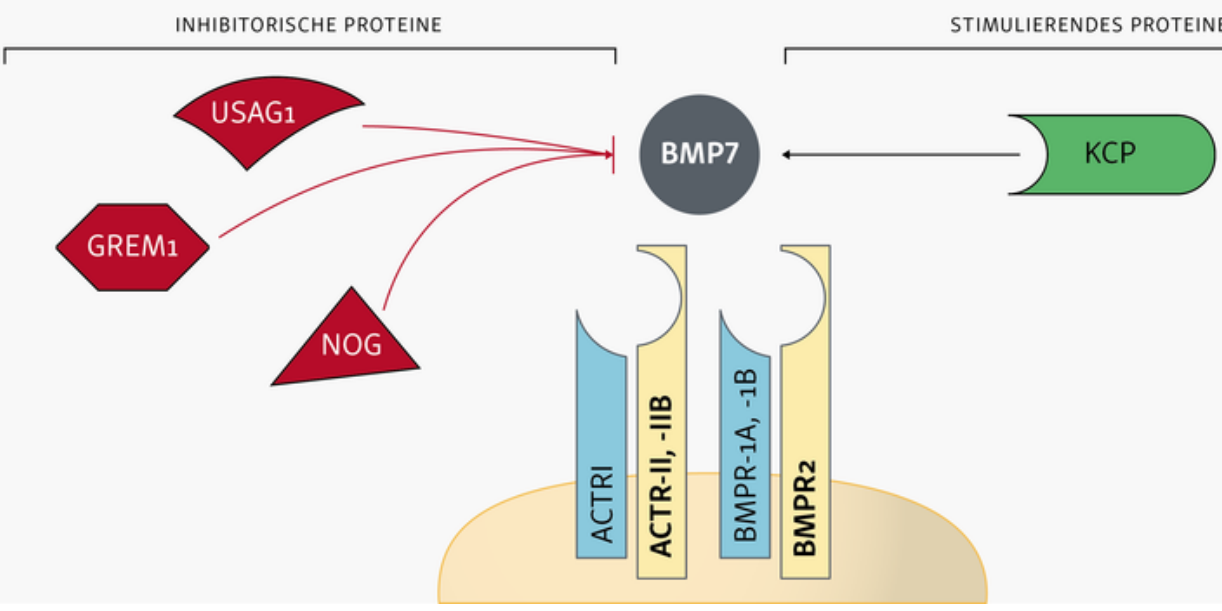


Abbildung 1: Prozessierung und Modulation des BMP7

(A) Prozessierung des Präpropeptids. Intra- und intermolekulare Disulfidbrücken bedingen dreidimensionale Molekülstruktur des aktivierten Homodimers. aa, amino acid; N, N-Glykosylierung; RXXR, konserviertes Signalmotiv; S-S, Disulfidbrücke (modifiziert nach Sampath et al. 1992, Seite 20355; Griffith DL et al. 1996, Seite 878). (B) Regulative Einflüsse exogener Modulatoren (modifiziert nach Bechtel und Zeisberg M 2009, Seite 1690).

Neben seiner elementaren Bedeutung für den Knochenstoffwechsel konnte dem BMP7 in einer Vielzahl morphogenetischer Prozesse eine zentrale Rolle zugesprochen werden. Erhöhte Expressionsmuster sind bereits während der frühen Embryogenese im viszeralen Entoderm, der Chorda dorsalis sowie im Kontext der Organogenese von Herz, Augen, Skelett und Nieren detektierbar. In der murinen Nephrogenese fungiert das Bmp7 als Mediator einer regelrechten Nierenentwicklung und lässt sich am Tag 11 post conceptionem im Epithel der Ureterknospe und nachfolgend in dessen Derivaten lokalisieren (Dudley und Robertson 1997, Vukicevic et al. 1996). Unter seinem Einfluss transdifferenziert das induzierte metanephrische Mesenchym über den Mechanismus der MET zu spezialisierten Zellen der Glomeruli und formiert erhebliche Teile des tubulären Apparats (Vukicevic et al. 1996). Homozygote Bmp $7^{-/-}$-defiziente Mäuse zeigen bei ihrer Geburt, neben Mikro- bzw. Anophthalmie und skelettalen Missbildungen, eine schwerwiegende bilaterale renale Dysplasie, sodass sie innerhalb von 24 Stunden infolge eines postnatalen Nierenversagens versterben (Godin et al. 1998). Ursächlich ist ein zunehmender Rückgang von Mesenchymzellen zwischen den Tagen 12,5 bis 14,5 post conceptionem, der letztlich die physiologisch stattfindende MET und somit den Differenzierungsprozess der Nephrone behindert (Dudley et al. 1995, Godin et al. 1998, Luo et al. 1995). Im gesunden adulten Organismus wird das BMP7 in Knochen und Knorpel exprimiert, primärer Syntheseort ist jedoch die Niere, vornehmlich das Sammelrohr, der distale Tubulus sowie die Podozyten (Ozkaynak et al. 1991, Gould et al. 2002). Allerdings korreliert sein Expressionsniveau deutlich negativ mit der Diagnose einer akuten oder chronischen Niereninsuffizienz, die systemische Applikation von exogenem rekombinantem humanem BMP7 (rhBMP7) hingegen resultiert in unterschiedlichen Tiermodellen in einer signifikant verbesserten Regenerationskapazität der beschädigten Nierenstruktur (Bramlage et al. 2010, Zeisberg M und Kalluri 2004 a). So zeigten Ratten infolge ischämisch bedingter akuter tubulärer Nekrosen eine reduzierte Zytokinsekretion bei konsekutiv geminderter Migration neutrophiler Granulozyten, wobei diese Reduktion vermutlich auf der supprimierten inflammatorischen Aktivität des Tubulusepithels basiert (Gould et al. 2002, Vukicevic et al. 1998). Die homozygote Deletion bzw. die Mutation selektiver Gene führt in Mausmodellen des Alport-Syndroms sowie der Lupusnephritis, ähnlich wie die Injektion von nephrotoxischem Serum und die unilaterale Ureterobstruktion (UUO), zu Formen der chronisch progredienten Niereninsuffizienz, deren charakteristische tubulointerstitielle Fibrose mit einhergehender Tubulusatrophie BMP7-abhängig gemildert wird (Hruska et al. 2000, Zeisberg M et al. 2003 a, Zeisberg M et al. 2003 b). Zurückzuführen sind diese Phänomene auf die Inhibition der TGF- $\beta 1$-modulierten Fibroblastenproliferation, die sich nachfolgend in einer maßgeblichen Reduktion profibrotischer Moleküle sowie einer verstärkten Degradation akkumulierender Matrixkomponenten äußert (Zeisberg $\mathrm{M}$ et al. 2003 a, Zeisberg M und Kalluri 2004 a). Im Zusammenhang mit der Schädigung tubulärer Epithelzellen antagonisiert das BMP7 die TGF- $\beta 1$-induzierte EMT und wirkt somit regenerativ auf die tubuloepitheliale Integrität (Zeisberg M et al. 2003 b). Einige Arbeitsgruppen sahen in Abhängigkeit vom jeweiligen 
Tiermodell Anhaltspunkte eines zusätzlichen antiapoptotischen Effekts auf das betroffene Epithelium (Hruska et al. 2000, Vukicevic et al. 1998).

Da dem TGF- $\beta 1$ auch bei der Fibrogenese anderer parenchymatöser Organe die Rolle des Hauptinitiators zuteil wird, sind die dargestellten Mechanismen keineswegs eine renale Spezifität. Entsprechend beförderte rekombinantes BMP7 auch in tierexperimentellen Studien chronisch entzündlicher Darmerkrankungen sowie der chronischen Leber- und Herzfibrose eine substantielle Milderung inflammatorischer und fibrotischer Prozesse (Maric et al. 2003, Zeisberg EM et al. 2007, Zeisberg M et al. 2007).

\subsubsection{BMP7-/TGF- $\beta$-Antagonismus}

Wesentliche Effekte des BMP7 gegenüber seinem Antagonisten TGF- $\beta 1$ beruhen auf der engen Kopplung der SMAD-Signalkaskaden und vermitteln ihm im Unterschied zu direkten Inhibitoren wie neutralisierende Antikörper die Fähigkeit, komplexe intrazelluläre Interventionsmechanismen zu initiieren. In-vitro-Studien in unterschiedlichen Zellsystemen führen die intrinsische Aktivität des BMP7 auf sogenannte inhibitor of DNA binding (ID)-Proteine zurück, die im Verlauf des BMP7-spezifischen SMAD-Signalweges verstärkt exprimiert, durch TGF- $\beta$ hingegen herunterreguliert werden (Derynck und Zhang 2003, Kang Y et al. 2003). Gemeinhin agieren die vier Mitglieder der ID-Familie als dominant negative Antagonisten der basic helixloop-helix (bHLH)-Transkriptionsfaktoren, sind in Proliferations- und Differenzierungsprozesse, den Zellzyklus, die Angiogenese sowie Tumorgenese involviert und besitzen zudem proapoptotische Eigenschaften (Norton 2000, Ruzinova und Benezra 2003, Sikder et al. 2003). Die Inhibition der ID-Proteine durch TGF- $\beta$ bzw. indirekt über dessen SMAD-Mediatoren behindert diese Funktionen in Epithelzellen und trägt stattdessen zum Wachstumsarrest bzw. zur terminalen Differenzierung bei (Derynck und Zhang 2003, Kang Y et al. 2003). Dagegen reprimiert insbesondere die BMP7-assoziierte ID2- und ID3-Induktion die Transkription der TGF- $\beta$-modulierten mesenchymalen, profibrotischen Gene CTGF (connective tissue growth factor), ACTA2 (actin, alpha 2 smooth muscle, aorta; Genname von aSMA), COLLAGEN-1A1, PAI-1 und FSP1 (Izumi et al. 2006, Kinoshita et al. 2007, Weiskirchen und Meurer 2013, Zeisberg M et al. 2003 b). Gleichzeitig wird das endogene E-Cadherin als Schlüsselmolekül eines epithelialen Zellphänotyps nach IDspezifischer Inaktivierung seines transkriptionellen Suppressors E2A hochreguliert, wohingegen die in Gegenwart des TGF- $\beta$ vermittelte Hemmung der ID-Proteine zur Generierung von E2A führt und über die Inhibition des E-Cadherins der EMT Vorschub leistet (Kondo et al. 2004). Die nukleäre Kolokalisation phosphorylierter SMAD2/3-Proteine sowie des PSMAD1 weist zudem auf die Fähigkeit des BMP7, das physiologische Expressionsniveau des E-Cadherins trotz vorangegangener TGF- $\beta 1$-Stimulation bzw. in dessen Anwesenheit wiederherzustellen. Ähnliche Mechanismen obliegen ihm hinsichtlich der epithelialen Markerproteine ZO-1, Cytokeratin und Desmoplakin (Weiskirchen und Meurer 2013, Zeisberg M et al. 2003 b).

Ferner beeinflussen inhibitorische SMADs die wechselseitige Beziehung zwischen TGF- $\beta$ und BMP7. Das über beide Signalkaskaden induzierte SMAD7 fungiert innerhalb der TGF- $\beta$-Signaltransduktion als negative Feedbackschleife, wobei dessen Überexpression mit einer substantiellen Milderung der EMT in Verbindung gebracht wird (Dooley et al. 2008, Hayashi et al. 1997, Nakao et al. 1997, Saika et al. 2004). Demgegenüber agiert das I-SMAD6 primär als autoregulativer Deaktivierungsschalter in der BMP-Signalkaskade, in deren 
Verlauf es durch unterschiedliche Mechanismen mit dem BMP-Typ I-Rezeptor und den regulatorischen SMADs interferiert bzw. deren Degradation initiiert sowie in funktionelle Konkurrenz zum Co-SMAD4 tritt (Hata et al. 1998, Hazen et al. 2001, Imamura et al. 1997, Ishida et al. 2000, Murakami et al. 2003).

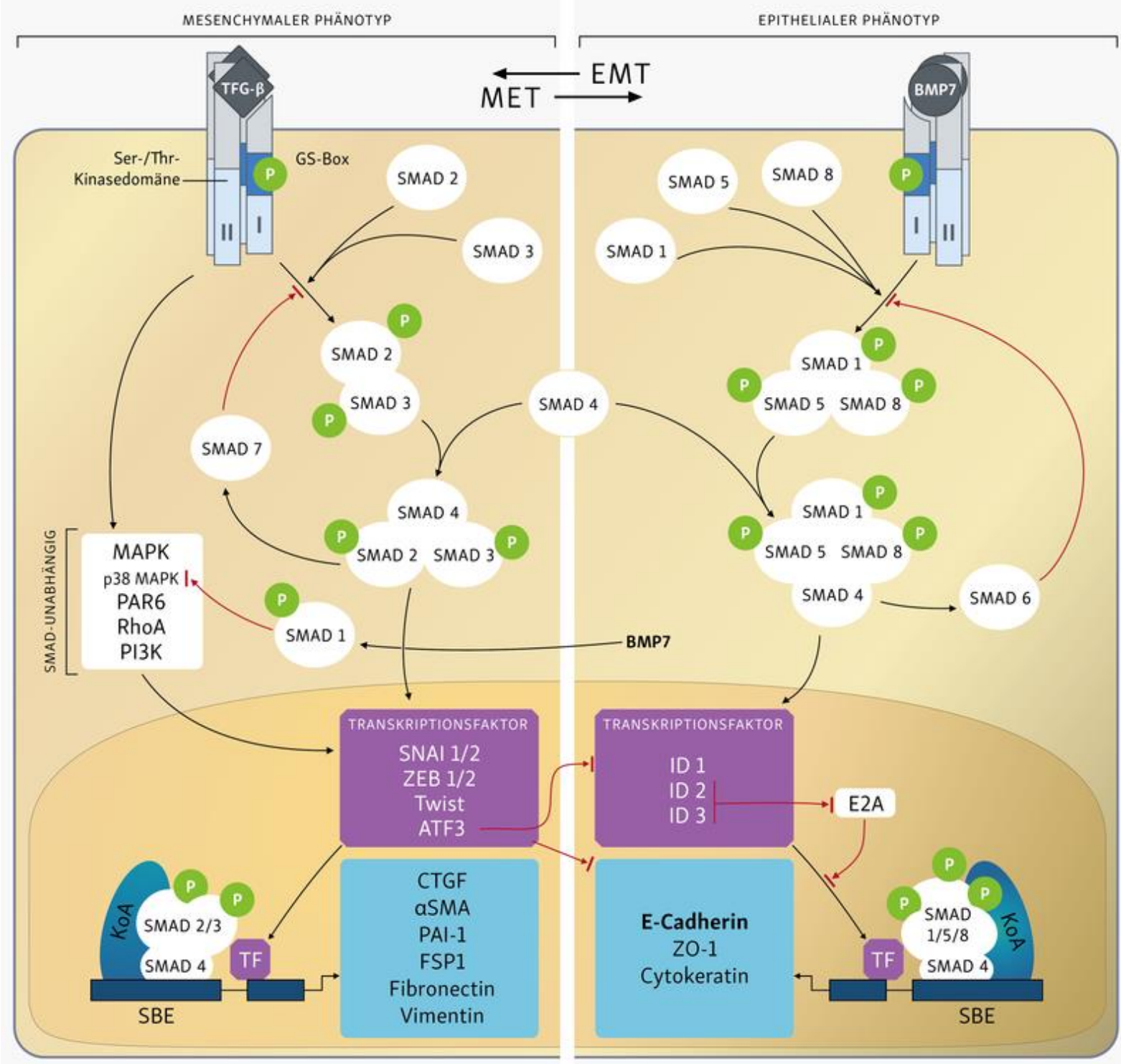

Abbildung 2: Schematische Übersicht antagonisierender Signalwege von BMP7 und TGF- $\boldsymbol{\beta}$

Die Induktion der spezifischen Zielgene unterstützt eine epitheliale bzw. eine mesenchymale Zellmorphologie. ATF3, activating transcription factor 3; P, Phosphorylierung; KoA, Koaktivator; SBE, SMAD binding element; TF, Transkriptionsfaktor; ZEB, zinc finger E-box binding homeobox (modifiziert nach Willis und Borok 2007, Seite 528).

Es lässt sich diskutieren, ob das bemerkenswerte Regenerationspotential des BMP7 ein Relikt des embryonalen Entwicklungsprozesses darstellt und, angesichts der hohen Plastizität mesenchymaler und epithelialer Zellen, in Form einer endogenen Reprogrammierung die Reparatur der Niere unterstützen könnte (Zeisberg $\mathrm{M}$ und Kalluri 2004 b). Diesbezüglich zeigten Zeisberg M et al., dass adulte renale Fibroblasten in vitro 
unter dem konstanten Einfluss des BMP7 befähigt sind, die mesenchymal-epitheliale Transition (MET) originärer embryonaler Mesenchymzellen zumindest in einem frühen Stadium zu imitieren (Zeisberg $M$ et al. 2005).

\subsubsection{Bone Morphogenetic Protein Receptor 1A (BMPR1A)}

Einst unter dem noch heute gültigen Synonym activin receptor-like kinase (ALK3) identifiziert, erfolgte in Anbetracht seiner hohen BMP-Affinität alsbald die Umbenennung des auf etwa 53 bis 58 kDa bemessenen Typ I-Rezeptors in bone morphogenetic protein receptor 1A (BMPR1A) (ten Dijke et al. 1994). Dabei bestätigten quantitative In-vitro-Analysen BMP7-assoziierter Rezeptoren die Prädominanz des BMPR1A in Tubulusepithelzellen und somit seine zentrale Bedeutung für die Niere (Wetzel et al. 2006). Da die konstitutive BMPR1A-Überexpression mit der Reproduktion BMP7-modulierter Charakteristika korreliert, ist eine lokal präferierte BMP7/BMPR1A-Interaktion für das renale Parenchym anzunehmen (Zeisberg M et al. 2003 b, Zeisberg M 2006).

In der murinen Embryonalentwicklung wird der Bmpr1a in nahezu allen Geweben exprimiert und kann bereits zwischen dem 9,5 und 12,5 Embryonaltag im meso- bzw. metanephrischen Epithelium und Mesenchym der sich formierenden Niere detektiert werden (Danesh et al. 2009, Dewulf et al. 1995, Di Giovanni et al. 2011). Eine Beteiligung an der Gastrulation scheint naheliegend, da Mausmutanten nach homozygoter Bmpr1a ${ }^{-}$-Deletion zwar eine reguläre Prä- und initiale Postimplantationsphase zeigen, die folgende Differenzierung zum Mesoderm jedoch defizitär verläuft und die embryonale Letalität der Mutanten um den Tag 9,5 post conceptionem induziert (Mishina et al. 1995). Indes entwickeln transgene Mäuse unter Cre-Rekombinase-vermittelter konditioneller Inaktivierung von Bmpr1a im intermediären Mesoderm und der Ureterknospe zwar eine physiologische Gewebearchitektur, allerdings bedingt die Bmpr1a-Defizienz einen hypoplastischen Phänotyp, der sich in Form von reduzierter Nierengröße und Nephronenzahl manifestiert. Demzufolge beeinflusst die BMPR1A-abhängige Signaltransduktion regulativ die Spezifizierung renaler Progenitorzellen sowie Wachstum und Verzweigung des entstehenden Sammelrohrsystems während der Morphogenese der Niere (Di Giovanni et al. 2011, Hartwig et al. 2008). Untersuchungen in adulten Mausgeweben sind hinweisend für ein annähernd ubiquitäres Expressionsmuster von Bmpr1a, wobei insbesondere im Herzen, dem Gehirn, der Lunge, der Leber, dem Skelettmuskel und den Nieren relativ hohe Anteile nachweislich sind (Dewulf et al. 1995, Mishina et al. 1995).

Weiterhin vermittelt der BMPR1A protektive Wirksamkeit im pathogenen Vernarbungsprozess der Niere. So führt die nephrotoxische Serumnephritis (NTN) im entsprechenden Mausmodell zur konsekutiv erhöhten Bmpr1a-Expression, wohingegen das BMP7 sowie dessen übrigen Korezeptoren (ActRI, Bmpr1b, Bmpr2) einer effektiven Negativregulation unterliegen. Infolge des konditionellen Bmpr1a ${ }^{-1-K n o c k d o w n s}$ im proximalen Tubulusepithel zeigen transgene Mäuse sechs Wochen nach NTN-Induktion in Relation zum Kontrollkollektiv eine sich mit deutlich größerer Progredienz entwickelnde interstitielle Fibrosierung. Wesentliche Merkmale stellen dabei die verstärkte nukleäre pSmad2-Expression als Beleg einer intensivierten Tgf- $\beta$-Signalkaskade, der exzessiven Makrophageninflux sowie eine ausgeprägte und für den epithelial-mesenchymalen Transdifferenzierungsprozess indikative zelluläre Kolokalisation epithelialer und mesenchymaler Markerproteine dar (Sugimoto et al. 2012). 
Entsprechend stellt die Induktion der endogenen BMP7-Signalkaskade über eine selektiv vermehrte BMPR1A-Präsenz im Tubulusepithel eine aussichtsreiche Therapieoption zur Remission chronisch progredienter Nierenleiden dar.

\subsection{Nierenersatztherapie}

Im Falle eines hochgradigen oder vollständigen Organversagens im Stadium der terminalen Niereninsuffizienz wird die renale Filtrations- und Eliminationsfunktion entweder durch die Dialyse, einem medizinisch technischen Blutreinigungsverfahren, oder durch eine allogene Nierentransplantation ersetzt. Letztere gilt bei Eintritt einer terminalen Niereninsuffizienz derzeit als Therapie der Wahl (Kaplan und Meier-Kriesche 2004). Obwohl sie heute ein standardisiertes Verfahren darstellt, gelang es erst 1954 dem Bostoner Ärzteteam um Joseph Murray, zwischen eineiigen Zwillingen erfolgreich eine Niere mit langfristig bestehender Transplantatfunktion zu übertragen (Merrill et al. 1956). Neben der Entwicklung und Etablierung chirurgischer Routinetechniken stellte insbesondere die immunologische Abstoßungsreaktion des Empfängers eine zunächst unüberwindbare Barriere dar. Schließlich postulierten Schwartz und Dameshek 1958 die immunsuppressive Wirksamkeit des Antimetaboliten 6-Mercaptopurin und legten mit dieser innovativen Erkenntnis den Grundstein für die medikamentöse Rejektionsprophylaxe (Schwartz et al. 1958). In den frühen 1960er Jahren applizierte Starzl erfolgreich eine Kombination aus dessen Prodrug Azathioprin sowie hochdosierten Kortikosteroiden in nierentransplantierten Patienten und schuf damit die Basis für ein bis Ende der 70er Jahre geltendes klinisches immunsuppressives Therapiekonzept (Barker und Markmann 2013, Starzl et al. 1963). Die oft als „Meilenstein“ bezeichnete Markteinführung des zyklischen Undekapeptids Cyclosporin A Anfang der 80er Jahre revolutionierte schließlich die Transplantationschirurgie. Als Prototyp der Calcineurininhibitoren (CNI) zeichnet es sich vor allem durch eine weitaus höhere Spezifität aus und führte zum bemerkenswerten Anstieg der 1-Jahr-Überlebensraten von bisher $50 \%$ auf $80 \%$ (Calne 2004, Oka und Yoshimura 1996). Das dauerhafte Risiko einer Transplantatdysfunktion bleibt allerdings weiterhin bestehen und bedingt eine lebenslange, angesichts relevanter Nebenwirkungen nicht unproblematische, Immunsuppression.

Im Vergleich der bei vollständiger Niereninsuffizienz praktizierten Therapieoptionen zeigt sich die deutliche Überlegenheit der Nierentransplantation hinsichtlich Lebensqualität, Lebenserwartung und Mortalität gegenüber den Dialyseverfahren. Entsprechend betrug die adjustierte Fünf-Jahres-Überlebenswahrscheinlichkeit eines inzidenten Dialysepatienten in Europa im Untersuchungszeitraum 2004 bis 2008 nur rund $54 \%$. Fünf Jahre nach Organtransplantation lebten in Abhängigkeit von der jeweiligen Spendenart, postmortal bzw. lebend, dagegen noch zwischen 92 bis $96 \%$ der Transplantierten (ERA-EDTA Registry 2015). Trotz der signifikant höheren Überlebensraten standen in Deutschland die $2.128 \mathrm{im}$ Jahr 2014 transplantierten Nieren im deutlichen Missverhältnis zu den 7.961 sich auf der aktiven Warteliste befindlichen Patienten, sind jedoch kennzeichnend für die seit Anfang der Dekade rückläufige Tendenz der durchgeführten Nierentransplantationen sowie eine mangelnde Organspendebereitschaft (DSO 2015). Angesichts der inhärenten Komplikationen von Dialysebehandlung bzw. Transplantation muss zukünftig die Ressourcenausschöpfung hinsichtlich regenerativer Therapiestrategien nachdrücklich forciert werden. 


\subsection{Immunsuppressive Therapie nach Nierentransplantation}

Bei Notwendigkeit einer pharmakologischen Immunsuppression nach erfolgter Transplantation ist eine Vielzahl unterschiedlicher Wirkstoffklassen bekannt, die zur Reduktion der medikamentenassoziierten Nebenwirkungen meist im Rahmen einer fundierten Kombinationstherapie appliziert werden. In Deutschland stützt sich das aktuelle Therapieregime nierentransplantierter Patienten auf die im Konsens eines internationalen Expertenkomitees erarbeitete und publizierte KDIGO - clinical practice guideline for the care of kidney transplant recipients (KDIGO Transplant Work Group 2009). Speziell in der prä-, peri- und postoperativ stattfindenden Induktionstherapie zur Reduktion akuter Rejektionen fungieren IL2Rezeptorantagonisten als Firstline-Therapeutika. In der folgenden initialen und langfristigen Erhaltungstherapie bewährte sich die kombinierte Gabe eines Calcineurininhibitors mit einem Antimetaboliten, wobei eine eigens formulierte Stellungnahme der DGfN und der Deutschen Transplantationsgesellschaft (DTG) aus dem Jahr 2012 in Anlehnung an die KDIGO-Leitlinie explizit Tacrolimus als Mittel der Wahl unter den Calcineurininhibitoren empfiehlt (Stellungnahme DGfN und DTG 2012, KDIGO Transplant Work Group 2009). Diese Vorgabe basiert auf den Ergebnissen des Efficacy Limiting Toxicity Elimination (ELITE)-Symphony-Projekts, einer 12-monatigen, prospektiven, randomisierten Multicenterstudie. In dessen Verlauf manifestierte sich eine signifikante Überlegenheit der Kombinationstherapie aus geringdosiertem Tacrolimus und antiproliferativem Mycophenolat Mofetil (MMF) hinsichtlich renaler Funktionalität, Überleben des Allotransplantats (94,2 \% nach 12 Monaten) und der Rate akuter Rejektionen (Ekberg et al. 2007).

In der gemeinsamen Erklärung von DGfN und DTG wird der Anteil der gemäß KDIGO-Richtlinien behandelten De-novo-Nierentransplantierten indes auf etwa $70 \%$ beziffert (DGfN und DTG 2012). Ein ähnliches Bild zeichnet der USRDS 2013 Annual Data Report der USA. Seit seiner Einführung 1994 stieg der Anteil der initial nach Nierentransplantation mit Tacrolimus behandelten Patienten kontinuierlich auf mittlerweile rund 91 \% im Jahr 2011 (USRDS 2013 Annual Data Report).

\subsubsection{Transplantatabstoßung (Rejektion)}

Das zentrale Problem der Transplantationsmedizin stellt die Abstoßungsreaktion des Empfängerorganismus dar, weshalb die immunsuppressive Therapie auf die Unterdrückung der transplantatspezifischen Immunantwort, also auf eine fortdauernde Immuntoleranz abzielt. Ursächlich für diesen Rejektionsprozess sind im Wesentlichen die über den Major-Histokompatibilitätskomplex (MHC)präsentierten Fremdantigene, die durch den T-Zell-Rezeptor (TZR) spezialisierter CD4+-T-Zellen erkannt werden. Zur vollständigen Aktivierung der naiven T-Lymphozyten ist überdies die Bindung ihres kostimulativen CD28-Rezeptors an professionelle antigenpräsentierende Zellen (APC) erforderlich (Denton et al. 1999). Die nachfolgende Rekrutierung unterschiedlicher Tyrosinkinasen sowie die Phosphorylierung der Phospholipase C (PLC) induziert über die Bildung von $\mathrm{IP}_{3}$ (Inositol-1,4,5-trisphosphat) die Erhöhung der intrazellulären Calciumkonzentration (Crabtree und Olson 2002, Duplay et al. 1994).

Die anschließende Bindung von Calciumionen $\left(\mathrm{Ca}^{2+}\right)$ an das zytoplasmatische multifunktionelle CalmodulinProtein (CaM) sowie die Serin/Threonin-Phosphatase Calcineurin (CN) führen zur Ablösung der autoinhibitorischen Domäne vom nun konformationsveränderten Calcineurin, woraufhin dessen Bindemotiv mit dem Calmodulin/ $\mathrm{Ca}^{2+}-K o m p l e x$ interagiert und sich ein aktiviertes Holoenzym formiert. 
Dieses wiederum initiiert die Dephosphorylierung des Transkriptionsfaktors NFAT (nuclear factor of activated T-cells), der nach nukleärer Translokation die Transkription diverser immunregulativer Zielgene moduliert (Crabtree und Olson 2002, Klee et al. 1998). Insbesondere durch die De-novo-Synthese von IL2 (interleukin 2) als das unmittelbare Ereignis einer effizienten antigenspezifischen T-Zellaktivierung wird die künftige T-Zell-abhängige Immunantwort organisiert (Malek und Bayer 2004). Die auto- und parakrinen Effekte dieses potenten Wachstumsfaktors induzieren die Proliferation und klonale Vervielfältigung der CD4+-T-Zellen, sodass sie im Zuge dieser Fremdaktivierung über direkten Zellkontakt und Zytokinsekretion zur Interaktion mit den Effektorzellen der Abstoßungsreaktion befähigt sind. Insgesamt begünstigen die Aktivitäts- und Funktionalitätssteigerung der beteiligten Lymphozyten und Makrophagen die Produktion von Alloantikörpern, die antigenspezifische Zelllyse und letztlich auch die verzögert eintretende hypersensitive Reaktion. Die finale Konsequenz all dieser Mechanismen stellt letztlich die Zerstörung des Transplantats dar (Denton et al. 1999).

\subsubsection{Wirkmechanismus der Calcineurininhibitoren (CNI)}

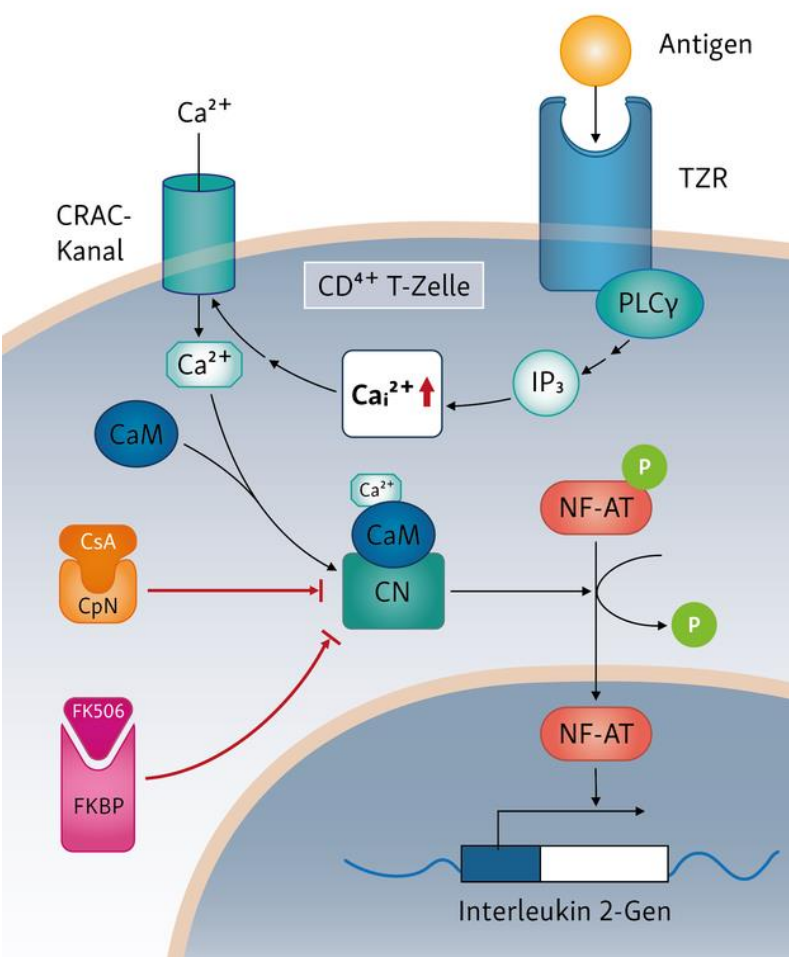

Abbildung 3: Wirkmechanismus der Calcineurininhibitoren. CRAC, $\mathrm{Ca}^{2+}$ release-activated $\mathrm{Ca}^{2+}$ (Becknell et al. 2012, Seite 1050).
Im Kontext einer permanenten medikamentösen Rejektionsprophylaxe etablierten sich die mikrobiellen, chemisch jedoch völlig differenten Pharmaka, Cyclosporin A (CsA) und Tacrolimus (FK506) als besonders effektive Immunsuppressiva, indem sie die eingangs skizzierte Signaltransduktionskaskade durch Inhibition des Schlüsselenzyms Calcineurin unterbinden. Der Wirkmechanismus beruht dabei auf einer Komplexbildung mit endogenen ubiquitären Peptidyl-Prolyl-cis/trans-Isomerasen, sogenannten Immunophilinen, die daraufhin die $\mathrm{Ca}^{2+} /$ Calmodulin-aktivierte Phosphatase Calcineurin sterisch blockieren und ferner die Translokation des Transkriptionsfaktors NFAT sowie die T-Zellabhängige Produktion von IL2 hemmen. Während CsA spezifisch mit dem Immunophilin Cyclophilin (CpN) interagiert, stellt Tacrolimus, vermutlich aufgrund einer höheren Bindungsaffinität zu seinem charakteristischen Rezeptor FKBP12 (FK506-binding protein) das 10- bis 100-fach potentere Therapeutikum dar (Crabtree und Olson 2002, Denton et al. 1999, Griffith JP et al. 1995, Oka und Yoshimura 1996). 


\subsubsection{Tacrolimus}

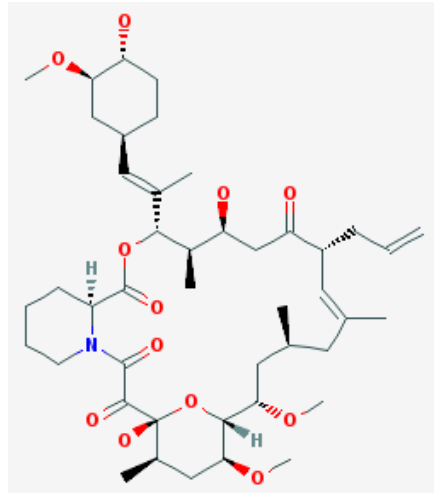

Abbildung 4: Strukturformel Tacrolimus (PubChem Substance Database, NCBI 2015).
Das 23-gliedrige makrocyclische Polyketid Tacrolimus wurde erstmalig 1984 von Wissenschaftlern der Fujisawa Pharmaceutical Co. Ltd (Osaka, Japan) aus den Fermentationsprodukten des grampositiven Bakteriums Streptomyces tsukubaensis, eines ubiquitären pilzähnlichen Bodenmikroorganismus, isoliert und im Jahre 1994 aufgrund seiner potenten immunsuppressiven Eigenschaften in der Transplantatmedizin sowie zur therapeutischen Anwendung bei Autoimmunerkrankungen zugelassen (Barbarino et al. 2013, Barreiro et al. 2012, Kino et al. 1987).

Trotz eines bereits ein bis zwei Stunden nach oraler Applikation eintretenden Blutkonzentrationsmaximums bedingen die physikochemischen Charakteristika des Tacrolimus wie ausgeprägte Lipophilie mit einhergehender Wasserunlöslichkeit äußerst niedrige Absorptionsraten. Die orale Bioverfügbarkeit des Pharmakons beträgt aufgrund eines umfangreichen präsystemischen Metabolismus näherungsweise $25 \%$, kann intra- und interindividuell jedoch in einem Bereich zwischen 4 und $89 \%$ variieren. Angesichts seiner ausgeprägten Bindungsaffinität zu Erythrozyten ist der messbare Tacrolimusspiegel im Vollblut signifikant etwa 15-fach höher als korrespondierende Konzentrationen im Plasma, wo der Wirkstoff bis zu 99 \% gebunden an spezifische Plasmaproteine vorliegt (Nagase et al. 1994, Wallemacq und Verbeeck 2001, Venkataramanan et al. 1995). Das somit wenig prädiktive pharmakologische Profil wird wesentlich durch die gastrointestinalen Isoenzyme CYP3A4 und CYP3A5 der Cytochrom P450 (CYP) 3A-Subfamilie und das P-Glykoprotein, ein in den Zottenspitzen der Dünndarmenterozyten ansässigen Effluxtransporter, bestimmt (Benet et al. 1999, Hebert 1997, Iwasaki 2007). Die durchschnittliche Halbwertszeit von 12 Stunden zeigt mit Abweichungen von 3,5 bis 40,5 Stunden ebenfalls starke Heterogenität (Wallemacq und Verbeeck 2001). Infolge des insgesamt äußerst umfangreichen Detoxifikationsprozesses werden weniger als 0,5 bis $1 \%$ des Tacrolimus unverändert über Urin und Fäkes abgesondert, wohingegen die Elimination der bislang rund 15 identifizierten Metabolite zu über 95 \% biliär erfolgt (Barbarino et al. 2013, Möller et al. 1999). Da auch zahlreiche weitere Wirkstoffe einem CYP3A4/5- bzw.

Tabelle 3: Tacrolimus-Zielspiegel Nierentransplantation (modifiziert nach Wallemacq et al. 2009, Seite 142).

\begin{tabular}{c|c}
\hline \multicolumn{2}{|c}{ Tacrolimus } \\
\hline $\begin{array}{c}\text { Monate nach } \\
\text { Transplantation }\end{array}$ & $\begin{array}{c}\text { Co-Zielspiegel } \\
\text { (ng/ml) }\end{array}$ \\
\hline $0-3$ & $10-15$ \\
$3-12$ & $5-15$ \\
$>12$ & $5-10$ \\
\hline
\end{tabular}

${ }^{1}$ Ohne Induktionstherapie
P-Glykoprotein-abhängigen Firstpass-Effekt unterliegen, evoziert deren Koadministration relevante Arzneiwechselwirkungen und erfordert eine entsprechende Dosisanpassung (Christians et al. 2002).

Die Kontrolle des Medikamentenspiegels basiert in der Klinik auf der Bestimmung des Talspiegels $\left(C_{0}\right)$, der signifikant mit Effektivität und Toxizität des Tacrolimus korreliert (Venkataramanan et al. 2001). Die etablierten Standards nach erfolgter Nierentransplantation empfehlen initial einen Zielspiegel von 10 bis $15 \mathrm{ng} / \mathrm{ml}$, wohingen in der Erhaltungstherapie die therapeutische Dosis des Talspiegels auf 5 bis $10 \mathrm{ng} / \mathrm{ml}$ reduziert wird (siehe Tabelle 3). Pharmakokinetische, -dynamische sowie -genetische Variabilitäten bedingen jedoch eine stark 
individualisierte Langzeittherapie unter engmaschigem Monitoring (Laskow et al. 1996, Wallemacq et al. 2009).

Wie sich bereits frühzeitig in umfangreichen Dosisfindungsstudien zeigte, entstehen die mehrheitlich im initialen Intervall der immunsuppressiven Therapie konstatierten Nebenwirkungen dosisabhängig und gehen infolge der angestrebten Wirkstoffreduktion und der damit einhergehenden restringierten Plasmakonzentration im Verlauf der Behandlung zurück (Kershner und Fitzsimmons 1996, Laskow et al. 1996). Als bedeutende, sowohl unter Tacrolimus als auch unter Cyclosporin auftretende Nebenwirkungen sind Neuro- und Nephrotoxizität, arterielle Hypertonie, Hyperglykämie, gastrointestinale Störungen, Infektionen sowie Malignome zu nennen. Indes zählen zu frequenten Tacrolimus-assoziierten Symptomen Alopezie, Tremor und Parästhesien sowie diabetogene Effekte (Barbarino et al. 2013, Grimm et al. 2006, Pirsch et al. 1997, Tricot et al. 2005).

Trotz ähnlicher Nebenwirkungsprofile bestehen weiterhin Kontroversen hinsichtlich des nephrotoxischen Potentials der Calcineurininhibitoren, welches den häufigsten dosislimitierenden Faktor der beiden Pharmakone darstellt und als „Achillesferse“ der modernen immunsuppressiven Therapie den Begriff CNINephrotoxizität prägte (Naesens et al. 2009). Da entsprechende Daten überwiegend auf der Evaluation nierentransplantierter Patienten basieren, kann allerdings schwerlich zwischen medikamenteninduzierten Organschäden und anderen pathogenetischen Faktoren renaler Dysfunktionen differenziert werden (Barbarino et al. 2013). Zudem leisten lokale Gegebenheiten wie Variabilitäten der CYP3A4/5-Isoenzymsowie der P-Glykoprotein-Expression, das Alter der transplantierten Niere, Salzdepletion, die Einnahme nichtsteriodaler Antirheumatika oder Polymorphismen im TGFB1-Gen einen weitaus wichtigeren Beitrag für die Suszeptibilität einer CNI-Nephrotoxizität als die systemische Exposition durch Calcineurininhibitoren selbst. Letztlich lieferten zahlreiche human- und tierexperimentelle Vergleichsstudien substantielle Hinweise für die geringeren nephrotoxischen Eigenschaften des Tacrolimus gegenüber dem Cyclosporin A (Naesens et al. 2009).

\subsection{Tacrolimus und BMPR1A}

Einen konkreten Zusammenhang zwischen dem Immunsuppressivum Tacrolimus sowie dem Typ I- Rezeptor BMPR1A stellt die Datenbank Nephroseq her (nephroseq.org). Die integrative Plattform erlaubt durch funktionale Annotation nierenrelevante Transkriptomdaten im Kontext spezifischer klinischer Phänotypen zu betrachten und somit generierte Daten speziesübergreifend zu konsolidieren (Mayer 2012). Der Abruf dieser Ressource lieferte eine umfassende Genexpressionsanalyse, in deren Rahmen die Stimulation des epithelialen Zelltypus MCF7 mit dem Pharmakon FK506 erfolgte und anschließend den BMPR1A als einer der $1 \%$ signifikant hochregulierten Gene identifi-

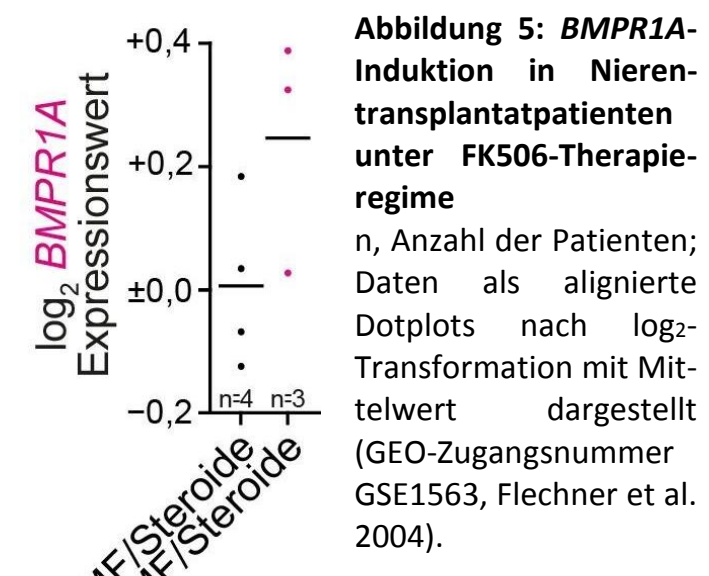


zierte. Der daraufhin erfolgte Abgleich mit assoziierten klinischen Studien führte schließlich auf die Publikation der Arbeitsgruppe Flechner et al., die mittels DNA-Mikroarray das Genexpressionsprofil transplantierter und nachfolgend biopsierter Patienten unter verschiedenen immunsuppressiven Therapieregimen bestimmt hatten (Flencher et al. 2004). Bei der Betrachtung von Patienten, die zum Zeitpunkt der Biopsie einen Serumkreatininwert von ungefähr $2 \mathrm{mg} / \mathrm{dl}$ aufwiesen, manifestierte sich im Kollektiv der mit Tacrolimus behandelten Patienten im Vergleich zu denjenigen unter alternativer Calcineurininhibitortherapie mit Cyclosporin eine deutliche Hochregulation von BMPR1A. ${ }^{1}$

\footnotetext{
${ }^{1}$ Angaben zu Material und Methodik von genontologischen Analysen mittels webbasierter Datenbanken befinden sich im Anhang (siehe 6.1, S. 98/99)
} 


\section{$1.7 \quad$ Zielsetzung}

Unterschiedliche tierexperimentelle Studien der akuten und chronischen Niereninsuffizienz konnten nach Applikation des rekombinanten humanen BMP7 (rhBMP7) das renoprotektive sowie das über den direkten TGF-ß1-Antagonismus vermittelte regenerative Potential des Wachstumsfaktors bestätigen. Hierzu bindet das Morphogen an spezifische BMP-Typ I- und Typ II-Rezeptoren, die wiederum über Induktion einer intrinsischen SMAD-Signalkaskade die Transkription BMP7-spezifischer Zielgene vermitteln. Im Tubulusepithel zeigten sich erhöhte Expressionsmuster des bone morphogenetic protein receptor $1 \mathrm{~A}$ (BMPR1A) und bedingen die lokal präferierte BMP7-Interaktion mit BMPR1A. Überdies implizieren die selektive Induktion des Bmpr1a im fibrotischen Nierenparenchym ebenso wie die nach Bmpr1a-Deletion im proximalen Tubulusepithel konstatierte Exazerbation der renalen Fibrogenese die nephroprotektive Wirksamkeit von BMPR1A. Gleichzeitig ergaben systembiologische Datenanalysen über die webbasierte Plattform Nephroseq fundierte Hinweise auf eine Tacrolimus-abhängige BMPR1A-Induktion in epithelialen Zellentitäten.

Ziel dieser Arbeit war es daher, den hypothetisch angenommenen Einfluss des Immunsuppressivums auf die Expression des BMP7-Rezeptors BMPR1A sowohl in vitro als auch in vivo im Tubulusepithel zu determinieren und zugrundeliegende molekulare Induktionsmechanismen näher zu charakterisieren. Als zentrales Moment wurden insbesondere die Sensibilisierung des Tubulusepithels für die antifibrotische Wirkung des BMP7 sowie die Intensivierung der BMP7-Signaltransduktion fokussiert und daraus die folgende Fragestellung abgeleitet:

(a) Inwiefern gelingt es, durch die Gabe des Immunsuppressivums Tacrolimus (sowie anderer immunsuppressiver Pharmaka) den BMP7-Rezeptor BMPR1A sowohl in vitro in der humanen proximalen Tubulusepithelzelllinie HK-2 als auch in vivo in fibrotischen murinen Nieren zu induzieren?

(b) Welchen Einfluss hat die hier diskutierte Tacrolimusexposition auf die Expression der BMP7Rezeptoren BMPR2 und BMPR1B? Lässt sich gegebenenfalls die Spezifität des Pharmakons hinsichtlich der BMPR1A-Modulation konkretisieren?

(c) Mildert die Supplementation von geringdosiertem Tacrolimus effektiv die experimentell induzierte renale Fibrosierung im Mausmodell der unilateralen Ureterobstruktion? In welchem Maße lässt sich durch Applikation des Immunsuppressivums der Prozess der epithelial-mesenchymalen Transition inhibieren?

(d) Welche molekularen Mechanismen können bei der postulierten Hochregulation des Rezeptors etabliert werden?

(e) Lassen sich mögliche charakteristische Induktionsphänomene des Tacrolimus auch in humanen Transplantatnieren nachweisen? 


\section{MATERIAL UND METHODEN}

\section{$2.1 \quad$ Material}

\subsubsection{Geräte}

Analysewaage

Ausgießstation Leica EG $1120 \mathrm{H}$

Autoklav

BRAUN Dampfgarer 3216

$\mathrm{CO}_{2}$-Inkubator BB 6220

ChemiDoc $^{\mathrm{TM}}$ MP System

Digitalkamera OLYMPUS SC30

Eismaschine

Fastblot $^{\mathrm{TM}}$

CCD-Kamera OLYMPUS XM10

Gewebeinfiltrationsautomat Leica TP1020

Kühl- $\left(+4{ }^{\circ} \mathrm{C}\right)$, Gefrierschrank $\left(-20^{\circ} \mathrm{C}\right)$

Kühlzentrifuge 3-18KS

Mikroliterzentrifuge $5424 \mathrm{R}$

Mikroskop OLYMPUS BX43

Mikroskop Axiovert S100 TV

Mikrotom Leica RM 2165

NanoDrop ${ }^{\text {TM }} 2000$ Spektralphotometer

Paraffin-Streckbad GFL 1052

Pipettierhilfe pipetus ${ }^{\circledR}$

Plattformschüttler Rotamax 120

Rollermixer SRT6

Spannungsgerät MS 300V Power Supply

Sterilbank NuAire Biological Safety Cabinets

StepOnePlus ${ }^{\text {TM }}$ Real-Time PCR-System

Stickstofftank APOLLO

Thermocycler Mastercycler ep gradient S

ThermoMixer ${ }^{\circledR}$ comfort

Tissuelyser LT

Trockenschrank

Ultratiefkühlgerät $\left(-80^{\circ} \mathrm{C}\right)$

Vortex Genie $2^{\text {TM }}$

Wärmebad GFL 1083

Zentrifuge PerfectSpin $\mathrm{P}$
Sartorius, Göttingen, Deutschland

Leica Microsystems, Wetzlar, Deutschland

INTEGRA Biosciences, Fernwald,Deutschland

BRAUN, Kronberg, Deutschland

Heraeus, Hanau, Deutschland

Bio-Rad, München, Deutschland

OLYMPUS, Hamburg, Deutschland

Scotsman Ice Systems, Vernon Hills, USA

Biometra, Göttingen, Deutschland

OLYMPUS, Hamburg, Deutschland

Leica Microsystems, Wetzlar, Deutschland

LIEBHERR, Bulle, Schweiz

Sigma, Osterode am Harz, Deutschland

Eppendorf, Hamburg, Deutschland

OLYMPUS, Hamburg, Deutschland

ZEISS, Oberkochen, Deutschland

Leica Microsystems, Wetzlar, Deutschland

Thermo Fisher Scientific, Waltham, USA

GFL mbH, Burgwedel, Deutschland

Hirschmann, Eberstadt, Deutschland

Heidolph Instruments, Schwabach, Deutschland Bibby Scientific Limited, Staffordshire, UK

Major Science, Saratoga, USA

NuAire, Plymouth, USA

Applied Biosystems (Life Technologies), Carlsbad, USA

Messer Griesheim, Krefeld, Deutschland

Eppendorf, Hamburg, Deutschland

Eppendorf, Hamburg, Deutschland

Qiagen, Hilden, Deutschland

Memmert, Schwabach, Deutschland

SANYO Electric Biomedical Co., Osaka, Japan

Bender \& Hobein, Zürich, Schweiz

GFL mbH, Burgwedel, Deutschland

PEQLAB Biotechnologie, Erlangen, Deutschland 


\subsubsection{Software und Datenbanken}

BLAST

cellSens Dimension 1.6

cell^D

Ensembl

GraphPad Prism 5.0

Image $1.49 \mathrm{n}$

MS Office

StepOne ${ }^{\mathrm{TM}}$-Software $\mathrm{V} 2.3$
http://blast.ncbi.nlm.nih.gov/Blast.cgi

OLYMPUS SIS, Münster, Deutschland

OLYMPUS SIS, Münster, Deutschland

http://www.ensembl.org/index.html

GraphPad Software Inc., La Jolla, USA

http://imagej.nih.gov/ij/

Microsoft, Redmond, USA

Applied Biosystems (Life Technologies), Carlsbad, USA

TFSEARCH: Searching Transcription Factor Binding Sites (ver 1.3) http://www.cbrc.jp/research/db/TFSEARCH.html

\subsubsection{Gebrauchsmaterialien}

CELLSTAR $^{\circledR}$ 6-Well-Zellkulturplatte

Greiner Bio-One, Frickenhausen, Deutschland

CELLSTAR $^{\circledast}$ Tubes, $15 / 50 \mathrm{ml}$

Dako Pen

Eindeckgläser SuperFrost ${ }^{\circledast}$ Plus

Filterpapier

MicroAmp ${ }^{\circledast}$ Fast 8-Tube Strip (0,1 ml)

MicroAmp ${ }^{\circledast}$ Fast Optical 96-Well Reaction Plate

MicroAmp ${ }^{\circledR}$ Optical Adhesive Film

Microscope Cover Slips, 24*40 mm

Mikroliterpipetten, 10/100/1000 $\mu \mathrm{l}$

Zählkammer Neubauer improved

Nunc $^{\text {TM }}$ CryoTube $^{\text {TM }}$ Vials $(1,8 \mathrm{ml})$

NuPAGE ${ }^{\circledR}$ Novex $^{\circledR} 4-12 \%$ Bis-Tris-Proteingel

(1,5 mm, 10 well bzw. $1,5 \mathrm{~mm}, 15$ well)

Pipetten, 5/10/25 ml

Biosphere ${ }^{\circledR}$ Filterspitzen, 10/100/1000 $\mu \mathrm{l}$

Rotilabo ${ }^{\circledR}$-Einbettkassetten für Biopsien, 500 Stück

Safe Lock Tubes (1,5/2 ml)

Skalpelle

Stainless Steel Beads, $5 \mathrm{~mm}$

Tissue-Tek ${ }^{\circledast}$ Cryomold $^{\circledR}$ Intermediate

Tissue-Tek O.C.T. Compound, $125 \mathrm{ml}$

XCell SureLock ${ }^{\text {TM }}$ Electrophoresis Cell

Zellkulturflasche mit Luftfilter T75

Zellschaber

Greiner Bio-One, Frickenhausen, Deutschland

Dako, Glostrup, Dänemark

Menzel-Gläser, Braunschweig, Deutschland

Bio-Rad, München, Deutschland

Applied Biosystems (Life Technologies), Carlsbad, USA

Applied Biosystems (Life Technologies), Carlsbad, USA

Applied Biosystems (Life Technologies), Carlsbad, USA

Menzel-Gläser, Braunschweig, Deutschland

Eppendorf, Hamburg, Deutschland

Hecht Assistent, Sondheim, Deutschland

Thermo Fisher Scientific, Waltham, USA

Invitrogen (Life Technologies), Carlsbad, USA

Sarstedt, Nümbrecht, Deutschland

Sarstedt, Nümbrecht, Deutschland

Carl Roth, Karlsruhe, Deutschland

Eppendorf, Hamburg, Deutschland

FEATHER Safety Razor Co., Osaka, Japan

Qiagen, Hilden, Deutschland

SAKURA, Alphen aan den Rijn, Niederlande

SAKURA, Alphen aan den Rijn, Niederlande Invitrogen (Life Technologies), Carlsbad, USA

Sarstedt, Nümbrecht, Deutschland

Sarstedt, Nümbrecht, Deutschland

\subsubsection{Chemikalien}

Accutase $^{\circledR}$ solution

AEC Substrate-Chromogen

Albumin Fraktion $\mathrm{V}$

Sigma-Aldrich, Steinheim, Deutschland

Dako, Glostrup, Dänemark

Carl Roth, Karlsruhe, Deutschland 
Amphotericin B, lyophilisiert

Bouin's solution

Bovine Serum Albumin (BSA)

cOmplete ULTRA Tablets, EDTA-free

Chloroform $\geq 99,8 \%\left(\mathrm{CHCl}_{3}\right)$

di-Natriumhydrogenphosphat-Dihydrat $\left(\mathrm{Na}_{2} \mathrm{HPO}_{4} \times 2 \mathrm{H}_{2} \mathrm{O}\right)$

DMEM, low glucose

DMSO

Dulbecco's PBS

Thermo Scientific ${ }^{\mathrm{TM}}$ Shandon ${ }^{\mathrm{TM}}$ Immu-Mount $^{\mathrm{TM}}$

Eosin G-Lösung 0,5 \% wässrig

Entellan ${ }^{\circledR}$

Essigsäure $100 \%\left(\mathrm{C}_{2} \mathrm{H}_{4} \mathrm{O}_{2}\right)$

Ethanol $\geq 99,8 \%\left(\mathrm{C}_{2} \mathrm{H}_{5} \mathrm{OH}\right)$

Ethanol $99 \%$

Fast SYBR ${ }^{\circledR}$ Green Mastermix

Forene ${ }^{\circledR} 100 \%$ (V/V), Wirkstoff: Isofluran

Hämalaunlösung sauer nach Mayer

Heparin-Natrium, 25000 I.E/5 ml

Kaliumchlorid $(\mathrm{KCl})$

di-Kaliumhydrogenphosphat-Trihydrat $\left(\mathrm{K}_{2} \mathrm{HPO}_{4} \times 3 \mathrm{H}_{2} \mathrm{O}\right)$

Magermilchpulver

2-Mercaptoethanol $99 \%\left(\mathrm{C}_{2} \mathrm{H}_{6} \mathrm{OS}\right)$

10 mM dNTP Mix

Natriumchlorid $(\mathrm{NaCl})$

Hybond $^{\mathrm{TM}}$-ECL Nitrocellulose Membran

Novex ${ }^{\circledR}$ Sharp Pre-stained Protein Standard

NP40 Cell Lysis Buffer

Nuclease-Free Water

NuPAGE ${ }^{\circledR}$ LDS Sample Buffer (4X)

NuPAGE ${ }^{\circledR}$ MOPS SDS Running Buffer (20X)

Oligo (dt) 12 - 18 Primer

PEG 40 Castor Oil

Penicillin-Streptomycin

Perjodsäurelösung $1 \%\left(\mathrm{H}_{5} \mathrm{IO}_{6}+\mathrm{H}_{2} \mathrm{O}\right)$

Phosphataseinhibitor Cocktail 2

Pierce $^{\mathrm{TM}}$ Fast Semi-Dry Transfer Buffer (10X)

Quantum 286

Restore $^{\mathrm{TM}}$ Western Blot Stripping Buffer

RNaseOut $^{\mathrm{TM}}$ Recombinant Ribonuclease Inhibitor

Roti ${ }^{\circledR}$-Histofix, Formaldehydlösung $4 \%$

$\mathrm{RT}^{2}$ SYBR Green ROX qRT-PCR-Mastermix
BIOCHROM, Berlin, Deutschland

Sigma-Aldrich, Steinheim, Deutschland

Sigma-Aldrich, Steinheim, Deutschland

Roche Diagnostics, Mannheim, Deutschland

Merck, Darmstadt, Deutschland

Merck, Darmstadt, Deutschland

Gibco (Life Technologies), Carlsbad, USA

Sigma-Aldrich, Steinheim, Deutschland

Gibco (Life Technologies), Carlsbad, USA

Thermo Fisher Scientific, Waltham, USA

Carl Roth, Karlsruhe, Deutschland

Merck, Darmstadt, Deutschland

Merck, Darmstadt, Deutschland

Carl Roth, Karlsruhe, Deutschland

Chemie-Vertrieb, Hannover, Deutschland

Applied Biosystems (Life Technologies), Carlsbad, USA

AbbVie, Ludwigshafen, Deutschland

Carl Roth, Karlsruhe, Deutschland

ROTEXMEDICA, Trittau, Deutschland

Merck, Darmstadt, Deutschland

Merck, Darmstadt, Deutschland

Carl Roth, Karlsruhe, Deutschland

Carl Roth, Karlsruhe, Deutschland

Invitrogen (Life Technologies), Carlsbad, USA

Carl Roth, Karlsruhe, Deutschland

GE Healthcare, Freiburg, Deutschland

Novex (Life Technologies), Carlsbad, USA

Invitrogen (Life Technologies), Carlsbad, USA

Qiagen, Hilden, Deutschland

Novex (Life Technologies), Carlsbad, USA

Novex (Life Technologies), Carlsbad, USA

Invitrogen (Life Technologies), Carlsbad, USA

Spectrum Chemical Mfg. Corp., New Brunswick, USA

Sigma-Aldrich, Steinheim, Deutschland

Carl Roth, Karlsruhe, Deutschland

Sigma-Aldrich, Steinheim, Deutschland

Thermo Fisher Scientific, Waltham, USA

PAA Laboratories, Pasching, Österreich

Thermo Fisher Scientific, Waltham, USA

Invitrogen (Life Technologies), Carlsbad, USA

Carl Roth, Karlsruhe, Deutschland

Qiagen, Hilden, Deutschland 
Schiffs Reagenz

1-Step ${ }^{\text {TM }}$ NBT/ BCIP Substrate Solution

Target Retrieval Solution, pH 9 (10X)

Trypsin-EDTA solution

TRIS PUFFERAN ${ }^{\circledR}$

TRIzol ${ }^{\circledR}$ Reagent

Tween ${ }^{\circledR} 20$ (Polyoxyethylen(20)-sorbitan-monolaurat)

VECTASHIELD Mounting Medium with DAPI

Wasserstoffperoxid $30 \%\left(\mathrm{H}_{2} \mathrm{O}_{2}\right)$

Xylol > $98 \%\left(\mathrm{C}_{8} \mathrm{H}_{10}\right)$

\subsubsection{Stimulanzien}

Cycloheximide $\geq 93,0 \%$ (HPLC), $\left(\mathrm{C}_{15} \mathrm{H}_{23} \mathrm{NO}_{4}\right)$

Cyclosporin $A \geq 95 \%$ (HPLC), $\left(\mathrm{C}_{62} \mathrm{H}_{111} \mathrm{~N}_{11} \mathrm{O}_{12}\right)$

FK506 monohydrate $\geq 98 \%$ (HPLC), $\left(\mathrm{C}_{44} \mathrm{H}_{69} \mathrm{NO}_{12} \times \mathrm{H}_{2} \mathrm{O}\right)$

FK506 $\geq 99 \%$

Mycophenolate mofetil $\geq 98 \%(\mathrm{HPLC}),\left(\mathrm{C}_{23} \mathrm{H}_{31} \mathrm{NO}_{7}\right)$

\subsubsection{Kitsysteme}

DNase I, Amplification Grade

FK506-ELISA Kit [HRP]

20X LumiGLO ${ }^{\circledR}$ Reagent and 20X Peroxide

PureLink ${ }^{\circledR}$ RNA Mini-Kit

Pierce $^{\mathrm{TM}}$ BCA Protein Assay Kit

$\mathrm{RT}^{2}$ Profiler ${ }^{\mathrm{TM}}$ PCR-Array Human Transcription Factors (PAHS-075Z)

SuperScript ${ }^{\circledR}$ || Reverse Transcriptase

SuperSignal ${ }^{\mathrm{TM}}$ West Pico Chemiluminescent Substrate

Trichrome Stain (Masson) Kit

Weigert's iron hematoxylin solution (Set)

VECTASTAIN Elite ABC Kit (Universal)
Carl Roth, Karlsruhe, Deutschland

Thermo Fisher Scientific, Waltham, USA

Dako, Glostrup, Dänemark

Sigma-Aldrich, Steinheim, Deutschland

Carl Roth, Karlsruhe, Deutschland

Ambion (Life Technologies), Carlsbad, USA

Carl Roth, Karlsruhe, Deutschland

VECTOR LABORATORIES, Burlingame, USA

Carl Roth, Karlsruhe, Deutschland

Carl Roth, Karlsruhe, Deutschland

Sigma-Aldrich, Steinheim, Deutschland Sigma-Aldrich, Steinheim, Deutschland Sigma-Aldrich, Steinheim, Deutschland abcam, Cambridge, UK

Sigma-Aldrich, Steinheim, Deutschland

Invitrogen (Life Technologies), Carlsbad, USA

Novus Biologicals LCC, Littleton, USA

Cell Signaling, Danvers, USA

Ambion (Life Technologies), Carlsbad, USA

Thermo Fisher Scientific, Waltham, USA

Qiagen, Hilden, Deutschland

Invitrogen (Life Technologies), Carlsbad, USA

Thermo Fisher Scientific, Waltham, USA

Sigma-Aldrich, Steinheim, Deutschland

Sigma-Aldrich, Steinheim, Deutschland

VECTOR LABORATORIES, Burlingame, USA 


\subsubsection{Puffer und Lösungen}

\section{Allgemeine Puffer und Lösungen}

10x PBS (phosphate-buffered saline), $\mathrm{pH} 7,5$

\begin{tabular}{rll} 
Menge & Substanz & Konzentration (10X) \\
\hline \hline $80,00 \mathrm{~g}$ & $\mathrm{NaCl}$ & $140 \mathrm{mM}$ \\
$2,00 \mathrm{~g}$ & $\mathrm{KCl}$ & $2,5 \mathrm{mM}$ \\
$11,50 \mathrm{~g}$ & $\mathrm{Na}_{2} \mathrm{HPO}_{4} \times 2 \mathrm{H}_{2} \mathrm{O}$ & $6,5 \mathrm{mM}$ \\
$2,00 \mathrm{~g}$ & $\mathrm{~K}_{2} \mathrm{HPO}_{4} \times 3 \mathrm{H}_{2} \mathrm{O}$ & $1,5 \mathrm{mM}$ \\
$1000 \mathrm{ml}$ & $\mathrm{ddH}_{2} \mathrm{O}$ &
\end{tabular}

10X TBS (Tris-buffered saline)

\begin{tabular}{lll} 
Menge & Substanz & Konzentration (10X) \\
\hline \hline $87,00 \mathrm{~g}$ & $\mathrm{NaCl}$ & $1,5 \mathrm{M}$ \\
$24,23 \mathrm{~g}$ & Tris & $200 \mathrm{mM}$
\end{tabular}

$1000 \mathrm{ml} \quad \mathrm{ddH}_{2} \mathrm{O}$

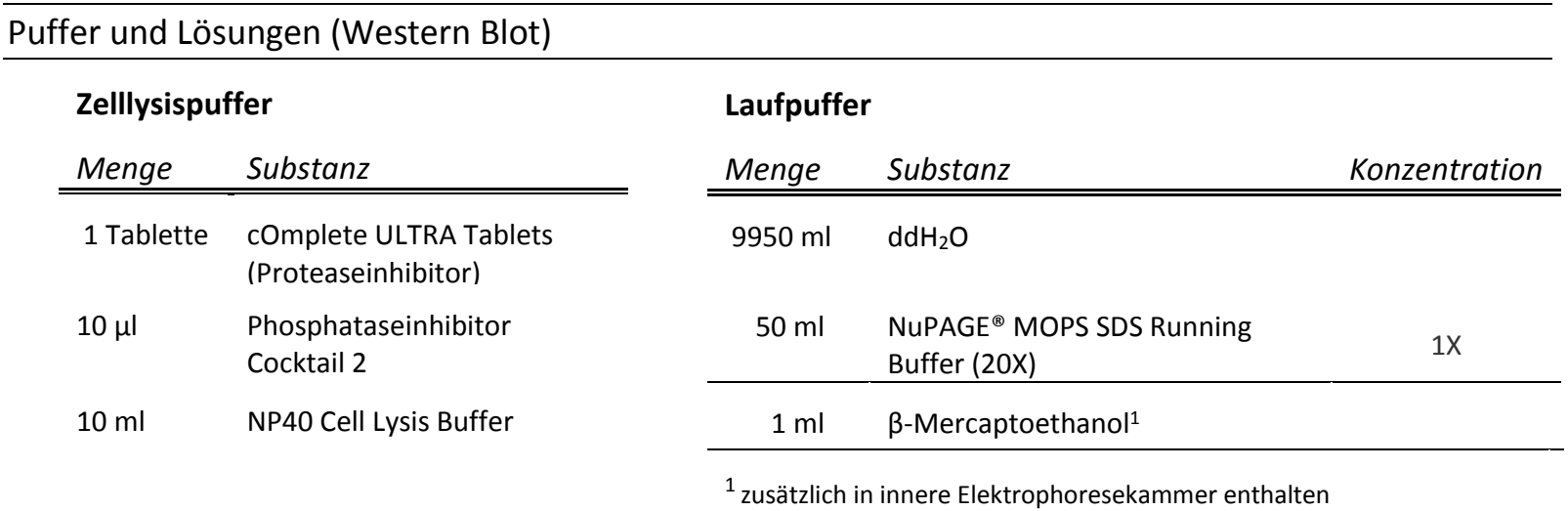

Sample Buffer

\begin{tabular}{rlr} 
Menge & Substanz & Konzentration \\
\hline \hline $200 \mu \mathrm{l}$ & $\begin{array}{l}\text { NuPAGE } \\
\text { Buffer }(4 \mathrm{X})\end{array}$ & $2 \mathrm{X}$ Sample \\
$120 \mu \mathrm{l}$ & $\mathrm{ddH}_{2} \mathrm{O}$ \\
$80 \mu \mathrm{l}$ & $\beta$-Mercaptoethanol &
\end{tabular}

Transferpuffer

\begin{tabular}{clc} 
Menge & Substanz & Konzentration \\
\hline \hline $5 \mathrm{ml}$ & $\begin{array}{l}\text { Pierce }{ }^{\mathrm{TM}} \text { Fast Semi-Dry } \\
\text { Transfer Buffer (10X) }\end{array}$ & $1 \mathrm{X}$ \\
$50 \mathrm{ml}$ & $\mathrm{dd}_{2} \mathrm{O}$
\end{tabular}

$50 \mathrm{ml} \quad \mathrm{ddH}_{2} \mathrm{O}$

\section{Waschpuffer}

TBS Tween (TBS-T)

\begin{aligned} & Menge Substanz \\ & \hline \hline $999 \mathrm{ml}$ TBS (1X) \\ & $1 \mathrm{ml}$ Tween $20 \% \\ &$\hline\end{aligned}

BSA (2 bzw. $5 \%)$

\begin{aligned} \multicolumn{1}{l}{ Menge } & Substanz \\ \hline \hline $1 \mathrm{~g} \mathrm{bzw.2,5 \textrm {g }} &$ BSA \\ $50 \mathrm{ml} &$ TBS-T \\ \hline Primär-AK: & $\begin{array}{l}\text { BMPR1A, Bmpr2, GAPDH, } \\ \text { Arnt, pSmad1/5/9 }\end{array}\end{aligned}$

Milch (2 bzw. $5 \%$ )

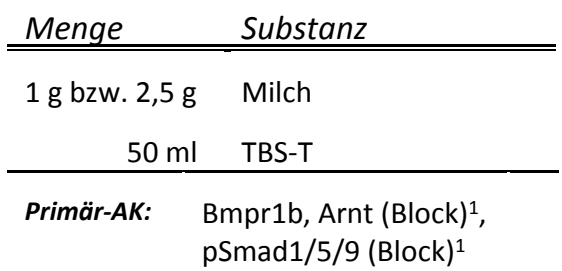

${ }^{1}$ Anwendung gemäß Herstellerprotokoll (Cell Signaling): Blockierlösung 5\%ige Milch; Verdünnung von Primär- und Sekundär-AK in $2 \%$ igem bzw.5\%igem BSA; bei übrigen primären AK stimmen Basis von Blockier- und Antikörperverdünnungslösung überein 


\section{Entwicklerlösung}

20X LumiGLO ${ }^{\circledR}$ Reagent and 20X Peroxide

\begin{tabular}{llc} 
Menge & Substanz & Konzentration \\
\hline \hline $0,5 \mathrm{ml}$ & LumiGLO $^{\circledR}(20 \mathrm{X})$ & $1 \mathrm{X}$ \\
$0,5 \mathrm{ml}$ & Peroxide (20X) & $1 \mathrm{X}$ \\
$9,0 \mathrm{ml}$ & $\mathrm{ddH}_{2} \mathrm{O}$ &
\end{tabular}

SuperSignalтм West Pico Chemiluminescent Substrate

\begin{tabular}{ll} 
Menge & Substanz \\
\hline \hline $0,5 \mathrm{ml}$ & SuperSignalтм Peroxide Solution \\
$0,5 \mathrm{ml}$ & SuperSignalтм Luminol Solution
\end{tabular}

\begin{tabular}{|c|c|c|}
\hline \multicolumn{3}{|c|}{ Blocklösung } \\
\hline Menge & Substanz & Konzentration \\
\hline $\begin{array}{c}1 \text { Tropfen } \\
(50 u l)\end{array}$ & $\begin{array}{l}\text { VECTASTAIN }{ }^{\circledR} \text { Normal } \\
\text { Horse Serum }\end{array}$ & 1:100 \\
\hline $5 \mathrm{ml}$ & PBS & \\
\hline \multicolumn{3}{|c|}{ Citratpuffer } \\
\hline Menge & Substanz & Konzentration \\
\hline $10 \mathrm{ml}$ & $\begin{array}{l}\text { Target Retrieval Solution, } \\
\text { pH } 9 \text { (10X) }\end{array}$ & $1 X$ \\
\hline $90 \mathrm{ml}$ & $\mathrm{ddH}_{2} \mathrm{O}$ & \\
\hline
\end{tabular}

\section{Peroxidaseblock}

\begin{tabular}{ccc} 
Menge & Substanz & Konzentration \\
\hline \hline $10 \mathrm{ml}$ & $\mathrm{H}_{2} \mathrm{O}_{2} 30 \%$ & $0,3 \%$ \\
$990 \mathrm{ml}$ & $\mathrm{ddH}_{2} \mathrm{O}$ &
\end{tabular}

\section{ABC-Lösung}

\begin{tabular}{llc} 
Menge & Substanz & Konzentration \\
\cline { 3 - 3 } 2 Tropfen & VECTASTAIN $^{\circledR}$ Reagent A $^{1}$ & $1: 50$ \\
2 Tropfen & VECTASTAIN $^{\circledR}$ Reagent B & $1: 50$ \\
$5 \mathrm{ml}$ & PBS & \\
\hline
\end{tabular}

${ }^{1}$ Reagent $\mathrm{A} \rightarrow$ Avidin $\mathrm{DH}$

${ }^{2}$ Reagent $\mathrm{B} \rightarrow$ Biotinylated Horseradish Peroxidase $\mathrm{H}$

\subsubsection{Antikörper}

Alexa Fluor $^{\circledR} 488$ Esel anti-Kaninchen polyklonal lgG

Alexa Fluor ${ }^{\circledR} 568$ Esel anti-Kaninchen polyklonal IgG

HRP-konjugiertes Kaninchen-anti-Maus polyklonal IgG

HRP-konjugiertes Ziege-anti-Kaninchen polyklonal IgG

Kaninchen-anti-Maus pSmad 1/5/9 polyklonal IgG

Kaninchen-anti-Maus- $\alpha$ SMA polyklonal IgG

Kaninchen-anti-Maus-Collagen-1 polyklonal IgG

Kaninchen-anti-Maus-Fsp1 polyklonal IgG

Kaninchen-anti-Mensch/Maus-ARNT polyklonal IgG

Kaninchen-anti-Mensch/Maus-BMPR1A polyklonal IgG

Kaninchen-anti-Maus-Bmpr1a polyklonal IgG

Invitrogen, Carlsbad, USA

Invitrogen, Carlsbad, USA

Dako, Glostrup, Dänemark

Dako, Glostrup, Dänemark

Cell Signaling, Danvers, USA

LifeSpan BioSciences, Seattle, USA

abcam, Cambridge, UK

Sigma-Aldrich, Steinheim, Deutschland

Cell Signaling, Danvers, USA

Merck Millipore, Billerica, USA

Santa Cruz, Dallas, USA 
Kaninchen-anti-Maus-Bmpr1b polyklonal IgG

Kaninchen-anti-Maus-Bmpr2 polyklonal IgG

Maus-anti-Kaninchen-GAPDH monoklonal IgG
Merck Millipore, Billerica, USA

abcam, Cambridge, UK

HyTest Ltd., Turku, Finnland

\subsubsection{Oligonukleotide}

\subsubsection{Primer für die qRT-PCR}

Tabelle 4: Ziel-mRNA und Primersequenzen für die qRT-PCR

\begin{tabular}{|c|c|c|c|}
\hline Ziel-mRNA & Primer Vorwärtsstrang & Primer Rückwärtsstrang & Hersteller \\
\hline$B M P R 1 A$ & GGA CAT TGC TTT GCC ATC ATA G & GGG CTT TTG GAG AAT CTT TGC & $\begin{array}{c}\text { Primerdesign, } \\
\text { Southampton, UK }\end{array}$ \\
\hline$B M P R 1 B$ & AGG TAA TTT GCT CTT GTG TTG TAA G & TTT CTT TGT GCT TCT GAG ATT GG & $\begin{array}{l}\text { Primerdesign, } \\
\text { Southampton, UK }\end{array}$ \\
\hline BMPR2 & CAA AGA TAG GTC CCA GTT TAA CAC & TCT CTA TGG AAA TGA AAT AAC AAG GC & $\begin{array}{c}\text { Primerdesign, } \\
\text { Southampton, UK }\end{array}$ \\
\hline GAPDH & Nicht einsehbar & Nicht einsehbar & $\begin{array}{c}\text { Primerdesign, } \\
\text { Southampton, UK }\end{array}$ \\
\hline Acta2 & CTC TTC CAG CCA TCT TTC ATT G & GTT GTT AGC ATA GAG ATC CTT CCT & $\begin{array}{c}\text { Primerdesign, } \\
\text { Southampton, UK }\end{array}$ \\
\hline$A c t b$ & Nicht einsehbar & Nicht einsehbar & $\begin{array}{c}\text { Primerdesign, } \\
\text { Southampton, UK }\end{array}$ \\
\hline Arnt & CCT TCA GTG CTA TGT CTC TTC C & CAG TCT CAG GAG GAA AGT TGG A & $\begin{array}{c}\text { Primerdesign, } \\
\text { Southampton, UK }\end{array}$ \\
\hline$A r$ & AAG AGC CGC TGA AGG GAA A & GAG ACG ACA AGA TGG GCA ATT & $\begin{array}{c}\text { Primerdesign, } \\
\text { Southampton, UK }\end{array}$ \\
\hline Bmpr1a & TGT CAT TCT AGC CAT GTT TTA CC & ACC AAG GAT CAG ATG TGA GAC & $\begin{array}{l}\text { Primerdesign, } \\
\text { Southampton, UK }\end{array}$ \\
\hline Bmpr1b & GCG GCC TAT GCC ATT TAC AC & AGT CTC GAT GGG CGA TTG C & $\begin{array}{c}\text { Eurofins MWG Operon, } \\
\text { Ebersberg, DE }\end{array}$ \\
\hline Bmpr2 & TCC ACC TGG GTC ATC TCC A & CCC TGT CAC TGC CAT TGT TG & $\begin{array}{c}\text { Eurofins MWG Operon, } \\
\text { Ebersberg, DE }\end{array}$ \\
\hline Cebpb & ACG GGA CTG ACG CAA CAC & AAC AAA AAC AAA ACC AAA AAC ATC AAC & $\begin{array}{c}\text { Primerdesign, } \\
\text { Southampton, UK }\end{array}$ \\
\hline Collagen-1a1 & ATG GAT TCC CGT TCG AGT ACG & TCA GCT GGA TAG CGA CAT CG & $\begin{array}{l}\text { Eurofins MWG Operon, } \\
\text { Ebersberg, DE }\end{array}$ \\
\hline Creb1 & TTG AGT AAG GCT GAG CAT GAT C & TCT TAA CTT TAA ACT GCG GAA CAC & $\begin{array}{c}\text { Primerdesign, } \\
\text { Southampton, UK }\end{array}$ \\
\hline Gapdh & Nicht einsehbar & Nicht einsehbar & $\begin{array}{c}\text { Primerdesign, } \\
\text { Southampton, UK }\end{array}$ \\
\hline Gata3 & GAA GAC TTT ATT GTA CCT GGA TAG C & TGG ACA TCA GAC TTA GTG GTT TC & $\begin{array}{c}\text { Primerdesign, } \\
\text { Southampton, UK }\end{array}$ \\
\hline Max & GTG AGT GAG TGA GCG AGT GA & GGA GGG GTG GAG GGA AGG & $\begin{array}{c}\text { Primerdesign, } \\
\text { Southampton, UK }\end{array}$ \\
\hline Fsp1 & AGA AGT GAA GAC TCC TCA GAT GA & TGT GCG AAG AAG CCA GAG T & $\begin{array}{c}\text { Primerdesign, } \\
\text { Southampton, UK }\end{array}$ \\
\hline
\end{tabular}




\subsubsection{SiRNA}

Tabelle 5: Verwendete siRNA mit Zielsequenzen (Santa Cruz Biotechnology, Dallas, USA)

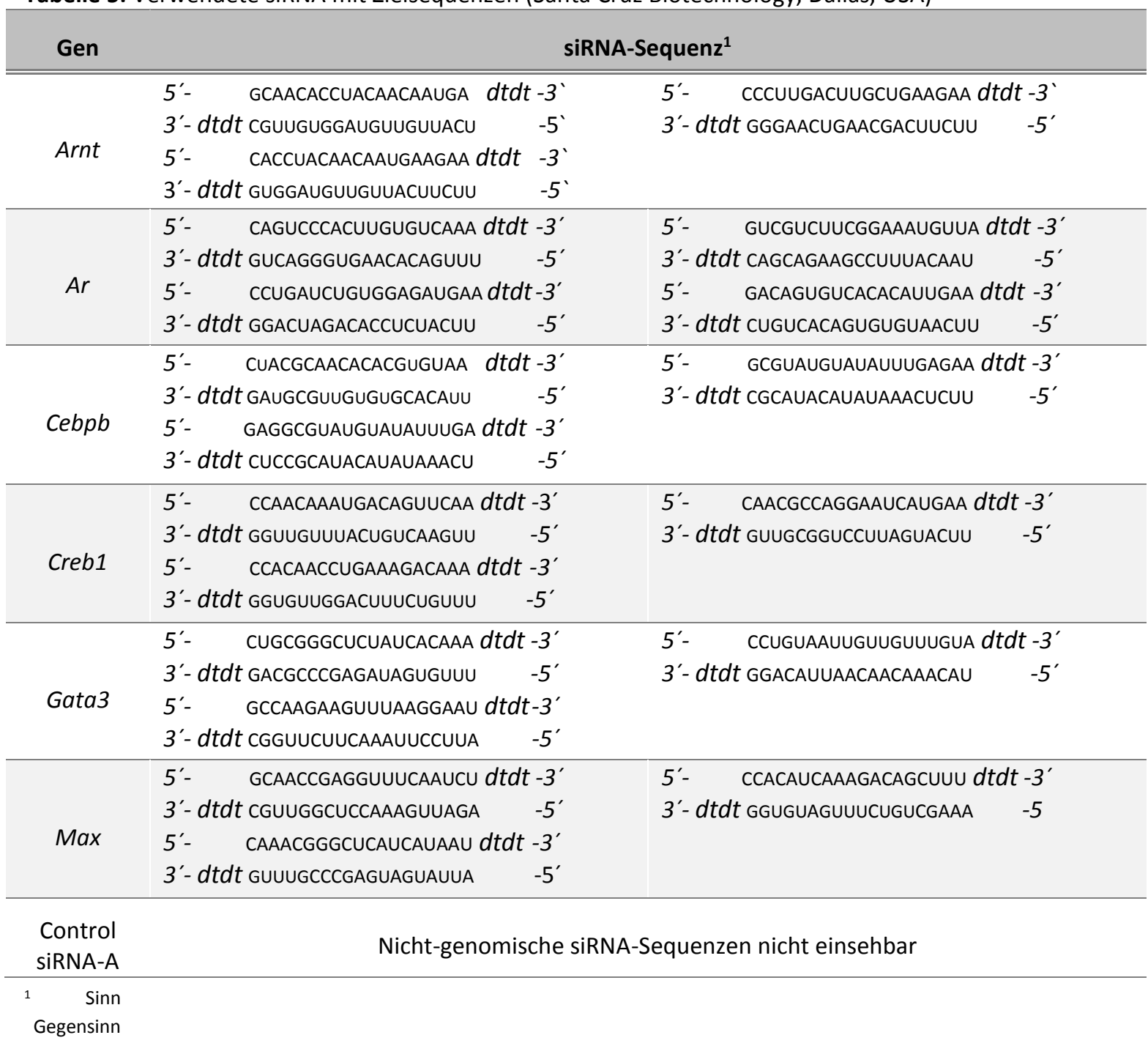

\subsubsection{Zelllinien}

\section{HK-2-Zellen}

Die von Ryan et al. etablierte Zelllinie human kidney-2 (HK-2) leitet sich von proximalen Tubulusepithelzellen des nicht infizierten humanen Nierenkortex ab und wird von der American Type Culture Collection (ATCC, Manassas, USA) mittels eines rekombinanten Retrovirusvektors, der die Gene E6 und E7 des humanen Papillomavirus 16 (HPV 16) transduziert, erzeugt. Die Immortalisierung gewährleistet die bessere Kultivierbarkeit einer stabilen Zellreihe mit kürzerer Generationsdauer unter Erhalt phäno- und funktionstypischer Charakteristika. Als Ausdruck einer signifikanten tubuloepithelialen Morphologie zeigen sich lange, dicht stehende Mikrovilli, junktionale Komplexe sowie die Expression typischer Enzyme des Bürstensaums wie die alkalische und die saure Phosphatase, die $\gamma$-Glutamyltranspeptidase und die Leucin-Aminopeptidase. Ferner sind die Moleküle Cytokeratin, $\alpha_{3} \beta_{1}$-Integrin, Fibronectin sowie die Reagibilität gegenüber Parathyrin nachweislich (Ryan et al. 1994). 


\section{MCT-Zellen}

Die murine proximale tubuloepitheliale Zelllinie MCT wurde aus dem mikrodissezierten renalen Kortex 8 bis 10 Wochen alter naiver Swiss Jim Lambert $(\mathrm{SJL}) / \mathrm{J}\left(\mathrm{H}-2^{\mathrm{s}}\right)$ Mäuse isoliert und zur Generierung einer kontinuierlichen Zellkultur in vitro mit einem replikationsdefizienten simian virus 40 (SV40) immortalisiert (Haverty et al. 1988). Transformierte MCT-Zellen weisen als deutliches morphologisches Charakteristikum proximaler Tubulusepithelzellen einen ausgeprägten Bürstensaum auf, dessen Membran die dort typischerweise lokalisierte alkalische Phosphatase enthält. Diese als adhärenter Monolayer wachsende Zellreihe exprimiert weiterhin Rezeptoren des Parathyrins und des Angiotensin II sowie spezifische, in die apikale Membran integrierte, Transportsysteme. Ferner gelangen die Detektion des epithelialen Markerproteins Cytokeratin und des für die tubuläre Basalmembran spezifische 3M-1 Glykoproteins sowie die Identifikation hochaffiner epidermal growth factor (EGF)-Bindungsstellen (Haverty et al. 1988, Wolf et al. 1993).

\subsubsection{Murines Nierengewebe}

Tierexperimentelle Studien erfolgten an 8 bis 12 Wochen alten C57BL/6J-Mäusen aus der Zucht der Arbeitsgruppe Zeisberg, Abteilung Nephrologie und Rheumatologie, Universitätsmedizin Göttingen. Die erforderliche Genehmigung zur Durchführung eines Tierversuchsvorhabens wurde von der Tierschutzkommission der Medizinischen Fakultät der Universität Göttingen und dem Niedersächsischen Landesamt für Verbraucherschutz und Lebensmittelsicherheit (LAVES) erteilt (Antragsnummer G14/1565).

\subsubsection{Humanes Nierengewebe}

Weiterhin wurden bioptisch gewonnene Gewebepräparate aus den Jahren 2004 bis 2008 von Transplantatpatienten verschiedener immunsuppressiver Therapieregime analysiert. Die Charakterisierung der durch HOPE-Technik fixierten und anschließend in Paraffin eingebetteten Resektate erfolgte mittels immunhistologischer Methoden. Ein positives Votum der Ethikkommission der Universitätsmedizin Göttingen bezüglich des Forschungsvorhabens an humanem Gewebematerial ist vorliegend (Antragsnummer DOK_128_2015).

Tabelle 6: Kohorte von Nierentransplantierten mit klinischen und histologischen Charakteristika

\begin{tabular}{c|c|c|c|c|c|c}
\hline ID\# & $\begin{array}{c}\text { Fibrosie- } \\
\text { rungsgrad } \\
{[\%]}\end{array}$ & Prämedikation & Histologische Diagnose & $\begin{array}{c}\text { Kreatinine } \\
{[\mathrm{mg} / \mathrm{dL}]}\end{array}$ & $\begin{array}{c}\text { BUN } \\
{[\mathrm{mg} / \mathrm{dL}]}\end{array}$ & $\begin{array}{c}\text { eGFR } \\
{[\mathrm{mL} / \mathrm{min}]}\end{array}$ \\
\hline \hline S3542 & $20-25$ & MMF+Cortison & Nephrosklerose, FSGS & 3,4 & 92 & 20 \\
\hline S3752 & $25-30$ & CSA & CNI-Nephrotoxizität & 3,3 & 56 & 25 \\
\hline S3696 & 25 & Cortison & FSGS & 5,2 & 72 & 12 \\
\hline S3564 & 20 & FK506 & Nephrosklerose & 3,2 & 74 & 16 \\
\hline S3896 & $15-20$ & FK506 & ADPKD & 3,03 & 97 & 23 \\
\hline
\end{tabular}

${ }^{1}$ ADKD: Autosomal dominante polyzystische Nierenerkrankung (autosomal dominant polycystic kidney disease) 


\section{$2.2 \quad$ Methoden}

\subsubsection{Zellkultur}

Sämtliche Arbeitsschritte in der Zellkultur vollzogen sich unter der Sterilbank und waren von gründlicher Hände- und Arbeitsplatzdesinfektion begleitet. Sowohl HK-2- als auch MCT-Zellen wuchsen als Monolayer in T75-Zellkulturflaschen in einem $37^{\circ} \mathrm{C}$ warm temperierten $\mathrm{CO}_{2}$-Inkubator bei $100 \%$ relativer Luftfeuchtigkeit und $5 \% \mathrm{CO}_{2}$-Begasung. Die kontinuierliche Kultur beider Zelllinien erfolgte in $10 \mathrm{ml}$ Nährmedium pro Zellkulturflasche bis zu einer etwa 80\%igen Konfluenz. Zur Subkultivierung wurde der Zellrasen in $10 \mathrm{ml}$ PBS gewaschen und die adhärenten Zellen mit $3 \mathrm{ml}$ der jeweiligen Enzymlösung vom Kulturflaschenboden abgelöst (Zellkulturmedien und Enzymlösungen siehe Tabelle 7). Anschließend wurde die Zellsuspension durch Hinzugabe von $10 \mathrm{ml}$ PBS verdünnt, in ein 15-ml-Falcon überführt und ein Zellpellet durch fünfminütige Zentrifugation bei $1200 \mathrm{U} / \mathrm{min}$ gewonnen. Dieses konnte nun in neue Zellkulturflaschen mit frischem Vollmedium resuspendiert werden. War im Rahmen der ausgeführten Experimente eine kontinuierliche Zellzahl erforderlich, erfolgte vor der Aussaat eine Auszählung in der Neubauer-Zählkammer.

Tabelle 7: Zellkulturmedien und Enzymlösungen der einzelnen Zelllinien

\begin{tabular}{ccc} 
Zelllinie & HK-2 & MCT \\
\hline \hline Quantum 286 & DMEM, low glucose \\
Zellkulturme- & +100 Units $/ \mathrm{ml}$ Penicillin & $+100 \mathrm{Units} / \mathrm{ml}$ Penicillin \\
dium (+Zusätze) & $+100 \mu \mathrm{g} / \mathrm{ml} \mathrm{Streptomycin}$ & $+100 \mu \mathrm{g} / \mathrm{ml}$ Streptomycin \\
& $+2,5 \mu \mathrm{g} / \mathrm{ml}$ Amphotericin B & $+2,5 \mu \mathrm{g} / \mathrm{ml}$ Amphotericin B \\
& & $+10 \%$ FCS \\
\hline Enzymlösung & Accutase & Trypsin-EDTA solution \\
\hline
\end{tabular}

Überschüssige Zellen wurden als $500 \mu \mathrm{l}$ Zellsuspension mit einem gleichen Volumen Einfriermedium (FCS + DMSO; 1 zu 5) versetzt, in ein Kryoröhrchen überführt und anschließend im Stickstofftank bei $-196^{\circ} \mathrm{C}$ kryokonserviert.

\subsubsection{Tiermodell und Studiendesign}

Weiterhin wurde der Einfluss des Pharmakons Tacrolimus auf die Expression von Bmpr1a in vivo in fibrotischen Nieren unter Anwendung des etablierten nicht-proteinurischen Mausmodells UUO untersucht. Die im European Neuroscience Institute Göttingen (ENI-G) untergebrachten C57BL/6J-Mäuse wurden bei konstanter Temperatur in Käfigen gehalten und unterlagen einem kontinuierlichem 12-Stunden-Licht- und 12Stunden-Dunkelzyklus. Die insgesamt 24 Tiere wurden vier Untersuchungsgruppen mit jeweils sechs Tieren zugewiesen. Bereits zwei Tage vor der Operation erfolgte in drei Gruppen die Gabe von FK506 per os. Als Kontrollkollektiv fungierte eine mit einem vehicle (5\%ige Glucoselösung) behandelte Gruppe.

\section{Berechnung der Medikamentendosierung}

In den drei behandelten Kollektiven betrugen die angestrebten Medikamentendosierungen 0,02, 0,075 und $0,2 \mathrm{mg} / \mathrm{kg} \mathrm{KG} / \mathrm{Tag}$ Tacrolimus. Je Maus wurde ein Gewicht von $20 \mathrm{~g}$ sowie eine durchschnittliche Trinkmenge von $3 \mathrm{ml}$ pro Tag kalkuliert. Zur Herstellung einer oral applizierbaren Suspension wurde zunächst 
das als kristallines Pulver erhältliche Medikament FK506 (Reinheitsgrad $\geq 98 \%$ ) mit einer isotonischen Kochsalzlösung, die als weitere Komponenten 1,25 \% PEG 40 Castor Oil sowie 2 \% Ethanol enthielt, vermengt. Vor Verabreichung konnte die daraus resultierende Stocklösung $(0,2 \mathrm{mg} / \mathrm{ml}) \mathrm{mit} 5 \%$ iger Glucoselösung auf die zuvor errechneten Konzentrationen Tacrolimus im Trinkwasser verdünnt werden (siehe Tabelle 8). Eine Lagerung der Suspension erfolgte als Aliquot bei $-20^{\circ} \mathrm{C}$.

Tabelle 8: Angestrebte FK506-Medikamentendosis pro Maus sowie FK506-Konzentration im Trinkwasser

\begin{tabular}{lcccc} 
& Kontrollkollektiv & Gruppe 1 & Gruppe 2 & Gruppe 3 \\
\hline \hline FK506 $[\mathrm{mg} / \mathrm{kg} \mathrm{KG} / \mathrm{Tag}]$ & 0 & 0,02 & 0,075 & 0,2 \\
\hline FK506/Trinkwasser $[\mathrm{\mu g} / \mathrm{ml}]$ & 0 & 0,13 & 0,5 & 1,3
\end{tabular}

\section{Tiermodell}

Zur Induktion einer experimentellen renalen Fibrogenese mittels unilateraler Ureterobstruktion (UUO) wurden die C57BL/6J-Mäuse zunächst per subkutaner Buprenorphininjektion (0,1 mg/kg KG) analgosediert und anschließend durch Inhalation von Isofluran ( 2 bis $3 \%$ ) anästhesiert. Sämtliche Operationen wurden vom stellvertretenden Leiter des Tierversuchsvorhabens, Herrn Dr. med. Björn Tampe, durchgeführt. Nach sorgfältiger Desinfektion des Abdomens und Inzision des Peritoneums konnte der Ureter der linken Niere vom umliegenden Gewebe freipräpariert und durch zwei Ligaturen im Abstand von etwa $5 \mathrm{~mm}$ in den oberen zwei Dritteln des Ureters abgebunden werden. Die kontralaterale Niere galt als scheinoperiert (sham) und fungierte demzufolge als Kontrolle.

\section{Präparation der Versuchstiere}

Im Anschluss an die zehntägige Harnleiterokklusion wurde den mit Isofluran narkotisierten Versuchstieren zunächst $500 \mu \mathrm{l}$ arterielles Blut mithilfe von Heparin-getränkten Glaspipetten aus dem Auge entnommen, in ein Eppendorftube überführt und bei $-80^{\circ} \mathrm{C}$ tiefgefroren. Die Sektion der Tiere umfasste deren Tötung mittels zervikaler Dislokation sowie die Eröffnung der Peritonealhöhle zur Entnahme von Herz, Milz sowie beider Nieren. Die herauspräparierten Organe wurden zu gleichen Teilen gedrittelt, je ein Teil in ein Kryoröhrchen, ein weiteres in Tissue-Tek ${ }^{\circledR}$ Cryomold $^{\circledR}$-Einbettformen überführt, übergangsweise in flüssigem Stickstoff gelagert und bei $-80^{\circ} \mathrm{C}$ kryokonserviert. Das letzte Gewebepräparat wurde auf eine Einbettkassette verteilt und mittels einer phosphatgepufferten $4 \%$ igen Formaldehydlösung (Roti ${ }^{\circledR}$-Histofix) fixiert. Die anschließende Entsorgung entsprach den allgemeinen Richtlinien.

\subsubsection{Enzym-gekoppelter Immunadsorptionstest (ELISA)}

Immunanalytische Nachweismethoden beruhen im Wesentlichen auf der Antigen-Antikörper-Komplexierung, einer grundlegenden Reaktion der funktionierenden adaptiven Immunabwehr, und ermöglichten bereits zu Beginn des 20. Jahrhunderts erste immunchemische Analysen zu quantitativen Zwecken (Arrhenius 1907). Grundstein für eine heutzutage vielseitige Anwendung legten schließlich Yalow und Berson durch die Etablierung der Radioimmunoassays (Yalow und Berson 1960). Mit dem Ersatz der kurzlebigen Radio- 
isotope durch enzymmarkierte Antikörper, die ein auf der Oberfläche immobilisiertes Analytmolekül konjugieren, gelang schließlich die kommerzielle Ausbreitung des Enzym-gekoppelten Immunadsorptionstests (enzyme-linked immunosorbent assay, ELISA) insbesondere als serologisches Nachweisverfahren in der klinischen Diagnostik (Engvall und Perlmann 1971, Van Weemen und Schuurs 1971). Gemäß der zugrundeliegenden Mechanismen erfolgt eine Klassifizierung in kompetitive und nonkompetitive Assays, wobei ersterer in der vorliegenden Arbeit zur Bestimmung der Tacrolimuskonzentration im Vollblut entsprechend behandelter Versuchstiere genutzt wurde.

\section{Direkter kompetitiver ELISA (cELISA)}

Das Prinzip des kompetitiven ELISA (cELISA) basiert auf der Kompetition zwischen Analyt und Analyt-Protein-Konjugat um eine limitierte Anzahl freier Antikörperbindungsstellen. Bei dem in dieser Arbeit verwendeten direkten Testformat fungiert das Analyt-Protein-Konjugat synchron als Kompetitor und Enzymtracer, da sein signalerzeugendes Label, die Meerrettichperoxidase (horseradish peroxidase, HRP), auch die Detektion und Quantifizierung des fraglichen Analyten erlaubt. Folglich korrelieren Serumpositivität und die Intensität der Farbreaktion negativ miteinander und bedingen geringe bzw. keine Farbreaktionen bei hohen Analytkonzentrationen. Vice versa überwiegt in negativen Seren die Bindung des Enzymtracers, woraus eine verstärkte Signalerzeugung resultiert.

Unter Verwendung des handelsüblichen spezifizierten FK506 ELISA Kits [HRP] wurden zunächst $25 \mu \mathrm{L}$ der Standardreihe bzw. der murinen Vollblutprobe auf eine bereits mit dem absorbierten Anti-FK506-Antikörper vorbeschichtete 96-well-Mikrotiterplatte aufgebracht und unter leichtem Schütteln gleichmäßig verteilt. Daraufhin erfolgte die Zugabe des FK506-HRP-Konjugats. Nach 30-minütiger Inkubation bei Raumtemperatur wurden die Mikrotiterwells mittels PBS-T-Puffer dreimalig gewaschen und somit ungebundene Bestandteile entfernt. Infolge der Zugabe und Einwirkung (15 min) der 3,3',5,5'-Tetramethylbenzidin (TMB)haltigen Substratlösung $(100 \mu \mathrm{L})$ katalysiert die Meerrettichperoxidase in Gegenwart von Wasserstoffperoxid $\left(\mathrm{H}_{2} \mathrm{O}_{2}\right)$ die Oxidation des Chromogens TMB, was in einer deutlichen Blaufärbung resultiert. Der Zusatz eines salzsäurebasierten Reagenz (100 $\mu \mathrm{L})$ führt zur Denaturierung der Peroxidase und induziert damit die Bildung eines gelben Endproduktes mit höherem Extinktionskoeffizienten. Die Messung der optischen Dichte (OD) per Photometer erfolgte abschließend bei einer Wellenlänge von $450 \mathrm{~nm}$.

\section{Quantitative Auswertung}

Zunächst wurde die durchschnittliche Absorption $\left(\mathrm{OD}_{s}\right)$ der internen Standards mit bekannter FK506-Konzentration sowie diejenige des negativen Kontrollserums $\left(\mathrm{OD}_{0}\right)$ berechnet, deren Relation zueinander wiederum die prozentuale Inhibition (PI) der Kontrollseren ausdrückt.

$$
\text { PI [\%] }=100-\frac{\text { ODs }}{\text { ODo }} * 100
$$

Die graphische Darstellung des Hemmungsprozentsatzes gegen die jeweils korrespondierende logarithmierte FK506-Konzentration $\left(\log _{10}\right)$ ergibt die sigmoidale Kalibrierkurve, sodass mittels linearer Interpolation auf den Tacrolimusspiegel im murinen Vollblut geschlossen werden konnte. 


\subsubsection{Histologische Methoden}

\section{Anfertigung und Vorbereitung der Gewebeschnitte}

Die bei der Sektion in der gebrauchsfertigen Formaldehydlösung (Roti ${ }^{\circledR}$-Histofix) gelagerten murinen Organpräparate verblieben dort zur Fixierung über Nacht. Zur Auswaschung des Fixiermittels wurden sie am Folgetag zunächst unter laufendem Leitungswasser $4 \mathrm{~h}$ lang gewässert. Es folgte die eigentliche Dehydrierung im Gewebeinfiltrationsautomaten mittels einer aufsteigenden Alkoholreihe, die Inkubation im Intermediärmedium Chloroform sowie die Durchtränkung mit Paraffin. Innerhalb der Ausgießstation wurde das Gewebe nun mit $56^{\circ} \mathrm{C}$ warmem, flüssigem Paraffin in Blöcke gegossen und auf der Kühlplatte des Gerätes abgekühlt, sodass mit einem Mikrotom Gewebeschnitte in einer Schnittdicke von $3 \mu \mathrm{m}$ angefertigt werden konnten. Diese wurden zur Entfaltung in ein Paraffinstreckbad überführt, glatt auf Objektträger platziert und anschließend über Nacht im Wärmeschrank bei $37^{\circ} \mathrm{C}$ getrocknet.

Die humanen Gewebepräparate wurden nach der von Olert et al. etablierten Fixierungsmethode HOPE (Hepes-glutamic acid buffer mediated Organic solvent Protection Effect), deren Prinzip auf der formaldehydfreien Prozessierung der Resektate sowie einer anschließenden Acetonentwässerung basiert, konserviert und nach der Einbettung in Paraffin mittels Mikrotom geschnitten (Olert et al. 2001).

\section{Hämatoxylin-Eosin-Färbung nach Mayer}

Zunächst erfolgte sowohl in humanen als auch murinen Nierenpräparaten eine Übersichtsfärbung mittels Hämatoxylin-Eosin (HE)-Färbung nach Mayer. Eingangs wurden entsprechende Paraffinschnitte in Xylol (2x $10 \mathrm{~min}$ ) entparaffiniert und innerhalb einer absteigenden Alkoholreihe ( $2 \times 5$ min in EtOH $100 \%$, 1x 5min in EtOH 95 \%, 1x 5 min in EtOH 70 \%, 1x 5 min in EtOH 50 \%, 1x 5 min in EtOH 30 \%) sowie in bidestilliertem Wasser (1x $5 \mathrm{~min}$ ) rehydriert. Es folgte die sechsminütige Inkubation mit Hämalaun sauer nach Mayer und das alkalische Bläuen unter lauwarmem fließendem Leitungswasser (10 min) zur spezifischen Darstellung basophiler Strukturelemente, insbesondere des Zellkernchromatins. Nach kurzem Verweilen der Gewebeschnitte in $\mathrm{ddH}_{2} \mathrm{O}$ wurde durch Anwendung der sauren Eosin G-Lösung 0,5 \% (1 bis 2 min) die Kontrastfärbung des eosinophilen Zytoplasmas erzielt. Abschließend konnten die gefärbten Präparate wiederholt dreimalig in $\mathrm{ddH}_{2} \mathrm{O}$ gespült, mittels einer aufsteigenden Alkoholreihe (1x 1 min in EtOH 96 \%, 1x 4 min in EtOH) sowie Xylol (2x 5 min) dehydriert und definitiv mit dem Schnelldeckmittel Entellan ${ }^{\circledR}$ eingedeckt werden.

\section{Perjodsäure-Schiff-Reaktion}

Der histochemische Nachweis kohlenhydratreicher Strukturen des Kollagens, der Basalmembranen oder der Glykokalyx gelingt mittels Perjodsäure-Schiff-Reaktion (periodic acid-Schiff reaction, PAS) und eignet sich insbesondere zur differenziellen Charakterisierung glomerulärer sowie tubuloepithelialer Strukturen in den humanen und murinen Nierenbiopsien.

Der Entparaffinierung in Xylol (2x $10 \mathrm{~min}$ ) und Inkubation in einer alkoholischen Rehydrierungsreihe (2x 5 min in EtOH 100 \%, 1x 5 min in EtOH 95\%, 1x 5 min in EtOH 70\%, 1x 5 min in EtOH 50 \%, 1x 5 min in EtOH $30 \%)$ sowie in $\mathrm{ddH}_{2} \mathrm{O}(1 \times 5 \mathrm{~min})$ folgte die Oxidation nicht-substituierter Glykolgruppen durch die wässrige 1\%ige Perjodsäurelösung (1x $10 \mathrm{~min}$ ) zu Aldehyden. Nach dem anschließenden Spülen in Leitungswasser (1x $10 \mathrm{~min}$ ) und bidestilliertem Wasser vermittelte die im Schiffs Reagenz enthaltene fuchsinschwef- 
lige Säure (Inkubation 1x 20 min) über die Komplexierung der zuvor oxidierten Aldehydgruppen den chromogenen Farbumschlag in magentarot. Zur Stabilisierung bzw. weiteren Differenzierung der Reaktion wurde das gefärbte Gewebe anschließend 5 min in warmem Leitungswasser gewaschen. Die nukleäre Gegenfärbung erfolgte mittels Hämalaun sauer nach Mayer (1x $5 \mathrm{~min}$ ) und zehnminütiger Bläuung unter laufendem Leitungswasser. Der Dehydrierung mittels absteigender Alkoholreihe (1x 1 min in EtOH $96 \%$, 1x 4 min in EtOH) und Xyxol (2x 5 min) schloss sich letztlich das blasenfreie Eindecken der Präparate mit dem Schnelldeckmittel Entellan ${ }^{\circledR}$ an.

\section{Masson-Trichrom-Färbung}

Die Masson-Trichrom-Färbung (Masson's trichrome stain, MTS) dient der differenzierten Bindegewebsdarstellung. Charakteristisch ist neben der bräunlich-schwarzen Darstellung der Zellkerne und dem ziegelroten Zytoplasma insbesondere die sich kontrastierend von der Umgebung abhebende Blaufärbung des Kollagens.

Zunächst verblieben die fertigen Paraffinschnitte zur Deparaffinierung zweimal für je $10 \mathrm{~min}$ in Xylol, durchliefen im Anschluss eine alkoholische Rehydrierungsreihe (2x 5 min in EtOH 100 \%, 1x 5 min in EtOH $95 \%$, $1 \times 5$ min in EtOH 70 \%, 1x 5 min in EtOH $50 \%, 1 \times 5$ min in EtOH $30 \%$ ) und verblieben für 5 min in bidestilliertem Wasser. Die Präparate wurden nun bei $56^{\circ} \mathrm{C}$ durch 15 -minütige Inkubation in der vorgewärmten Bouin'schen Lösung fixiert, danach für 10 min in Leitungswasser abgekühlt und schließlich bis zur Entfernung der gelben Farben unter fließendem Leitungswasser belassen. Zur Färbung der Zellkerne wurden die Gewebeschnitte 5 min lang in Weigert's Eisenhämatoxylin-Lösung (siehe Tabelle 9) eingetaucht, unter fließendem Leitungswasser über 5 min gebläut und abschließend dreimal mit bidestilliertem Wasser gespült. Daraufhin erfolgte das Einbringen der Präparate in die Biebrich-Scharlachrot-Säurefuchsin-Lösung des Trichrom Stain Kits für 5 min sowie eine weitere Spülung $(3 x)$ mit dd $\mathrm{H}_{2} \mathrm{O}$. Nach einer fünfminütigen Behandlung mit einer Phosphorwolframsäure-/Phosphormolybdän-Arbeitslösung (siehe Tabelle 9) wurden die Schnitte zum Kollagennachweis in Anilinblau (Trichrom Stain Kit) inkubiert, zur deutlicheren Abstufung der Farben zunächst kurz in 1\%iger Essigsäure und daraufhin in bidestilliertem Wasser eingetaucht. Nach dem Färbeprozess wurden die Präparate jeweils kurz mittels einer aufsteigenden Alkoholreihe (1x $1 \mathrm{~min}$ in EtOH 96 \%, 1x 4 min in EtOH) dehydriert sowie in Xylol (2x 5min) geklärt. Abschießend konnten die gefärbten Gewebeschnitte blasenfrei mit dem Schnelleindeckmittel Entellan ${ }^{\circledR}$ eingedeckt werden.

Tabelle 9: Färbelösung Masson-Trichrom

\begin{tabular}{|c|c|c|}
\hline Färbelösung & & Ansatz \\
\hline \multirow{2}{*}{$\begin{array}{l}\text { Weigert's Hämatoxylin-Lösung }{ }^{1} \\
\text { (Weigert's iron hematoxylin solution, Sigma Aldrich) }\end{array}$} & $100 \mathrm{ml}$ & Part A \\
\hline & $100 \mathrm{ml}$ & Part B \\
\hline \multirow{3}{*}{$\begin{array}{l}\text { Phosphorwolframsäure-/Phosphormolybdänsäure- } \\
\text { Arbeitslösung }^{1} \\
\text { (Trichrome Stain (Masson) Kit, Sigma Aldrich) }\end{array}$} & $50 \mathrm{ml}$ & Phosphorwolframsäure \\
\hline & $50 \mathrm{ml}$ & Phosphormolybdänsäure \\
\hline & & \\
\hline
\end{tabular}

\footnotetext{
${ }^{1}$ Hinweis: beide Färbelösungen sind für den jeweiligen Färbeprozess frisch anzusetzen
} 


\section{Immunhistochemie}

Die Anwendung immunhistologischer Färbemethoden erlaubt die Visualisierung im Gewebe vorhandener Makromoleküle im Lichtmikroskop, indem deren antigene Determinante (Epitop) durch gezielt erzeugte Antikörper spezifisch markiert und mithilfe eines zweiten enzymkonjugierten Antikörpers detektiert werden.

Die dazu vorliegenden humanen und murinen Paraffinschnitte wurden zunächst in Xylol entparaffiniert und durch eine absteigende Alkoholreihe (2x 5 min in $\mathrm{EtOH} 100$ \%, 1x 5 min in EtOH 95 \%, 1x 5 min in EtOH 70 \%, $1 \times 5$ min in $\mathrm{EtOH} 50$ \%, 1x 5 min in EtOH $30 \%$ ) sowie die fünfminütige Inkubation in bidestilliertem Wasser rehydriert. Dem anschließenden zweimaligen Waschen in PBS über je 5 min schoss sich die Antigendemaskierung im Citratpuffer an. Hierzu verweilten die Gewebeschnitte für 40 min bei $95^{\circ} \mathrm{C}$ im Dampfgarer, kühlten für weitere 10 min auf Raumtemperatur ab und wurden nochmals zweimal für 5 min in PBS gewaschen. Im Anschluss wurden endogene Peroxidasen durch den 0,3\%igen Peroxidaseblock 30 min lang neutralisiert. Nach drei erneuten Waschschritten in PBS à 5 min erfolgte zur Reduktion unspezifischer Antikörperbindungen die 20-minütige Inkubation der Blocklösung bei Raumtemperatur in der Feuchtkammer. Der Block wurde schließlich abgeklopft und die Gewebeschnitte vollständig mit dem primären Antikörper benetzt, der über Nacht bei $4{ }^{\circ} \mathrm{C}$ in der Feuchtkammer inkubierte (Verdünnung primärer Antikörper siehe Tabelle 10). Am darauffolgenden Tag wurde der in der Blocklösung verdünnte biotinylierte Sekundärantikörper (VECTASTAIN Elite ABC Kit) auf die Gewebeschnitte aufgebracht und dort für 30 min bei Raumtemperatur belassen (Sekundärantikörper siehe Tabelle 10). Dieser Schritt wurde von drei Waschgängen in PBS für 5 min jeweils vor und nach der Inkubation begleitet. Zur Bildung des mit einer Peroxidase konjugierten Avidin-Biotin-Komplexes erfolgte nun für 30 min die Inkubation mit der ABC-Lösung aus dem VECTASTAIN Elite ABC Kit bei Raumtemperatur in der Feuchtkammer. Die Gewebeschnitte wurden nach erneutem Waschen in PBS ( $3 \times 5$ min) mit dem Chromogen 3-Amino-9-ethylcarbazol (AEC) über etwa 6 min inkubiert, welches nach Oxidation durch die Peroxidase den roten Farbumschlag vermittelte. Weiteren drei Waschschritten folgten die Gegenfärbung durch sechsminütiges Verweilen in der Hämalaunlösung sauer nach Mayer sowie die Bläuung unter warmem fließendem Leitungswasser über 5 min. Anschließend konnten die Gewebeschnitte blasenfrei mit dem wässrigen Eindeckmedium Thermo Scientific ${ }^{\mathrm{TM}}$ Shandon $^{\mathrm{TM}}$ Immu-Mount $^{\mathrm{TM}}$ eingedeckt werden.

Tabelle 10: Verwendete Antikörper der Immunhistochemie

\begin{tabular}{c|c|c|c|c|c}
\hline \multicolumn{3}{c|}{ Primärantikörper } & \multicolumn{3}{c}{ Sekundärantikörper $^{1}$} \\
\hline \hline Antigen & Ursprung & Verdünnung & Ursprung & Markierung & Verdünnung \\
\hline BMPR1A $^{2}$ & Kaninchen & $1: 50$ & Pferd & Biotin & $1: 50$ \\
\hline Smad1/5/8 & Kaninchen & $1: 50$ & Pferd & Biotin & $1: 50$ \\
\hline ARNT $^{3}$ & Kaninchen & $1: 100$ & Pferd & Biotin & $1: 50$ \\
\hline
\end{tabular}

1 aus VECTASTAIN Elite ABC Kit: VECTASTAIN ${ }^{\circledR}$ Biotinylated, Universal (Anti-Mouse lgG/Rabbit IgG) Antibody

${ }^{2}$ Anti-BMPR1A und Anti-Smad1/5/8 sowohl für humane als auch murine Gewebeschnitte verwendet

${ }^{3}$ Anti-ARNT ausschließlich für humane Gewebeschnitte verwendet 


\section{Immunfluoreszenz}

Ähnlich dem Prinzip der Immunhistochemie gelingt die Detektion des spezifisch an das Epitop des Zielantigens bindenden Primärantikörpers erst durch Anwendung eines zweiten fluorochromkonjugierten Antikörpers, der wiederum nach Anregung durch Licht einer bestimmten Wellenlänge Fluoreszenzsignale emittiert. Hierzu wurden die murinen Paraffinschnitte durch zweimaliges Verweilen in Xylol für 10 min entparaffiniert und anschließend durch eine absteigende Ethanolreihe (2x 5 min in EtOH $100 \%, 1 \times 5$ min in EtOH $95 \%$, 1x 5 min in $\mathrm{EtOH} 70$ \%, 1x 5 min in EtOH 50 \%, 1x 5 min in EtOH $30 \%$ ) sowie durch fünfminütige Inkubation in bidestilliertem Wasser rehydriert. Nach zwei Waschschritten in PBS für je fünf weitere Minuten wurden die Objektträger in den Citratpuffer überführt und zur Antigendemaskierung für $40 \mathrm{~min}$ bei $95^{\circ} \mathrm{C} \mathrm{im} \mathrm{Dampf-}$ garer belassen. Die Gewebeschnitte verblieben zunächst zur Abkühlung $10 \mathrm{~min}$ bei Raumtemperatur und wurden erneut zweimal für 5 min auf der Kippe gewaschen. Um unspezifische Bindungsstellen zu reduzieren, erfolgte nun zur Absättigung freier Bindungsstellen bei Raumtemperatur in der Feuchtkammer die 30-minütige Inkubation mittels einer Blocklösung. Im Anschluss wurden die in der Blocklösung verdünnten primären Antikörper (siehe Tabelle 11) aufgebracht und über Nacht bei $4^{\circ} \mathrm{C}$ in der Feuchtkammer inkubiert. Am Folgetag wurde nach dreimaliger Waschung der Gewebeschnitte für jeweils 5 min der fluoreszenzmarkierte Sekundärantikörper (siehe Tabelle 11) hinzugefügt und für 45 min bei Raumtemperatur in der Dunkelkammer belassen. Nach weiteren drei Waschgängen à 5 min unter Lichtausschluss erfolgte die Kernfärbung sowie das gleichzeitige Eindecken unter Verwendung des mit dem Fluoreszenzfarbstoff 4',6Diamidin-2-phenylindol (DAPI, blau) versehenen Eindeckmediums VECTASHIELD Mounting Medium.

Tabelle 11: Verwendete Antikörper der Immunfluoreszenz in murinen Gewebeproben

\begin{tabular}{c|c|c|c|c|c}
\hline \multicolumn{3}{c|}{ Primärantikörper } & \multicolumn{3}{c}{ Sekundärantikörper } \\
\hline \hline Antigen & Ursprung & Verdünnung & Ursprung & Markierung & Verdünnung \\
\hline$\alpha$ SMA & Kaninchen & $1: 100$ & Esel & Alexa Fluor 568 & $1: 400$ \\
\hline Fsp1 & Kaninchen & $1: 100$ & Esel & Alexa Fluor 568 & $1: 400$ \\
\hline Collagen-1 & Kaninchen & $1: 500$ & Esel & Alexa Fluor 488 & $1: 400$ \\
\hline
\end{tabular}

\section{Anfertigung histologischer Abbildungen}

Die Aufnahmen der HE-, PAS-, MTS- und immunhistologischen Färbungen wurden am Lichtmikroskop OLYMPUS BX43 mit der installierten Digitalkamera OLXMPUS SC30 in 400-facher Vergrößerung erstellt. Die Anfertigung repräsentativer Abbildungen der Immunfluoreszenz-gefärbten Gewebeschnitte erfolgte am konfokalen Lasermikroskop ZEISS LSM480 der Universitätsmedizin Göttingen in 630-facher Vergrößerung. Dessen 405-nm-Diode ermöglicht durch Anregung des Fluoreszenzfarbstoffs DAPI die Darstellung der Zellkerne in blauer Farbe. Weitere im Konfokalmikroskop integrierte Laser emittieren Licht größerer Wellenlängen, die nach Absorption durch Alexa Fluor ${ }^{\circledR} 488$ - und Alexa Fluor ${ }^{\circledR} 568$-konjugierte Antikörper zur Realisierung grüner bzw. roter Fluoreszenzsignale führen. Das anschließende computergestützte Zusammenlegen der einzelnen Farbkanäle erlaubt die digitale Rekonstruktion des Gesamtereignisses und somit die Lokalisation der jeweiligen Zielantigene. 


\section{Morphometrische Quantifizierung histologischer Präparate}

In PAS-, MTS- und immunhistologischen Färbungen erfolgten die morphometrischen Bildanalysen der murinen Gewebepräparate unter Anwendung der Software cellSens Dimension 1.6. Hierzu wurden zunächst mit der am Lichtmikroskop OLYMPUS BX43 installierten Digitalkamera OLXMPUS SC30 in jedem zu quantifizierenden Schnitt zehn zufällig ausgewählte und sich nicht überlappende Gesichtsfelder am Übergang von Nierenkortex zu Medulla in 200-facher Vergrößerung abfotografiert.

\section{$\underline{\text { PAS-Färbung }}$}

Im Zuge der unilateralen Ureterligation manifestieren sich massive hämodynamische und metabolische Veränderungen, die u. a. zum apoptotischen und nekrotischen Zelluntergang, Minderung des proximalen Bürstensaums und zur Auflösung der kontinuierlich ausgeprägten Basalmembran führen. Als weiteres morphologisches Korrelat ist neben einer ausgeprägten tubulären Dilatation die Formation hyaliner Zylinder (cast) charakteristisch (Chevalier et al. 2009). Diese entstehen infolge der konsekutiven Desquamation des Tubulusepithels sowie durch gelartige Polymerisierung des von Tubuluszellen sezernierten Tamm-HorsfallGlykoproteins und induzieren die intraluminäre Verlegung entsprechender Tubuli (Wangsiripaisan et al. 2001). Die Ausprägung derartiger histopathologischer Veränderungen wurde in PAS-gefärbten Gewebeschnitten anhand des folgenden semiquantitativen Graduierungsschemas bemessen: $0=$ normal, $1=$ mild, $2=$ moderat, 3 = schwerwiegend.

\section{Masson-Trichrom-Färbung}

Zur histopathologischen Beurteilung der interstitiellen Fibrose wurden nach Anlegen eines exakt die Fläche bedeckenden Rasters mit insgesamt 391 × 10 mm² großen Quadraten alle zehn Gesichtsfelder mäanderförmig abgefahren, spezifisch blau gefärbte Kollagenfasern des Interstitiums als positive Fläche identifiziert und ausgezählt. Bereiche wie die sich ebenfalls blau darstellende Adventitia der lokalen Gefäße sowie die Glomeruli selbst wurden nicht quantifiziert. Der Fibrosierungsgrad in Prozent ergab sich schließlich aus dem arithmetischen Mittel der aufsummierten positiven Fläche in Relation zur Gesamtanzahl vorhandener Rasterquadrate.

\section{Immunhistochemie}

Die Evaluierung der visualisierten Zielantigene in ihrer zellulären und subzellulären Lokalisation erfolgte gemäß der in der MTS-Färbung etablierten bildanalytischen Systematik. Nach der Fotografie von je zehn Gesichtsfeldern pro histologischem Schnitt wurden die spezifisch durch das AEC-Chromogen rot gefärbten Flächenanteile mittels der $391 \times 10 \mathrm{~mm}^{2}$ großen Rasterquadrate morphometrisch quantifiziert. Aus dem Verhältnis des pro Niere errechneten Mittelwertes zur insgesamt vorhandenen Bildpunktanzahl ließ sich die prozentuale Proteinexpression ermitteln.

\section{$\underline{\text { Immunfluoreszenz }}$}

Die morphometrische Validierung des Expressionsmusters profibrotischer Antigene wurde am Mikroskop Axiovert S100TV in 400-facher Vergrößerung realisiert. Hierzu wurden je Präparat zunächst zehn zufällig ausgewählte und sich nicht überschneidende Areale am Übergang von renalem Kortex zur Medulla mit der 
CCD-Kamera OLYMPUS XM10 abgebildet und anschließend durch die Software cell^D und ein zum Bildausschnitt kongruentes individualisiertes Raster mit $638 \times 10 \mathrm{~mm}^{2}$ Quadraten analysiert. Vor der systematischen Quantifizierung wurde das Farbschwellenintervall durch das Programm automatisch festgelegt und der Blaufilter zur Darstellung der Zellkerne verwendet. Glomeruli sowie Areale um lokale Blutgefäße wurden nicht ausgezählt. Die relative Expression des Antigens in Prozent ergab sich aus dem Mittelwert der positiv quantifizierten Flächenanteile dividiert durch die Gesamtzahl der Rasterquadrate.

\section{Bildanalyse humaner Gewebepräparate}

Im Falle der aus humanen Biopsien gewonnenen Gewebeschnitten ließ sich aufgrund der teilweise unzureichend erhaltenen Gewebemorphologie keine vollständige Rasterdeckung erstellter Abbildungen realisieren. Statistisch signifikante Bilddatensätze der PAS-, MTS- und immunhistologischen Färbungen konnten dementsprechend nicht generiert werden.

\subsubsection{Quantitative Real-Time PCR (qRT-PCR)}

\section{Stimulation von HK-2-Zellen in vitro}

Zunächst wurden die HK-2-Zellen in 6-Well-Zellkulturplatten zu je 0,6 × $10^{5}$ Zellen pro Well ausgesät und in $2 \mathrm{ml}$ Quantum 286 bis zu einer etwa 80\%igen Konfluenz kultiviert. Die zu untersuchenden Immunsuppressiva CSA, FK506 und MMF wurden in DMSO gelöst und auf die in der Tabelle 12 näher aufgeführten Konzentrationen verdünnt. Die Stimulationsdauer in den entsprechend konzentrierten Substanzen belief sich auf 30 min und $6 \mathrm{~h}$, wobei die gleichzeitige Inkubation je eines Wells in reinem DMSO als Kontrolle diente.

Tabelle 12: Stimulationsschema von HK-2-Zellen für qRT-PCR und Western Blot

\begin{tabular}{cccccc|c}
\hline Medikament & \multicolumn{7}{c}{ Konzentration (ng/ml) } \\
\hline \hline FK506 & 1500 & 150 & 15 & 1,5 & 0,15 & Stimulationsdauer \\
Cyclo A & 1500 & 150 & 15 & 1,5 & 0,15 & 30 min/ \\
MMF & 1500 & 150 & 15 & 1,5 & 0,15 & $6 \mathrm{~h}$ \\
\hline
\end{tabular}

Um den Einfluss des Tacrolimus auf die Translation des BMPR1A zu untersuchen, erfolgte die Aussaat und Kultivierung der HK-2-Zellen in 6-Well-Zellkulturplatten wie eingangs beschrieben. Zunächst wurden die Zellen mit dem Translationsinhibitor Cycloheximid für $1 \mathrm{~h}$ in den Konzentrationen 2, $\mu \mathrm{g} / \mathrm{ml}, 5 \mu \mathrm{g} / \mathrm{ml}$ sowie $10 \mu \mathrm{g} / \mathrm{ml}$ inkubiert und anschließend mit DMSO und Tacrolimus in den Verdünnungen 0,15 ng/ml und $150 \mathrm{ng} / \mathrm{ml}$ für einen Zeitraum von $6 \mathrm{~h}$ stimuliert. Als Kontrolle fungierte eine mit DMSO behandelte Probe, der zuvor kein Cycloheximid beigefügt worden war.

Beiden Stimulationsvorgängen schloss sich ein dreimaliger Waschgang an. Nach Hinzugabe von je $1 \mathrm{ml}$ Trizol pro Well konnten die Zellen mittels Zellschaber vom Boden der 6-Well-Kulturplatte gelöst und in ein Eppendorftube überführt werden.

\section{Murines Nierengewebe}

Um einen sicheren Probenaufschluss der kryokonservierten nativen Mausnieren zu erreichen, wurde zunächst ein etwa $3 \mathrm{~mm}^{3}$ großes Gewebestück abgetrennt, in ein Eppendorftube mit $1 \mathrm{ml}$ Trizol überführt 
und in Gegenwart einer Edelstahlkugel im TissueLyser LT mittels hochfrequentem Schütteln $(50 \mathrm{~Hz})$ für 5 min homogenisiert. Zur direkten Weiterverarbeitung wurde $1 \mathrm{ml}$ des in Trizol befindlichen Lysats in ein neues Eppendorftube pipettiert.

\section{Isolation der mRNA}

Die auf der single step-Methode nach Chomczynski (Chomczynski und Sacchi 1987) basierende Isolation der mRNA wurde im modifizierten säulenchromatographischen spin column-Verfahren unter Verwendung des Kitsystems PureLink ${ }^{\circledast}$ RNA Mini realisiert. Die zuvor gewonnenen Zell- und Gewebelysate wurden zur optimalen Phasentrennung mit $200 \mu \mathrm{l}$ Chloroform versetzt und für $15 \mathrm{~min}$ bei $12.000 \mathrm{U} / \mathrm{min}$ zentrifugiert. Anschließend konnten $500 \mu \mathrm{l}$ der oberen wässrigen Phase vorsichtig abpipettiert und die RNA durch Hinzugabe einer äquivalenten Menge 70\%igen Ethanols auf der Silicagelmembran einer Spin-Säule präzipitiert werden. Anschließend wurde die Säule für $15 \mathrm{~s}$ bei $12.000 \mathrm{U} / \mathrm{min}$ zentrifugiert und der Überstand verworfen. Zur weiteren Aufbereitung wurden verschiedene Pufferlösungen (1x $700 \mu \mathrm{l}$ Wash Buffer I, 2x $500 \mu \mathrm{l}$ Wash Buffer II) für je $15 \mathrm{~s}$ bei $12.000 \mathrm{U} / \mathrm{min}$ hinzugefügt. Nach einer weiteren Trockenzentrifugation für 2 min konnte die RNA schließlich mit $50 \mu$ nukleasefreiem Wasser durch einminütige Zentrifugation aus der Membran eluiert werden.

Die Konzentration der extrahierten RNA wurde mithilfe des NanoDrop ${ }^{\mathrm{TM}} 2000$ Spektralphotometers quantifiziert. Hierzu wurde die Absorption von $1 \mu$ l Eluat im Verhältnis zu einem Leerwert bestimmt. Der relative Reinheitsgrad der RNA wird grundsätzlich durch den Quotienten der Absorptionskoeffizienten bei 260 und $280 \mathrm{~nm}$ definiert, wobei ein Wert von 2,0 reiner RNA entspricht, ein deutlich niedrigerer hingegen auf Protein-, Phenol- oder andere Kontaminationen hinweist.

\section{cDNA-Synthese mittels Reverser Transkription der RNA}

Standardmäßig wurde vor der Umschreibung der aufgereinigten mRNA ein DNA-Verdau in das Protokoll integriert, um Kontaminationen durch genomische DNA zu eliminieren und somit Artefakte und unspezifische Amplifikate in der nachfolgenden qRT-PCR auszuschließen. Die hierzu verwendete DNase I wurde mit 400 ng eluierter mRNA über 15 min bei Raumtemperatur inkubiert und anschließend nach Hinzugabe von EDTA $10 \mathrm{~min}$ bei $65^{\circ} \mathrm{C}$ im Thermocycler Mastercycler ep gradient $\mathrm{S}$ inaktiviert (Pipettierschema des DNA-Verdaus siehe Tabelle 13).

Tabelle 13: Schema des DNA-Verdaus

\begin{tabular}{cc} 
& $\begin{array}{c}\text { DNA-Verdau } \\
\text { Pro Probe }\end{array}$ \\
\hline \hline Volumen & Reagenz \\
\hline $1 \mu \mathrm{l}$ & $10 X$ DNase I Reaction Buffer \\
$1 \mu \mathrm{l}$ & DNase I, Amp Grade (100 U) \\
\hline 15 min bei Raumtemperatur \\
\hline $1 \mu \mathrm{l}$ & 25 nM EDTA (pH 8,0) \\
\hline \multicolumn{3}{c}{10 min bei $65^{\circ} \mathrm{C}$}
\end{tabular}

Im Folgenden wurde die verdaute mRNA in die sogenannte cDNA (complementary DNA) revers transkribiert, wozu sie zunächst mit $2 \mu \mathrm{l}$ des Oligonukleotidansatzes (siehe Tabelle 14) versetzt und zur Anlagerung eines Primers für $5 \mathrm{~min}$ bei $65^{\circ} \mathrm{C}$ belassen wurde. Um die Degradation der mRNA sowie deren Abbau durch endogene Ribonukleasen zu verringern, wurde der mRNA-Probe der Ribonukleaseinhibitor RNaseOut ${ }^{\mathrm{TM}}$ (Ansatz siehe Tabelle 15) beigefügt und dieses Gemisch für weitere $2 \mathrm{~min}$ bei $42^{\circ} \mathrm{C}$ im Thermocycler inkubiert. Durch Hinzugabe von $1 \mu$ der reversen Transkriptase SuperScript ${ }^{\circledast}$ II erfolgte während der 50-minütigen 
Inkubationszeit bei $42{ }^{\circ} \mathrm{C}$ die Synthese eines zur mRNA komplementären DNA-Stranges. Nach anschließender Inaktivierung der Polymerase bei $70^{\circ} \mathrm{C}$ über 15 min konnten die Proben nun mit $80 \mu \mathrm{NFW}$ auf eine cDNA-Endkonzentration von $4 \mathrm{ng} / \mu \mathrm{l}$ verdünnt und als Template zur Genexpressionsanalyse mittels qRTPCR verwendet bzw. bei $-20^{\circ} \mathrm{C}$ gelagert werden.

Tabelle 14: Oligonukleotidansatz

\begin{tabular}{c|c}
\multicolumn{2}{c}{$\begin{array}{c}\text { Oligonukleotidansatz } \\
\text { Pro Probe }\end{array}$} \\
\hline Volumen & Reagenz \\
\hline $1 \mu \mathrm{l}$ & Oligo(dt) $12-18$ Primer \\
\hline $1 \mu \mathrm{l}$ & $10 \mathrm{mM}$ dNTP Mix \\
\hline $5 \mathrm{~min}$ bei $65^{\circ} \mathrm{C}$, Pause bei $4{ }^{\circ} \mathrm{C}$ \\
\hline
\end{tabular}

Tabelle 15: RNaseOut ${ }^{\mathrm{TM}}$-Ansatz

\begin{tabular}{c|c}
\multicolumn{2}{c}{$\begin{array}{c}\text { RNaseOut } \\
\text { Pro Probe }\end{array}$} \\
\hline Volumen & \multicolumn{1}{c}{ Reagenz } \\
\hline $4 \mu \mathrm{l}$ & $5 x$ First Strand Buffer \\
\hline $2 \mu \mathrm{l}$ & $0,1 \mathrm{M} \mathrm{DTT}^{1}$ \\
\hline $1 \mu \mathrm{l}$ & RNaseOUT $^{\mathrm{TM}}$ \\
\hline \multicolumn{2}{|c}{2 min bei $42^{\circ} \mathrm{C}$} \\
\hline 1 .
\end{tabular}

\section{Quantitative Real-Time PCR (qRT-PCR)}

Die Polymerasekettenreaktion (polymerase chain reaction, PCR) stellt eine In-vitro-Technik zur gezielten Amplifikation von DNA-Fragmenten dar (Mullis und Faloona 1987). Dabei dissoziiert die doppelsträngige DNA (dsDNA) durch Hitzedenaturierung in eine Einzelstrangmatrize, an die sich nach Abkühlung auf eine definierte Annealingtemperatur ein zur Zielsequenz komplementäres Primerpaar anlagert (Annealing). Die Bindung dieser beiden spezifischen Oligonukleotide an den Vorwärts- und Rückwärtsstrang der TemplateDNA nutzt die Taq-Polymerase, eine DNA-abhängige DNA-Polymerase aus dem thermostabilen Bakterium Thermus aquaticus, als Startpunkt und synthetisiert in Anwesenheit freier Desoxyribonukleosidtriphosphate (dNTPs) und Magnesiumionen einen komplementären DNA-Strang (Saiki et al. 1988). Die nach der Elongation entstandenen Amplifikate stehen nun den folgenden Zyklen als Matrize zur Verfügung.

Unter Berücksichtigung dieses Vervielfältigungsprinzips erlaubt die quantitative Real-Time PCR (qRT-PCR) die Detektion des Amplikons während des Reaktionszyklus in Echtzeit. Diese von Higuchi et al. etablierte Methode beruht auf der Interkalation von Fluoreszenzfarbstoffen mit doppelsträngiger DNA, woraufhin sich unter UV-Licht die Emission sichtbaren Lichts verstärkt (Higuchi et al. 1992). Das generierte Fluoreszenzsignal ist letztlich proportional zur vorhanden dsDNA-Konzentration.

\section{Amplifikationsprotokoll}

Die Durchführung der qRT-PCR erfolgte stets auf einer MicroAmp ${ }^{\circledR}$ Fast Optical 96-Well-Reaktionsplatte, wobei jede Probe sowohl für das Ziel- als auch für das Haushaltsgen (GAPDH, ACTB) als Triplett pipettiert wurde. Letztlich enthielt jedes Well $5 \mu \mathrm{l}$ cDNA der Endkonzentration $20 \mathrm{ng}$ sowie $15 \mu \mathrm{l}$ des Mastermixes (Ansatz siehe Tabelle 16). 
Tabelle 16: Ansatz für den qRT-PCR-Mastermix

\begin{tabular}{|c|c|}
\hline \multicolumn{2}{|c|}{$\begin{array}{c}\text { qRT-PCR-Mastermix } \\
\text { Pro Probe }\end{array}$} \\
\hline Volumen & Reagenz \\
\hline $10 \mu \mathrm{l}$ & Fast SYBR ${ }^{\circledR}$ Green Mastermix \\
\hline $0,5 \mu \mathrm{l}$ & Vorwärtsprimer $(4 \mathrm{pmol} / \mu \mathrm{l})^{1}$ \\
\hline $0,5 \mu \mathrm{l}$ & Rückwärtsprimer (4 pmol/ $\mu \mathrm{l})$ \\
\hline $3 \mu l$ & Nukleasefreies Wasser (NFW) \\
\hline
\end{tabular}

\footnotetext{
${ }^{1}$ Angaben bezogen auf Eurofins-Produkte, finale Primer-Konzentration pro Reaktion = 200 nM; Primerdesign liefert ein Vorwärts- und Rückwärtsprimer enthaltenes Assay (Primer-Konzentration/Reaktion = $300 \mathrm{nM}$ )
}

Unter Nutzung des StepOnePlus ${ }^{\mathrm{TM}}$ Real-Time PCR-Systems begann nach einer initialen Phase über $20 \mathrm{~s}$ bei $95^{\circ} \mathrm{C}$ zur Aktivierung der DNA-Polymerase ein 40-Zyklen-Modus. Dieser umfasste die Denaturierung des cDNA-Doppelstranges für $3 \mathrm{~s}$ bei $95^{\circ} \mathrm{C}$, die Primer-Hybridisierung sowie die Elongation der entstandenen Amplifikate bei durchschnittlicher Annealingtemperatur von $60^{\circ} \mathrm{C}$. Zur Determination der Reaktionskinetik wurde die Einstellung Quantitation - comparative $C_{T}\left(\Delta \Delta C_{T}\right)$ der StepOne ${ }^{T M}$-Software gewählt. Die Synthese verwendeter Primer erfolgte nach Abgleich mit dem Algorithmus Basic Local Alignment Search Tool (BLAST) des National Center for Biotechnology Information (NCBI, Bethesda, USA) und Spezifitätsprüfung der Firma Primerdesign. Bei erstmaliger Primerverwendung diente eine Schmelzpunktanalyse im Anschluss der qRTPCR dazu, zwischen artifiziell amplifiziertem Primerdimer und dem Zielfragment zu differenzieren und entsprechend quantitative Aussagen hinsichtlich der Oligonukleotidspezifität zu treffen. Etablierte Sequenzen wurden vom Hersteller Eurofins MWG Operon bezogen (Sequenzen siehe Tabelle 4, Seite 26).

\section{Relative Quantifizierung des Probenmaterials}

Zur Analyse der absoluten Expression wurde ein bestimmter Fluoreszenzschwellenwert (threshold) definiert, der für alle zu detektierenden PCR-Produkte in der exponentiellen Phase des Amplifikationsplots lag. Die jeweilige Zykluszahl, bei der der Fluoreszenzgraph den threshold schneidet, wird als threshold cycle (Ct) bezeichnet und dient aufgrund seiner reziproken Proportionalität zum Logarithmus der DNA-Ausgangsmenge als Bezugsgröße (Higuchi et al. 1993). Der für das Zielgen aufgezeichnete Ct-Wert kann im Anschluss auf den Ct-Wert eines konstant exprimierten Haushaltsgens normalisiert werden (Radonić et al. 2004). Eine quantitative Aussage über die Expression verschiedener Proben ergibt sich letztlich, indem der $\Delta \mathrm{Ct}-$ Wert des Zielgens in Relation zu einer Kalibratorprobe gesetzt wird und der aus der Differenz ermittelte $\Delta \Delta \mathrm{Ct}$ Wert in die folgende Formel zur Berechnung der relativen Expression einfließt:

Relative Expression $=2^{-\Delta \Delta C t}$ 
Als Kalibratorprobe fungierte bei allen Zellexperimenten die gewonnene cDNA der mit DMSO stimulierten Zellen, während im Rahmen der Mausstudie die unbehandelten sham-Nieren des Kontrollkollektivs zur Kalibrierung hinzugezogen wurden. Die Auswertung der Ct-Rohdaten erfolgte unter Zuhilfenahme des Programms Microsoft Excel.

\subsection{6 $\quad \mathrm{RT}^{2}$ Profiler ${ }^{\mathrm{TM}} \mathrm{PCR}-$ Array Human Transcription Factors}

Weiterhin sollte der molekulare Aktivierungsmechanismus durch Tacrolimus im Hinblick auf eine mögliche transkriptionelle BMPR1A-Induktion näher charakterisiert werden. Dabei erlaubt die Anwendung des $\mathrm{RT}^{2}$ Profiler ${ }^{\mathrm{TM}}$ PCR-Arrays in Kombination mit der hochsensitiven qRT-PCR-Technologie, die Expression von 84 humanen Transkriptionsfaktoren zu quantifizieren und somit involvierte Faktoren zu identifizieren (Transkriptionsfaktoren siehe Abbildung 6).

\begin{tabular}{l|c|c|c|c|c|c|c|c|c|c|c|c|}
\hline $\mathbf{A}$ & $\mathbf{1}$ & $\mathbf{2}$ & $\mathbf{3}$ & $\mathbf{4}$ & $\mathbf{5}$ & $\mathbf{6}$ & $\mathbf{7}$ & $\mathbf{8}$ & $\mathbf{9}$ & $\mathbf{1 0}$ & $\mathbf{1 1}$ & $\mathbf{1 2}$ \\
\hline $\mathbf{B}$ & DR1 & E2F1 & E2F6 & EGR1 & ELK1 & ESR1 & ETS1 & ETS2 & FOS & FOXA2 & FOXG1 & FOXO1 \\
\hline $\mathbf{C}$ & GATA1 & GATA2 & GATA3 & GTF2B & GTF2F1 & HAND1 & HAND2 & HDAC1 & HIF1A & HNF1A & HNF4A & HOXA5 \\
\hline $\mathbf{D}$ & HSF1 & ID1 & IRF1 & JUN & JUNB & JUND & MAX & MEF2A & MEF2C & MYB & MYC & MYF5 \\
\hline $\mathbf{E}$ & MYOD1 & NFAT5 & NFATC1 & NFATC2 & NFATC3 & NFATC4 & NFKB1 & NFYB & NR3C1 & PAX6 & POU2AF1 & PPARA \\
\hline $\mathbf{F}$ & PPARG & RB1 & REL & RELA & RELB & SMAD1 & SMAD4 & SMAD5 & SMAD9 & SP1 & SP3 & STAT1 \\
\hline $\mathbf{G ~}$ & STAT2 & STAT3 & STAT4 & STAT5A & STAT5B & STAT6 & TBP & TCF7L2 & TFAP2A & TGIF1 & TP53 & YY1 \\
\hline H & ACTB & B2M & GAPDH & HPRT1 & RPLP0 & HGDC & RTC & RTC & RTC & PPC & PPC & PPC \\
\hline
\end{tabular}

Haushaltsgene Genomische DNA-Kontrolle $\quad$ Reverse Transkriptionskontrolle Positive PCR-Kontrolle

Abbildung 6: $\quad$ RT $^{2}$ Profiler ${ }^{\mathrm{TM}}$ PCR-Array Human Transcription Factors (PAHS-075Z) (modifiziert nach http://www.sabiosciences.com/genetable.php?pcatn=PAHS-075).

Wie bereits unter den vorangehenden Punkten ausführlich erläutert, wurden zunächst HK-2-Zellen in 6-Well-Zellkulturplatten mit DMSO und FK506 in der Dosis $150 \mathrm{ng} / \mathrm{ml}$ über $6 \mathrm{~h}$ inkubiert, deren RNA isoliert und anschließend in CDNA transkribiert. Die gewonnene cDNA der Proben wurde auf eine einheitliche Endkonzentration von $25 \mathrm{ng} / \mu \mathrm{l}$ gepoolt und zum RT ${ }^{2}$ SYBR Green ROX qRT-PCR-Mastermix hinzugegeben (Ansatz siehe Tabelle 17). Zur Durchführung des $\mathrm{RT}^{2}$ Profiler $^{\mathrm{TM}}$ PCR-Arrays wurden gemäß Herstellerprotokoll $25 \mu \mathrm{l}$ des Mastermixes in jedes Well einer speziellen 96-Well-Reaktionsplatte, die die zu untersuchenden Transkriptionsfaktoren in getrockneter Form enthielt, pipettiert. Im StepOnePlus ${ }^{\mathrm{TM}}$ Real-Time PCR-Thermocycler durchliefen die Reaktionsansätze daraufhin ein zehnminütiges Intervall bei $95^{\circ} \mathrm{C}$, gefolgt von einem 40-Zyklen-Modus, der kontinuierlich von $15 \mathrm{~s}$ bei $95^{\circ} \mathrm{C}$ zu 1 min bei $60^{\circ} \mathrm{C}$ wechselte. Um die Spezifität der Amplifikate zu bestimmen, erfolgte eine Schmelzkurvenanalyse. Zudem gewährleistete die Reaktionsplatte eine interne Qualitätsprüfung der eingesetzten cDNA durch Aufzeichnung von genomischer DNA-, reverser Transkriptions- sowie positiver PCR-Kontrolle. 
Anschließend wurden die detektierten Ct-Werte als Rohdatensatz im Excel-Format in die webbasierte $\mathrm{RT}^{2}$ Profiler $^{\mathrm{TM}}$ PCR-Array Data Analysis-Software der Firma Qiagen transferiert (http://pcrdataanalysis .sabiosciences.com/pcr/arrayanalysis.php). Unter Angabe von DMSO- bzw. Tacrolimus-stimulierter Probe berechnete das Portal daraufhin automatisch den $\Delta \Delta \mathrm{Ct}$-Wert und stellte die kalkulierten Daten tabellarisch sowie in Form graphischer Plots dar.

\begin{tabular}{|c|c|}
\hline \multicolumn{2}{|c|}{$\mathrm{RT}^{2}{ }^{\text {Profiler }} \mathrm{TM}^{\mathrm{M}}$ PCR-Array-Mastermix } \\
\hline \multicolumn{2}{|r|}{ Pro Probe } \\
\hline Volumen & Reagenz \\
\hline $1350 \mu \mathrm{l}$ & $\begin{array}{l}\mathrm{RT}^{2} \text { SYBR Green ROX qRT-PCR- } \\
\text { Mastermix }\end{array}$ \\
\hline $102 \mu l$ & cDNA \\
\hline $1248 \mu l$ & Nukleasefreies Wasser (NFW) \\
\hline
\end{tabular}

\section{Identifikation putativer Transkriptionsfaktoren in der BMPR1A-Promotorregion}

Um putative Bindungsstellen von unter FK506-induzierten Transkriptionsfaktoren im BMPR1A-Promotor zu identifizieren, wurden, ausgehend vom humanen BMPR1A-Gen, 5000 bp upstream des Transkriptionsstartpunkts (transcription start site, TSS) mit dem internetbasierten Analyseprogramm TFSEARCH version 1.3 (Yutaka Akiyama, Kyoto University, Japan) der Datenbank TRANSFAC (TRANScription FACtor database, Heinemeyer et al. 1998) auf übereinstimmende Bindungsmotive geprüft. Die entsprechende Nukleotidsequenz des BMPR1A-Gens lieferte das bioinformatische Softwaresystem Ensembl (Flicek et al. 2014).

\subsubsection{Western Blot}

\section{Stimulation und Proteinextraktion von HK-2-Zellen in vitro}

Zunächst erfolgte die Aussaat von je 0,7 x 106 HK-2-Zellen in T75-Zellkulturflaschen in 10 ml Quantum 286 bis zum Erreichen einer Konfluenz von nahezu 90 \%. Anschließend wurden die Zellen mit den in DMSO gelösten Stimulanzien CsA, FK506 und MMF der Konzentrationen 0,15, 1,5, 15 und 150 ng/ml 6 h lang behandelt (Stimulationsschema siehe Tabelle 12, Seite 37).

Zur weiteren Spezifizierung Tacrolimus-assoziierter Mechanismen erfolgte die kontrollierte Translationshemmung durch Präinkubation mit Cycloheximid $(2,5 \mu \mathrm{g} / \mathrm{ml}, 5 \mu \mathrm{g} / \mathrm{ml}, 10 \mu \mathrm{g} / \mathrm{ml})$ sowie die konsekutive Stimulation mit DMSO und FK506 (0,15 ng/ml, 150 ng/ml) über 6 h. Als Kontrolle dienten in beiden Versuchsaufbauten unbehandelte sowie mit DMSO behandelte Zellen.

Nach Beendigung der Inkubationszeit wurden die Zellen in PBS gewaschen, mittels Zellschaber mechanisch vom Zellkulturflaschenboden gelöst, zentrifugiert und das gewonnene Pellet je Probe in $200 \mu$ l eines proteaseinhibitorhaltigen Zelllysispuffers resuspendiert. Zur Lysathomogenisierung und Trennung zellulärer Bestandteile folgten die 30-minütige Lagerung auf Eis unter regelmäßigem Vortexen alle 10 min sowie ein 15 -minütiger Zentrifugationsschritt $\left(12.000 \mathrm{U} / \mathrm{min}, 4^{\circ} \mathrm{C}\right)$. Die sich im Überstand befindliche Proteinfraktion konnte direkt weiterverarbeitet bzw. bei $-80{ }^{\circ} \mathrm{C}$ kryokonserviert werden. 


\section{Proteinextraktion aus murinem Nierengewebe}

Zur Proteinextraktion wurde von den kryokonservierten nativen Mausnieren ein etwa $3 \mathrm{~mm}^{3}$ großes Gewebestück abgetrennt, in ein Eppendorftube überführt und in $300 \mu \mathrm{l}$ Zelllysispuffer aufgenommen. Letzterer beinhaltete zusätzlich zum Protease- einen Phosphataseinhibitor, um im Folgenden die Detektion phosphorylierter Proteine zu gewährleisten. Die Homogenisierung erfolgte über 5 min im Tissuelyser LT in Gegenwart einer Edelstahlkugel bei einer konstanten Hochfrequenz von $50 \mathrm{~Hz}$. Das Gewebelysat wurde für weitere $30 \mathrm{~min}$ auf Eis belassen, dabei alle $10 \mathrm{~min}$ gevortext und zur zellulären Fraktionierung $15 \mathrm{~min}$ $\left(12.000 \mathrm{U} / \mathrm{min}, 4^{\circ} \mathrm{C}\right)$ zentrifugiert. Der Überstand konnte abgenommen und die darin enthaltenen Proteine wie oben beschrieben gelagert werden.

\section{Bestimmung der Proteinkonzentration nach der BCA-Methode}

Die Messung von Proteinen nach der von Smith PK et al. etablierten BCA-Methode basiert auf der Reduktion eines zweiwertigen Kupferions $\left(\mathrm{Cu}^{2+}\right)$ durch anwesende Peptidbindungen innerhalb eines alkalischen $\mathrm{Me}-$ diums (Biuret-Reaktion), woraufhin das reduzierte Kupferion $\left(\mathrm{Cu}^{1+}\right)$ mit zwei Molekülen der Bicinchoninsäure (BCA) zu einem violettfarbenen lichtabsorbierenden Chelatkomplex reagiert (Smith PK et al. 1985). Die Bildung dieses Farbkomplexes steht im proportionalen Zusammenhang zur vorhandenen Proteinkonzentration und kann bei einem Extinktionskoeffizienten von $562 \mathrm{~nm}$ mit dem Spektralphotometer NanoDrop $^{\text {TM }} 2000$ detektiert werden.

Zur Bestimmung der Proteinkonzentration wurden unter Verwendung des Kitsystems Pierce ${ }^{\mathrm{TM}}$ BCA $^{\mathrm{TM}}$ Protein Assay je $25 \mu \mathrm{l}$ der Gesamtproteinlösung bzw. $25 \mu \mathrm{l}$ des gemäß Herstellerprotokolls verdünnten Albuminstandards (Arbeitsbereich 25 bis $2000 \mu \mathrm{g} / \mathrm{ml}$ ) mit $200 \mu \mathrm{l}$ des Arbeitsreagenz (BCA ${ }^{\mathrm{TM}}$ Reagent A + BCA ${ }^{\mathrm{TM}}$ Reagent $B ; 50$ zu 1) versetzt und 30 min lang bei $37^{\circ} \mathrm{C}$ inkubiert. Die Quantifizierung der Proteinproben erfolgte nach Etablierung einer Standardkurve bei $562 \mathrm{~nm}$.

\section{Polyacrylamid-Gelelektrophorese (SDS-Page)}

Die analytische Auftrennung der Proteine nach Molekulargewicht erfolgt in Anlehnung an die diskontinuierliche Natriumdodecylsulfat-Polyacrylamidgelelektrophorese (SDS-PAGE) nach Laemmli (Laemmli 1970). Dabei wird durch Hinzugabe des anionischen Detergens SDS im Überschuss und entsprechende Erhitzung der Verlust der Sekundär- und Tertiärstruktur der Polypeptide fokussiert. Zudem bindet das SDS an die kationischen Reste des linearisierten Proteins und sorgt somit für die Überdeckung der Eigenladung, sodass der nun konstant negativ geladene Protein-SDS-Komplex entsprechend seiner Polypeptidkettenlänge vom dreidimensionalen Porennetzwerk der Gelmatrix aufgetrennt wird.

Zur Durchführung der SDS-PAGE gemäß dem durch die Firma Invitrogen (Life Technologies, Carlsbad, USA) modifizierten Lithiumdodecylsulfat (LDS)-NuPAGE ${ }^{\circledR}$ Elektrophoresesystem wurden die Proteinlösungen zunächst auf eine einheitliche Konzentration verdünnt, mit einem gleichen Volumen Sample Buffer (Ansatz siehe 2.1.7, Seite 24) versetzt und dessen native Polypeptidstrukturen durch Inkubation über 5 min bei $95^{\circ} \mathrm{C}$ im Thermomixer denaturiert. Dabei enthielt der Probenpuffer neben dem Detergens LDS das Thiol $\beta$-Mercaptoethanol, welches die Reduktion der Disulfidbrücken vermittelte. Nach Befüllen der inneren und äußeren Elektrophoresekammern mit den entsprechenden Laufpuffern (Ansatz siehe 2.1.7, Seite 24) konnten die dissoziierten Proteine im Sammelgel (4\% Polyacrylamid) des industriell gefertigten (sog. precast) NuPAGE ${ }^{\circledR}$ Novex ${ }^{\circledast} 4-12$ \% Bis-Tris-Proteingels konzentriert werden. Das neutrale Milieu der Puffersubstanz 
Bis-Tris erhöht dabei die Stabilität von Gel und Proteinen. Durch Anlegen einer initialen Gleichstromspannung von $80 \mathrm{~V}$ über 20 min und einem anschließenden etwa zweistündigen Intervall bei $120 \mathrm{~V}$ erfolgte die Auftrennung der Proteine im Trenngel mit 12\%igem Polyacrylamidgehalt. Als Größenreferenz dienten $10 \mu \mathrm{l}$ des Novex ${ }^{\circledR}$ Sharp Pre-stained Proteinstandards, sodass sich Molekulargewichte zwischen 3,5 bis 260 kDa differenzieren ließen.

\section{Semi-Dry-Western Blot}

Der gewichtsspezifischen Auftrennung der Proteine mittels LDS-PAGE folgte der elektrophoretische Transfer auf eine Nitrozellulosemembran nach einer von Towbin et al. etablierten Technik (Towbin et al. 1992). Hierzu wurde das LDS-Gel auf eine zuvor im Transferpuffer äquilibrierte Membran gelegt und anschließend zwischen jeweils drei mit Transferpuffer getränkte Filterpapiere angeordnet. Die, ähnlich eines Sandwiches, gebetteten Komponenten sind dabei zwingend luftblasenfrei auf die Anode (+) der Fastblot-Apparatur zu stapeln. Der Transfer der Proteine senkrecht zur Trennrichtung des LDS-Gels auf die Membran erfolgte nach Anschluss des als Kathode (-) fungierenden Deckels zunächst über 15 min bei einer Stromstärke von $150 \mathrm{~mA}$ und für weitere $45 \mathrm{~min}$ bei $250 \mathrm{~mA}$.

\section{Immunodetektion}

Nach dem Transfer wurden die auf der Nitrozellulosemembran immobilisierten Proteine mit spezifischen Antikörpern markiert und mittels Chemilumineszenzreaktion visualisiert. Hierzu wurde die Nitrozellulosemembran in ein 50-ml-Tube überführt, zur Absättigung unspezifischer Bindungsstellen für $1 \mathrm{~h}$ in der entsprechenden 5\%igen Blockierlösung (BSA bzw. Milch) belassen und anschließend mit dem in BSA oder Milch (jeweils $2 \%$ ) verdünnten Primärantikörper über Nacht bei $+4{ }^{\circ} \mathrm{C}$ inkubiert. Ungebundene Primärantikörper konnten am Folgetag durch dreimaliges Waschen für jeweils 5 min mit dem Waschpuffer TBS-T entfernt werden. Es folgten die Inkubation der Membran mit dem HRP-konjugierten Sekundärantikörper in der $5 \%$ igen Blockierlösung über $1 \mathrm{~h}$ bei Raumtemperatur sowie drei Waschschritte à 5 min in TBS-T (Verdünnung siehe Tabelle 18).

Zur Detektion von Primärantikörpern anderer Ursprungsspezies wurde die Membran über 30 min mit dem Restore $^{\mathrm{TM}}$ Western Blot Stripping Buffer behandelt und bereits gebundene Immunkomplexe entfernt. Nach dreimaligem Waschen über 5 min in TBS-T mussten freie Bindungsstellen erneut durch 5\%iges BSA geblockt und die Membranen mit den jeweiligen Primär- und Sekundärantikörpern, wie eingangs beschrieben, inkubiert werden. Um eine gleichmäßige Benetzung zu gewährleisten, wurden die in den 50-ml-Tubes befindlichen Membranen während des Blockierens sowie der Anwendung von Primär- und Sekundärantikörpern konstant auf der Rollermixer-Apparatur rotiert. Die Basis von Waschpuffern (TBS-T) und Blockierlösungen (BSA bzw. Milch) richtete sich nach der Herstellerempfehlung des jeweiligen Primärantikörpers (siehe 2.1.7, Seite 24).

Die Detektion der Antigen-Antikörper-Komplexe erfolgte mithilfe der Kitsysteme 20X LumiGLO ${ }^{\circledR}$ Reagent and 20X Peroxide oder SuperSignal ${ }^{\mathrm{TM}}$ West Pico Chemiluminescent Substrate. Hierzu wurden die Komponenten gemäß Herstellerangaben miteinander vermischt (siehe 2.1.7, Seite 25) und gleichmäßig auf die Membran in Höhe der zu erwartenden Bande pipettiert. Die an den Sekundärantikörper gekoppelte Meerrettichperoxidase katalysierte daraufhin die Oxidation des in der Entwicklerlösung enthaltenen Luminols (Chemilumineszenzreaktion), sodass das entstandene lichtemittierende Reaktionsprodukt durch die hochauflösende CCD-Kamera des ChemiDoc ${ }^{\mathrm{TM}}$ MP Imaging Systems digital erfasst werden konnte. Die Länge der 
Expositionszeit sowie die Verwendung des jeweiligen Kitsystems wurden individuell in Abhängigkeit von der Stärke des detektierten Signals gewählt.

Tabelle 18: Verwendete Antikörper für den Western Blot

\begin{tabular}{c|c|c|c|c|c|c}
\multicolumn{4}{c}{ Primärantikörper } & \multicolumn{3}{c}{ Sekundärantikörper } \\
\hline \hline Antigen & Gewicht(kDa) ${ }^{1}$ & Ursprung & Verdünnung & Ursprung & Markierung & Verdünnung \\
\hline $\begin{array}{c}\text { BMPR1A } \\
\text { (human/mouse) }\end{array}$ & 75 & Kaninchen & $1: 1000$ & Ziege & HRP & $1: 2000$ \\
\hline Bmpr1b & 50 & Kaninchen & $1: 1000$ & Ziege & HRP & $1: 2000$ \\
\hline Bmpr2 & 115 & Kaninchen & $1: 1000$ & Ziege & HRP & $1: 2000$ \\
\hline GAPDH & 36 & Maus & $1: 2500$ & Kaninchen & HRP & $1: 2000$ \\
\hline Arnt & 87 & Kaninchen & $1: 625$ & Ziege & HRP & $1: 20000$ \\
\hline pSmad & 60 & Kaninchen & $1: 500$ & Ziege & HRP & $1: 20000$ \\
\hline
\end{tabular}

${ }^{1}$ Gewichtsangaben der Antikörper nach Herstellerangaben; Differenzen bei Anwendung im Ergebnisteil vermerkt

\section{Auswertung}

Die densitometrische Auswertung erfolgte durch optometrische Dichtemessung der jeweils prominentesten Einzelbande mithilfe der Bildverarbeitungssoftware ImageJ (Wayne Rasband, National Institutes of Health, Bethesda, USA). Anschließend konnte der für das Zielprotein quantifizierte Wert gegen das detektierte Signal eines konstant exprimierten Haushaltsgens (GAPDH) normalisiert werden. Für statistische Analysen wurde die ermittelte relative Expression der jeweiligen Kontrolle arbiträr auf den Wert eins festgelegt.

\subsubsection{Transfektion von small interfering RNA (siRNA)}

\section{RNA-Interferenz (RNAi)}

Der von Andrew Fire und Craig Mello 1998 in der eukaryotischen Zelle etablierte Mechanismus der RNAInterferenz (RNAi) basiert auf dem Vorhandensein doppelsträngiger RNA (dsRNA), die sequenzkomplementäre mRNA spezifisch degradiert und somit die posttranskriptionelle „Stummschaltung“ (engl. gene silencing) eines Gens induziert (Fire et al. 1998). Während dieser evolutionär konservierte Prozess in der Zelle selbst als physiologisches Regulationssystem der Genexpression, u. a. zum Schutz vor viraler Infektion fungiert und damit dem Erhalt der Genomintegrität dient (Sioud 2005), erlaubt die experimentelle Anwendung des zielgerichteten Knockdowns homologer Gene, mittels In-vitro-Studien die Funktion ihrer kodierenden Proteine im Organismus zu charakterisieren. Initial führt die lange dsRNA zur Aktivierung der Endoribonuklease Dicer, deren funktionelle Untereinheiten den langen Doppelstrang ATP-abhängig in die kürzere 
21 bis 23 Nukleotide umfassende siRNA (small interfering RNA) prozessieren (Bernstein et al. 2001, Tuschl und Borkhardt 2002). Diese Fragmente involvieren eine zentrale doppelsträngige Region, die von einem phosphorylierten 5'Ende sowie zwei bis drei unpaaren Nukleotidüberhängen am unphosphorylierten 3 '-Ende flankiert werden (Elbashir et al. 2001). Im Folgenden wird die interferierende RNA in den Multienzymkomplex RISC (RNA induced silencing complex) integriert, dessen HelikaseDomäne unter ATP-Verbrauch den Doppelstrang entwindet und den Abbau des sense-Stranges initiiert (Nykänen et al. 2001). Der antisense-Strang hingegen verbleibt im RISC und interagiert mittels komplementärer Basenpaarung mit der homologen Ziel-mRNA, woraufhin die Endonukleaseaktivität des RISC deren Degradation einleitet (Sledz und Williams 2005).

\section{Verwendete siRNA und scrambled siRNA (scrRNA)}

Im Folgenden sollte gezielt die Inhibition selektiver Gene forciert werden. Die Inkorporation von langen dsRNA-Molekülen (> $30 \mathrm{bp}$ ) triggert im Zytoplasma der eukaryotischen Zelle allerdings die Freisetzung von Interferon als Teil der Immunantwort und induziert letztlich eine globale mRNA-Degradation sowie den Arrest der Proteinsynthese. Um die Spezifität des Gene Silencings zu optimieren, bietet sich daher die Verwendung chemisch synthetisierter kurzkettiger siRNA an. Zu berücksichtigende Kriterien implizieren u. a. die Entfernung möglicher Sequenzhomologien zu anderen Genen, die Beachtung des Angriffsorts in der Ziel-mRNA, des GC-Gehalts sowie der Duplexstabilität, die entscheidend für die Integration des antisenseStranges in den RISC-Komplex ist (Reynolds et al. 2004, Sandy et al. 2005).

In der vorliegenden Arbeit wurde die kommerziell hergestellte small interfering RNA der Firma Santa Cruz Biotechnology verwendet, die ein Gemisch bestehend aus drei bis fünf RNA-Doppelsträngen der Länge 19 bis 25 nt in einem äquivalenten Verhältnis liefert (Sequenzen siehe Tabelle 5, Seite 27). Zur Überprüfung der Knockdown-Effizienz fungierte eine nicht-genomische, sogenannte scrambled siRNA (scrRNA), deren Sequenz keine bekannte Homologie zum Transkriptom von Eukaryoten und damit keinerlei Funktionalität hinsichtlich interferierender Effekte aufweist. Ein Instrument zum zusätzlichen Sequenzabgleich stellt der 
BLAST-Algorithmus dar, indem er die statistische Signifikanz möglicher Überstimmungen berechnet und somit die Spezifität der Nukleotide sichert.

\section{Prinzip der transienten Transfektion}

Der nicht-virale Transfer genetischer Information in Eukaryoten wird als Transfektion bezeichnet. Allerdings stellt die aktive Aufnahme von Nukleinsäuren in die Zelle ein überaus seltenes Ereignis dar, weshalb zur Überwindung der Zellmembran deren temporäre Permeabilisierung mittels etablierter physikalischer oder biochemischer Methoden fokussiert wird. Da eine Integration des inkorporierten Nukleotidduplex in das Genom der Zelle und somit die Amplifikation des übermittelten Impulses nach dessen enzymatischer Degradation ausbleibt, handelt es sich bei der Transfektion von siRNA allenfalls um ein transientes Phänomen. Der im Folgenden erfolgte Nukleotidtransfer wurde nach dem von Felgner beschriebenen Prinzip der Lipofektion durchgeführt (Felgner et al. 1987). Die dabei verwendeten kationischen Transfektionsreagenzien formen aufgrund ihrer lipo- und hydrophilen Eigenschaften im wässrigen Milieu micellenähnliche dreidimensionale Kugeln. Werden diese Liposomen nun mit den anionischen Nukleinsäuren der siRNA inkubiert, komplexieren sie deren Phosphatrückgrat. Dieser den Aufbau der Zellmembran imitierende Lipoplex vermittelt nun über die Fusion mit der Zellmembran die Inkorporation der Fremd-RNA in die eukaryotische Zelle.

\section{Liposomale Transfektion von siRNA in MCT-Zellen}

Zunächst wurden MCT-Zellen in 6-Well-Zellkulturplatten zu je 1,5 × $10^{5}$ Zellen pro Well in $2 \mathrm{ml}$ Wachstumsmedium ohne antibiotische Zusätze ausgesät und über einen Zeitraum von 18 bis $24 \mathrm{~h}$ bis zu einer Konfluenz von 60 bis 70 \% kultiviert. Die Ausnutzung der exponentiellen Wachstumsphase führt zu einer erhöhten Transfektionseffizienz, wohingegen die durch eine intakte Monolayer-Kultur induzierte Kontaktinhibition die Aufnahme der Nukleotide behindert.

Die nachfolgend eingesetzten Mengenverhältnisse beziehen sich auf je eine Vertiefung einer 6-Well-Zellkulturplatte. Zur Vorbereitung des Transfektionsansatzes wurden $245 \mu \mathrm{l}$ des vorgewärmten Opti-MEM ${ }^{\circledR}$ Reduced Serum Mediums mit $5 \mu \mathrm{l}$ des kationischen Reagenz Lipofectamine ${ }^{\circledR} 2000$ versetzt und für 5 min bei Raumtemperatur inkubiert. Währenddessen konnten $60 \mathrm{pmol}$ der jeweiligen siRNA-Sequenz in $250 \mu \mathrm{l}$ Opti-MEM ${ }^{\circledR}$ verdünnt und anschließend im Lipidgemisch aufgenommen werden. Als Kontrolle dienten mit nicht-genomischer scrRNA transfizierte Zellen. Zur Erzeugung der Liposomenkomplexe erfolgte über 20 min die erneute Inkubation der präparierten Komponenten bei Raumtemperatur. Daraufhin wurden die MCTZellen mit $500 \mu \mathrm{l}$ des jeweiligen Transformationsansatzes für $4 \mathrm{~h}$ im Inkubator ( $37^{\circ} \mathrm{C}, 5 \% \mathrm{CO}_{2}$-Gehalt) kultiviert und regenerierten nach vollzogenem Mediumwechsel mit supplementiertem antibiotikafreiem Medium über Nacht. Am Folgetag konnten die mit siRNA transfizierten Zellen mit Tacrolimus in den Konzentrationen $150 \mathrm{ng} / \mathrm{ml}$ und $1500 \mathrm{ng} / \mathrm{ml}$ für $3 \mathrm{~h}$ stimuliert werden, wobei die parallele Inkubation je eines Wells mit DMSO als Kontrolle fungierte. Um neben dem posttranskriptionellen Gene Silencing auch den Effekt des Tacrolimus auf die Expression der einzelnen Gene zu charakterisieren, wurden zuvor mit unfunktionaler scrRNA transfizierte MCT-Zellen mit FK506 in unterschiedlichen Dosen $(15 \mathrm{ng} / \mathrm{ml}, 150 \mathrm{ng} / \mathrm{ml}, 1500 \mathrm{ng} / \mathrm{ml}$, $3000 \mathrm{ng} / \mathrm{ml}, 4500 \mathrm{ng} / \mathrm{ml}$ ) sowie DMSO für $6 \mathrm{~h}$ inkubiert. Anschließend wurden die Zellen vorsichtig in PBS gewaschen, deren gewonnenen Lysate der Protein- und RNA-Isolation zugeführt und Expressionsanalysen mittels PCR und Western Blot-Methoden vollzogen. 


\subsubsection{Statistische Auswertung}

Die statistische Auswertung und graphische Darstellung der experimentell gewonnenen Datensätze erfolgte unter Verwendung der GraphPad Prism-Software, Version 5.00. Die mindestens als Triplikate generierten Untersuchungsergebnisse wurden als Mittelwert mit Standardabweichung und Signifikanzniveau angegeben. Hierzu wurde zunächst eine Testung von Mittelwertunterschieden mittels einfaktorieller Varianzanalyse (One-Way-ANOVA) durchgeführt und nachfolgend signifikante Globaleffekte mit auf dem T-Test basierendem multiplem Vergleichsverfahren nach Bonferroni (Bonferroni-Post-Hoc-Analyse) korrigiert. Ein p-Wert kleiner als 0,05 wurde als statistisch signifikant definiert und entsprechende Graphen wie folgt gekennzeichnet: ${ }^{*} p<0,05,{ }^{* *} p<0,01,{ }^{* * *} p<0,001$ und ${ }^{* * * *} p<0,0001$. 


\section{ERGEBNISSE}

\subsection{Induktion des BMP7-Rezeptors BMPR1A nach FK506-Supplementation in vitro}

\subsubsection{Selektiv vermehrte Expression des BMPR1A unter FK506-Exposition in HK-2-Zellen}

Zunächst sollte der Einfluss der immunsuppressiven Substanzen Mycophenolat Mofetil (MMF), Cyclosporin A (CsA) und FK506 auf die Expression des BMP-Typ I-Rezeptors BMPR1A in der humanen proximalen Tubulusepithelzelllinie HK-2 innerhalb eines zeitabhängigen Versuchs mittels qRT-PCR analysiert werden. Während sich nach 30-minütiger Inkubation der niedrigkonzentrierten Pharmaka $(0,15,1,5,15,150$, $1500 \mathrm{ng} / \mathrm{ml}$ ) kein Effekt auf die relative BMPR1A-Expression im Tubulusepithel manifestierte, zeigte die sechsstündige FK506-Exposition in äquivalenten Stoffmengen eine signifikante dosisabhängige Induktion des Zielgens. Hingegen führte auch die längerfristige Stimulation mit den immunsuppressiven Therapeutika CsA und MMF zu keinen relevanten Veränderungen des BMPR1A-Expressionsniveaus. Sämtliche Werte wurden gegen parallel mit DMSO inkubierte HK-2-Zellen normalisiert.

A

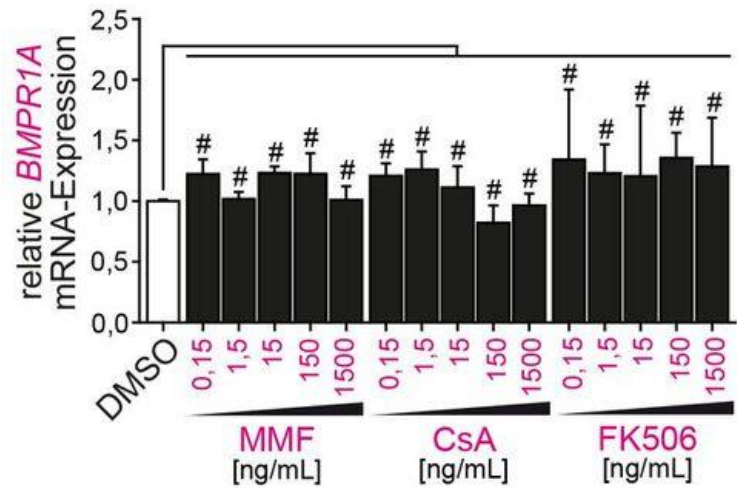

B

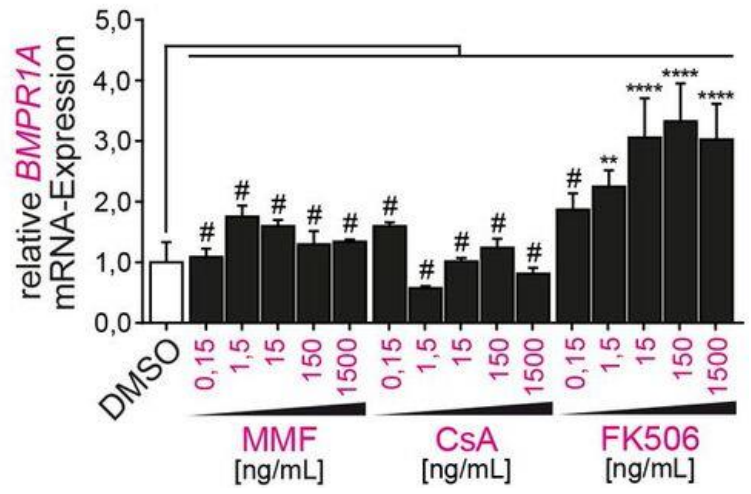

Abbildung 8: Selektiv vermehrte Expression des BMPR1A in vitro unter FK506-Exposition auf Transkriptionsebene

(A+B) Analyse der BMPR1A-Expression mittels qRT-PCR in humanen proximalen Tubulusepithelzellen (HK-2) nach 30-minütiger (A) bzw. sechsstündiger Stimulation (B) mit den immunsuppressiven Pharmazeutika MMF, CsA und FK506. Für statistische Analysen wurde die relative Expression parallel mit DMSO behandelter Zellen arbiträr auf den Wert eins festgelegt (Messung der Proben als Triplikate, Mittelwert, Standardabweichung, $* * p<0,01$, $* * * * \mathrm{p}<0,0001$, \# nicht signifikant; Kalkulation der $\mathrm{p}$-Werte mittels einfaktorieller ANOVA mit Bonferroni-PostHoc-Analyse in Relation zu DMSO-behandelten HK-2-Zellen).

Die Validierung der auf mRNA-Ebene detektierbaren Tendenzen erfolgte anschließend auf Proteinebene durch die Western Blot-Methodik. Die diesbezüglich angestrebte Densitometrie unter Zuhilfenahme der Analysesoftware ImageJ bestätigte nach sechsstündiger Inkubation FK506 als potentes Stimulanz einer effizienten BMPR1A-Induktion. Demgegenüber ließ sich ein signifikanter Einfluss der Pharmaka MMF und CsA auf die Expression des BMP-Rezeptors nicht eruieren. 
A

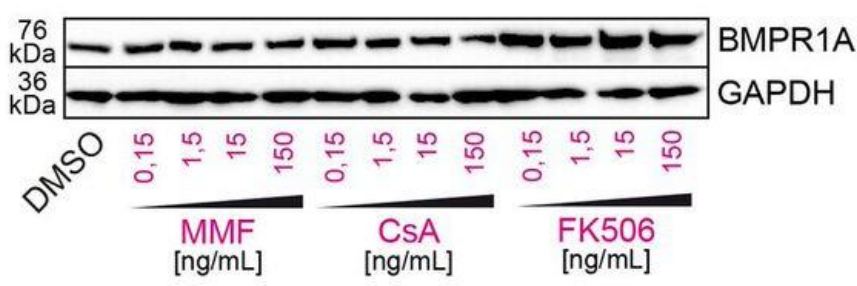

B

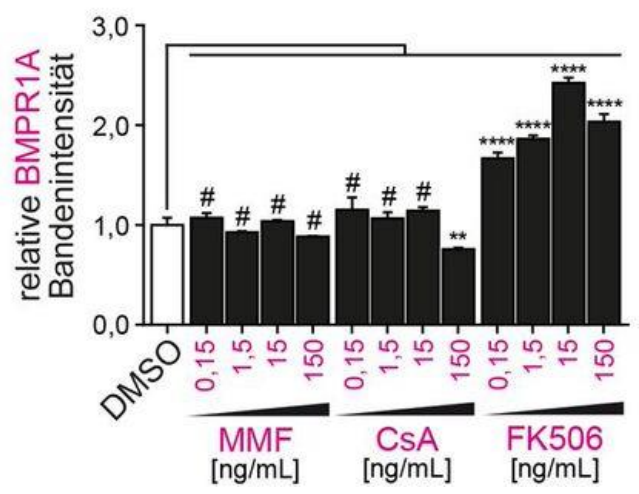

Abbildung 9: Selektiv vermehrte Expression des BMPR1A in vitro unter FK506-Exposition auf Proteinebene (A) Western Blot präsentiert die Induktion des BMPR1A in HK-2-Zellen nach sechsstündiger Inkubation mit den immunsuppressiven Pharmaka MMF, CsA und FK506. (B) Densitometrische Auswertung des Western Blots auf BMPR1A. Für statistische Analysen erfolgte eine optometrische Dichtemessung an drei prominenten Einzelbanden sowie die Normalisierung des für das Zielprotein BMPR1A quantifizierten Wertes gegen das detektierte Signal des Haushaltsgens GAPDH. Die relative Expression DMSO-behandelter Zellen wurde arbiträr auf den Wert eins festgelegt (Messung der Proben als Triplikate, Mittelwert, Standardabweichung, ${ }^{* *} p<0,01,{ }^{* * * *} p<0,0001$, \# nicht signifikant; Kalkulation der $p$-Werte mittels einfaktorieller ANOVA mit Bonferroni-Post-Hoc-Analyse in Relation zu DMSO-behandelten HK-2-Zellen). ${ }^{2}$

\subsubsection{Effekt immunsuppressiver Substanzen auf die Regulation der BMP7-Rezeptoren BMPR1B und BMPR2 in HK-2-Zellen}

Die folgenden Untersuchungen fokussierten den weiterhin kritischen Aspekt, inwiefern die konsekutive BMPR1A-Induktion unter FK506 auf weitere BMP7-spezifische Rezeptoren übertragbar sein könnte.

Hierzu initial für den BMPR1B realisierte qRT-PCR-Analysen führten nach sechs Stunden andauernder Inkubation tubuloepithelialer HK-2-Zellen mit entsprechenden Dosen MMF, CsA sowie FK506 (0,15, 1,5, 15, 150 , 1500 ng/ml) zu keinen signifikanten Divergenzen im Expressionsprofil des Typ I-Rezeptors.

Während die im Anschluss erfolgte Determination der relativen BMPR2-Expression für die Pharmaka MMF und CsA eine geringfügige, jedoch nicht repräsentativ konsistente Repression des Rezeptors ergab, zeigte die FK506-Supplementation einen leicht stabilisierenden, allerdings ebenfalls nicht signifikanten Effekt auf die BMPR2-Expression. Eine generalisierte rezeptorassoziierte Wirksamkeit der immunsuppressiven Stimulanzien darf demzufolge ausgeschlossen werden.

\footnotetext{
2 Die vollständigen unbearbeiteten Western Blot-Gele befinden sich im Anhang (siehe 6.2, Seite $100 \mathrm{ff}$., Abbildung 32 bis 39).
} 
A

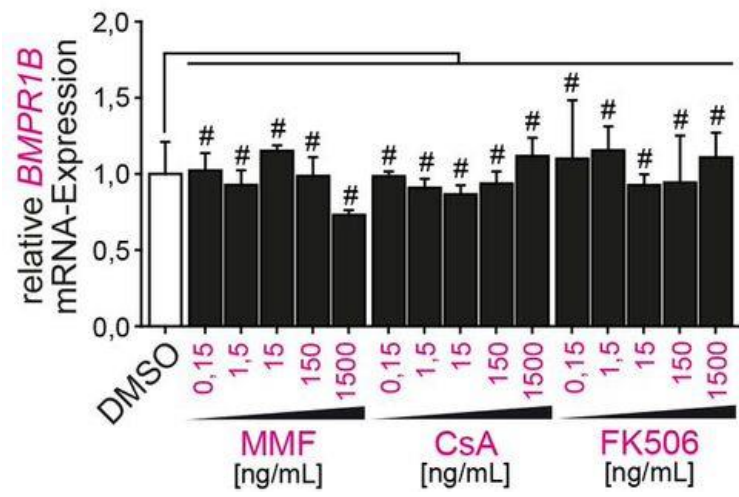

B

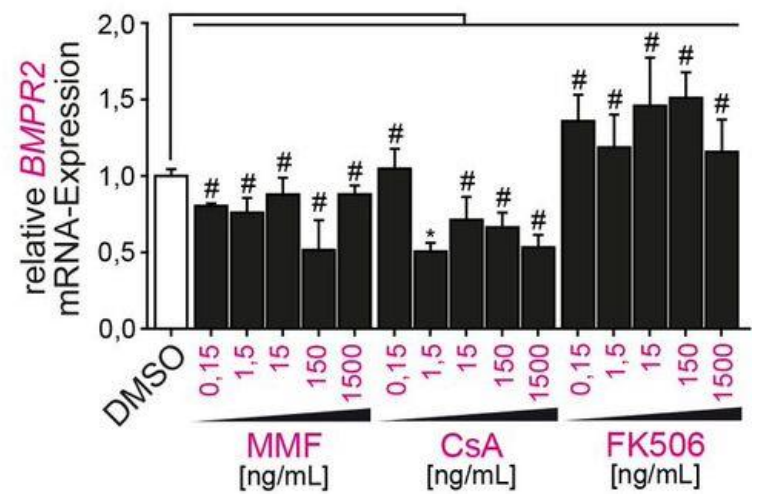

Abbildung 10: Immunsuppressive Substanzen in vitro ohne Effekt auf die Regulation der BMP7-Rezeptoren BMPR1B und BMPR2

(A+B) Analyse der BMPR1B- (A) bzw. der BMPR2-Expression (B) mittels qRT-PCR in humanen Tubulusepithelzellen (HK-2) nach sechsstündiger Stimulation der immunsuppressiven Substanzen MMF, CsA und FK506 (Messung der Proben als Triplikate, Mittelwert, Standardabweichung, * $p<0,05$, \# nicht signifikant; Kalkulation der $p$-Werte mittels einfaktorieller ANOVA mit Bonferroni-Post-Hoc-Analyse in Relation zu DMSO-behandelten HK-2-Zellen).

\subsection{Spezifische FK506-abhängige Induktion des Bmpr1a in vivo}

\subsubsection{Vermehrte Expression des Bmpr1a im Mausmodell der unilateralen Ureterobstruktion}

Die in humanen tubuloepithelialen Zellen (HK-2) quantifizierbare signifikante Hochregulation des Bmpr1a durch niedrigkonzentriertes FK506 sollte anschließend im Mausmodell der unilateralen Ureterobstruktion (UUO) nach Induktion einer experimentellen Nierenfibrose untersucht werden. Hierzu erhielten die aus je sechs Tieren bestehenden Kohorten bereits einen Tag präoperativ entweder einen unveränderten (vehicle) bzw. einen mit drei unterschiedlichen Dosen FK506 supplementierten 5\%igen Glucosepuffer. Als Kontrollen sämtlicher folgender Untersuchungen fungierte die kontralaterale „scheinoperierte“ (sham) Niere. Die Quantifizierung des relativen Bmpr1a-Expressionsmusters erfolgte zunächst mithilfe der qRTPCR- sowie der Western Blot-Technik.

Die mittels qRT-PCR durchgeführten mRNA-Analysen zeigten im Kollektiv der zehn Tage lang mit UUO behandelten Kontrollmäuse eine signifikante, um 2,7-fach erhöhte relative Expression von Bmpr1a gegenüber den sham-Nieren vehicle-behandelter Mäuse. Insgesamt ließ sich jedoch durch die zusätzliche orale Applikation von FK506 eine weitaus effizientere Hochregulation realisieren, wobei die höchste FK506-Dosierung $(0,2 \mathrm{mg} / \mathrm{kg} \mathrm{KG} / \mathrm{Tag})$ den potentesten Stimulus der Rezeptorexpression darstellte. Eine generelle Dosisabhängigkeit manifestierte sich jedoch nicht.

Der Einfluss des FK506 hinsichtlich der Bmpr1a-Expression konnte anschließend auf Proteinebene durch Anwendung der Western Blot-Methodik verifiziert werden. Während sich in UUO-Nieren des Kontrollkollektivs zwar eine geringe, jedoch nicht signifikant erhöhte Expression des Bmpr1a im Vergleich zur kontralateralen Niere verdeutlichte, führte die orale Administration von FK506 zu einer potenten dosisabhängigen Stimulation des Rezeptors. Dabei zeigte das Pharmakon seine effektivste Wirksamkeit in Tieren, denen mittlere Dosen (0,075 mg/kg KG/Tag) verabreicht worden waren. 


\subsubsection{Verminderte Expression der Bmpr1b- und Bmpr2-Rezeptoren nach unilateraler Ureterob- struktion}

In welchem Maße das Pharmakon FK506 während der renalen Fibrogenese auch die Expression der BMPRezeptoren Bmpr1b und Bmpr2 beeinflusst, wurde im Weiteren mittels qRT-PCR und Western Blot in ureterligierten Nieren entsprechender Versuchstiere analysiert.

Die zehn Tage andauernde permanente Harnleiterokklusion führte in den präparierten Nieren der vehiclesowie der FK506-behandelten Mäuse zu einer deutlich signifikanten Reduktion der durch qRT-PCR ermittelten relativen Bmpr1b-Expression in Relation zu scheinoperierten Nieren des Kontrollkollektivs. Der Vergleich der UUO-Nieren untereinander zeigte unabhängig von einer FK506-Supplementation keine relevanten Unterschiede.

Weiterführende Western Blot-Analysen auf Grundlage renaler Proteinlysate untermauerten die markante Herunterregulation der Bmpr1b-Expression in obstruierten Nieren gegenüber normierten kontralateralen Nieren und ließen keinen Rückschluss auf eine FK506-abhängige Regulation zu.

Auch bei der anschließenden Determination der Bmpr2-Expression verdeutlichte sich sowohl auf mRNAals auch auf Proteinebene eine signifikante Reduktion des Typ II-Rezeptors im Parenchym der ligierten Nieren im Vergleich zur sham-Niere vehicle-behandelter Mäuse, wobei die Gabe von FK506 das relative Expressionsniveau des Bmpr2 in UUO-Nieren unbeeinflusst ließ.

Die Ergebnisse korrelieren mit den aus stimulierten HK-2-Zellen generierten qRT-PCR-Daten und legen einen Bmpr1a-spezifischen Regulationsmechanismus nahe, der durch FK506-Exposition potenziert wird. 
A

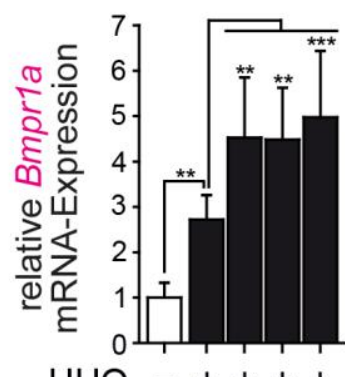

UUO -++++

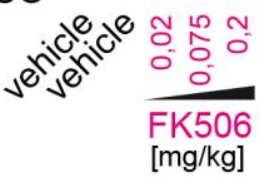

B

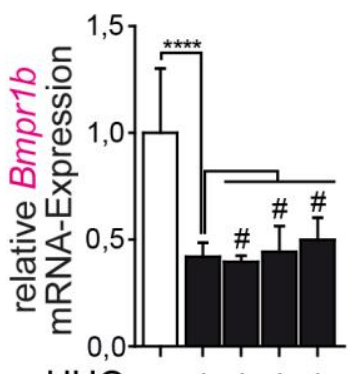

UUO -+++

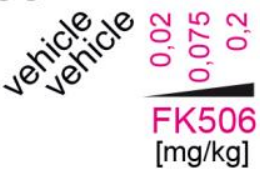

C

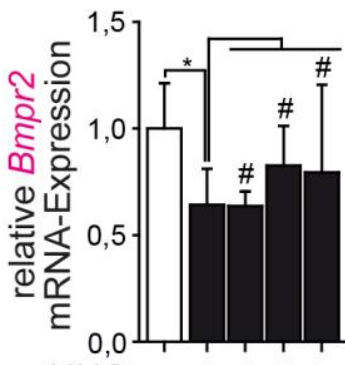

UUO -+++

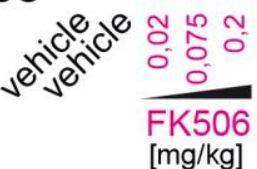

D

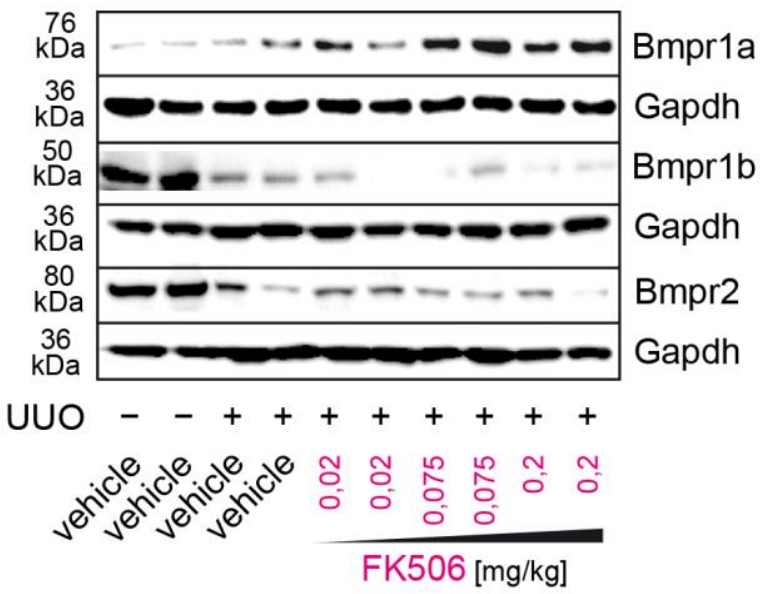

E

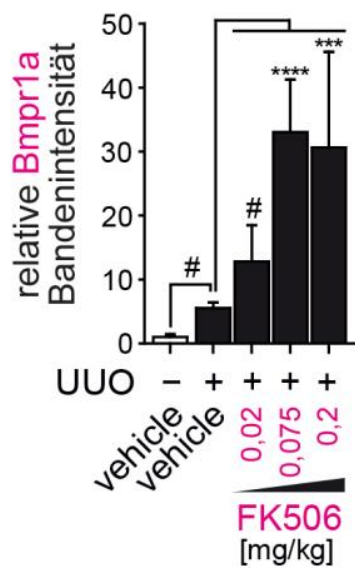

$\mathbf{F}$

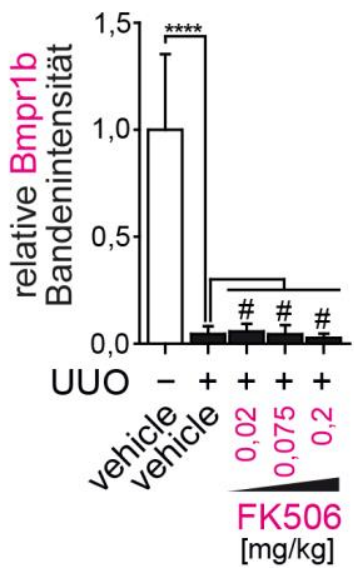

G

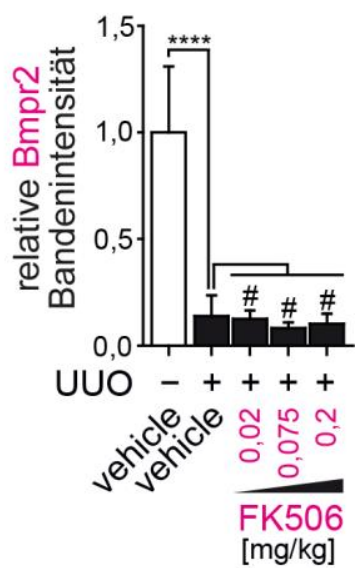

Abbildung 11: Spezifische FK506-abhängige Induktion des Bmpr1a in UUO-Nieren

(A-C) Analyse der Bmpr1a- (A), Bmpr1b- (B) und Bmpr2-Expression (C) mittels qRT-PCR nach RNA-Isolation aus murinen Nierenbiopsaten nach zehntägiger UUO. Für statistische Analysen wurde die relative Expression von sham-operierten Nieren des Kontrollkollektivs arbiträr auf den Wert eins festgelegt (Messung der Proben als 
Triplikate, $\mathrm{n}=4$ in jeder Gruppe, Mittelwert, Standardabweichung, ${ }^{*} \mathrm{p}<0,05,{ }^{* *} \mathrm{p}<0,01,{ }^{* * *} \mathrm{p}<0,001$, **** $\mathrm{p}<0,0001$, \# nicht signifikant; Kalkulation der $\mathrm{p}$-Werte mittels einfaktorieller ANOVA mit Bonferroni-PostHoc-Analyse in Relation zur sham-Niere bzw. zur UUO-Niere vehicle-behandelter Mäuse).(D) Western Blot präsentiert die Bmpr1a-, Bmpr1b- und Bmpr2-Expression in sham- und UUO-Nieren vehicle- bzw. FK506-behandelter Mäuse. (E-G) Densitometrische Analyse des Western Blots auf Bmpr1a (E), Bmpr1b (F) und Bmpr2 (G). Der für das jeweilige Zielgen quantifizierte Wert wurde gegen das detektierte Signal des Haushaltsgens Gapdh normalisiert und aus den beiden pro Gruppe generierten Werten ein Mittelwert berechnet. Für statistische Analysen wurde die absolut optometrisch quantifizierbare Expression von sham-operierten Nieren des Kontrollkollektivs arbiträr auf den Wert eins festgelegt (Messung der Proben als Triplikate, $n=2$ in jeder Gruppe, Mittelwert, Standardabweichung, $* * * * p<0,0001$; Kalkulation der $p$-Werte mittels einfaktorieller ANOVA mit Bonferroni-PostHoc-Analyse in Relation zur sham-Niere bzw. zur UUO-Niere vehicle-behandelter Mäuse).

\subsubsection{FK506-abhängige Bmpr1a-Induktion in Assoziation mit aktivierter Smad1/5/8-Signaltrans- duktionskaskade}

Im Folgenden sollte die im UUO-Modell eruierte Hochregulation des Bmpr1a insbesondere nach der Applikation von FK506 auf ihre Funktionalität hin überprüft werden. Diese impliziert die Bmpr1a-induzierte Phosphorylierung der zytoplasmatischen rezeptorregulierten Smad1/5/8-Proteine zu pSmad1/5/8 und ist somit ein Ausdruck für die effektive Aktivierung der intrinsischen Signalkaskade und der sich anschließenden Genregulation. Hierzu erfolgten in allen Mauskollektiven quantitative Expressionsanalysen des Bmpr1a sowie der pSmad1/5/8-Proteine mittels immunhistochemischer Färbungen sowie auf Proteinebene mittels Western Blot.

Nach zehntägiger einseitiger obstruktiver Nephropathie zeigten immunhistochemisch mit Anti-Bmpr1a markierte UUO-Nieren des Kontrollkollektivs nur einen geringfügig erhöhten Anteil lokalisierbarer Bmpr1a+Tubulusepithelzellen, wohingegen sich signifikante und sogar dosisabhängige Unterschiede infolge einer systemischen FK506-Exposition manifestierten.

Einen ersten Anhaltspunkt für eine signifikante Induktion der intrinsischen Signaltransduktion nach FK506Applikation lieferte zunächst die morphometrische Flächenanteilbestimmung immunhistochemisch auf pSmad1/5/8 gefärbter Nierenpräparate. Während sowohl in sham- wie auch in UUO-Nieren vehicle-behandelter Mäuse äquivalente Areale phosphorylierter Smad1/5/8-Proteine quantifizierbar waren, manifestierte sich im Tubulusepithel der mit FK506 supplementierten Mäuse infolge der permanenten Harnleiterokklusion eine signifikant erhöhte dosisabhängige Steigerung der Zielproteine pSmad1/5/8.

Der Western Blot bestätigte die wirkungsvolle Hochregulation phosphorylierter Smad1/5/8-Proteine in UUO-Nieren FK506-behandelter Kohorten, wobei dieser induktive Effekt, analog zu den mittels Immunmarkierung vollzogenen bildanalytischen Messungen durch kontinuierliche Konzentrationssteigerung des Pharmakons potenziert werden konnte. Demgegenüber reduzierte sich in obstruierten Nieren der Kontrollgruppe die relative Expression der Zielproteine $\mathrm{pSmad1/5/8}$ und somit das Aktivitätsniveau der rezeptorassoziierten intrazellulären Signalkaskade. 
A

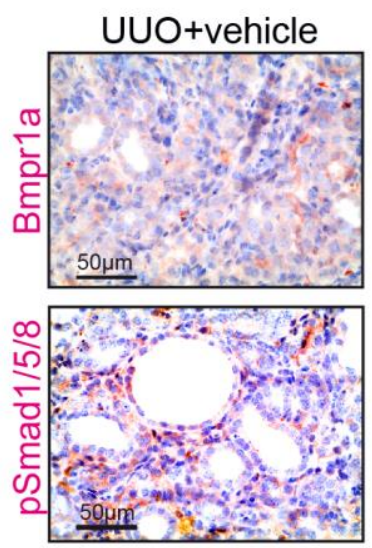

B

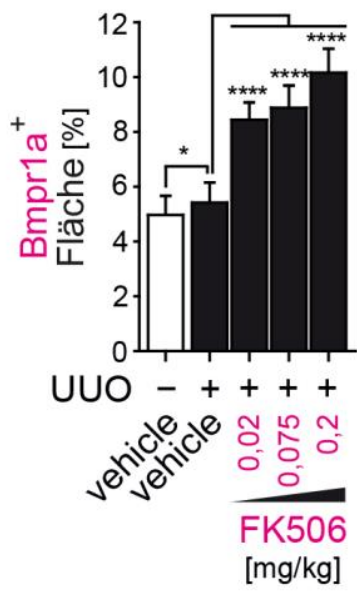

UUO+FK506 [mg/kg]

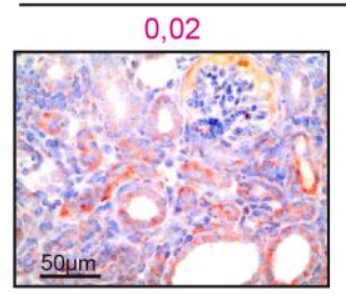

0,075
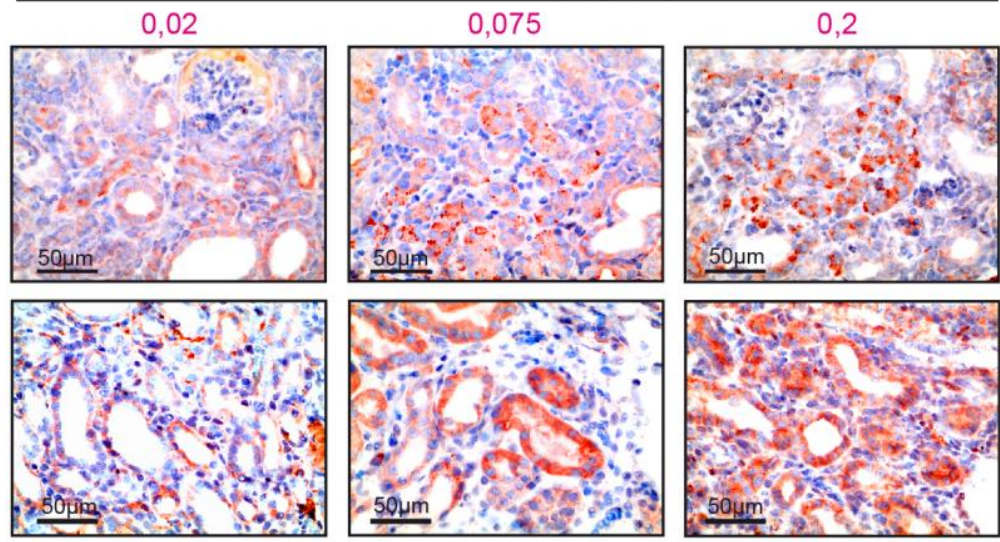

C

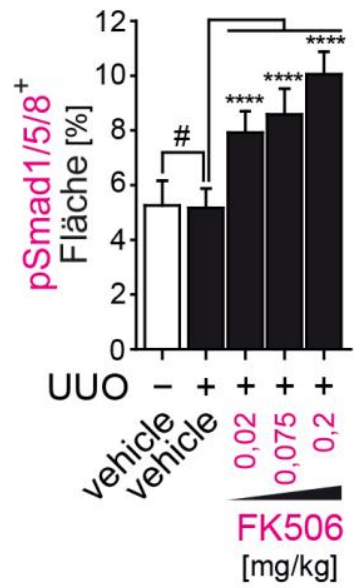

D

E

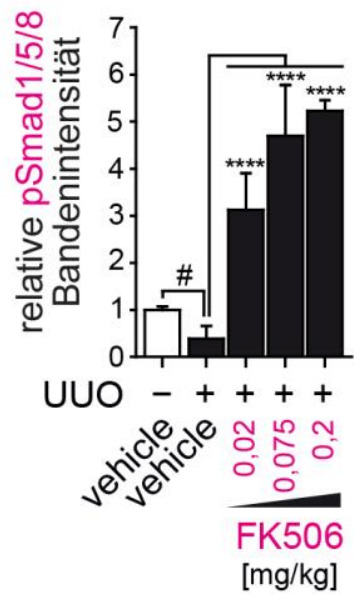

Abbildung 12: Assoziation der FK506-abhängigen Bmpr1a-Induktion mit konsekutiv aktivierter Smad1/5/8Signaltransduktionskaskade in UUO-Nieren

(A) Repräsentative Mikrophotographie von immunhistochemisch mit primären Antikörpern gegen Bmpr1a und 
pSmad1/5/8 markierten Nierenpräparaten (Messbalken $50 \mu \mathrm{m}$ ). Die Bildausschnitte zeigen UUO-Nieren von vehicle- und FK506-behandelten Mäusen zehn Tage nach unilateraler Ureterobstruktion. (B+C) Morphometrische Quantifizierung der Bmpr1a- (B) und pSmad1/5/8-Expression (C) in immunhistochemisch markierten Nierengewebeschnitten (Bildanalytische Messung erfolgte in je zehn Gesichtsfeldern pro Niere bei 400x Vergrößerung, $\mathrm{n}=6$ in jeder Gruppe, Mittelwert, Standardabweichung, * $p<0,05, * * * * p<0,0001$, \# nicht signifikant; Kalkulation der $p$-Werte mittels einfaktorieller ANOVA mit Bonferroni-Post-Hoc-Analyse in Relation zur sham-Niere bzw. zur UUO-Niere vehicle-behandelter Mäuse). (D) Western Blot zeigt die Expression der pSmad1/5/8-Proteine in shamund UUO-Nieren vehicle- bzw. FK506-behandelter Mäuse. (E) Densitometrische Analyse des Western Blots auf pSmad. Für statistische Analysen wurde der für das Zielgen quantifizierte Wert gegen das detektierte Signal des Haushaltsgens Gapdh normalisiert und aus den beiden pro Gruppe generierten Werten ein Mittelwert berechnet. Aus technischen Gründen wurde für die sham-operierte Niere des Kontrollkollektivs eine Probe aufgetragen und somit nur ein Wert generiert (Messung der Proben als Triplikate, $n=2$ in jeder Gruppe, Mittelwert, Standardabweichung, $* * * * p<0,0001$; Kalkulation der $p$-Werte mittels einfaktorieller ANOVA mit Bonferroni-PostHoc-Analyse in Relation zur sham-Niere bzw. zur UUO-Niere vehicle-behandelter Mäuse).

\subsubsection{Einfluss der FK506-Exposition auf die Expression des Bmpr1a- und der pSmad1/5/8-Prote- ine in sham-operierten Nieren}

Weiterhin sollte die Wirkung von FK506 auf die Expression des Bmpr1a sowie die als Kennzeichen seiner Funktionalität zu interpretierende Phosphorylierung der Smad1/5/8-Proteine im gesunden Nierenparenchym analysiert werden. Entsprechende Untersuchungen erfolgten in immunhistochemisch gefärbten Gewebeschnitten scheinoperierter Nieren, die Versuchstieren infolge der üblichen vehicle- bzw. FK506-Applikation entnommen worden waren. Dabei betrugen die morphometrisch quantifizierbaren Bmpr1a ${ }^{+}-$und pSmad1/5/8+-Flächenanteile in allen sham-Nieren durchschnittlich etwa $5 \%$ und gaben aufgrund der fehlenden Signifikanz keinen Hinweis auf einen FK506-abhängigen Effekt. Übereinstimmendes zeigte auch die anschließende mittels qRT-PCR vollzogene Verifizierung der Bmpr1a-Expression. 
A

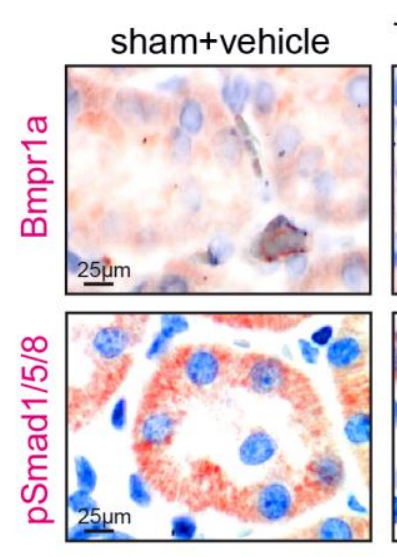

B

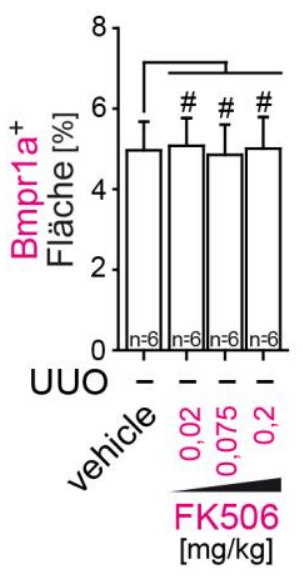

C

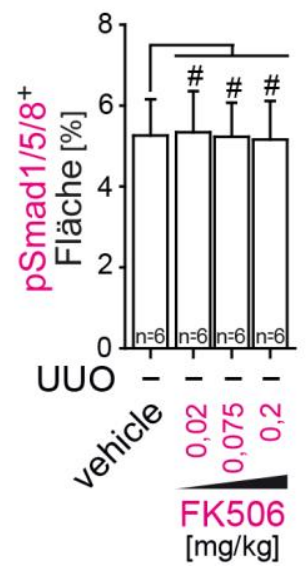

sham+FK506 [mg/kg]

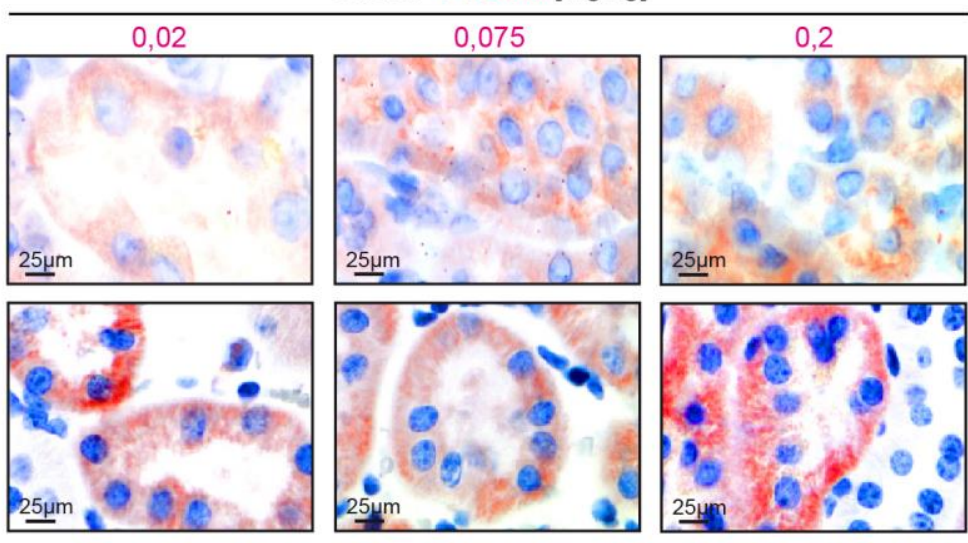

D

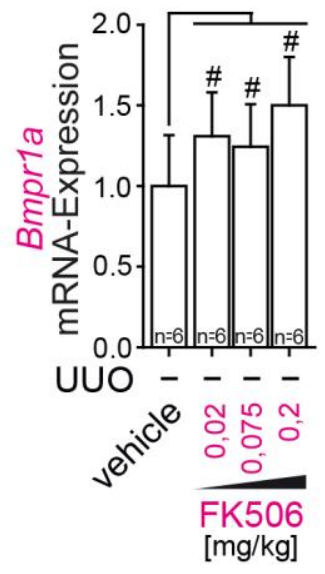

Abbildung 13: FK506-Exposition ohne Einfluss auf die Bmpr1a- und pSmad1/5/8-Expression in sham-Nieren (A) Repräsentative Mikrophotographie von immunhistochemisch mit primären Antikörpern gegen Bmpr1a und pSmad1/5/8 markierten Nierenpräparaten (Messbalken $25 \mu \mathrm{m}$ ). Die Bildausschnitte zeigen sham-operierte Nieren von vehicle- und FK506-behandelten Mäusen. (B+C) Morphometrische Quantifizierung der Bmpr1a- (B) und pSmad1/5/8-Expression (C) in immunhistochemisch markierten Nierengewebeschnitten (Bildanalytische Messung erfolgte in je zehn Gesichtsfeldern pro Niere bei 400x Vergrößerung, $n=6$ in jeder Gruppe, Mittelwert, Standardabweichung, \# nicht signifikant; Kalkulation der p-Werte mittels einfaktorieller ANOVA mit BonferroniPost-Hoc-Analyse in Relation zur sham-Niere vehicle-behandelter Mäuse). (D) Analyse der Bmpr1a-Expression mittels qRT-PCR nach RNA-Isolation aus murinen sham-Nieren (Messung der Proben als Triplikate, $\mathrm{n}=4$ in jeder Gruppe, Mittelwert, Standardabweichung, \# nicht signifikant; Kalkulation der p-Werte mittels einfaktorieller ANOVA mit Bonferroni-Post-Hoc-Analyse in Relation zur sham-Niere vehicle-behandelter Mäuse).

Somit lassen die molekularbiologische und immunhistologische Charakterisierung des fibrotischen Nierengewebes auf eine effiziente Induktion von Bmpr1a mit implizierter Phosphorylierung der zytoplasmatischen R-Smads 1/5/8 nach geringdosierter Gabe des immunsuppressiven Therapeutikums Tacrolimus schließen und sprechen daher für den Erhalt der Rezeptorfunktionalität. 


\subsection{Milderung der experimentellen renalen Fibrogenese in vivo mittels FK506-assoziierter Bmpr1a-Induktion}

Inwiefern die FK506-assoziierte Bmpr1a-Induktion mit der Repression profibrotischer Stimuli korreliert, sollte im UUO-Mausmodell durch morphometrische Quantifizierung histologisch gefärbter Nierenpräparate sowie durch mRNA-Expressionsanalysen spezifischer mesenchymaler Markerproteine mithilfe der qRTPCR validiert werden.

Nach zehntägiger unilateraler Ureterobstruktion stellten die in der PAS-Färbung als Ausdruck progredienter Nierenschädigung reproduzierbare tubuläre Dilatation ebenso wie die Formierung hyaliner Zylinder schwerwiegende Komplikationen dar. Demgegenüber zeigte das mit FK506 behandelte Kollektiv dosisabhängig eine substantielle Milderung derartiger pathohistologischer Phänomene. Entsprechend betrug der mittels MTS-Färbung quantifizierbare Fibrosierungsgrad in UUO-Nieren vehicle-behandelter Mäuse bis zu $17 \%$, konnte jedoch durch die Applikation steigender FK506-Konzentrationen signifikant supprimiert werden.

Weiterhin erfolgte der immunfluoreszenzoptische Nachweis des $\alpha$ SMA ( $\alpha$-smooth muscle actin), des Collagen-1 sowie des Fsp1 (fibroblast-specific protein 1), deren Synthese eng an die Akkumulation von (Myo-)Fibroblasten gekoppelt ist. Als Merkmal ihrer potenten Hochregulation nahm der quantifizierbare Anteil spezifisch fluoreszierender Areale des Interstitiums in ligierten Nieren der Kontrollgruppe signifikant zu, während im ipsilateralen Nierengewebe von Mäusen unter sukzessiv steigender FK506-Exposition eine Reduktion der mesenchymalen Markerproteine zu beobachten war. 
A

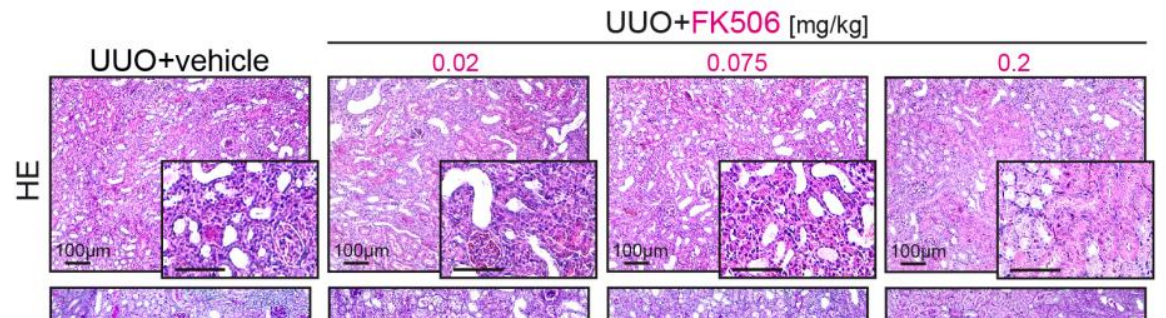

B
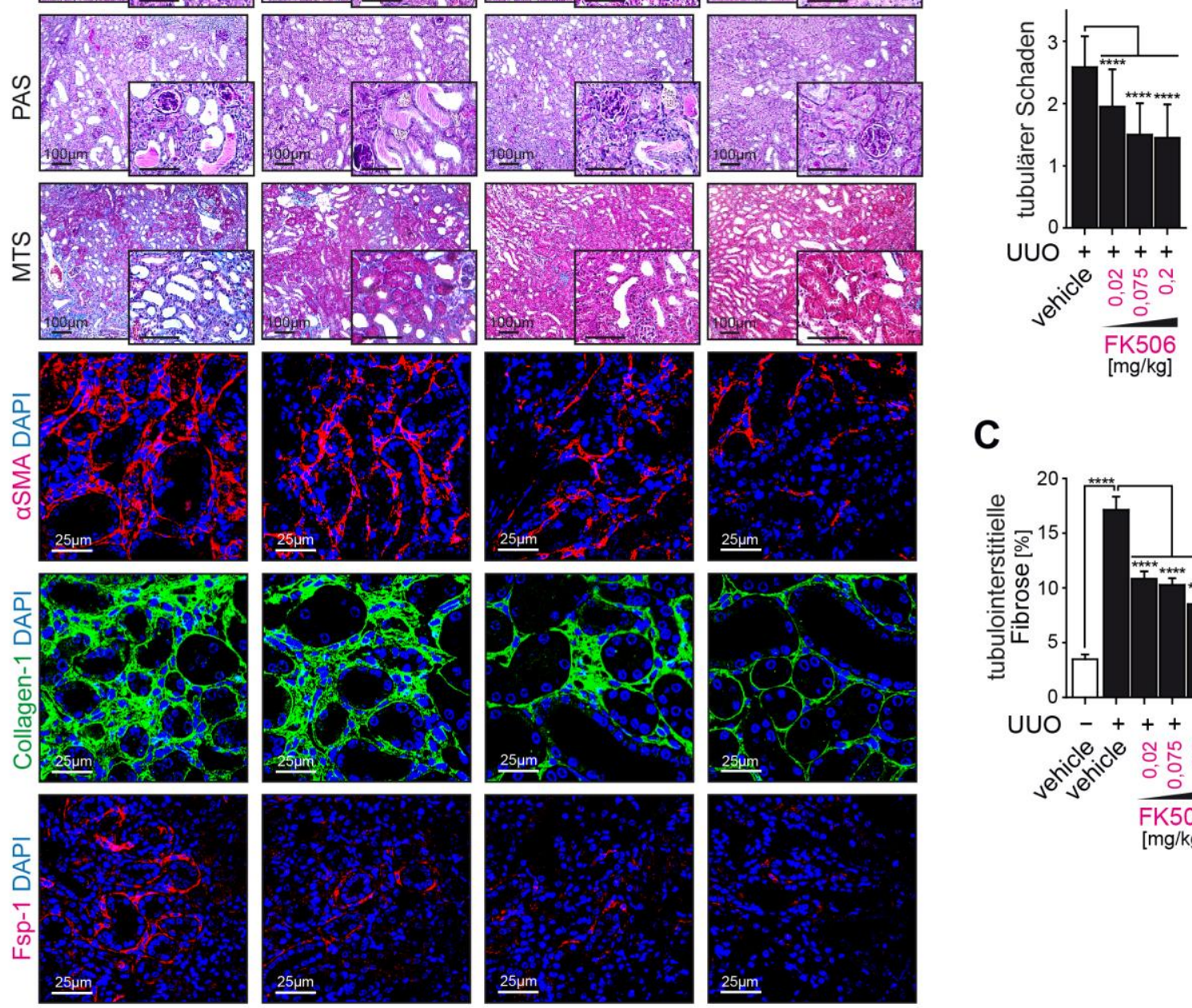

C

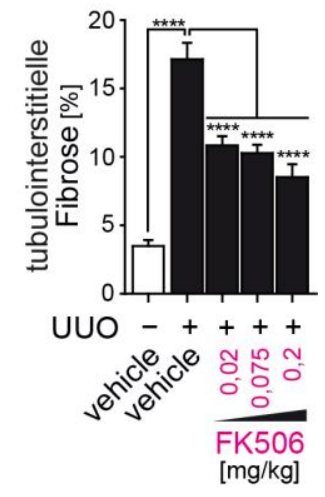

D

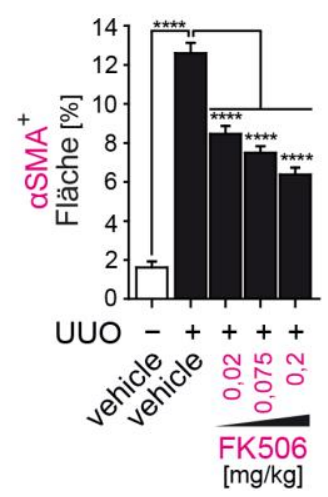

E

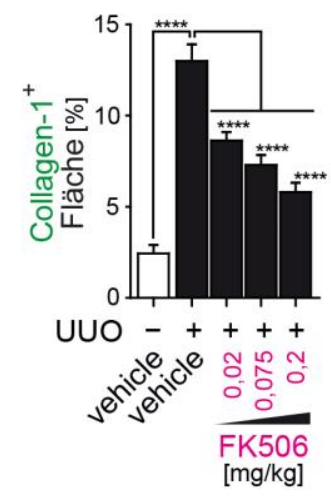

F

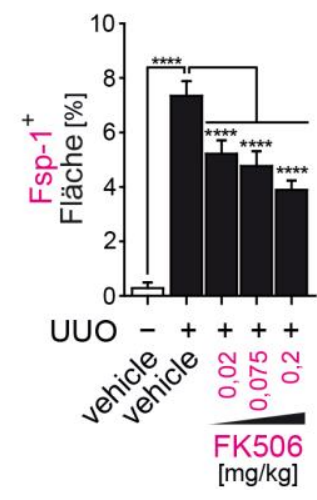


Abbildung 14: Milderung der experimentellen renalen Fibrogenese mittels FK506-assoziierter Bmpr1a-Induktion im histopathologischen Korrelat der UUO-Niere

(A) Repräsentative Mikrophotographie von mittels Hämatoxylin-Eosin (HE), Perjodsäure-Schiff-Reaktion (PAS) und Masson-Trichrom (MTS) gefärbten Nierenpräparaten (Messbalken $100 \mu \mathrm{m}$ ) sowie von Gewebeschnitten nach Immunfluoreszenzmarkierung gegen aSMA, Collagen-1 und Fsp1 (Messbalken $25 \mu \mathrm{m}$ ). Die Bildausschnitte zeigen fibrotische UUO-Nieren von vehicle- und FK506-behandelten Mäusen zehn Tage nach unilateraler Ureterobstruktion. (B) Semiquantitative Graduierung tubulärer Schäden in PAS-gefärbten Nierengewebeschnitten $(0=$ normal, 1 = mild, 2 = moderat, 3 = schwerwiegend, Bewertung erfolgte in je zehn Gesichtsfeldern pro Niere bei 400x Vergrößerung, $n=6$ in jeder Gruppe, Mittelwert, Standardabweichung, $* * * * p<0,0001$; Kalkulation der p-Werte mittels einfaktorieller ANOVA mit Bonferroni-Post-Hoc-Analyse in Relation zur UUO-Niere vehicle-behandelter Mäuse).(C) Morphometrische Quantifizierung der interstitiellen Fibrose in MTS-gefärbten Nierengewebeschnitten (Bildanalytische Messung erfolgte in je zehn Gesichtsfeldern pro Niere bei 200x Vergrößerung, $\mathrm{n}=6$ in jeder Gruppe, Mittelwert, Standardabweichung, $* * * * p<0,0001$; Kalkulation der $\mathrm{p}$-Werte mittels einfaktorieller ANOVA mit Bonferroni-Post-Hoc-Analyse in Relation zur sham-Niere bzw. zur UUO-Niere vehicle-behandelter Mäuse). (D-F) Morphometrische Quantifizierung der aSMA- (D), Collagen-1- (E) und Fsp1-Expression (F) zur Validierung der Fibroblasten-Akkumulation in fluoreszenzmarkierten Nierengewebeschnitten (Bildanalytische Messung erfolgte in je zehn Gesichtsfeldern pro Niere bei 400x Vergrößerung, $n=6$ in jeder Gruppe, Mittelwert, Standardabweichung, $* * * * p<0,0001$; Kalkulation der $\mathrm{p}$-Werte mittels einfaktorieller ANOVA mit Bonferroni-Post-Hoc-Analyse in Relation zur sham-Niere bzw. zur UUO-Niere vehicle-behandelter Mäuse).

Die aufgezeigten Tendenzen ließen sich in daraufhin erfolgten Analysen der Acta2 (aSMA)-, Collagen-1a1sowie der Fsp1-Expression mittels qRT-PCR verifizieren.

A

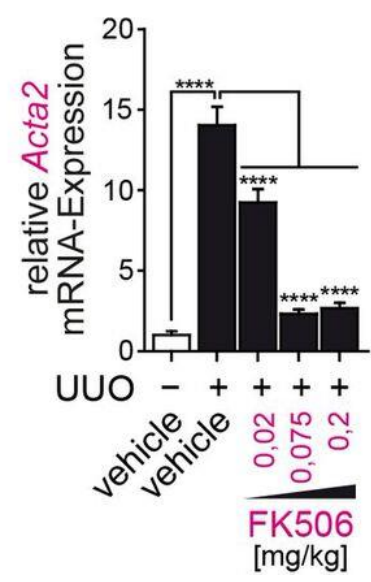

B

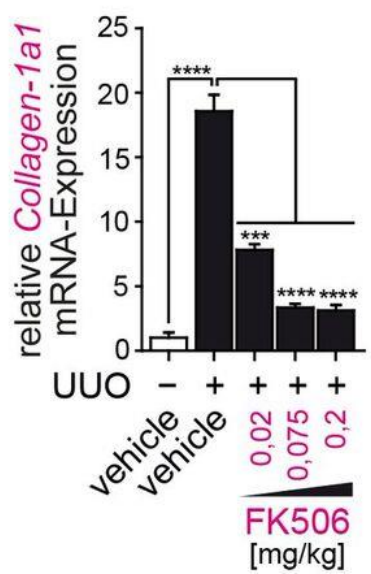

C

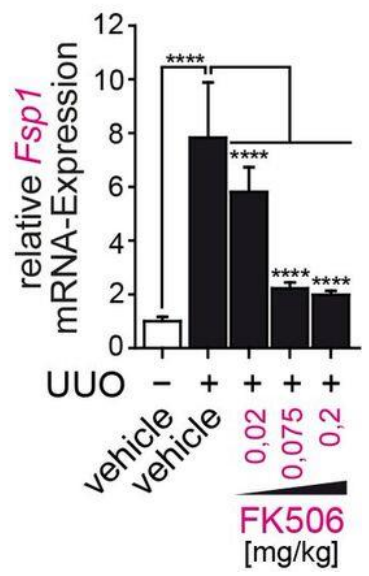

Abbildung 15: Milderung der experimentellen renalen Fibrogenese in vivo durch FK506-assoziierte Bmpr1aInduktion auf Transkriptionsebene

(A-C) Analyse der Acta2- (A), Collagen-1a1- (B), und Fsp1-Expression (C) mittels qRT-PCR nach RNA-Isolation aus murinen Nierenbiopsaten nach zehntägiger UUO (Messung der Proben als Triplikate, $\mathrm{n}=4$ in jeder Gruppe, Mittelwert, Standardabweichung, $* * * p<0,001, * * * * p<0,0001$; Kalkulation der $p$-Werte mittels einfaktorieller ANOVA mit Bonferroni-Post-Hoc-Analyse in Relation zur sham-Niere bzw. zur UUO-Niere vehicle-behandelter Mäuse). 


\subsubsection{Effekt der FK506-Exposition auf die Histologie scheinoperierter Nieren}

Nachfolgend sollte der Einfluss von FK506 auf die sensible Architektur des gesunden Nierenparenchyms nachvollzogen werden. In hierzu herangezogenen Gewebeschnittpräparaten von nicht-ligierten Nieren vehicle- und FK506-behandelter Mäuse konnte nach PAS-Färbung zunächst ein unter Pharmakonapplikation induzierter Tubulusepithelschaden ausgeschlossen werden. Weiterhin ergaben weder die morphometrische Quantifizierung der tubulointerstitiellen Fibrosierung in MTS-gefärbtem Gewebe noch die mittels Immunfluoreszenzmarkierung visualisierte $\alpha \mathrm{SMA}^{+}$-, Collagen-1 $1^{+}$- und Fsp ${ }^{+}$-Fläche signifikante Unterschiede zwischen sham-Nieren der einzelnen Kollektive. 
A
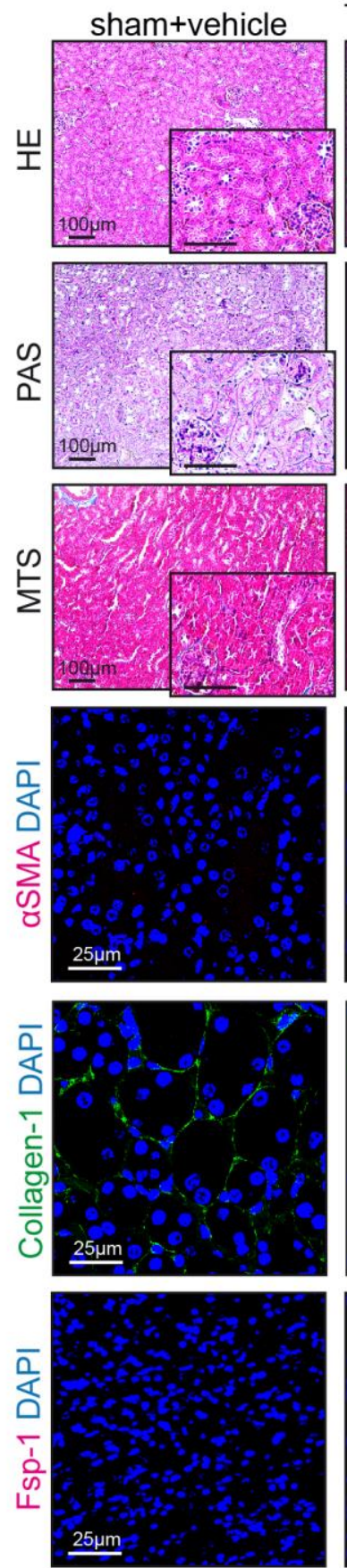

sham+FK506 [mg/kg]
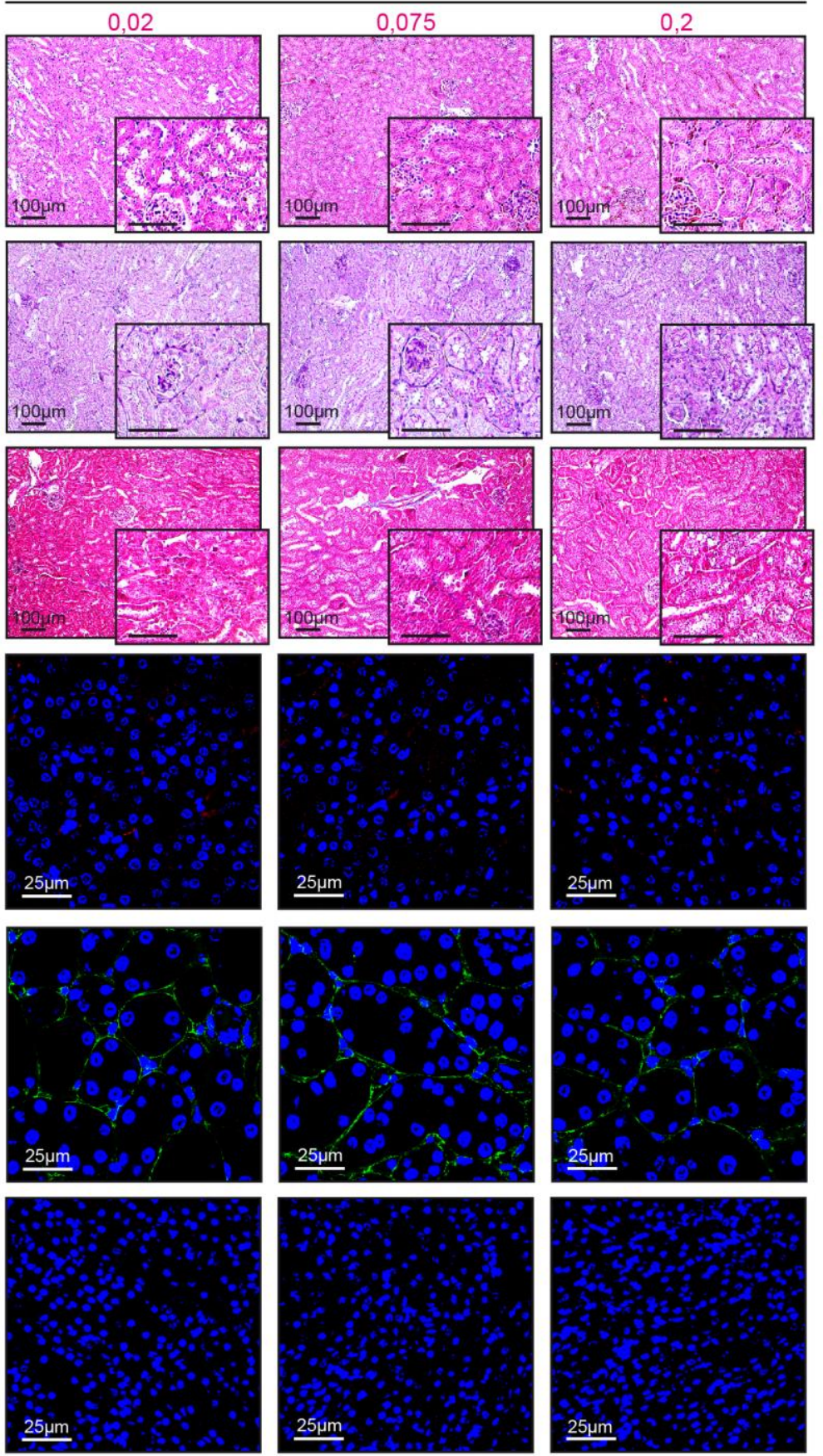
B

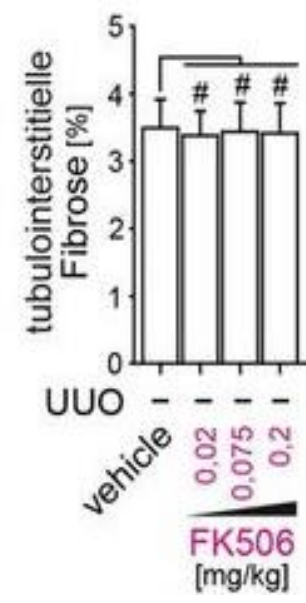

C

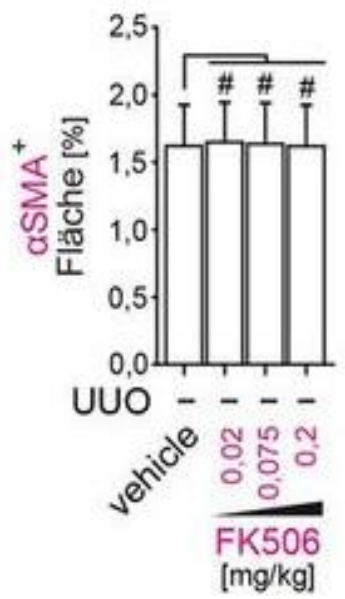

D

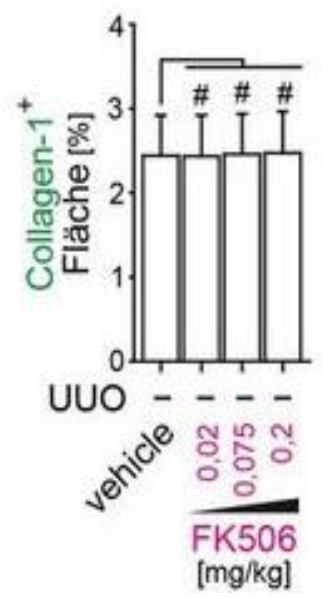

E

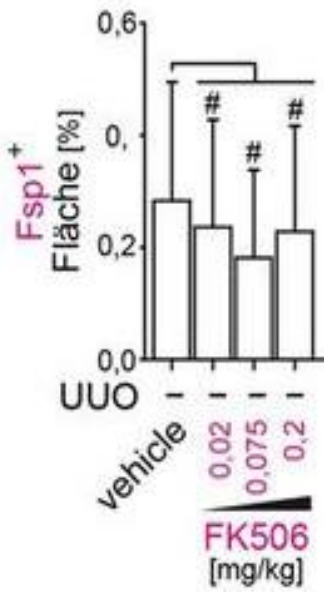

Abbildung 16: FK506-Exposition ohne Effekt auf die Histologie scheinoperierter Nieren

(A) Repräsentative Mikrophotographie von HE-, PAS- und MTS-gefärbten Nierenpräparaten (Messbalken $100 \mu \mathrm{m}$ ) sowie von fluoreszenzmarkierten Gewebeschnitten gegen aSMA, Collagen-1 und Fsp1 (Messbalken $25 \mu \mathrm{m}$ ). Die Bildausschnitte zeigen sham-operierte Nieren von vehicle- und FK506-behandelten Mäusen. (B) Morphometrische Quantifizierung der interstitiellen Fibrose in MTS-gefärbten Nierengewebeschnitten (Bildanalytische Messung erfolgte in je zehn Gesichtsfeldern pro Niere bei 200x Vergrößerung, $n=6$ in jeder Gruppe, Mittelwert, Standardabweichung, \# nicht signifikant; Kalkulation der p-Werte mittels einfaktorieller ANOVA mit Bonferroni-Post-Hoc-Analyse in Relation zur sham-Niere vehicle-behandelter Mäuse). (C-E) Morphometrische Quantifizierung der aSMA- (C), Collagen-1- (D) und Fsp1-Expression (E) zur Validierung der Fibroblasten-Akkumulation in fluoreszenzmarkierten Nierengewebeschnitten (Bildanalytische Messung erfolgte in je zehn Gesichtsfeldern pro Niere bei 400x Vergrößerung, $n=6$ in jeder Gruppe, Mittelwert, Standardabweichung, \# nicht signifikant; Kalkulation der $p$-Werte mittels einfaktorieller ANOVA mit Bonferroni-Post-Hoc-Analyse in Relation zur shamNiere vehicle-behandelter Mäuse).

\subsection{Pikomolarer FK506-Vollblutspiegel in FK506-supplementierten UUO-Mäusen}

Unter Anwendung eines kommerziellen kompetitiven Enzym-gekoppelten Immunadsorptionstests (cELISA) erfolgte die Bestimmung des FK506-Spiegels im Vollblut der mit unterschiedlichen Dosen FK506 behandelten Mauskollektive. Die messbaren Konzentrationen lagen im pikomolaren Bereich zwischen 0,4 ng/ml in der niedrigsten Applikationsdosis (0,02 mg/kg KG/Tag) bzw. 0,6 ng/ml in den beiden höher supplementierten Untersuchungsgruppen ( 0,075 und $0,02 \mathrm{mg} / \mathrm{kg} \mathrm{KG} / \mathrm{Tag})$.

In Relation zu dem bei einer immunsuppressiven FK506-Langzeittherapie angestrebten $\mathrm{C}_{0}$-Zielspiegel ( 5 bis $10 \mathrm{ng} / \mathrm{ml}$ ) manifestiert sich somit eine rund 10- bis 20-fach geringere murine Blutkonzentration des Markolid-Lactons (Wallemacq et al. 2009). 


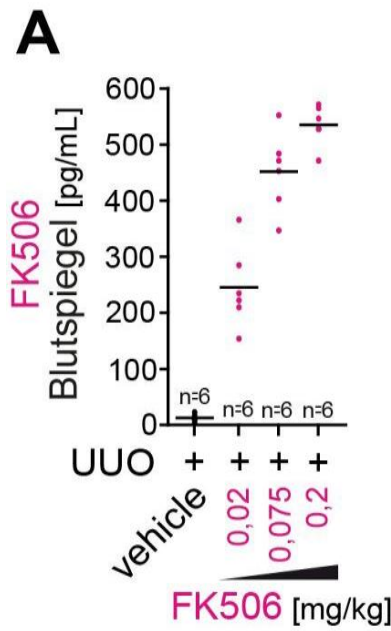

\section{Abbildung 17: Pikomolarer FK506-Vollblutspiegel in FK506-supplementierten Versuchstieren}

(A) Bestimmung der FK506-Konzentration mittels cELISA in Vollblutproben der UUO-Mäuse, die einen Tag präoperativ bis zehn Tage nach UUO mit einem vehicle oder FK506 in den Dosen 0,02, 0,075, 0,2 mg/kg KG/Tag behandelt wurden (Messung der Proben als Triplikate, $n=6$ in jeder Gruppe, Daten als alignierte Dotplots mit Mittelwert dargestellt).

\subsection{FK506-vermittelte BMPR1A-Induktion in vitro durch De-novo-Translation unbekannter Transkriptionsfaktoren}

Die sowohl in vitro im humanen Tubulusepithel wie auch in vivo im Mausmodell der unilateralen Ureterobstruktion quantifizierbare signifikante Induktion der BMPR1A-Expression durch FK506 stellt die Frage nach möglichen, zugrundeliegenden molekularen Aktivierungsmechanismen. Für eine weiterführende Spezifizierung erfolgte in tubuloepithelialen HK-2-Zellen die kontrollierte Translationshemmung durch Präinkubation mit der antibiotischen Substanz Cycloheximid. Entsprechende Expressionsanalysen auf das Zielgen BMPR1A wurden nach erneuter sechsstündiger FK506-Stimulation (0,15 ng/ml bzw. $150 \mathrm{ng} / \mathrm{ml}$ ) zunächst mittels qRT-PCR sowie anschließend im Rahmen des Western Blot-Verfahrens vollzogen.

Dabei führte die Applikation von unterschiedlich hochkonzentriertem Cycloheximid (2,5,5,10 $\mu \mathrm{g} / \mathrm{ml})$ in mit DMSO bzw. mit geringsten Stoffmengen FK506 $(0,15 \mathrm{ng} / \mathrm{ml})$ stimulierten HK-2-Zellen zu keinen statistisch relevanten Unterschieden hinsichtlich der relativen Rezeptorexpression, wohingegen höhere Dosen FK506 $(150 \mathrm{ng} / \mathrm{ml})$ trotz Präinkubation von niedrigkonzentriertem Cycloheximid $(2,5 \mathrm{bzw} .5 \mathrm{\mu g} / \mathrm{ml})$ eine signifikante Hochregulation des BMPR1A bewirkten. Dieser Effekt konnte allerdings durch die Gabe von $10 \mu \mathrm{g} / \mathrm{ml}$ des Translationsinhibitors unterbunden werden.

Die daraufhin erfolgte Western Blot-Analyse ergab unabhängig von der jeweils applizierten Dosis Cycloheximid die Blockade einer FK506-spezifischen Rezeptorinduktion, die jedoch durch alleinige Stimulation des Immunsuppressivums vollständig aufgehoben wurde. 
A

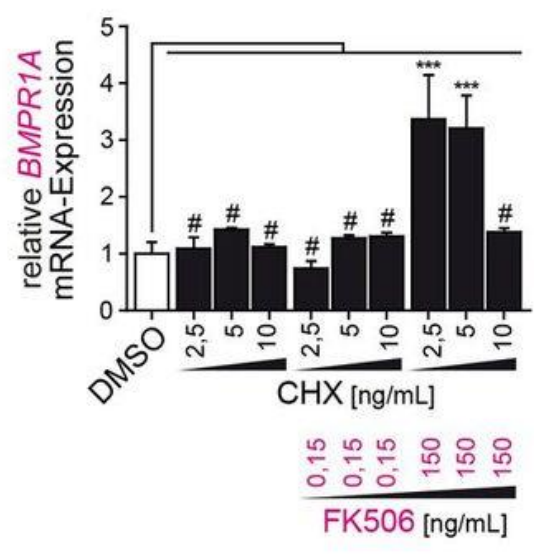

B

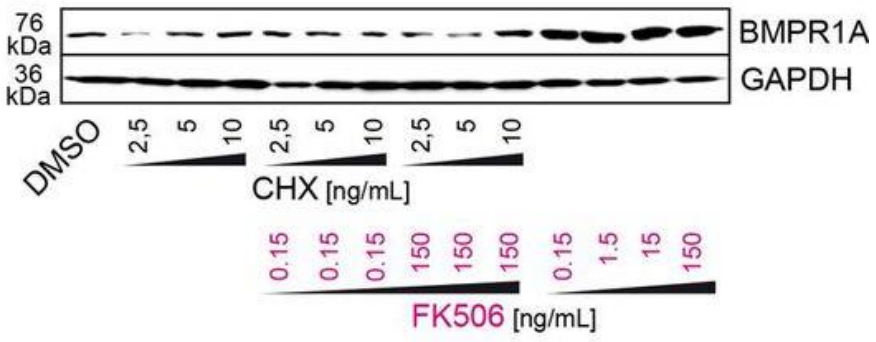

C

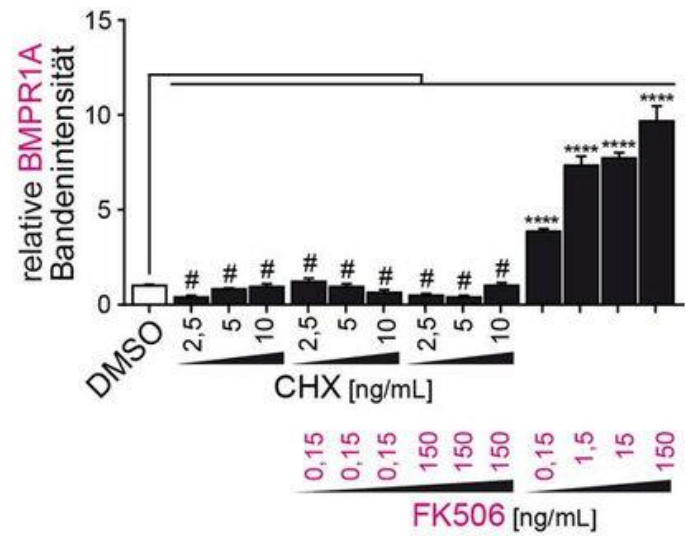

Abbildung 18: FK506-vermittelte BMPR1A-Induktion in vitro basiert auf der De-novo-Translation unbekannter Transkriptionsfaktoren

(A) Analyse der BMPR1A-Expression mittels qRT-PCR in humanen Tubulusepithelzellen (HK-2) nach Präinkubation $(1 \mathrm{~h}$ ) des Translationsinhibitors Cycloheximid sowie darauffolgender FK506-Stimulation über $6 \mathrm{~h}$ (Messung der Proben als Triplikate, Mittelwert, Standardabweichung, ${ }^{* * *} p<0,001$, \# nicht signifikant; Kalkulation der p-Werte mittels einfaktorieller ANOVA mit Bonferroni-Post-Hoc-Analyse in Relation zu DMSO-behandelten Zellen). (B) Western Blot auf BMPR1A unter Anwendung des in (A) erläuterten Stimulationsschemas. (C) Densitometrische Auswertung der relativen BMPR1A-Expression. Für statistische Analysen erfolgte eine optometrische Dichtemessung an drei prominenten Einzelbanden sowie die Normalisierung des für das Zielprotein BMPR1A quantifizierten Wertes gegen das detektierte Signal des Haushaltsgens GAPDH (Messung der Proben als Triplikate, Mittelwert, Standardabweichung, ${ }^{* * *} p<0,001,{ }^{* * * *} p<0,0001, \#$ nicht signifikant; Kalkulation der $\mathrm{p}$-Werte mittels einfaktorieller ANOVA mit Bonferroni-Post-Hoc-Analyse in Relation zu DMSO-behandelten Zellen).

Den In-vitro-Ergebnissen zufolge wird die FK506-assoziierte BMPR1A-Induktion somit nicht durch eine direkte Induktion des BMPR1A-Promotors vermittelt. Hingegen lässt sich auf eine FK506-abhängige De-novoTranslation eines bislang unbekannten Transkriptionsfaktors schließen, der wiederum die Transkription des BMP-Typ I-Rezeptors durch Bindung entsprechender Sequenzmotive in der Promotorregion initiiert. 


\subsection{Detektion FK506-induzierter Transkriptionsfaktoren in vitro mittels $\mathbf{R T}^{2}$ Profiler $^{\mathrm{TM}}$ PCR-Ar- rays}

Ferner sollte unter Anwendung des kommerziell erhältlichen $\mathrm{RT}^{2}$ Profiler ${ }^{\mathrm{TM}}$ PCR-Arrays die Expression 84 verschiedener Transkriptionsfaktoren in DMSO- und FK506-behandelten humanen HK-2-Zellen quantifiziert und über den unmittelbaren Vergleich ihrer Expressionsprofile ein putativer Transkriptionsfaktor im postulierten Modell des indirekten Induktionsmechanismus identifiziert werden.

Daneben führte die Supplementation von FK506 zu einer mindestens zweifachen Induktion diverser Transkriptionsfaktoren, unter denen der bioinformatische Sequenzabgleich auf Basis der internetgestützten Datenbanken TFSEARCH version 1.3 (Heinemeyer et al. 1998) und Ensembl (Flicek et al. 2014) die folgenden sechs potentiellen Kandidatengene mit putativen Bindungsmotiven in der Promotorregion des humanen BMPR1A-Gens identifizierte: CAMP responsive element binding protein 1 (CREB1), GATA binding protein 3 (GATA3), androgen receptor (AR), CCAAT/enhancer binding protein beta (CEBPB), MYC associated factor $X$ (MAX) und aryl hydrocarbon receptor nuclear translocator (ARNT).

Diese sowie die übrigen infolge der FK506-Stimulation differentiell exprimierten Transkriptionsfaktoren sind der Heatmap (siehe Abbildung 19 (A)) zu entnehmen. 
A

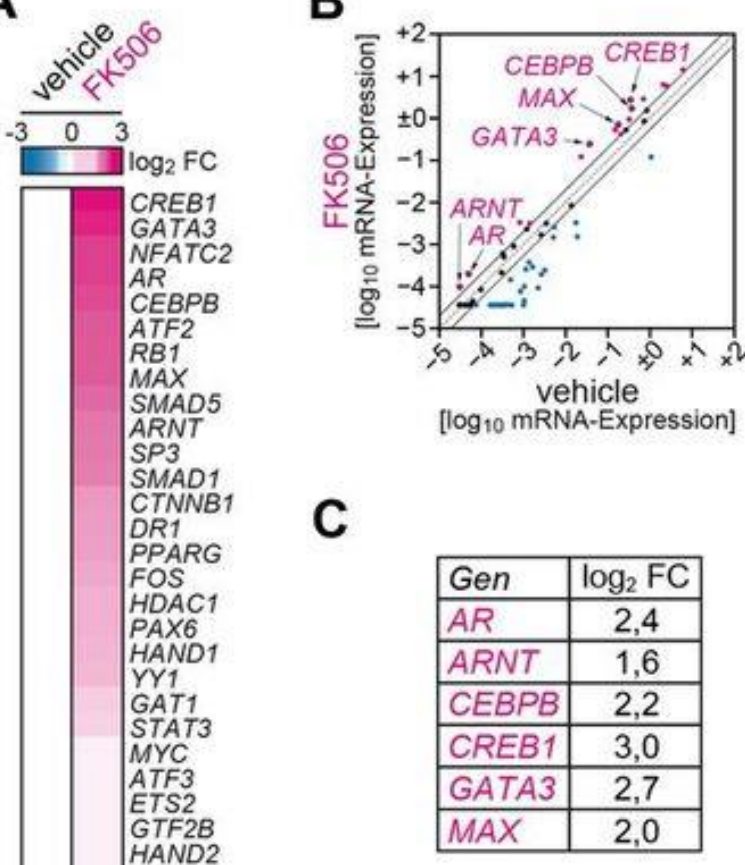

Abbildung 19: Detektion FK506-induzierter Transkriptionsfaktoren in vitro mittels $\mathbf{R T}^{2}$ Profiler $^{\mathrm{TM}} \mathrm{PCR}$ Arrays

(A) Heatmap zeigt vermehrt bzw. reduziert exprimierte humane Transkriptionsfaktoren in tubuloepithelialen HK-2-Zellen nach sechsstündiger FK506-Stimulation gegenüber den mit DMSO behandelten Zellen. Eine Normalisierung erfolgte über das quantifizierte Expressionsniveau verschiedener Haushaltsgene ( $\left.\log _{2} \mathrm{FC}\right)$.

(B,C) FK506-induzierte Faktoren mit putativen Bindungsdomänen upstream der TSS des humanen BMPR1A-Gens. FC, fold change. 


\subsection{Validierung der ermittelten Transkriptionsfaktoren in vivo}

Die Expression der sechs Kandidatengene mit Bindungsdomänen im humanen BMPR1A-Gen zur putativen Aktivierung seines Promotors wurde zunächst in vivo in ureterligierten Nieren FK506-supplementierter Mäuse mittels qRT-PCR validiert.

Insgesamt ergaben die mRNA-Analysen in präparierten Nieren sämtlicher Kollektive eine effiziente Induktion aller zu untersuchender Transkriptionsfaktoren in Relation zur kontralateralen sham-Niere vehicle-behandelter Mäuse. Eine im Zusammenhang mit der FK506-Applikation stehende signifikant erhöhte Expression konnte in fibrotischen UUO-Nieren nur für die Kandidatengene Max und Arnt eruiert werden, wobei die proportional zur applizierten Menge FK506 verlaufende Hochregulation des Transkriptionsfaktors Arnt einen dosisabhängigen Effekt mutmaßen lässt.

A

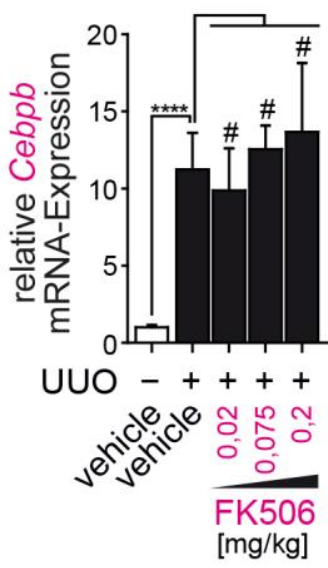

D

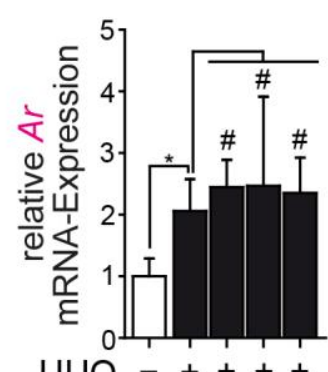

UUO -+++

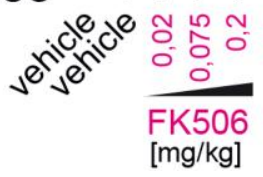

B

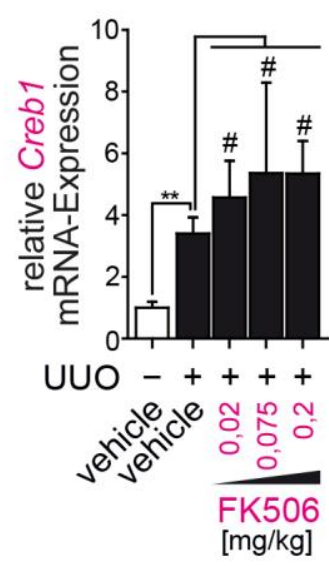

E

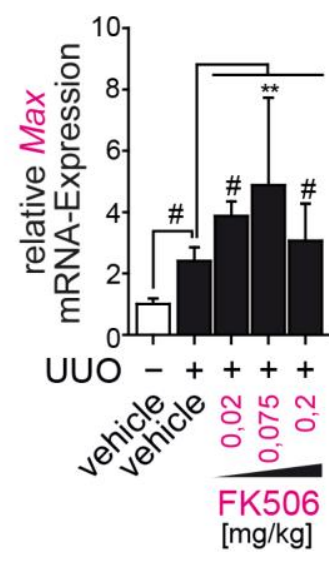

C

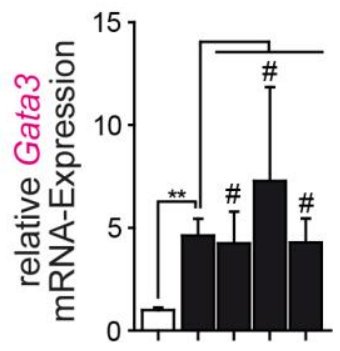

UUO -+++

9

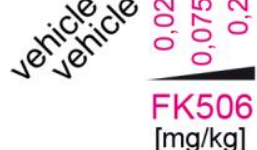

[mg/kg]

$\mathbf{F}$

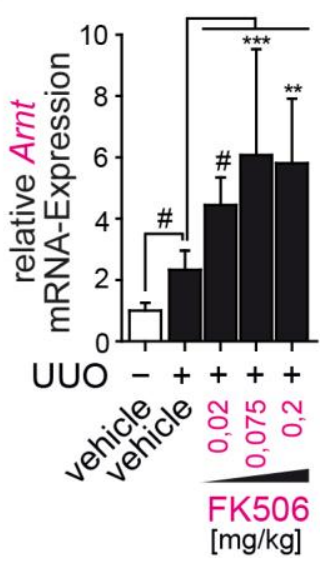

Abbildung 20: FK506-modulierte Induktion der Kandidatengene Max und Arnt in UUO-Nieren

(A-F) mRNA-Expressionsanalysen der Kandidatengene mittels qRT-PCR nach RNA-Isolation aus murinen NierenIysaten nach zehntägiger UUO (Messung der Proben als Triplikate, $n=4$ in jeder Gruppe, Mittelwert, Standardabweichung, * $p<0,05, * * p<0,01, * * * p<0,001, * * * * p<0,0001, \#$ nicht signifikant; Kalkulation der $p$-Werte mittels einfaktorieller ANOVA mit Bonferroni-Post-Hoc-Analyse in Relation zur sham-Niere vehicle-behandelter Mäuse). 


\subsection{Induktion des Bmpr1a und der pSmad1/5/8-Proteine unter FK506-Exposition in MCT-Zellen}

Das postulierte Modell der FK506-abhängigen BMPR1A-Induktion impliziert einen indirekten Aktivierungsprozess, in dessen Verlauf ein durch FK506 regulierter putativer Transkriptionsfaktor mit Bindungsmotiv in der BMPR1A-Promotorregion involviert ist. Die Funktionalität eines derartigen Prozesses sollte im Weiteren in der murinen proximalen tubuloepithelialen Zelllinie MCT näher charakterisiert werden. Zur Verifizierung geeigneter Medikamentendosen und Zeitpunkte erfolgten zunächst Bmpr1a-Expressionsanalysen mittels qRT-PCR bzw. der Western Blot-Methodik. Eine signifikante Induktion des Rezeptors in MCT-Zellen ließ sich auf mRNA-Ebene bereits nach dreistündiger, auf Proteinebene hingegen nach sechsstündiger Inkubation mit FK506 eruieren. Charakteristikum einer funktionellen BMP-Rezeptoraktivierung stellt die Phosphorylierung der zytoplasmatischen Smad1/5/8-Proteine zu pSmad1/5/8 als Teil der intrinsischen Signalkaskade und Grundlage der anschließenden Genregulation dar. Dementsprechend wurde anschließend das Expressionsniveau phosphorylierter Smad1/5/8-Proteine quantifiziert, deren Expression nach FK506-Inkubation signifikant hochreguliert wurde. Eine Dosisabhängigkeit ließ sich hingegen weder im Falle von Bmpr1a noch für die regulatorischen pSmad-Proteine bestätigen.

A

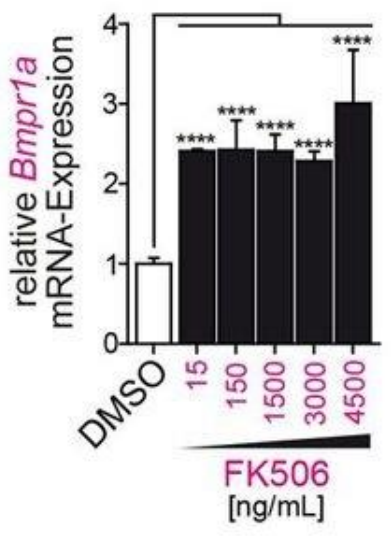

C

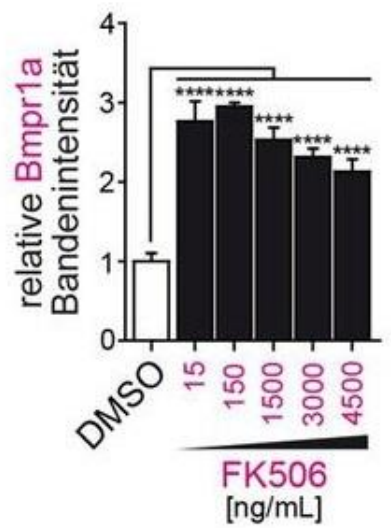

B

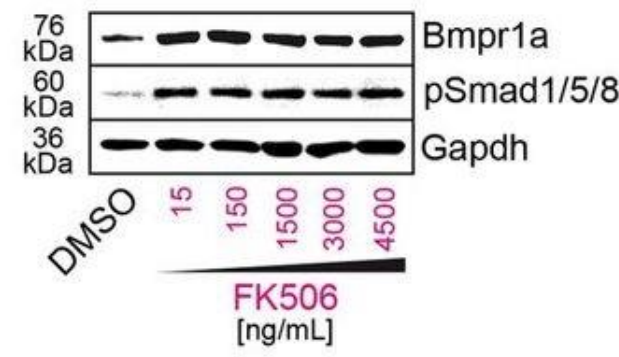

D

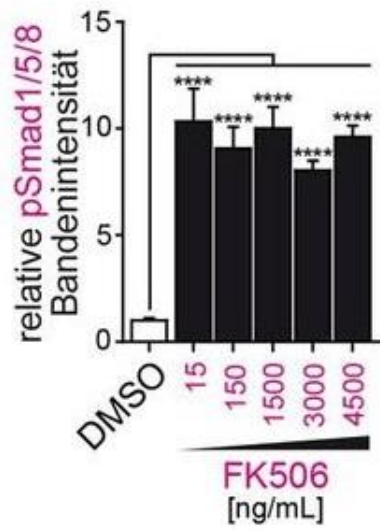


Abbildung 21: Induktion des Bmpr1a und der pSmad1/5/8-Proteine in FK506-supplementierten MCT-Zellen (A) Analyse der Bmpr1a-Expression mittels qRT-PCR in murinen Tubulusepithelzellen (MCT) nach dreistündiger DMSO- bzw. FK506-Stimulation (Messung der Proben als Triplikate, Mittelwert, Standardabweichung, $* * * p<0,001, * * * * p<0,0001$; Kalkulation der $\mathrm{p}$-Werte mittels einfaktorieller ANOVA mit Bonferroni-Post-HocAnalyse in Relation zu DMSO-behandelten Zellen). (B) Western Blot zeigt die Expression des Bmpr1a bzw. der phosphorylierten Proteine pSmad1/5/8 nach sechsstündiger DMSO- bzw. FK506-Inkubation in bezeichneten Dosen in MCT-Zellen. (C+D) Densitometrische Auswertung der relativen Bmpr1a-Expression. (C) bzw. der Proteine pSmad1/5/8 (D). Für statistische Analysen erfolgte eine optometrische Dichtemessung an drei prominenten Einzelbanden sowie die Normalisierung der für die Zielproteine Bmpr1a bzw. pSmad1/5/8 quantifizierten Werte gegen das detektierte Signal des Haushaltsgens Gapdh (Messung in Triplikaten, Mittelwert, Standardabweichung, **** $p<0,0001$; Kalkulation der $\mathrm{p}$-Werte mittels einfaktorieller ANOVA mit Bonferroni-Post-Hoc-Analyse in Relation zu DMSO-behandelten Zellen).

\subsection{Validierung der ermittelten Transkriptionsfaktoren in vitro}

Zunächst wurde das Expressionsmuster der durch den $\mathrm{RT}^{2}$ Profiler ${ }^{\mathrm{TM}}$ PCR-Array identifizierten Kandidatengene nach dreistündiger FK506-Inkubation in murinen proximalen Tubulusepithelzellen (MCT) mittels qRTPCR analysiert. Lediglich Ar (androgen receptor) wurde infolge der Stimulation mit FK506 nicht explizit induziert. Bei den übrigen potentiellen Transkriptionsfaktoren (Cebpb, Creb1, Gata3, Max, Arnt) manifestierte sich hingegen eine signifikante Hochregulation unter FK506-Exposition, die insbesondere für die Gene Max und Arnt einen dosisabhängigen Effekt implizierte. 
A

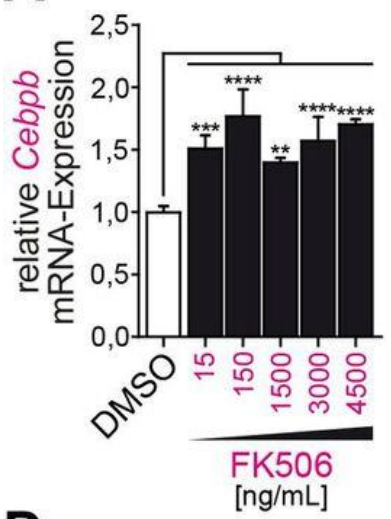

D

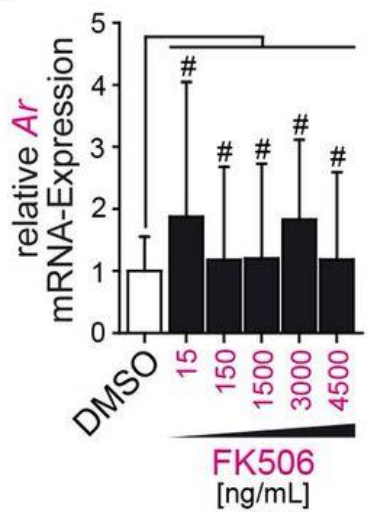

B

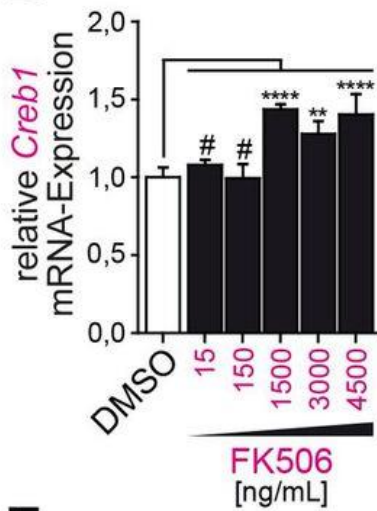

E

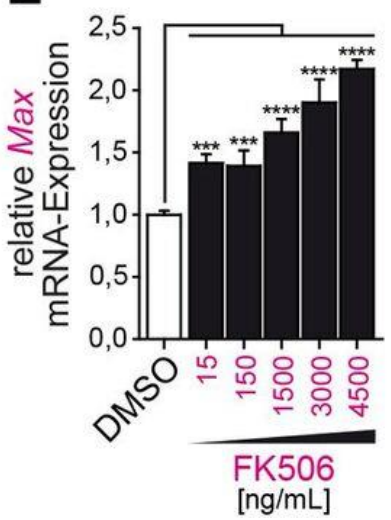

C

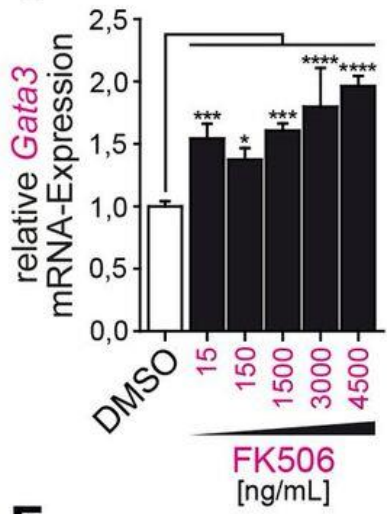

$\mathbf{F}$

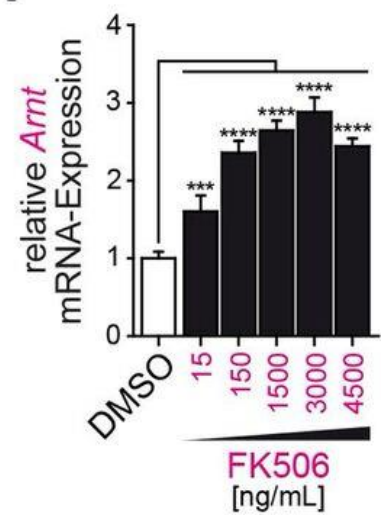

Abbildung 22: FK506-modulierte Induktion der putativen Transkriptionsfaktoren in vitro

(A-F) Mittels qRT-PCR analysierte mRNA-Expression der putativen Transkriptionsfaktoren Cebpb (A), Creb1 (B), Gata3 (C), $\operatorname{Ar}(\mathrm{D}), \operatorname{Max}(\mathrm{E})$ und Arnt (F) in murinen Tubulusepithelzellen (MCT) nach dreistündiger DMSO- bzw. FK506-Inkubation (Messung der Proben als Triplikate, Mittelwert, Standardabweichung, * $p<0,05, * * p<0,01$, $* * * p<0,001 * * * * p<0,0001$, \# nicht signifikant; Kalkulation der $p$-Werte mittels einfaktorieller ANOVA mit Bonferroni-Post-Hoc-Analyse in Relation zu DMSO-behandelten Zellen).

\subsection{Spezifisches Gene Silencing der putativen Transkriptionsfaktoren in vitro}

\subsubsection{Effizienz des Gene Silencings in MCT-Zellen}

Der Mechanismus der RNA-Interferenz (RNAi) erlaubt über die Inkorporation kurzer doppelsträngiger siRNA in die eukaryotische Zelle die zielgerichtete posttranskriptionelle Stummschaltung (engl. gene silencing) sequenzkomplementärer mRNA und somit die Funktion, ihrer kodierenden Proteine im Organismus zu definieren. Unter Ausnutzung dieses Prinzips sollte im Folgenden die selektive Inhibition der sechs Kandidatengene (Cebpb, Creb1, Gata3, Ar, Max, Arnt) in MCT-Zellen forciert und anschließend die FK506-abhängige Bmpr1a-Expression zur Etablierung eines oder mehrerer involvierter Transkriptionsfaktoren eruiert werden.

Hierzu erfolgte nach Einschleusung der interferierenden RNA-Sequenzen in die murinen Tubulusepithelzellen sowie der dreistündigen DMSO- bzw. FK506 (150, 1500 ng/ml)-Stimulation zunächst die Effizienzprüfung des spezifischen Gene Silencings mittels qRT-PCR. Als Kontrolle dienten in allen folgenden RNAi-Experimenten MCT-Zellen, die mit scrambled siRNA (scrRNA) transfiziert und in DMSO inkubiert worden waren. 
A

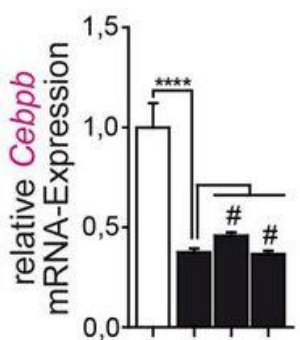

Cebpb siRNA

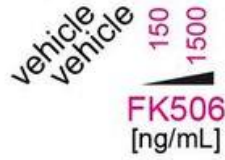

D

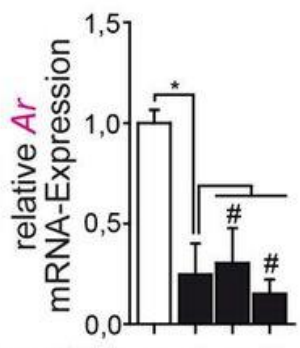

Ar SiRNA - + + +

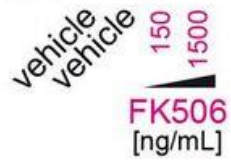

B

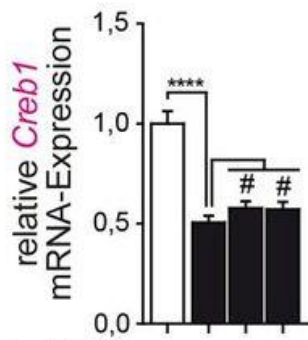

Creb1 siRNA

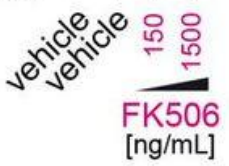

E

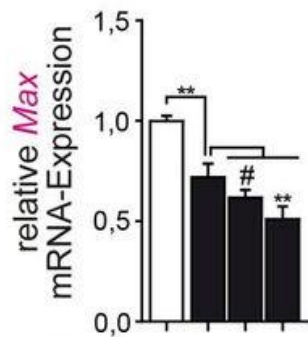

Max SiRNA -+++

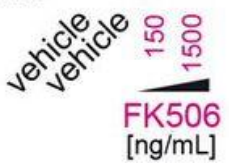

C

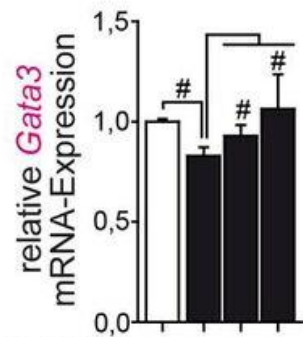

Gata3 siRNA - + + +

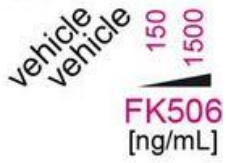

$\mathbf{F}$

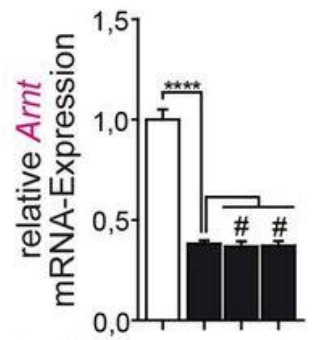

Arnt SiRNA - + + +

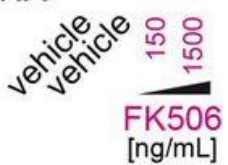

\section{Abbildung 23: Effizienz des Gene Silencings in vitro}

(A-F) Effizienzanalyse mittels qRT-PCR in murinen Tubulusepithelzellen (MCT) nach Transfektion mit unfunktionaler scrRNA und siRNA zur Inaktivierung der Gene Cebpb (A), Creb1 (B), Gata3 (C), Ar (D), Max (E) und Arnt (F). Der Graph zeigt die mRNA-Expression nach DMSO- bzw. FK506-Inkubation über drei Stunden (Messung der Proben als Triplikate, Mittelwert, Standardabweichung, $* p<0,05, * * p<0,01, * * * * p<0,0001$, \# nicht signifikant; Kalkulation der $p$-Werte mittels einfaktorieller ANOVA mit Bonferroni-Post-Hoc-Analyse in Relation zu DMSO-behandelten Zellen).

\subsubsection{Expression des Bmpr1a unter FK506-Exposition nach Gene Silencing in MCT-Zellen}

Nach Validierung des RNAi-vermittelten Gene Silencings sollte im Folgenden die Expression von Bmpr1a in siRNA-transfizierten und FK506-stimulierten MCT-Zellen durch das Western Blot-Verfahren quantifiziert werden.

Nach sechsstündiger FK506-Inkubation (1500 ng/ml) zeigten die tubuloepithelialen Zellen trotz transienter RNAi-basierender Stummschaltung je eines der zuvor identifizierten Kandidatengene eine signifikante Induktion der relativen Rezeptorexpression, die vergleichbar mit dem quantifizierbaren Niveau von parallel scrRNA-transfizierter und FK506-supplementierter Zellen war. 
Demgegenüber führte das selektive siRNA-vermittelte Arnt-Silencing zu einer geringfügig signifikanten Suppression der Bmpr1a-Expression und kann als Indiz seiner rezeptorregulatorischen Funktionalität aufgefasst werden.

A

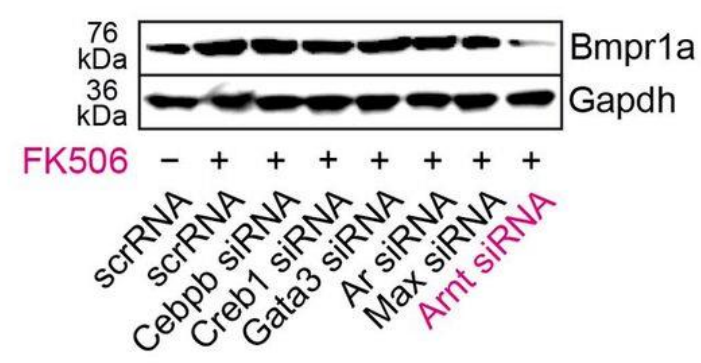

B

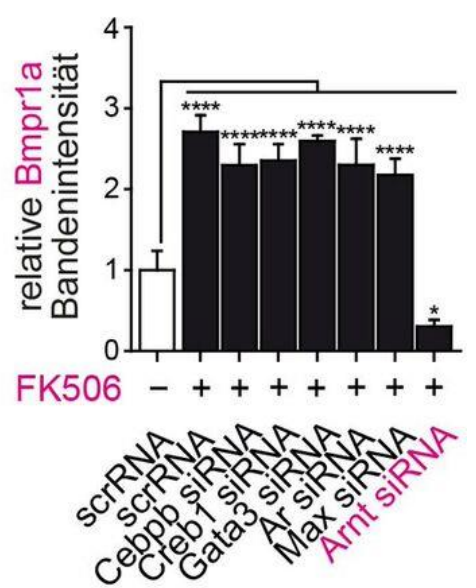

Abbildung 24: siRNA-vermitteltes Arnt-Silencing evoziert in vitro die Suppression der Bmpr1a-Expression nach initialer FK506-Stimulation

(A) Western Blot präsentiert die Expression von Bmpr1a im transienten siRNA-basierenden Knockdown-System nach sechsstündiger DMSO- bzw. FK506-Inkubation in MCT-Zellen. (B) Densitometrische Auswertung der relativen Bmpr1a-Expression. Für statistische Analysen erfolgte eine optometrische Dichtemessung an drei prominenten Einzelbanden sowie die Normalisierung des für das Zielprotein Bmpr1a quantifizierten Wertes gegen das detektierte Signal des Haushaltsgens Gapdh (Messung der Proben als Triplikate, Mittelwert, Standardabweichung, * $\mathrm{p}<0,05, * * * * \mathrm{p}<0,0001$; Kalkulation der $\mathrm{p}$-Werte mittels einfaktorieller ANOVA mit Bonferroni-PostHoc-Analyse in Relation zu DMSO-behandelten Zellen).

\subsection{Validierung des Transkriptionsfaktors Arnt in vitro und in vivo}

\subsubsection{Vermehrte Expression von Arnt nach FK506-Stimulation in MCT-Zellen}

Um die funktionale Relevanz des Transkriptionsfaktors Arnt als mutmaßlichen Initiator der indirekten FK506-abhängigen BMPR1A-Induktion etablieren zu können, wurde seine Proteinexpression zunächst in vitro im murinen Tubulusepithel (MCT) sowie anschließend in vivo im UUO-Mausmodell der experimentellen Nierenfibrose verifiziert und mittels Densitometrie quantifiziert. In diesem Zusammenhang ließ sich nach sechsstündiger FK506-Stimulation in MCT-Zellen eine effiziente konzentrationsabhängige Arnt-Induktion gegenüber dem mit DMSO behandelten Tubulusepithel dokumentieren. 
A

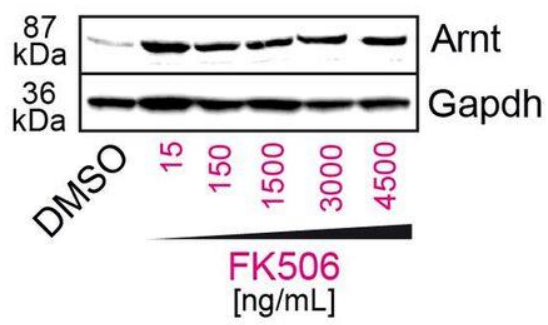

B

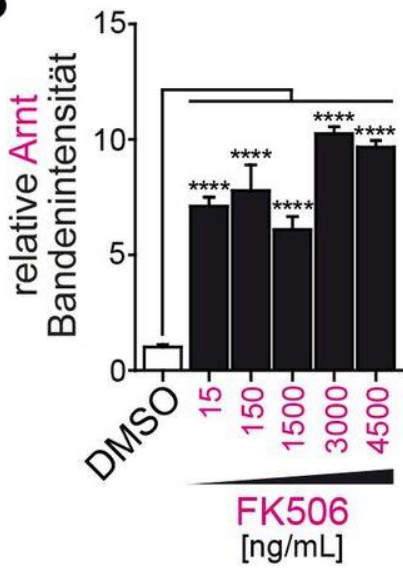

Abbildung 25: Vermehrte Arnt-Expression unter FK506-Exposition in vitro und in vivo im UUO-Modell

(A) Western Blot zeigt die Expression von Arnt nach sechsstündiger DMSO- und FK506-Inkubation in MCT-Zellen. (B) Densitometrische Auswertung der relativen Arnt-Expression. Für statistische Analysen erfolgte eine optometrische Dichtemessung an drei prominenten Einzelbanden sowie die Normalisierung des für das Zielprotein Arnt quantifizierten Wertes gegen das detektierte Signal des Haushaltsgens Gapdh (Messung der Proben als Triplikate, Mittelwert, Standardabweichung, $* * * * p<0,0001$; Kalkulation der $\mathrm{p}$-Werte mittels einfaktorieller ANOVA mit Bonferroni-Post-Hoc-Analyse in Relation zu DMSO-behandelten Zellen).

\subsubsection{Vermehrte Expression von Arnt nach FK506-Applikation in UUO-Nieren}

Die nach zehntägiger chronischer Harnstauung durchgeführten densitometrischen sowie morphometrischen Expressionsanalysen im fibrotischen Nierenparenchym verdeutlichten in sämtlichen Kollektiven die signifikante Hochregulation des Transkriptionsfaktors Arnt in Relation zur normierten kontralateralen sham-Niere. In Abhängigkeit vom gewählten Analyseverfahren zeigte sich in UUO-Nieren der FK506-supplementierten Mäuse nach der Applikation niedrigster Dosen (0,02 mg/kg KG/Tag) eine geringfügige bis deutliche Hochregulation des zu untersuchenden Proteins, wobei sich dieser stimulierende Effekt durch kontinuierliche Dosissteigerung des Pharmakons potenzierte und in höchster Konzentration $(0,2 \mathrm{mg} / \mathrm{kg}$ KG/Tag) seine größte Wirksamkeit erzielte. 

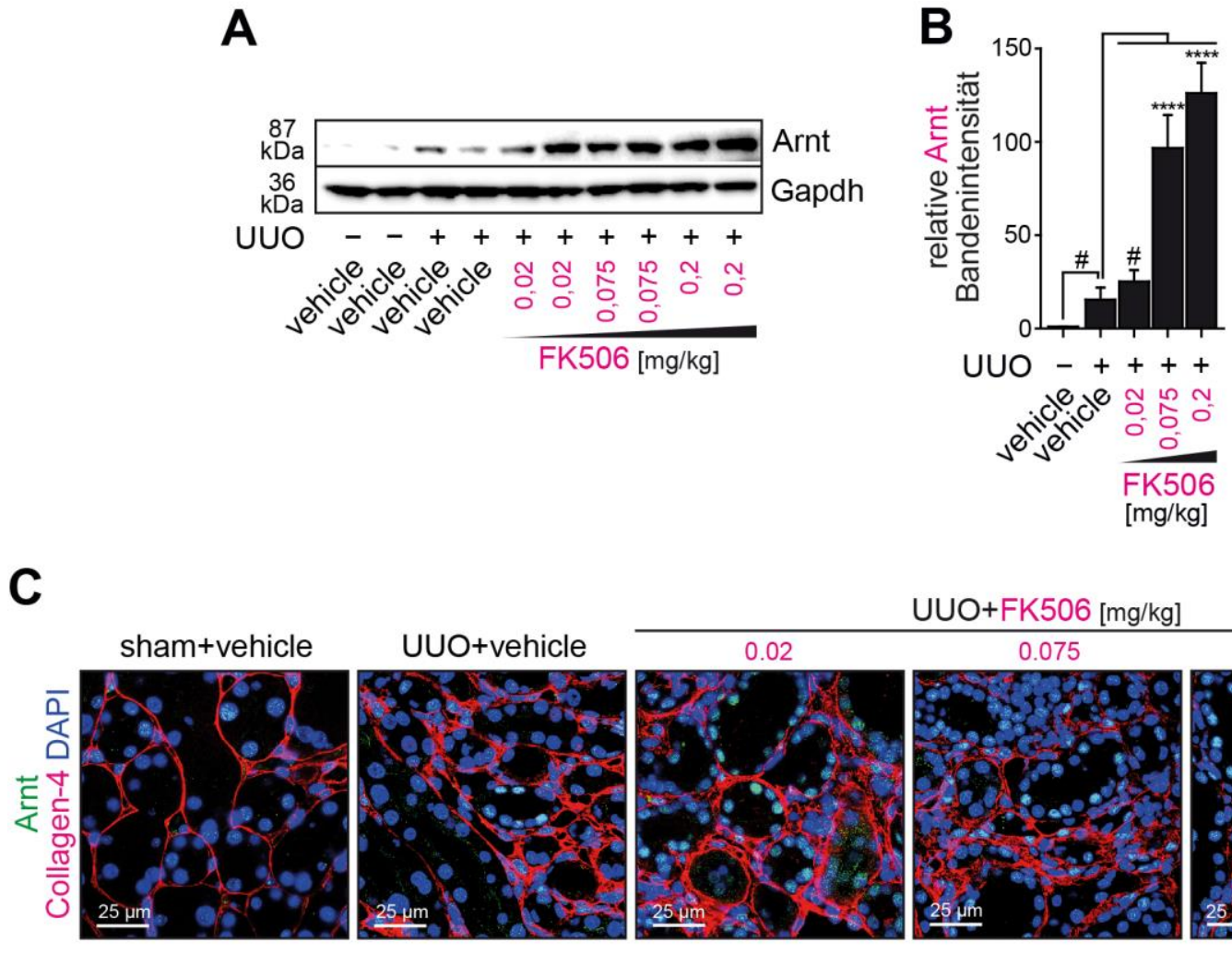

UUO+FK506 [mg/kg]
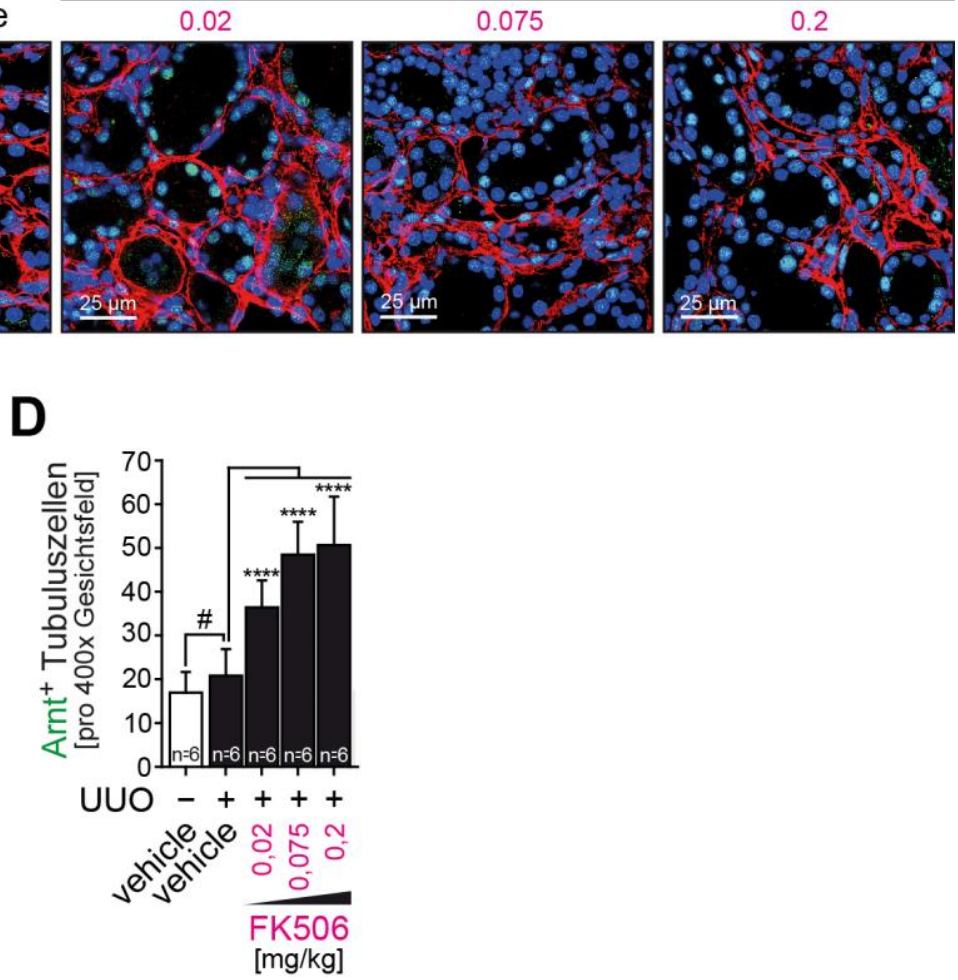

\section{Abbildung 26: Vermehrte Arnt-Expression unter FK506-Exposition in vivo im UUO-Modell}

(A) Western Blot präsentiert die Induktion von Arnt nach vehicle- bzw. FK506-Applikation in sham-Nieren und in fibrotischen UUO-Nieren vehicle- bzw. FK506-behandelter Mäuse. (B) Densitometrische Analyse des Western Blots auf Arnt. Für statistische Analysen wurde der für das Zielgen quantifizierte Wert gegen das detektierte Signal des Haushaltsgens Gapdh normalisiert und aus den beiden pro Gruppe generierten Werten ein Mittelwert berechnet (Messung der Proben als Triplikate, $n=2$ in jeder Gruppe, Mittelwert, Standardabweichung, $* * * *$ p $<0,0001$, \# nicht signifikant; Kalkulation der $\mathrm{p}$-Werte mittels einfaktorieller ANOVA mit Bonferroni-PostHoc-Analyse in Relation zur sham-Niere vehicle-behandelter Mäuse). (C) Repräsentative Mikrophotographie von Gewebeschnitten nach Immunfluoreszenzmarkierung gegen Arnt (Messbalken $25 \mu \mathrm{m}$ ). Die Bildausschnitte zeigen sham-operierte Nieren von vehicle-behandelten Mäusen und fibrotische UUO-Nieren von vehicle- und FK506-behandelten Mäusen zehn Tage nach unilateraler Ureterobstruktion. (D) Morphometrische Quantifizierung der Arnt-Expression in fluoreszenzmarkierten Nierengewebeschnitten (Bildanalytische Messung erfolgte in 
je zehn Gesichtsfeldern pro Niere bei 400x Vergrößerung, $n=6$ in jeder Gruppe, Mittelwert, Standardabweichung, **** $p<0,0001$, \# nicht signifikant; Kalkulation der $\mathrm{p}$-Werte mittels einfaktorieller ANOVA mit BonferroniPost-Hoc-Analyse in Relation zur sham-Niere vehicle-behandelter Mäuse).

\subsection{Validierung der FK506-vermittelten ARNT-, BMRR1A- und pSMAD1/5/8-Induktion in huma- nen Transplantatnieren}

Ferner wurden in Transplantatnieren von Patienten unterschiedlicher immunsuppressiver Therapieregime (MMF+Cortison, CSA, Cortison, FK506) die Expression von ARNT und BMPR1A sowie die nachfolgend induzierte Phosphorylierung der SMAD-Proteine SMAD1/5/8 als Charakteristikum einer funktionalen Rezeptoraktivität morphometrisch validiert. Um eine gemeinsame Vergleichsbasis des inhomogenen humanen Untersuchungsguts zu erzielen, erfolgte in entsprechenden MTS-gefärbten Gewebeschnitten zunächst die quantitative Flächenanteilbestimmung der interstitiellen Fibrose. Anschließend wurden komparative Analysen in immunhistochemisch gegen ARNT, BMPR1A und PSMAD markierten Nierenpräparaten mit äquivalenten Fibrosierungsgraden (15 bis $20 \%$ ) forciert. Im Vergleich zu den übrigen immunsuppressiven Therapiestrategien ließen sich im Tubulusepithel der unter systemischer FK506-Exposition stehender Patienten deutlich komplexere $\mathrm{ARNT}^{+}$- und BMPR1A $\mathrm{A}^{+}$-gefärbte Areale lokalisieren, die in Assoziation mit einer nachträglichen Aktivierung der pSMAD1/5/8-Signaltransduktionskaskade standen. 
A

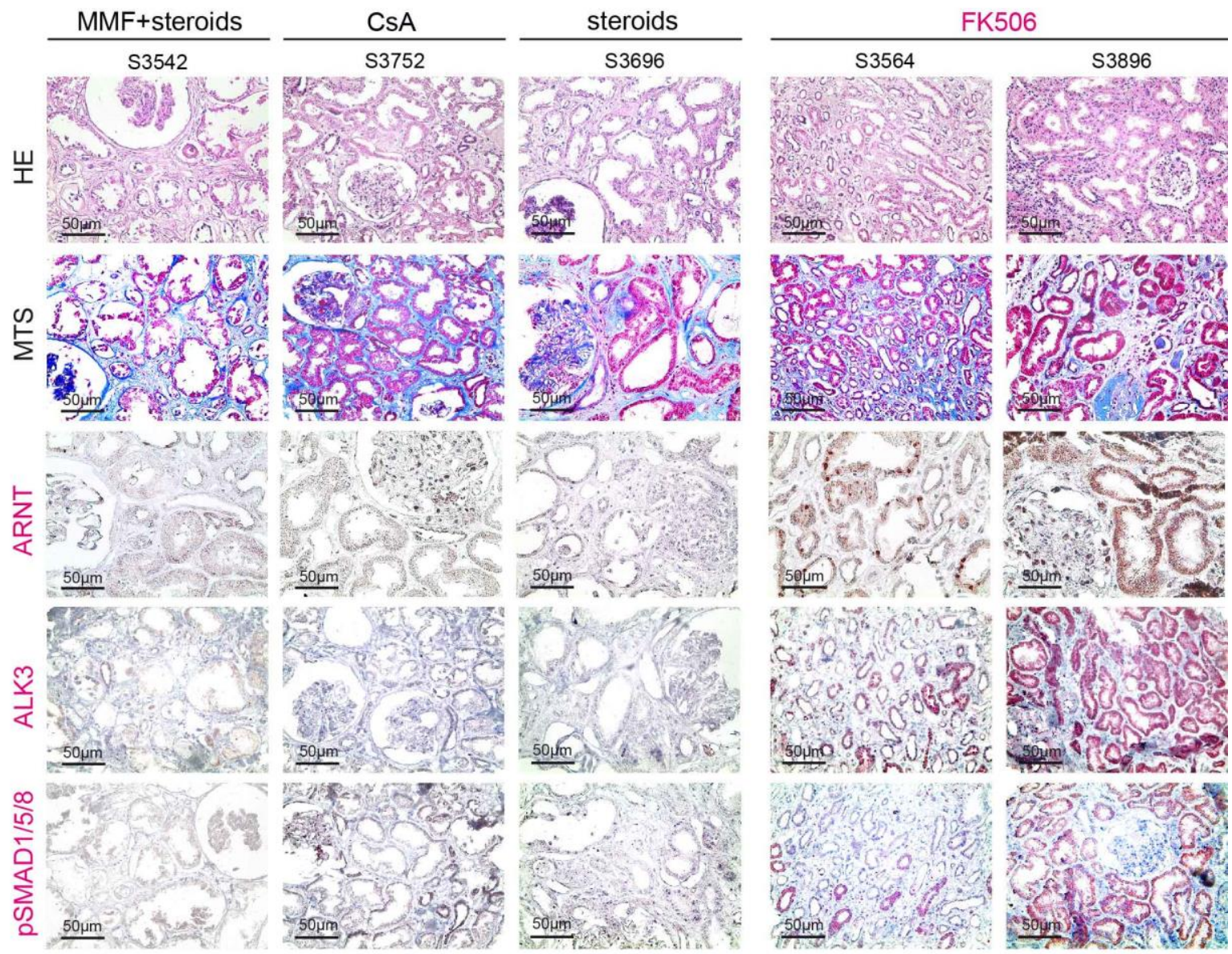

Abbildung 27: ARNT- und BMPR1A-Induktion mit konsekutiver pSMAD1/5/8-Aktivierung in humanen Transplantatnieren unter FK506-Therapie

(A) Repräsentative Mikrophotographie von HE- und MTS-gefärbten Nierenpräparaten sowie von immunhistochemisch mit Anti-BMPR1A, Anti-ARNT und Anti-pSMAD1/5/8 markierten Gewebeschnitten (Messbalken 50 $\mu \mathrm{m})$. Die Bildausschnitte zeigen eine kleine Kohorte nierentransplantierter Patienten unter verschiedenen immunsuppressiven Therapieregimen (MMF+Cortison, CsA, Cortison, FK506). 


\section{DISKUSSION}

In der Vergangenheit dokumentierten zahlreiche tierexperimentelle Studien die zentrale Bedeutung des Morphogens BMP7 innerhalb der renalen Fibrogenese, während der es die Protektion und Regeneration des beschädigten Nierenparenchyms vermittelt und somit die Progredienz der jeweiligen Erkrankung unterbindet (Zeisberg M und Kalluri 2004 a). Allerdings unterliegt der endogene Wachstumsfaktor im Zuge fortschreitender funktioneller und struktureller Veränderungen einer effektiven Negativregulation (Bramlage et al. 2010, Bramlage et al. 2011, Furic-Cunko et al. 2015, Hruska et al. 2000, Ivanac-Janković et al. 2015, Jia et al. 2015, Lin J et al. 2005, Morrissey et al. 2002, Neuwirt et al. 2014, Sugimoto et al. 2007, Sugimoto et al. 2012, Tampe B et al. 2014, Tampe D und Zeisberg M 2014, Wang S und Hirschberg 2003, Wang S et al. 2003, Wang S et al. 2006, Wang SN et al. 2001, Zeisberg M et al. 2003 a, Zeisberg M et al. 2003 b, Zeisberg M et al. 2005), wohingegen sein wesentlicher Signaltransduktor BMPR1A nachhaltig induziert wird. Gleichzeitig korreliert dessen Defizienz im Tubulusepithel mit der Progression fibrotischer Prozesse (Sugimoto et al. 2012). In diesem Kontext liefert die webbasierte Datenbank Nephroseq fundierte Anhaltspunkte einer Tacrolimus-modulierten BMPR1A-Induktion (nephroseq.org, Flechner et al. 2004). Inwiefern der Einfluss des Makrolid-Lactons sich auf die BMPR1A-Expression im proximalen Tubulusepithel bzw. innerhalb der renalen Fibrogenese reproduziert und nachfolgend renoprotektive Wirksamkeit zeigt, war, ebenso wie zugrundeliegende molekulare Mechanismen, bislang völlig unbekannt.

\subsection{Quantitative Effektivitätsanalysen unter FK506-Exposition im Nierenparenchym}

\subsubsection{Spezifische Induktion des BMP7-Rezeptors BMPR1A nach FK506-Supplementation}

Die angestrebten Untersuchungen im humanen proximalen Tubulusepithel (HK-2) implizierten Effektivitätsvergleiche unterschiedlicher immunsuppressiver Therapeutika und ergaben die selektiv vermehrte Expression von BMPR1A ausschließlich unter geringdosierter FK506-Exposition. Demgegenüber zeigten äquivalente Mengen des Antimetaboliten MMF bzw. des Calcineurininhibitors CsA allenfalls geringe Wirksamkeit. Diese Ergebnisse decken sich mit In-vitro-Studien der Arbeitsgruppe Spiekerkoetter et al., die mittels Hochdurchsatz-Screening in stabil mit BMP-responsiven ID1-Promotorelementen transfizierten C2C12-Zellen die deutliche Überlegenheit des Tacrolimus gegenüber zahlreichen FDA (Food and Drug Administration)-geprüften Pharmazeutika bestätigten (Spiekerkoetter et al. 2013). Gleichzeitig konnte in den tubuloepithelialen HK-2-Zellen ein Einfluss der verschiedenen immunsuppressiven Therapeutika auf weitere BMP7-spezifische Rezeptoren, den BMPR1B und den BMPR2, ausgeschlossen werden.

Um die Effektivität des Tacrolimus im Kontext der progredienten tubulointerstitiellen Fibrose näher zu beleuchten, wurden In-vivo-Untersuchungen im nicht-proteinurischen Schädigungsmodell der unilateralen Ureterobstruktion (UUO) angestrebt. Die zunächst in ligierten Nieren entsprechend präparierter C57BL/6JMäuse durchgeführten Expressionsanalysen bekräftigten die bereits von Sugimoto et al. verifizierte Bmpr1a-Induktion, wie auch die signifikante Repression des Bmpr1b und des Bmpr2 (Sugimoto et al. 2012). Darüber hinaus gelang es, einen zusätzlich stimulierenden Effekt des immunsuppressiven Pharmakons Ta- 
crolimus auf die Bmpr1a-Expression im fibrotisch destruierten Nierenparenchym unter Anwendung verschiedener molekularbiologisch etablierter Verfahren wie der Western Blot-Methodik und der qRT-PCR sowie mittels immunhistologischer Gewebecharakterisierung nachzuweisen. In Korrelation zu den aus humanen proximalen Tubulusepithelzellen generierten mRNA-Analysen ließ sich eine globale Wirkung des Makrolid-Lactons auf weitere substantielle Bindungspartner (Bmpr1b und Bmpr2) des Bmp7 nicht eruieren, sodass insgesamt die zunächst hypothetisch angenommene Spezifität der FK506-modulierten BMPR1A-Positivregulation untermauert werden konnte. Die Möglichkeit, den BMPR1A selektiv ohne eine simultane Rekrutierung weiterer BMP7-Rezeptoren zu induzieren, ist insofern von großer Relevanz, als dass das Morphogen während der embryonalen Chondro- und Osteogenese wie auch der postnatalen Knochenbildung seine regulative Funktionalität über die Bindung des BMPR1B realisiert (Chen D et al. 1998, Haaijman et al. 2000, Yi et al. 2000, Zhao et al. 2002). Der Ausschluss zusätzlicher BMP7-spezifischer BMPR1B-Interaktionen gewährleistet bei Applikation von rekombinantem humanem BMP7 (rhBMP7) eine bessere Kontrollierbarkeit hinsichtlich der diskutierten ektopen Knochenformation. Neben der Niere bestehen auch im Herzen, im Gehirn, in den Lungen, der Leber und im Skelettmuskel des adulten murinen Organismus nachweislich ausgeprägte Bmpr1a-Expressionsmuster (Dewulf et al. 1995, Mishina et al. 1995). Bedeutsam wäre daher, die Bmpr1a-Expression in genannten Organen im CKD-Tiermodell nach FK506-Supplementation zu determinieren, um die Option eines systemischen FK506/Bmpr1a-Zusammenspiels faktisch auszuschließen. Im Rahmen dieser Arbeit ergaben allerdings weder histomorphologische noch mRNA-Rezeptoranalysen scheinoperierter Nieren Anhaltspunkte eines FK506-induktiven Einflusses und sprechen für einen ausschließlich fibroseassoziierten Effekt.

Ein weiterhin drängender Aspekt fokussiert die Frage, inwiefern die dokumentierte Rezeptorinduktion mit einem Funktionserhalt interferiert, da die rein quantitative Erhöhung eines passiven BMPR1A kein probates Instrument darstellt, das nephroprotektive und regenerative Potential des BMP7 zu transduzieren. Entscheidend für die effektive Modulation BMP7-vermittelter Signale ist die Formierung eines heterotetrameren Rezeptorkomplexes nach erfolgter extrazellulärer Ligandenbindung. Der konformationsveränderte Typ II-Rezeptor aktiviert daraufhin den Typ I-Rezeptor, der wiederum zytoplasmatische regulatorische SMADProteine zu pSMAD1/5/8 phosphoryliert und somit eine intrinsische Signaltransduktionskaskade initiiert (Shi und Massagué 2003, Tamaki et al. 1998). Folglich lässt sich nur indirekt über die Quantifizierung phosphorylierter R-SMAD-Proteine auf die Aktivität des Typ I-Rezeptors rückschließen. Die hierzu angestrebten Analysen auf Protein- und lichtmikroskopischer Ebene ergaben eine im Kontext der Bmpr1a-Induktion stehende Phosphorylierung rezeptorregulierter Smad1/5/8-Proteine in ureterligierten Nieren FK506-behandelter Mäuse sowie in vitro im FK506-stimulierten proximalen Tubulusepithel (MCT). Übereinstimmende Resultate dokumentierten auch Spiekerkoetter und Kollegen in humanen pulmonalen Endothelzellen, wobei bestehende Differenzen hinsichtlich der Inkubationszeit und der supplementierten Dosis Tacrolimus vermutlich durch zellspezifische Charakteristika, das jeweilige Untersuchungsmodell sowie methodische Divergenzen bedingt sind (Spiekerkoetter et al. 2013). Insgesamt lässt die Konservierung der Rezeptorfunktionalität auf die Interaktion mit dem common-mediator SMAD4 und - im Zuge der nukleären Translokation - auf die Transkription BMP7-spezifischer Gene schließen (Derynck et al. 1998, Tamaki et al. 1998). 
Letztlich geht die BMP7-modulierte Aktivierung intrinsischer Transduktionskomponenten mit der Antagonisierung TGF- $\beta 1$-assoziierter Effektoren einher. Im Wesentlichen beruhen diese indirekten komplexen Interventionsmechanismen auf der über die pSMAD1/5/8-Signalkaskade regulierte konsekutive Induktion der ID-Proteine, welche vice versa durch SMAD-Mediatoren des TGF- $\beta$ gehemmt werden (Kang Y et al. 2003, Korchynskyi und ten Dijke 2002, López-Rovira et al. 2002, Tampe D und Zeisberg M 2014). Als Ausdruck der wechselseitigen Beziehung manifestiert sich infolge der BMP7-initiierten ID-Aktivierung beispielhaft die transkriptionelle Repression der TGF- $\beta 1$-gesteuerten profibrotischen Gene CTFG, ACTA2 ( $\alpha$ SMA), COLLAGEN-1A1, PAl-1 oder FSP1 (Izumi et al. 2006, Kinoshita et al. 2007, Weiskirchen und Meurer 2013, Zeisberg $M$ et al. 2003 b). Weiterhin unterbindet das BMP7 das orchestrierte TGF- $\beta 1$-abhängige Phänomen der EMT und entsprechend den ID-spezifischen Verlust des epithelialen Markerproteins E-Cadherin. Als Ausdruck der interagierenden Funktionskaskaden manifestiert sich entsprechend die nukleäre Kolokalisation von TGF-B1- und BMP7-modulierten pSMAD-Proteinen (Kondo et al. 2004, Yang J und Liu 2001, Zeisberg M et al. 2003 b). Ferner bedingt die BM7-induzierte SMAD1-Phosphorylierung die Inhibition des nicht-kanonischen TGF- $\beta 1$-regulierten p38-MAPK (mitogen-activated protein kinase)-Signalweges sowie die damit korrelierende Reduktion der Fibronectin-Sekretion (siehe Abbildung 2, Seite 11) (Motazed et al. 2008).

Zusammenfassend lässt sich infolge der Tacrolimus-vermittelten BMPR1A-Induktion zwar eine Sensibilisierung des Tubulusepithels für die antifibrotische Wirkung des Morphogens BMP7 konstatieren, diskutabel bleibt jedoch zunächst, inwiefern die nachweisliche Signalintensivierung mit der skizzierten Antagonisierung des TGF- $\beta 1$, Hauptmediator der EMT, einhergeht und damit letztlich der renalen Fibrogenese Aufschub leistet.

\subsubsection{Milderung der experimentellen renalen Fibrogenese in vivo mittels FK506-assoziierter Bmpr1a-Induktion}

Gemeinhin kennzeichnet die tubulointerstitielle Fibrose mit einhergehender Tubulusatrophie sowie glomerulärer Sklerosierung eine homogene Endstrecke pathogenetisch divergenter progressiver Nierenerkrankungen (Boor et al. 2010, Bröcker et al. 2010). Die Reproduktion derartiger struktureller Veränderungen durch einseitige Ureterligatur in geeigneten Versuchstieren erlaubt die während der renalen Fibrogenese auftretenden Phasen des arbiträren Vernarbungsprozesses experimentell nachzuvollziehen (Chevalier et al. 2009, Eddy et al. 2012). Der Verzicht auf exogene tubulotoxische Noxen, die Kontrollierbarkeit der Methode unter Funktionserhalt der kontralateralen Niere, die somit als adäquates Kontrollorgan fungiert, sowie der komparable Ausprägungsgrad morphologischer Merkmale in den stenosierten Nieren sind als wesentliche Vorteile der obstruktiven Nephropathie zu nennen (Chevalier et al. 2009).

Insgesamt manifestierte sich in obstruierten Nieren des FK506-behandelten Mauskollektivs eine deutliche Remission des progredienten Nierenschadens, der sich in der PAS-Färbung durch die Reduktion dilatierter Tubuli und die gemilderte Synthese hyaliner Zylinder (cast) äußert. Unter Anwendung eines vergleichbaren semiquantitativen Graduierungsschemas lieferten Wang $L$ et al. in konditionellen transgenen Mäusen nach Induktion einer Puromycin-Aminonukleosid-Nephrose (PAN) sowie infolge der FK506-Applikation diesbezüglich übereinstimmende Resultate (Wang L et al. 2015). Eine Linderung des tubulointerstitiellen Inflammations- und Fibrosierungsprozesses konnten sie entgegen den Ergebnissen der vorliegenden Arbeit nicht 
eruieren. Hierzu erfolgte morphometrische Bildanalysen Masson-Trichrom-gefärbten Nierenschnittpräparate verdeutlichten allerdings anschaulich die unter der chronischen Harnstauung symptomatische Zunahme der tubulointerstitiellen Fibrose sowie deren deutlich signifikante Suppression unter dosisabhängiger Tacrolimussupplementation. Differenzen zu Erkenntnissen der Arbeitsgruppe Wang $L$ et al. finden insbesondere im divergenten Mausmodell, welches morphologisch eher einer fokal-segmentalen Glomerulosklerose entspricht, sowie in der Integration eines binären mittels Doxyzyklin induzierbaren Transgens ihre Begründung. Weitere methodische Diskrepanzen sind maßgeblich in der über 50 -fach (10 mg/kg KG) höheren Dosierung des subkutan injizierten Makrolid-Lactons zu sehen mit dem vorrangigen Ziel, renoprotektive Effekte über die direkte pharmakologische Inhibition des Calcineurins zu modulieren. Dementsprechend führten die Autoren die signifikante Abnahme tubulärer Strukturschäden auf die über die Calcineurinhemmung vermittelte Blockade der Mitochondrien-Fragmentierung zurück, aus der letztlich ein antiapoptotischer Effekt auf das proximale Tubulusepithel resultiert (Cho et al. 2010, Wang L et al. 2015). Dieser molekulare Mechanismus mag gewiss Teil komplexer CNI-assoziierter Induktionsprogramme sein und ist dementsprechend sowohl unter CsA- als auch FK506-Applikation zu eruieren. Allerdings gibt dieses weitgehend theoriebasierte Verständnis nur unzureichend Antwort auf in der Fortführung dieses Projektes generierte Daten, aus denen explizit die selektiv Tacrolimus-vermittelte Remission der renalen Fibrogenese hervorgeht, wohingegen eine CSA-Exposition eng mit der Exazerbation derartiger Prozesse korrelierte. Demzufolge lassen sich die unter FK506-Gabe verifizierten protektiven Effekte auf das Tubulusepithel nicht ausschließlich auf eine Calcineurinhemmung zurückführen, sondern finden vielmehr in divergenten konzeptionellen Modellen eine Erklärung.

Der progrediente Charakter der renalen Fibrogenese ist nicht ausschließlich in der Aktivierung und Proliferation residenter EZM-produzierender Bindegewebszellen zu sehen: Adäquate profibrotische Stimuli spezifischer Zytokine und Wachstumsfaktoren induzieren im tubuloepithelialen Zellverband den Verlust ihrer Integrität sowie die kontinuierliche Herunterregulation charakteristischer Adhäsionsmoleküle. Im Zuge dieses sukzessiven als epithelial-mesenchymale Transition (EMT) bezeichneten Dedifferenzierungsprozesses erlangen sie neben einem zunehmend spindelförmigen Phänotyp, die Fähigkeit zur De-novo-Expression mesenchymaler Marker wie aSMA, FSP1 und Collagen-1 (Kalluri und Weinberg 2009, Strutz und Neilson 2003). Der molekulare Mechanismus der EMT findet seinen Ursprung in der hohen Plastizität adulter Epithelzellen (Zeisberg M und Kalluri 2004 b), wobei mehrere Arbeitsgruppen übereinstimmend seinen signifikanten Beitrag zur Progression der renalen Destruktion in ureterligierten murinen Nieren nachwiesen (Grande et al. 2015, Iwano et al. 2002, Lovisa et al. 2015, Yang J et al. 2002).

In der vorliegenden Arbeit wurde über den immunfluoreszenzoptischen Nachweis der genannten spezifischen Markerproteine sowie die morphometrische Validierung ihrer Expressionsmuster auf aktivierte (Myo-)Fibroblasten-Populationen und die Rekrutierung transformierter adulter Tubulusepithelzellen rückgeschlossen. Dabei ließ sich die unter der obstruktiven Nephropathie dokumentierte Akkumulation der fokussierten Indikatoren im Zuge einer sukzessiv zunehmenden Tacrolimusexposition dosisabhängig supprimieren.

Nachweislich fungiert die exogene Applikation des rhBMP7 auch im UUO-Mausmodell als kritischer Faktor der renalen Homöostase, indem es durch sein antiapoptotisches und antiinflammatorisches Potential die 
phänotypische tubuloepitheliale Zellstruktur konserviert, die Transformation aktivierter interstitieller Fibroblasten inhibiert und somit die transkriptionelle Aktivierung profibrotischer Moleküle unterdrückt (Hruska et al. 2000). Demnach lieferte der signifikante Rückgang dieser vornehmlich vom EMT-Schlüsselzytokin TGF- $\beta 1$ modulierten Effektoren einen weiteren zentralen Anhaltspunkt für eine über die Tacrolimusassoziierte BMPR1A-Induktion realisierbare Intensivierung von BMP7-spezifischen Signalen. Neben der durch Antagonisierung zentraler Gegenspieler vermittelten Inhibition bzw. Umkehrung des EMT-Prozesses (vgl. Kapitel 4.1) lassen sich weitere BMP7-assoziierte antifibrotische Effekte auch in mesenchymalen Zellen beobachten. So sind die reprimierte $\alpha$ SMA- und Collagen-1-Expression auch hinweisend für ein verringertes Aktivitätsniveau residenter Fibroblasten sowie eine möglicherweise verstärkte Degradation pathologisch angehäufter Matrixkomponenten (Zeisberg M et al. 2003 a).

Demgegenüber ist ein Tubulusepithelschaden eng mit dem endogenen Verlust des Morphogens BMP7 verknüpft, wobei die systemische rhBMP7-Supplementation abgesehen von rein kompensatorischen Effekten, auch zur Normalisierung seines eigenen Expressionsniveaus beiträgt (Bramlage et al. 2010, Bramlage et al. 2011, Furic-Cunko et al. 2015, Hruska et al. 2000, Ivanac-Janković et al. 2015, Jia et al. 2015, Lin J et al. 2005, Morrissey et al. 2002, Neuwirt et al. 2014, Sugimoto et al. 2007, Sugimoto et al. 2012, Tampe B et al. 2014, Tampe D und Zeisberg M 2014, Wang S und Hirschberg 2003, Wang S et al. 2003, Wang S et al. 2006, Wang SN et al. 2001, Zeisberg M et al. 2003 a, Zeisberg M et al. 2003 b, Zeisberg M et al. 2005). Diese intrinsische Protektion durch BMP7 basiert vermutlich auf dem inhibierten Morphologieverlust des Tubulusepithels und könnte umgekehrt auch über die Tacrolimus-vermittelte BMPR1A-Expression wirksam werden. Inwiefern die supplementierten Niedrigdosen des Immunsuppressivums mit der Konservierung des Morphogens einhergehen, sollte im Rahmen zukünftiger Arbeiten Berücksichtigung finden. Ferner bedarf es der Klärung, in welchem Maße sich über eine simultane Applikation von FK506 und rhBMP7 synergistische Effekte erzielen lassen. Als Optimum wäre die Potenzierung BMP7-regulierter nephroprotektiver und regenerativer Wirkmechanismen anzunehmen.

Insgesamt wird die postulierte Schutzfunktion von BMPR1A über den Dualismus zweier experimenteller Herangehensweisen gestützt: Während in der vorliegenden Arbeit die In-vivo-Induktion des Rezeptors in Einklang mit der signifikanten Repression tubulärer Schäden, des Fibrosegrades sowie der reduzierten Expression profibrotischer Marker gebracht werden konnten, demonstrierten Sugimoto et al. infolge einer Bmpr1a-Deletion im proximalen Tubulusepithel die Aktivitätssteigerung der TGF- $\beta$-Signalkaskade und des EMT-Programms. Entsprechend unterstreicht der identifizierte Zusammenhang von Bmpr1a-Defizienz und Exazerbation der renalen Fibrogenese die Bedeutung des Rezeptors für den Erhalt der physiologischen Nierenarchitektur und -funktion (Sugimoto et al. 2012).

\subsubsection{Methodische Differenzen und Limitationen}

Da sich mittels unilateraler Ureterobstruktion die einzelnen Phasen des arbiträren Fibrosierungsprozesses im histomorphologischem Korrelat rekonstruierten lassen, erscheinen Methodenwahl und Tiermodell für Studien der chronisch progredienten Niereninsuffizienz prinzipiell geeignet. Limitationen implizieren die unter der permanenten Harnleiterokklusion mit verhältnismäßig abnormer Aggressivität voranschreitende renale Destruktion gegenüber regulär im chronisch nierenkranken Patienten auftretenden Pathomechanismen. Die frühzeitig persistierende renale Vasokonstriktion in Korrelation mit einer signifikant reprimierten 
Nierenperfusion sind bei der Verabreichung exogener Therapeutika und der Übertragbarkeit applizierter Dosen zu kalkulieren (Eddy et al. 2012, Klahr und Morrissey 2002). Kritisch lässt sich zudem der gewählte Beobachtungszeitpunkt der Studie diskutieren: Zwar erfolgte die morphometrische Quantifizierung der interstitiellen Fibrose in MTS-gefärbten Nierenschnittpräparaten sowohl drei, sieben und zehn Tage nach der Ureterobstruktion, histopathologische Bild- sowie detaillierte Expressionsanalysen wesentlicher Zielgene, zu späteren Zeitpunkten waren jedoch nicht Gegenstand der vorliegenden Arbeit. Anzumerken sei, dass signifikante Differenzen der unter Tacrolimusexposition eruierten Rezeptorinduktion möglicherweise zu früheren oder späteren Stichtagen nicht mehr reproduzierbar sein könnten (Eddy et al. 2012).

Limitationen sind überdies in der fehlenden Standardisierung histologischer Validierungsmethoden zu sehen, die trotz vorheriger Festlegung definierter Kriterien die Subjektivität des Betrachters, speziell bei Anwendung semiquantitativer Verfahren, nicht ausschließt. Insbesondere immunhistochemische Nachweisreaktionen erschweren aufgrund von Variabilitäten zugrundeliegender Färbeprotokolle und handelsüblicher Antikörper eine prinzipielle Normierung. Ferner können unspezifische Bindungen oder Kreuzreaktivitäten zu unerwünschten nieder- und mittelaffinen Interaktionen und Hintergrundsignalen führen und durch falsche Positivität Fehler in der Interpretation bedingen. Obgleich auch etablierte molekularbiologische Technologien wie die quantitative Real-Time PCR (qRT-PCR) und die Western Blot-Methodik generellen inhärenten Interferenzen unterliegen, ist eine zusätzliche Prüfung in Anbetracht höherer Spezifitäten und Sensitivitäten ratsam (Chang MM und Lovett 2011, Deepak et al. 2007). Infolge posttranskriptioneller und posttranslationaler Modifikationen sowie differenter Proteinhalbwertszeiten korrelieren die detektierten DNA-Amplifikate allerdings nicht zwangsläufig mit der Menge exprimierter Proteine und erklären die sich auch in der vorliegenden Studie manifestierenden Diskrepanzen zwischen den beiden Verfahren (Greenbaum et al. 2003, Pascal et al. 2008). Weiterhin repräsentiert die Densitometrie ein teils eingeschränkt reliables Messinstrument und limitiert aufgrund einer fehlenden allgemeingültigen Vereinheitlichung eine universelle Reproduzierbarkeit (Gassmann et al. 2009). Für das Aufzeigen genereller Tendenzen ist die quantitative Proteinanalytik allerdings durchaus praktikabel.

Die angeführten Aspekte müssen bei der Auswertung generierter Daten und der Planung zukünftiger Projekte entsprechende Berücksichtigung finden. Zudem ist die Inklusion eines zusätzlichen CKD-Mausmodells empfehlenswert.

\subsection{Charakterisierung molekularer Induktionsmechanismen}

\subsubsection{FK506-modulierte BMPR1A-Induktion durch De-novo-Synthese von ARNT}

Über das FK506-Bindeprotein FKBP12, ein zytosolisches Immunophilin, konnte bereits eine Beziehung zwischen dem Immunsuppressivum Tacrolimus sowie der Signalfunktion der zur TGF- $\beta$-Superfamilie gehörenden Typ I-Rezeptoren nachgewiesen werden (Charng et al. 1996, Wang T et al. 1996). Dabei interagiert FKBP12 mit einem konservierten Motiv der GS-Box des unstimulierten Typ I-Rezeptors, woraufhin dessen Phosphorylierung durch den Typ II-Rezeptor inhibiert und ein passiver Konformationszustand stabilisiert wird (Charng et al. 1996, Chen YG et al. 1997, Huse et al. 1999). Die nachfolgend gehemmte Signalübertragung korreliert mit einem reduzierten Niveau phosphorylierter SMAD-Proteine und fungiert als eine Art Sicherheitsmechanismus, um eine konstitutive ligandenunabhängige Signalaktivierung zu unterbinden 
(Chen YG et al. 1997). Tacrolimus wiederum konkurriert mit dem Typ I-Rezeptor um die Bindung des FKBP12, da beide mit derselben hydrophoben Tasche des Immunophilins interagieren (Chen YG et al. 1997, Huse et al. 1999). Dabei geht die Bildung des binären FKBP12/FK506-Komplexes, analog einer Rezeptorligandenbindung, mit der Dissoziation des FKBP12 vom Typ I-Rezeptor einher (Chen YG et al. 1997, Wang T et al. 1996), woraufhin die Phosphorylierung des Rezeptors sowie die pSMAD-abhängige Transduktionskaskade initiiert wird (Chen YG et al. 1997, Spiekerkoetter et al. 2013, Stockwell und Schreiber 1998). In diesem Zusammenhang identifizierten Spiekerkoetter et al. niedrigdosiertes Tacrolimus als ein wirkungsvolles ID1-Stimulanz, das in entsprechender Konzentration die potente Aktivierung von BMP-Typ I-Rezeptoren induziert, ohne gleichzeitig ein signifikantes TGF- $\beta$-Signal zu rekrutieren. Die Autoren mutmaßten ein duales Wirkprinzip, welches auf der Fähigkeit des Tacrolimus, sowohl mit dem FKBP12 zu interagieren als auch die Phosphatase Calcineurin sterisch zu blockieren, basiert (Spiekerkoetter et al. 2013).

Im Rahmen von In-vitro-Untersuchungen der vorliegenden Studie konnte hingegen durch Präinkubation des Translationsinhibitors Cycloheximid die rezeptorspezifische Induktion von BMPR1A vollständig unterbunden werden, woraus sich wiederum die Tacrolimus-abhängige De-novo-Translation eines bislang unbekannten Transkriptionsfaktors ableitet. Entsprechend wurde der Beitrag einer potentiellen transkriptionellen BMPR1A-Induktion direkt durch FK506 nicht weiter verfolgt. Mittels $\mathrm{RT}^{2}$ Profiler ${ }^{\mathrm{TM}}$ PCR-Array und bioinformatischem Sequenzabgleich auf Basis internetgestützter Datenbanken konnten sechs potentielle Kandidatengene mit putativer Bindungsdomäne in der Promotorregion des humanen BMPR1A-Gens detektiert werden. Da im FK506-stimulierten murinen Tubulusepithel (MCT) nach transientem RNAi-basierendem posttranskriptionellem Gene Silencing allein die selektive Stummschaltung des Transkriptionsfaktors Arnt zu keiner effizienten Bmpr1a-Induktion führte, kann auf dessen zentrale Funktionalität geschlossen werden. Sowohl in vitro als auch in vivo in obstruierten Nieren entsprechender Versuchstiere resultierte die Inkubation bzw. Applikation des Makrolid-Lactons in einer signifikanten Induktion des Transkriptionsfaktors und untermauert dementsprechend seine hypothetische Bedeutung. Die im Wesentlichen konzentrationsabhängigen und insbesondere in den beiden höheren FK506-Stimulationsdosen eindeutig evidenten Invivo-Effekte sind dahingehend bemerkenswert, als dass die anderen fünf putativen Kandidatengene infolge der chronischen Harnstauung zwar ebenfalls einer Hochregulation unterlagen, innen jedoch aufgrund der ausbleibenden Tacrolimus-assoziierten Wirkung ein mechanistischer Einfluss während der Bmpr1a-Induktion abgesprochen werden musste. Vor diesem Hintergrund scheint die sich nach FK506-Exposition in MCTZellen manifestierende verstärkte Expression der übrigen potentiellen Transkriptionsfaktoren nicht im Kontext einer Rezeptorregulation zu stehen. Einen weiteren Anhaltspunkt für eine mögliche relevante Mediatorfunktion von ARNT ergab der erneute Abgleich mit dem bereits zu Beginn der Studie abgerufenen Transkriptomarray der integrativen disease platform Nephroseq: Basierend auf Genexpressionsanalysen in der humanen epithelialen Mammakarzinomzellinie MCF7 befand sich unter den $1 \%$ signifikant durch FK506 induzierten Genen analog zum BMPR1A auch der Transkriptionsfaktor ARNT (nephroseq.org).

Zwar erfuhren die bislang generierten Resultate durch die Kopplung mit bioinformatischen Verfahren eine zusätzliche Konsolidierung, der auf transkriptioneller RNA-Interferenz beruhende Nachweis konnte jedoch bislang einzig mittels Immunoblot erbracht werden. Demgegenüber stellt die Etablierung eines Plasmidvektors mit integriertem BMPR1A-Promotorkonstrukt sowie seine anschließende transiente Transfektion in die tubuloepitheliale Zielzelle eine valide Möglichkeit dar, die postulierte Tacrolimus-abhängige De-novo- 
Translation des Transkriptionsfaktors ARNT sowie dessen folgende Bindung in der BMPR1A-Promotorregion eindeutig nachzuvollziehen. Letztlich bedingt dieser Transfer zusätzlicher genetischer Information eine hohe Kopienzahl des sich im Nukleus befindlichen extrachromosomalen Transgens und führt nachfolgend zur Überexpression der klonierten BMPR1A-Promotorsequenz. Inwiefern nun sowohl eine Tacrolimusstimulation als auch das selektive siRNA-vermittelte ARNT-Silencing mit der transkriptionellen Aktivität der inserierten BMPR1A-Promotorregion interferieren, kann anschließend durch ein der multiplen Klonierungsstelle (multiple cloning site, MCS) nachgeschaltetes hochsensitives Reportergen (Bsp. firefly luciferase, green fluorescent protein) quantitativ validiert werden (Schenborn und Groskreutz 1999). Demgegenüber erlaubt das bislang genutzte proteinanalytische Nachweisverfahren erst im Anschluss der Translation auf die Initiation der Gentranskription rückzuschließen. Folglich sind Interferenzen durch die Prozessierung von Proteinen zu bedenken. Prinzipiell korrelieren die emittierten Lumineszenzsignale der erwähnten Reportergenkonstrukte direkt mit der Promotoraktivierung. Da das green fluorescent protein in Anbetracht seiner autofluoreszenten Eigenschaft und im Gegensatz zu den häufig verwendeten dualen Luciferase-Reportergenassays keiner weiteren enzymatischen Reaktion unterliegt, ermöglicht seine fluoreszenzmikroskopische Detektion eine Beurteilung der Transkriptionsregulation im intakten Zellsystem kontinuierlich in Echtzeit und gestattet somit Aussagen über kinetische Aspekte der Tacrolimusstimulation (Lu et al. 2004, Soboleski et al. 2005). Folgt im Idealfall dem zielgerichteten ARNT-Knockdown die Repression des auf dem Vektor kodierenden und durch FK506-Exposition induzierten BMPR1A-Steuerelements, erlaubt die episomal erhöhte Promotorpräsenz den interagierenden Synergismus in einem separierten Minimalsystem zu analysieren und entsprechende Signale unter Ausschluss exogener Komponenten explizit aufeinander zu beziehen. Zudem erhöht die Klonierung einer bekannten Promotorsequenz von definierter Länge in das Plasmid die Spezifität der Ereignisse und offeriert zukünftig das ARNT-Bindungsmotiv zu lokalisieren. Einschränkungen der transienten Transfektionsmethodik beruhen auf der fehlenden Genomintegration bzw. einer allenfalls partiellen nukleosomalen Konfiguration des Plasmids und sind durch Generierung stabil transfizierter Klone zu umgehen (Smith CL und Hager 1997).

Letztlich liefert die theoretisierte Funktionalität des Transkriptionsfaktors ARNT ein plausibles Erklärungsmodell für die sowohl in vitro als auch in vivo detektierbare Spezifität der FK506-modulierten BMPR1AInduktion und gegen den von Spiekerkoetter et al. postulierten Wirkungsdualismus.

\subsubsection{Postulat der transkriptionellen ARNT-Aktivierung durch FK506-Mediation}

Gemeinhin stellt der Transkriptionsfaktor ARNT die konstitutiv exprimierte $\beta$-Untereinheit des heteromeren hypoxia inducible factor 1 (HIF-1) dar, welche im Nukleus zahlreicher Gewebe lokalisiert ist (Eguchi et al. 1997, Hirose et al. 1996). Bereits während der murinen Embryogenese manifestiert sich seine biologisch essentielle Bedeutung, da die homozygote Arnt $^{-}{ }^{-}$-Deletion einen embryonal letalen Phänotyp bedingt (Kozak et al. 1997, Maltepe et al. 1997). Seine strukturelle Architektur inkludiert ein aminoterminales DNAbindendes bHLH-Motiv angrenzend an die hochkonservierte PAS (PER-ARNT-SIM)-Domäne sowie eine potente, im Carboxyterminus integrierte Transaktivierungsfunktion (Whitelaw et al. 1994). Daher obliegt es inm, über die Dimerisierung mit anderen Mitgliedern der bHLH/PAS-Proteinsubfamilie ihre charakteristischen Signale zu transduzieren. Seine Komplexierung mit dem ligandengebundenen aryl hydrocarbon receptor (AhR) begünstigt etwa die Transkription der Xenobiotika-responsiven Elemente (Poland und Knutson 
1982, Rowlands und Gustafsson 1997). Ebenso bindet die unter hypoxischen Konditionen stabilisierte HIF-1 $\alpha$-Untereinheit erst nach Heterodimerisierung mit ARNT das hypoxia response-Element, was über die Transaktivierung der HIF-1-Zielgene zur Regulation der Sauerstoffhomöostase beiträgt (Déry et al. 2005, Semenza et al. 1997). Weiterhin ist eine Interaktion mit single-minded (SIM)-Proteinen bekannt, die die Repression der initial beschriebenen Mechanismen bedingt (Woods und Whitelaw 2002). Seine Relevanz als zentrales Partnerprotein der bHLH/PAS-Familienmitglieder ist demnach seit Jahren etabliert. Hingegen bestehen weiterhin Kontroversen hinsichtlich der Formation homodimerer ARNT-Komplexe, deren Funktion während der transkriptionellen Aktivierung sowie der in diesem Kontext regulierten Zielgene (Hirose et al. 1996, Sogawa et al. 1995, Wang F et al. 2006). Dabei könnte eine derartige Homodimerisierung durchaus zur BMPR1A-Promotorbindung beitragen. Wie Tacrolimus die in dieser Arbeit eruierte ARNT-Induktion evoziert, bleibt abschließend jedoch ungeklärt.

In den Fokus der Überlegungen rückten daher die FK506-binding proteins, ihrerseits ubiquitäre PeptidylProlyl-cis/trans-Isomerasen, an deren gemeinsame annähernd sequenzhomologe FKBP-Domäne (FKBD, FK506-like binding domain) der Immunmodulator FK506 bindet und nachfolgend die Inhibition der Rotamase-Aktivität bedingt (Galat 2013, Rulten et al. 2006, Van Duyne et al. 1991). Während der Archetyp FKBP12 ausschließlich eine Monodomäne besitzt, weisen höhermolekulare Multidomänenproteine neben einer größeren Zahl an konsekutiven FKBDs weitere funktionelle Bindemotive auf. In Anbetracht dieser strukturellen Charakteristika sowie ihrer intrazellulären Omnipräsenz sind die hochkonservierten Immunophiline in zahlreiche regulative Prozesse des Zytoplasmas und des Nukleus involviert. Entsprechend können selbst zytosolische FKBPs mit der DNA assoziieren und über die Regulation von Transkriptionsfaktoren sowie die Modifikation des Chromatins an der Genexpression partizipieren (Galat 2013, Yao et al. 2011). Das FKBP12 reguliert beispielsweise über die Interaktion mit dem ubiquitär exprimierten Transkriptionsfaktor YY1 (YIN YANG 1), einem zur GLI-Krüppel-Genfamilie gehörigem Zinkfingerprotein (Shi et al. 1991), in Abhängigkeit vom jeweiligen Promotorkontext dessen transkriptionelle Aktivität. Die Integration der 5'-YY1Bindungsdomäne in die Kontrollregion des frühen SV40-Promotor/Enhancer etwa führt bei Überexpression des FKBP12 zur Formation eines transkriptionellen Repressorkomplexes, wobei diese FKBP12/YY1-Wechselwirkungen in vitro durch Applikation von FK506 konzentrationsabhängig inhibiert werden (Yang WM et al. 1995). Im Zuge weiterführender Studien bestätigte zudem eine Protein-Interaktionsnetzwerk-Analyse über die Software STRING (Search Tool for the Retrieval of Interacting Genes/Proteins) YY1 als relevanten FKBP12-Bindungspartner (siehe Abbildung 28 (A)) (Szklarczyk et al. 2015). Mittels Nephroseq wurden überdies Motivanalysen von differentiell unter FK506-Supplementation induzierten Genen in genomweiten Transkriptionsdatensätzen bioaktiver small molecules implementiert, welche in Korrelation zu akkumulierenden ARNT- auch eine Anreicherung von YY1-Motiven eruierten (siehe Abbildung 28 (B)) (Hieronymus et al. 2006, Lamb et al. 2006, Roider et al. 2007). 

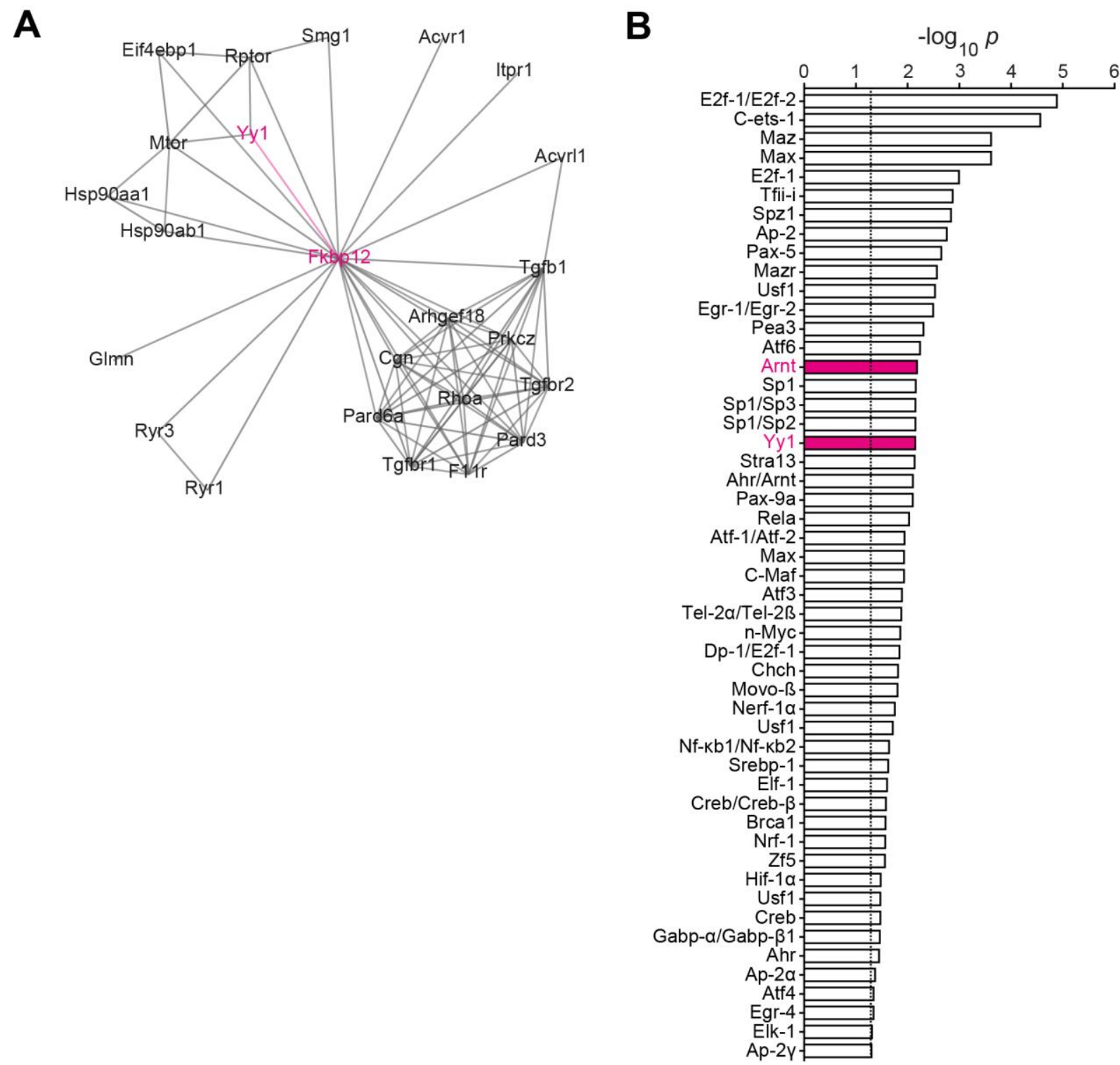

Abbildung 28: (A) FKBP12-Interaktionsnetzwerk. Bindungsaffinitäten von FKBP12 zu interagierenden Proteinen einschließlich YY1, dargestellt als Netzwerk (Szklarczyk et al. 2015). (B) FK506-modulierte Gene. Basierend auf genomweiten Transkriptionsdatensätzen bioaktiver small molecules (GEO-Zugangsnummer GSE5258) ergab die Motivanalyse von differentiell mittels FK506 induzierten Genen eine Anreicherung von ARNT- und YY1-Motiven. Angaben als Prozessanalysen der Anreicherung nach $-\log _{10} p$-Transformation (Hieronymus et al. 2006, Lamb et al. 2006, Roider et al. 2007).

Im Rahmen von Sequenzanalysen ließen sich weiterhin DNA-Bindungsmotive des Transkriptionsfaktors YY1 in der ARNT-Promotorregion identifizieren und führten zur Formulierung eines weitaus komplexeren hypothetischen Induktionsmechanismus, beruhend auf der transkriptionellen ARNT-Repression durch Ausbildung eines FKBP12/YY1-Synergismus an dessen Promotor. Die mit der Exposition des kompetitiven FKBPLiganden FK506 einhergehende Dissoziation der FKBP12/YY1-Komplexierung könnte über die Freisetzung der spezifischen YY1-Bindungsdomäne im ARNT-Promotor die transkriptionelle Induktion von ARNT initiie- 
ren. Als finaler Schritt dieser Transaktivierungskaskade ist letztlich die eingangs postulierte ARNT-Interaktion mit entsprechenden Sequenzmotiven des BMPR1A-Promotors zu sehen, die die Induktion des Rezeptors inkludiert.

A

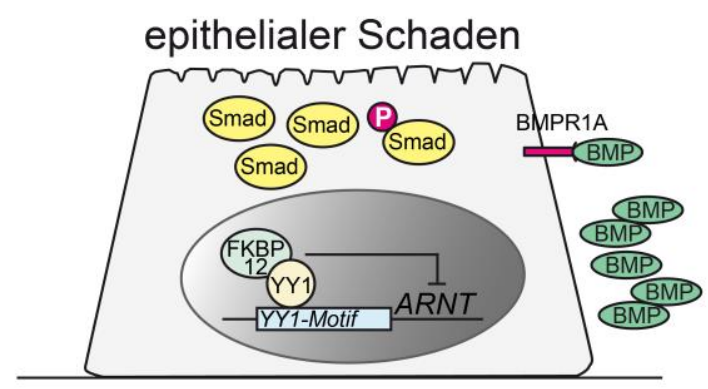

C

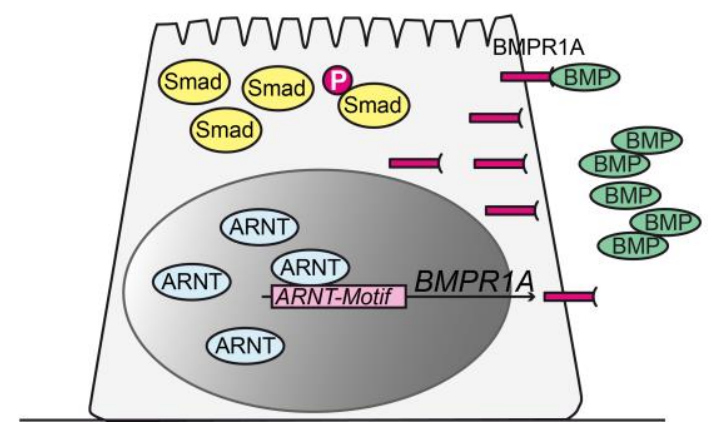

B

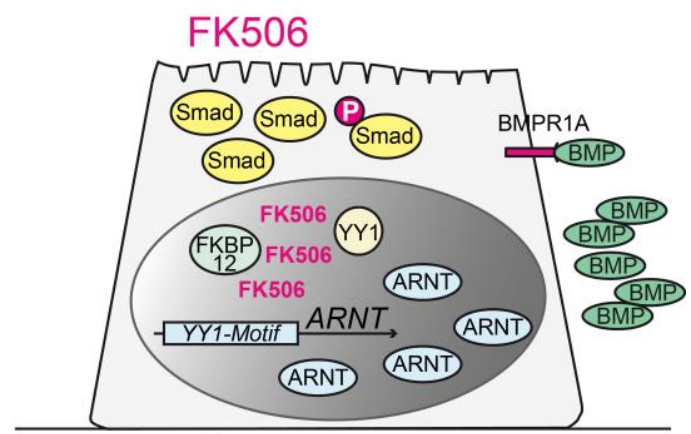

D

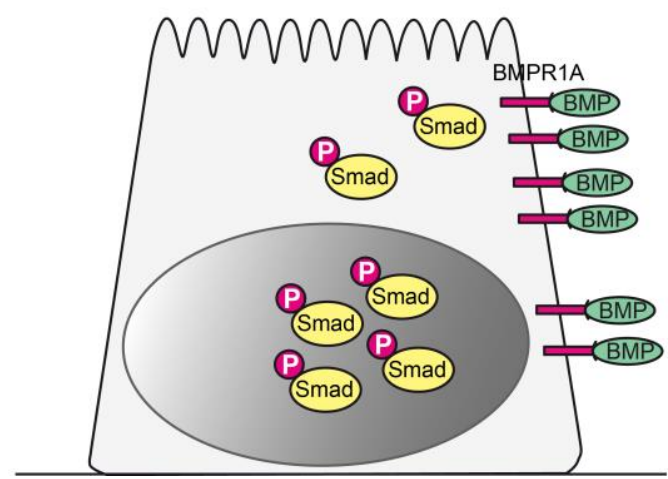

Abbildung 29: Hypothetischer BMPR1A-Induktionsmechanismus durch FK506-Mediation

(A) Transkriptionelle ARNT-Repression durch FKBP12/YY1-Synergismus. (B) Der Dissoziation des FKBP12/YY1-Repressorkomplexes durch Supplementation pikomolarer Tacrolimusmengen folgt die transkriptionelle ARNT-Aktivierung (C) mit konsekutiver ARNT-Bindung in der BMPR1A-Promotorregion. (D) Die nachfolgende Rezeptorinduktion korreliert mit einer verstärkten Rekrutierung der Signaltransduktionskaskade und der Protektion des renalen Tubulusepithels.

In der Fortführung des Projekts gelang es, durch pikomolare Tacrolimusmengen sowohl die FKBP12/YY1Interaktion zu blockieren als auch eine verminderte YY1-Bindung an den ARNT-Promotor zu initiieren. Zudem ließ sich infolge des Yy1- bzw. des Fkbp12-Knockdowns, basierend auf injizierten Vivo-Morpholinomodifizierten antisense-Oligonukleotiden (Gene Tools, Philomath, USA), ein erhöhtes Bmpr1a-Expressionsniveau bei gleichzeitiger Milderung des renalen Fibrosierungsprozesses in ureterligierten murinen Nieren detektieren. Additive Effekte durch FK506-Supplementation blieben hingegen aus. Als weiteres Indiz für die funktionale Bedeutung des FKBP12/YY1-Repressorkomplexes und ARNT innerhalb der FK506-modulierten Induktionskaskade kann die Aufhebung der Tacrolimuswirkung nach Vivo-Morpholino-induzierter ArntSuppression in UUO-Nieren entsprechender Versuchstiere interpretiert werden. 


\subsection{Potentielle klinische Relevanz der FK506-vermittelten BMPR1A-Induktion}

\subsection{1 Übertragbarkeit generierter In-vivo-Resultate in einen klinischen Kontext}

In Anlehnung an klinische Dosisfindungsstudien ermöglichte die Applikation verschiedener Konzentrationen des Calcineurininhibitors Tacrolimus die optimale Wirksamkeitsspanne des Medikaments zu identifizieren. Dabei verdeutlichte sich in den experimentellen Analysen ein offenkundig konzentrationsabhängiger Effekt, wobei Mauskohorten der höheren Stimulationsdosen (0,075 und 0,2 mg/kg KG/Tag) mit deutlicher Tendenz den größten Profit aus dem Wirkungspotential des Immunsuppressivums zogen. Fraglich bleibt an dieser Stelle allerdings, in welchem Maße eine Übertragbarkeit der gewonnenen Erkenntnisse auf den niereninsuffizienten Patienten realistisch erscheint. Obwohl sich mit der Sequenzierung des murinen Transkriptoms und Epigenoms erhebliche phänotypische Differenzen zum Menschen offenbarten (Lin S et al. 2014), repräsentiert die Hausmaus (Mus musculus) noch immer ein etabliertes Untersuchungsgut, um die Ätiopathogenese humaner Erkrankungen sowie die Wirksamkeit eines Pharmakons im Säugetierorganismus näher zu charakterisieren (Rossant und McKerlie 2001, Zambrowicz und Sands 2003). In definierten experimentellen Konstellationen stellen Versuchstiere jedoch eine genetisch identische Population dar, die wiederum konstanten, nahezu sterilen, äußeren Rahmenbedingungen und kontinuierlichen Zyklen unterliegt. Demgemäß kann die Heterogenität des fokussierten Patientenkollektivs in ihrer Komplexität nur schwerlich nachvollzogen bzw. in das Studiendesign integriert werden. Um dennoch einen direkten klinischen Bezug herstellen zu können, erfolgte die Determination der verfügbaren Pharmakonkonzentration im murinen Vollblut. Interessanterweise lagen messbare Vollblutspiegel von Versuchstieren etwa 10- bis 20-fach niedriger als der nach Nierentransplantation empfohlene $C_{0}$-Zielspiegel (5 bis $10 \mathrm{ng} / \mathrm{ml}$ ) einer FK506-Erhaltungstherapie (Wallemacq et al. 2009).

Gemeinhin ist die therapeutische Gabe des Makrolids mit einer Reihe von relevanten Nebenwirkungen assoziiert, welche allerdings einer deutlichen Dosisabhängigkeit unterliegen und demnach im Verlauf einer Langzeitbehandlung durch Anstreben einer Wirkstoffreduktion effektiv gemildert werden (Laskow et al. 1996, Venkataramanan et al. 2001). Obwohl Ekberg et al. in einer fundierten prospektiven Multicenterstudie (ELITE-Symphony-Studie) nierentransplantierter Patienten niedrigdosiertes Tacrolimus in Einklang mit signifikant verbesserter renaler Funktion und Überlebensraten des Allotransplantats bringen konnten (Ekberg et al. 2007), steht das propagierte nephrotoxische Potential der Calcineurininhibitoren immer wieder im Spektrum kontroverser Diskussionen. Faktisch bleibt die zugrundeliegende Ätiopathogenese dieser offenkundigen, jedoch recht unspezifischen histologischen Strukturveränderungen allerdings ungeklärt, da sowohl primär mittels Calcineurininhibition vermittelte systemische Effekte als auch lokale Ursachen eine manifeste Rolle zu spielen scheinen. Erstere finden weitgehend in der Blockade der NFAT-Signalkaskade ihren Ursprung, sind jedoch in ihrer Komplexität noch weitgehend unerforscht und teilweise rein spekulativer Natur (Naesens et al. 2009). Trotz allem waren diese Aspekte Motivation genug, um in bislang unveröffentlichten Folgestudien dieser Arbeitsgruppe die Expression des Transkriptionsfaktors NF-kB, eines wesentlich durch Calcineurin regulierten Effektors, zu analysieren (Palkowitsch et al. 2011, Vafadari et al. 2013). Demzufolge war dieses ubiquitäre Regulatorprotein sowohl im Blut als auch im Nierenparenchym FK506-behandelter Mäuse nicht substantiell verändert. Entsprechend lässt sich folgern, dass die kalkulierten Tacrolimusdosen bzw. der damit erreichte Konzentrationsspiegel im murinen Vollblut zwar ausreichend 
waren, um die Induktion von Bmprla, nicht jedoch eine wirkungsvolle Calcineurininhibition zu modulieren. Ergo könnten bei derart geringen Stoffmengen des Makrolids CNI-assoziierte Nebenwirkungen nicht zum Tragen kommen, wohingegen die durch den Off-Label-Use vermittelten renoprotektiven Effekte dominieren.

Das Wirkprofil des Tacrolimus ist aufgrund starker pharmakokinetischer, -dynamischer sowie genetischer Variabilitäten wenig prädiktiv und bedingt ein engmaschiges Monitoring sowie die starke Individualisierung der Erhaltungstherapie (Wallemacq et al. 2009). Dabei sind diese signifikanten intra- und interindividuellen Diskrepanzen im Wesentlichen auf die inkonsistente lokale Expression und Aktivität der metabolisierenden Enzyme CYP3A4/5 und des Effluxtransporters P-Glykoprotein bzw. auf Polymorphismen ihrer kodierender Gene zurückzuführen und können bei regulär konzentrierten CNI-Dosen manifeste nephrotoxische Reaktionen verursachen (Barbarino et al. 2013, Naesens et al. 2009). Zwar sind derlei Effekte im vorliegenden Studiendesign in Anbetracht der gemessenen murinen Tacrolimus-Vollblutspiegel mit hoher Wahrscheinlichkeit vernachlässigbar, jedoch limitieren die erwähnten arzneimittelspezifischen Schwankungen die direkte Übertragbarkeit ermittelter Dosisgrößen von der Maus auf den Menschen. Angesichts dessen sowie im Hinblick auf das multivariable Patientenprofil sei auf die Dringlichkeit prospektiver humaner Kohortenstudien verwiesen, zumal es durch eindeutige Definition des sehr engen optimalen Wirkfensters die simultane Calcineurininhibition und entsprechend deren assoziierte Nebenwirkungen zu vermeiden gilt.

Abschließende morphometrische Untersuchungen konnten in humanen Transplantatnieren von Patienten unter therapeutischer FK506-Exposition die effiziente Induktion des Transkriptionsfaktors ARNT, des Typ IRezeptors BMPR1A sowie der phosphorylierten SMAD1/5/8-Proteine als Kennzeichen einer funktionalen Rezeptoraktivität bestätigen und stützen somit die Existenz postulierter Mechanismen im menschlichen Tubulusepithel. Allerdings untersagt die Anzahl verfügbarer Biopsate sowie die ausschließliche Anwendung immunhistologischer Nachweisverfahren die Generierung signifikanter Daten. In Anbetracht der angeführten Limitationen erfolgte eine fundierte Datenkonsolidierung mittels der integrativen disease platform Nephroseq (nephroseq.org).

\subsubsection{Ausblick und mögliche Therapieoptionen}

Trotz ihrer ätiologischen Vielschichtigkeit unterliegt die CKD nahezu ausnahmslos einem gemeinsamen histopathologischen Mechanismus, der tubulointerstitiellen Fibrose (Boor et al. 2010, Floege und Gröne 1995). Dies führte zu der Annahme mittels spezifisch antifibrotischen Konzepten, wie beispielsweise der exogenen BMP7-Supplementation, die Regeneration der Niere befördern und damit einen substantiellen Durchbruch hinsichtlich der „Untherapierbarkeit“ der CKD erzielen zu können (Bechtel und Zeisberg M 2009).

Obwohl zahlreiche tierexperimentelle Modelle akuter und chronischer Nierenerkrankungen die propagierte Regenerationskapazität des Morphogens bestätigten (Hruska et al. 2000, Vukicevic et al. 1998, Wang S et al. 2003, Zeisberg M et al. 2003 a, Zeisberg M et al. 2003 b) und damit die klinische Anwendung des rhBMP7 am Patienten nahelegten, bestanden massive Vorbehalte, rhBMP7 befördere die ektope Knochenbildung, und verzögerten somit zunächst die therapeutische Applikation. Trotz eines etablierten Einsatzes als topisch injizierbares osteoanaboles Präparat in Oralchirurgie und Orthopädie, konnte dem rhBMP7 in der intraperitonealen und intravenösen Verabreichungsform jegliche osteoinduktive Aktivität nachweislich abgespro- 
chen werden (Bechtel und Zeisberg M 2009, Sampath et al. 1992, Zeisberg M et al. 2003 a). Als problematisch erwiesen sich jedoch die Synthese von biologisch aktivem BMP7, seine bei systemischer Applikation relevante relative Instabilität sowie die komplexe Pharmakokinetik, sodass die Herstellung sogenannter small molecules, synthetischer Proteine, die die Funktion des rekombinanten BMP7 reproduzieren, in den Fokus rückte (Bechtel und Zeisberg M 2009). Sugimoto et al. gelangen es, mittels dreidimensionaler Strukturanalysen des BMP7 putative Rezeptorbindungsstellen zu identifizieren und daraufhin das zyklische Peptidanalogon THR-123 mit selektiver Bindungskapazität zum BMPR1A zu konstruieren. Die orale Gabe des THR-123 zeigte in verschiedenen akuten und chronischen Niereninsuffizienzmodellen der Maus ein ähnliches renoprotektives Wirksamkeitsspektrum wie sein natives Äquivalent BMP7, ohne dabei osteogenes Potential zu entwickeln (Sugimoto et al. 2012).

An dieser Stelle erscheint die Wirkstoffkombination mit niedrigkonzentriertem Tacrolimus die logische Konsequenz: Basierend auf der identifizierten FK506-modulierten BMPR1A-Induktion sowie der selektiven BMPR1A-Affinität des THR-123 ergibt sich ein möglicher additiver Synergismus, der wiederum in der Potenzierung BMP7-assoziierter Effekte resultieren und auf Grundlage der impliziten Selektivität beider Prozesse ein mutmaßlich recht nebenwirkungsarmes Therapeutikum der renalen Fibrogenese darstellen könnte.

Während das erste synthetische BMP-Analogon THR-184 zur Therapie des akuten Nierenversagens nach operativen Interventionen bereits erfolgreich die klinische Phase I abgeschlossen hat und derzeit im Rahmen einer klinischen Phase II-Studie hinsichtlich Tolerierbarkeit, Effektivität und Dosierung am Patienten geprüft wird (ClinicalTrials.gov - Kennung: NCT01830920), befindet sich die THR-500-Serie für die Behandlung der chronischen Niereninsuffizienz noch in der Produktentwicklung (Thrasos Therapeutics 2015).

Unter Nutzung bioinformatischer Methoden wurde initial das deskriptive molekulare Konzept der FK506abhängigen BMPR1A-Induktion entwickelt. Dabei implementiert die Datenbank Nephroseq durch nachfolgende Verschneidung mit klinischen Studien eine Möglichkeit zur In-silico-Evaluierung assoziierter Biomarkerkandidaten (Mayer 2012). Dementsprechend ließ sich in humanen Transplantatnieren von Patienten unterschiedlicher immunsuppressiver Therapieregime sowohl auf das Expressionsprofil des BMPR1A als auch auf jenes des Transkriptionsfaktors $A R N T$ rückschließen. Die vorherige Definition klinischer Laborparameter (Serumkreatininwert von ungefähr $2 \mathrm{mg} / \mathrm{dl}$ ) stellte dabei die gemeinsame Basis aller inkludierter Patienten sicher. Auf Grundlage eines umfassenden DNA-Mikroarrays der Arbeitsgruppe Flechner et al. war eingangs bereits eine signifikante BMPR1A-Hochregulation nachgewiesen worden. Im Hinblick auf die neuen wissenschaftlichen Befunde konnten nun folgende systembiologische Datenanalysen die Induktion des putativen Kandidatengens ARNT und damit die in dieser Arbeit in einer kleinen Patientenkohorte verifizierten Resultate untermauern (siehe Abbildung 30 (A)). Weiterhin verdeutlichte sich im FK506-behandelten Patientenkollektiv eine signifikante Korrelation zwischen der ARNT-Expression in peripheren Leukozyten des Bluts und des korrespondierenden Nierenparenchyms (siehe Abbildung 30 (B)) und könnte somit die Möglichkeit offerieren, den Transkriptionsfaktor als potentiellen prognostisch relevanten Indikator im Rahmen eines therapeutischen Monitoring zu etablieren. Die BMP-Rezeptoren BMPR1B und BMPR2 blieben hingegen von den induktiven Effekten des Tacrolimus unbeeinflusst, womit sich die diskutierte BMPR1A-Spezifität auch für die humane Niere bestätigte (Flechner et al. 2004). 
A

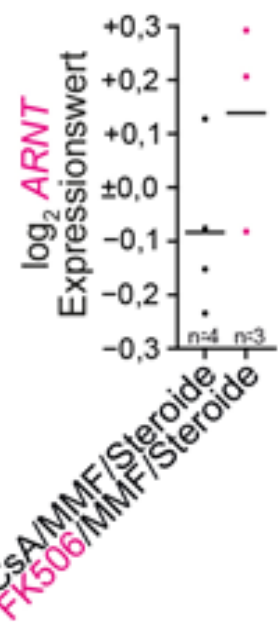

B

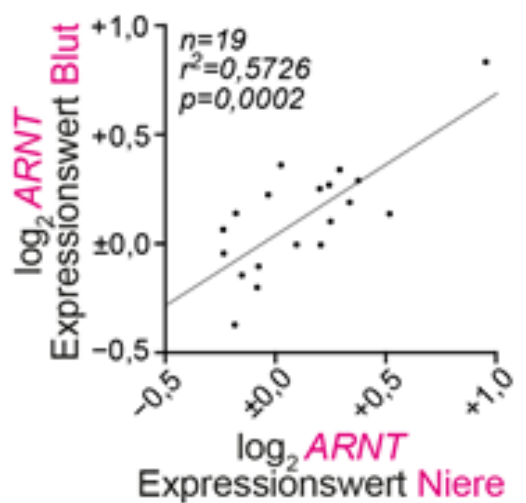

C

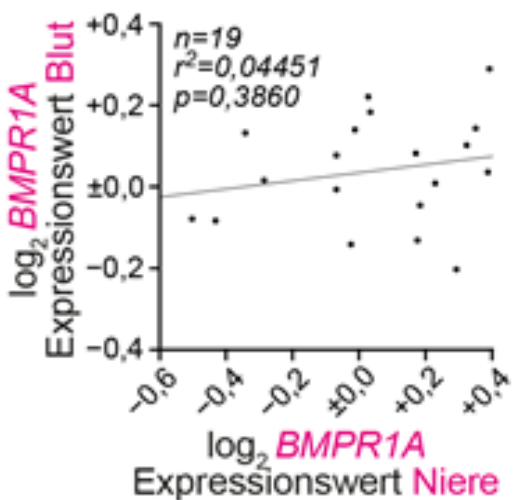

Abbildung 30: Systembiologische Datenanalyse in humanen Transplantatnieren

(A) ARNT-Induktion in nierentransplantierten Patienten (GEO-Zugangsnummer GSE1563) unter FK506-Therapieregime ( $n$, Anzahl der Patienten; Daten als alignierte Dotplots nach $\log _{2}$-Transformation des Expressionswertes mit Mittelwert dargestellt). (B+C) Während die ARNT-Expression (B) signifikant in peripheren Leukozyten des Bluts und des korrespondierenden Nierenparenchyms korreliert, ließ sich ein ähnlicher Zusammenhang hinsichtlich der BMPR1A-Expression (C) nicht validieren. Dies unterstreicht die potentielle prognostische Relevanz von ARNT im Rahmen eines therapeutischen Monitoring. $n$, Anzahl der Patienten; Kalkulation der $r^{2}$ - und p-Werte mittels linearer Regression (Flechner et al. 2004).

Ferner gelang es, die inverse Korrelation zwischen FKBP12/YY1 und der ARNT/BMP-Signaltransduktion sowohl im Kontext verschiedener Nierenerkrankungen (siehe Abbildung 31) (Flechner et al. 2004, Ju et al. 2015, Nakagawa et al. 2015, Reich et al. 2010, Schmid et al. 2006, Woroniecka et al. 2011) als auch im kardiovaskulären, gastrointestinalen und zentralen Nervensystem nachzuweisen (siehe Tabelle 19) (Roth et al. 2006). 
$\log _{2}$ Expressionswert
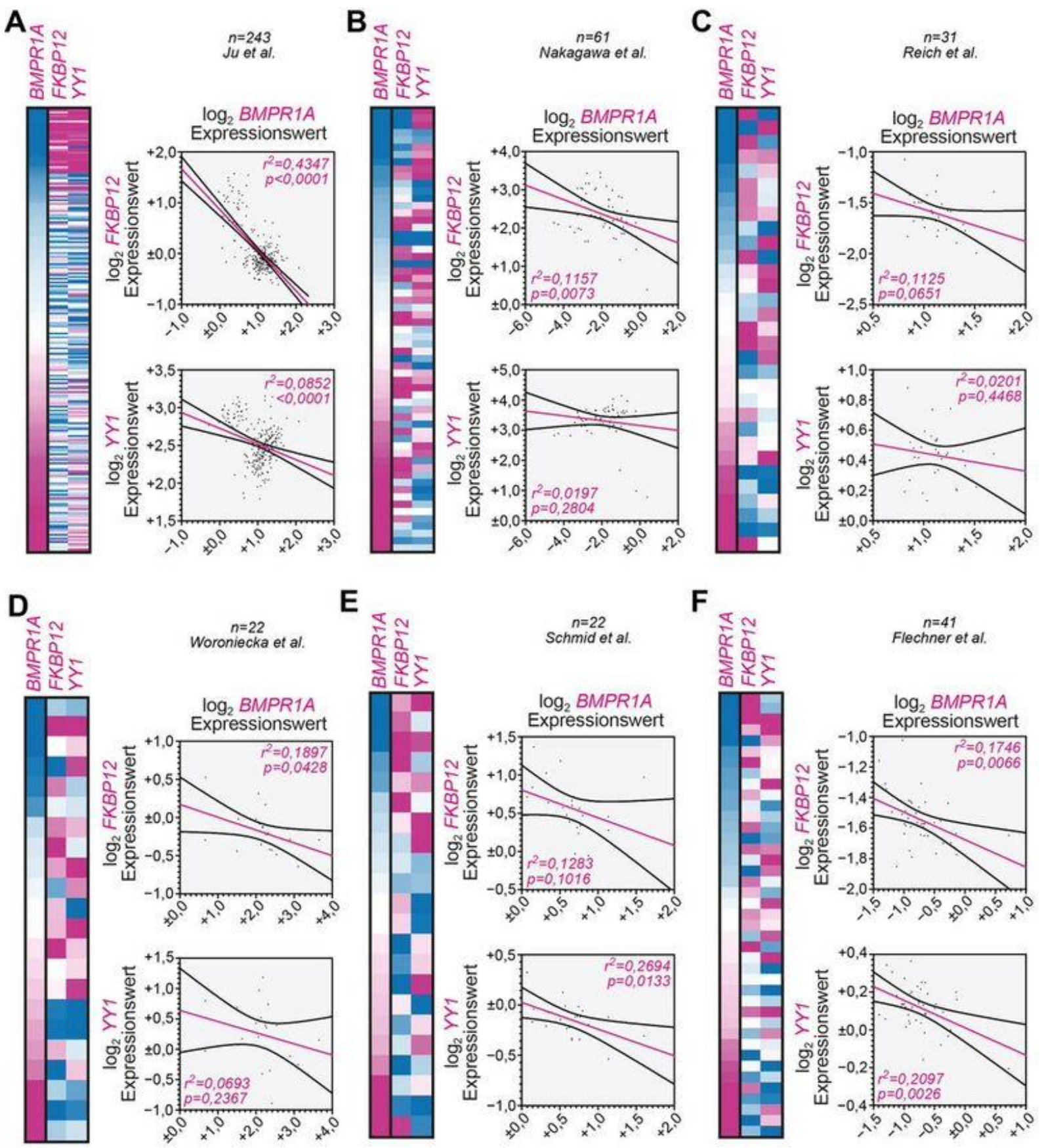

Abbildung 31: Inverse Korrelation von BMPR1A und FKBP12/YY1 in verschiedenen Nierenerkrankungen

(A-F) In-silico-Evaluierung nierenrelevanter Transkriptom-Arraydaten mittels Nephroseq bestätigt inverse Expressionskorrelation zwischen BMPR1A und FKBP12/YY1 in verschiedenen CKD-Kohorten (GEO-Zugangsnummer GSE69438, Ju et al. 2015 (A); GEO-Zugangsnummer GSE66494, Nakagawa et al. 2015, (B)), im Kontext der IgANephritis (GEO-Zugangsnummer GSE35487, Reich et al. 2010, (C)) und der diabetischen Nephropathie (GEO-Zugangsnummern GSE30566, Woroniecka et al. 2011, (D); GEO-Zugangsnummer GSE21785, Schmid et al. 2006, (E)) sowie in Transplantatnieren (GEO-Zugangsnummer GSE1563, Flechner et al. 2004, (F)). n, Anzahl der Patienten; 
Präsentation der Daten als Heatmap in \%-Quantil mit entsprechender Korrelationsanalyse nach $\log _{2}$-Transformation des Expressionswertes; Kalkulation der $r^{2}$ - und $p$-Werte mittels linearer Regression.

Tabelle 19: Inverse Korrelation zwischen ARNT und FKBP12/YY1 in humanen Organsystemen

Systembiologische Datenanalyse in humanen Transkriptomarrays (GEO-Zugangsnummer GSE3526) verdeutlicht evidente inverse Expressionskorrelation von ARNT in Relation zum FKBP12/YY1-Komplex in der Niere und darüber hinaus im kardiovaskulären, gastrointestinalen und zentralen Nervensystem. Kalkulation der Steigung, der $r^{2}$ - und $p$-Werte mittels linearer Regression (Roth et al. 2006).

\begin{tabular}{c|c|c|c|c}
\hline \multirow{2}{*}{ System } & Vergleich & Steigung & $\mathbf{r}^{\mathbf{2}}$ & p-Wert \\
\hline \hline \multirow{2}{*}{ Renaler Kortex } & $A R N T$ vs. FKBP12 & $-2.6 \pm 0.4$ & 0.9618 & 0.0193 \\
& $A R N T$ vs. $Y Y 1$ & $-0.6 \pm 0.0$ & 0.9922 & 0.0039 \\
\hline \multirow{2}{*}{ Kardiovaskulär } & $A R N T$ vs. FKBP12 & $-1.8 \pm 0.8$ & 0.2843 & 0.0606 \\
& $A R N T$ vs. YY1 & $-1.1 \pm 0.5$ & 0.3012 & 0.0521 \\
\hline \multirow{2}{*}{ Gastrointestinal } & $A R N T$ vs. FKBP12 & $-1.2 \pm 0.5$ & 0.1439 & 0.0093 \\
\hline Zentrales Nerven- & $A R N T$ vs. YY1 & $-0.7 \pm 0.3$ & 0.1152 & 0.0210 \\
system & $A R N T$ vs. FKBP12 & $-0.9 \pm 0.3$ & 0.0590 & 0.0015 \\
\hline
\end{tabular}

Da die Fibrogenese einen in sämtlichen parenchymatösen Organen existenten komplexen Inflammationsprozess darstellt, in dem das zentrale Mediatorzytokin TGF- $\beta 1$ über die intrinsische Kopplung der SMADSignaltransduktionskaskaden mit seinem natürlichen Gegenspieler BMP7 eine effektive Antagonisierung erfährt (Border und Noble 1994, Spiekerkoetter et al. 2013, Weiskirchen und Meurer 2013, Zeisberg EM et al. 2007, Zeisberg M et al. 2007), sind die antifibrotischen Effekte der mit einer BMPR1A-Induktion assoziierten FKBP12/YY1/ARNT-Signalkaskade nicht ausschließlich als renale Spezifität anzunehmen (Liang et al. 2013). Die deutliche Remission des chronischen Vernarbungsprozesses infolge einer Depletion des Transkriptionsfaktors Yy1 ist auch im Lungengewebe detektierbar (Lin X et al. 2011) und untermauert somit die Theorie eines ubiquitär existenten Induktionsmechanismus mit therapeutischem Potential hinsichtlich einer Vielzahl von fibroseassoziierten Erkrankungen.

Weiterhin bestehen relevante Zusammenhänge zum Verfahren der ischämischen Präkonditionierung, eines seit 1986 bekannten endogenen Schutzimpulses, bei dem kurze intermittierende Ischämie-Reperfusionsphasen die Toleranz, Reparatur- und Regenerationsfähigkeit des Gewebes gegenüber Auswirkungen eines konsekutiven irreversiblen Organschadens erhöhen. Es stellt ein in Niere, Herz, Lunge, Leber, Darm, Haut und Gehirn dokumentiertes Phänomen dar, dessen zugrundeliegenden molekularen Mechanismen bislang jedoch nicht abschließend geklärt werden konnten (Aksöyek et al. 2002, Clavien et al. 2000, Iliodromitis et al. 2007, Jensen et al. 2011, Kapitsinou und Haase 2015, Ma et al. 2009, Murry et al. 1986, Soncul et al. 1999, Yoon et al. 2015, Zahir et al. 1998). Interessanterweise fungiert das HIF-1 mit seiner $\beta$-Untereinheit ARNT über die Reprogrammierung des zellulären Energiemetabolismus und die Organisation zytoprotektiver antiapoptotischer Mediatoren sowie reaktiver Sauerstoffspezies als ein zentraler Modulator und wird insofern als eine potentielle Therapiestrategie zur Protektion akuter ischämischer Organschäden gehandelt (Bishop und Ratcliffe 2015, Guo et al. 2015, Hadjipanayi und Schilling 2013, Kapitsinou und Haase 2015, Murry et al. 1986). Um prinzipiell eine bessere Kontrollierbarkeit der Präkonditionierungsmethodik zu realisieren, versuchte man endogene Signalkaskaden pharmakologisch zu imitieren. In diesem Kontext zeigte 
die Vorbehandlung mit niedrigdosiertem FK506 in verschiedenen In-vitro- und In-vivo-Modellen des akuten Organversagens signifikante Prävention gegenüber experimentell induzierten Ischämie-Reperfusionsschäden (IRI, ischemia-reperfusion injury) (Cicora et al. 2012, Feng X et al. 2011, Hüser et al. 2009, Labrande et al. 2006, Spiekerkoetter et al. 2013, Stringa et al. 2016, Yang CW et al. 2001). Basierend auf der in vielfachen präklinischen Versuchsmodellen dargelegten Effektivität der FK506-Präkonditionierung werden derzeit marginale Lebertransplantate im Rahmen einer randomisierten Multicenterstudie vor Transplantation ex vivo mit dem Pharmakon perfundiert, mit der Intention zukünftig den komplexe Inflammationsprozess des IRI sowie eine mögliche Transplantatdysfunktion wirkungsvoll zu inhibieren (ClinicalTrials.gov - Kennung: NCT01564095, Pratschke et al. 2013).

Da auch in der vorliegenden Arbeit einen Tag vor Induktion eines irreversiblen Parenchymschadens die zu untersuchenden Mauskollektive mit dem Immunmodulator präkonditioniert wurden, darf spekuliert werden, inwiefern die explizit verfrühte Supplementation pikomolarer FK506-Dosen unabhängig von einer Calcineurininhibition die Resistenz des Tubulusepithels gegenüber den Pathomechanismen des chronischen Fibrosierungsprozesses steigert. Diskutabel bleibt die Rolle des Transkriptionsfaktors ARNT, der sowohl physiologisch über ein hypoxiebedingtes zelluläres Adaptationsprogramm als auch exogen über pikomolare Mengen FK506 - und damit weitaus spezifischer - zukünftig die Restitution der beschädigten Gewebearchitektur modulieren könnte.

Insgesamt stellt die Dissoziation des FKBP12/YY1-Repressorkomplexes durch Präkonditionierung mit pikomolaren Tacrolimusmengen bzw. durch Repression von FKBP12 oder YY1 und die konsekutive transkriptionelle ARNT-Aktivierung mit ARNT-Bindung in der BMPR1A-Promotorregion ein in zahlreichen parenchymatösen Organen existentes Phänomen dar und könnte damit eine aussichtsreiche Therapieoption zur Protektion des chronischen Organversagens offerieren. In welchem Maße die Tacrolimus-assoziierte BMP-Signaltransduktion als positiver Regulator einer phänotypischen epithelialen Integrität fungiert, müssen zukünftige (prä-)klinische Studien unter Berücksichtigung der hier diskutierten Limitationen beantworten. 


\section{ZUSAMMENFASSUNG}

Die Progression der chronischen und terminalen Niereninsuffizienz stellt aufgrund mangelnder regenerativer Therapiestrategien ein globales sozioökonomisches und gesundheitspolitisches Problem dar. Mit Etablierung ihres renoprotektiven Potentials eröffnen das BMP7 und seine sich bereits in der klinischen Phase II-Prüfung befindlichen Wirkstoffanaloga nun erstmals die Möglichkeit eines zielgerichteten antifibrotischen Behandlungskonzepts. Der fortschreitende Strukturverlust der Niere resultiert allerdings in einer effektiven Negativregulation des Morphogens, wohingegen der Typ I-Rezeptor Bmpr1a, wesentlicher Transduktor der BMP7-spezifischen SMAD1/5/8-Signalkaskade im Tubulusepithel, im murinen Niereninsuffizienzmodell selektiv induziert wird. Weiterhin korreliert die tubuloepitheliale Bmpr1a-Defizienz der Maus mit einer Exazerbation des renalen Destruktionsprozesses. Der Calcineurininhibitor Tacrolimus (FK506) gilt als Firstline-Therapeutikum nach erfolgter Nierentransplantation. Diesbezüglich ergaben systembiologische Datenanalysen unter Abruf der webbasierten disease platform Nephroseq Hinweise auf eine durch den Immunmodulator vermittelte BMPR1A-Stimulation in epithelialen Zellentitäten. Überdies ist die protektive Triggerfunktion einer pharmakologischen FK506-Präkonditionierung im Zusammenhang akuter Organschäden hinreichend untersucht.

Ziel dieser Arbeit war es daher, den Einfluss des Pharmakons auf die BMPR1A-Expression in vitro in immortalisierten proximalen Tubulusepithelzelllinien (HK-2-, MCT-Zellen), in vivo im murinen Fibrosemodell der unilateralen Ureterobstruktion (UUO) sowie in Biopsaten humaner Transplantatnieren zu determinieren. Ferner erforderten die hypothetisierten Induktionsmechanismen eine nähere Charakterisierung.

Molekularbiologische Analysen bestätigten in der Zellkultur infolge einer Präkonditionierung mit verschiedenen immunsuppressiven Therapeutika (MMF, CSA, FK506) die Spezifität einer FK506modulierten BMPR1A-Induktion. Indes zeigte FK506 keine Wirksamkeit auf die Expression der BMP7Rezeptoren BMPR1B und BMPR2.

Die Effektivität von geringdosiertem Tacrolimus $(0,02,0,075,0,2 \mathrm{mg} / \mathrm{kg} \mathrm{KG} / \mathrm{Tag})$ auf den arbiträren Pathomechanismus der renalen Fibrogenese wurde nach zehntägiger einseitiger Harnleiterokklusion in C57BL/6J-Mäusen untersucht. Im Vergleich zum vehicle-behandelten Kontrollkollektiv manifestierte sich unter FK506-Exposition die signifikante dosisabhängige Bmpr1a-Hochregulation in Assoziation mit einer konsekutiven Phosphorylierung der Smad1/5/8-Proteine als Charakteristikum einer funktionalen Rezeptoraktivität. Demgegenüber unterlagen die Typ I- und Typ II-Rezeptoren Bmpr1b bzw. Bmpr2 in sämtlichen Behandlungsgruppen einer deutlichen Suppression und untermauerten die Selektivität der detektierten FK506/BMPR1A-Interaktion. Weiterhin waren die sich als Ausdruck progredienter Nierenschädigung darstellende interstitielle Fibrose mit simultaner tubulärer Atrophie sowie die Akkumulation der profibrotischen Markerproteine aSMA, Fsp1 und Collagen-1 im histomorphologischen Korrelat der ureterligierten Niere durch Tacrolimusapplikation sukzessiv reprimiert. Dagegen konnte in jeglichen Mauskollektiven mittels analog vollzogener Expressionsanalysen ein FK506-spezifischer Effekt auf die kontralaterale scheinoperierte Niere ausgeschlossen werden. Bei der ELISA-basierten Spiegelmessung lag die Tacrolimuskonzentration im murinen Vollblut etwa 10 - bis 20 -fach niedriger als der nach Nierentransplantation empfohlene 
immunsuppressive Talspiegel. Folglich geht die FK506-evozierte Nephroprotektion nicht mit einer pharmakologischen Calcineurininhibition und deren assoziierten Nebenwirkungen einher.

Die zur Spezifizierung zugrundeliegender Induktionsmechanismen erfolgte kontrollierte zellexperimentelle Translationshemmung ließ auf die De-novo-Translation eines unbekannten Transkriptionsfaktors schließen, welcher durch Bindung von Sequenzmotiven in der BMPR1A-Promotorregion dessen Transkription initiiert. Mittels $\mathrm{RT}^{2}$ Profiler PCR Array und nachfolgendem Sequenzabgleich konnten sechs potentielle Kandidaten mit Bindungsmotiven in der BMPR1A-Promotorregion identifiziert werden. Während der RNAi-vermittelten Stummschaltung putativer Transkriptionsfaktoren führte einzig das transiente Arnt-Silencing zu keiner potenten FK506-assoziierten Bmpr1a-Induktion und stützt dessen funktionelle rezeptorspezifische Relevanz. Zudem gelang bei Validierung ermittelter Transkriptionsfaktoren in vitro im proximalen Tubulusepithel sowie in vivo in obstruierten Mausnieren der Nachweis einer signifikanten FK506-abhängigen Arnt-Induktion. Abschließende morphometrische Analysen in Transplantatnieren von Patienten unterschiedlicher immunsuppressiver Therapieregime zeigten im FK506-behandelten Kollektiv verstärkte Expressionsmuster der Zielgene BMPR1A und ARNT, die in Assoziation mit einer konsekutiven Aktivierung der pSMAD1/5/8Signaltransduktionskaskade standen. In diesem Kontext erlaubte die in Nephroseq implementierte nachträgliche Verschneidung mit klinischen Phänotypen, die generierten Resultate in silico in weiteren Transplantatnieren zu konsolidieren. Gleichzeitig ließ sich durch die funktionale Annotation eine signifikante Korrelation zwischen der FK506-modulierten transkriptionellen ARNT-Reprogrammierung in peripheren Leukozyten des Bluts und des korrespondierenden Nierenparenchyms determinieren. Als potentieller nierenrelevanter Biomarker offeriert ARNT somit die Option auf ein therapeutisches Monitoring. Zusammenfassend konnte sich die Tacrolimus-assoziierte BMPR1A-Induktion als positiver Regulator der tubuloepithelialen Integrität bestätigen. Dabei sensibilisiert die konservierte Rezeptorfunktionalität die beschädigte Gewebearchitektur für die antifibrotische Wirkung des Morphogens BMP7 und bedingt die Remission des tubulointerstitiellen Fibrosierungsprozesses. Kausale molekulare Mechanismen inkludieren die De-novo-Synthese des Transkriptionsfaktors ARNT, wobei dessen Induktion vermutlich auf der FK506-modulierten Dissoziation eines transkriptionellen Repressorkomplexes aus dem Immunophilin FKBP12 und dem Transkriptionsfaktor YY1 beruht. Diese reziproke Korrelation von FKBP12/YY1 einerseits und der $A R N T / B M P$-Signaltransduktion andererseits ist ferner in zahlreichen parenchymatösen Organen determinierbar, sodass die über FK506-Präkonditionierung vermittelte endogene Toleranzerhöhung insgesamt eine vielversprechende Therapiestrategie zur Protektion des chronischen Organversagens darstellen könnte. Entsprechende Zusammenhänge bedürfen einer weiteren Präzision im Rahmen humaner Kohortenstudien. 


\section{ANHANG}

\subsection{Genontologie-Analyse mittels webbasierter Datenbanken}

\section{Material}

Software und Datenbanken

GEO

Nephroseq

PASTAA

STRING http://www.ncbi.nlm.nih.gov/geo/

https://www.nephroseq.org/resource/login.html

http://trap.molgen.mpg.de/PASTAA.htm

http://string-db.org/

\section{Methoden}

Die Datensätze wurden gemäß allgemeinen Empfehlungen und Richtlinien analysiert (Rung und Brazma 2013) und sind in der Gene Expression Omnibus (GEO)-Datenbank unter Angabe der jeweiligen GEO-Zugangsnummer (GSE) öffentlich zugänglich.

\section{Prädiktion FK506-regulierter Transkriptionsfaktoren}

Durch Abruf der disease platform Nephroseq (nephroseq.org) wurden die 5 \% der unter FK506-Exposition signifikant höchst induzierten Gene identifiziert. Die Analyse von Bindungsaffinitäten inkludierte genomweite Transkriptionsdatensätze bioaktiver small molecules (GEO-Zugangsnummer GSE5258) und erfolgte 200 bp upstream der TSS des jeweiligen Gens unter Zuhilfenahme des Algorithmus PASTAA (Predicting ASsociated Transcription factors from Annotated Affinities) bei maximalen Zugehörigkeitsniveau und einem Signifikanzniveau von p<0.05 (Hieronymus et al. 2006, Lamb et al. 2006, Roider et al. 2007).

\section{Erstellen eines funktionalen Gen-Netzwerk-Diagramms}

Die Protein-Interaktionsnetzwerk-Analyse und die Darstellung der Protein-Protein-Interaktionen wurden mittels der Software STRING (Search Tool for the Retrieval of Interacting Genes/Proteins) unter Benutzung des höchsten Konfidenzniveaus (0,900) vollzogen (Szklarczyk et al. 2015).

\section{Analyse von humanen Transkriptom-Arraydaten}

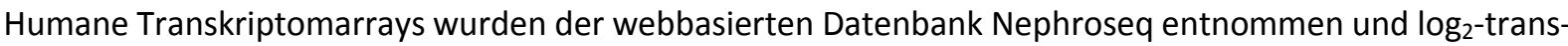
formiert. Die GEO-Zugangsnummern sowie die jeweils korrespondierenden Publikationen sind in der Tabelle 20 dargestellt. 
Tabelle 20: GEO-Zugangsdaten und korrespondierende Publikationen

\begin{tabular}{c|c}
\hline GEO-Zugangsnummer & Publikation \\
\hline \hline GSE1563 & Flechner et al. 2004 \\
\hline GSE69438 & Ju et al. 2015 \\
\hline GSE66494 & Nakagawa et al. 2015 \\
\hline GSE35487 & Reich et al. 2010 \\
\hline GSE3526 & Roth et al. 2006 \\
\hline GSE21785 & Schmid et al. 2006 \\
\hline GSE30566 & Woroniecka et al. 2011 \\
\hline
\end{tabular}

\section{Statistische Auswertung}

Mittels linearer Regressionsanalysen erfolgte der Vergleich der jeweils forcierten Parameter. Angaben bezüglich der Größe des Korrelationskoeffizienten (r), des Gruppenumfangs (n) sowie des Signifikanzniveaus ( $p$-Wert) sind den korrespondierenden Graphen und Tabellen zu entnehmen.

Die in Einleitung und Diskussion dargestellten systembiologischen Datenanalysen wurden von Herrn Dr. med. Björn Tampe durchgeführt. 


\subsection{Vollständige unbearbeitete Western Blot-Gele}

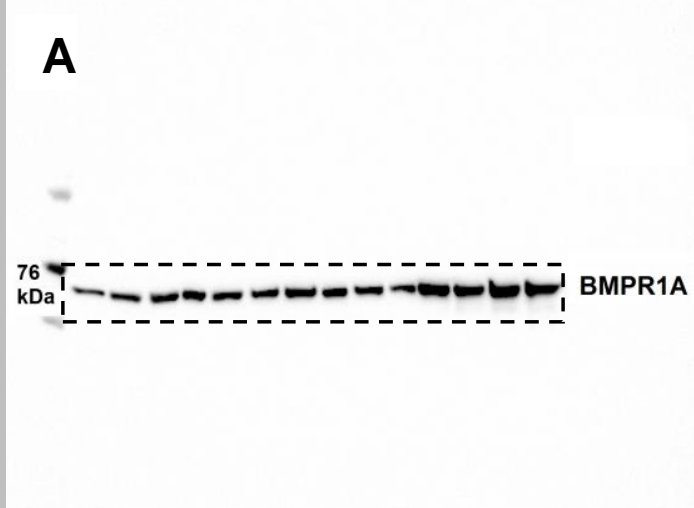

\section{B}

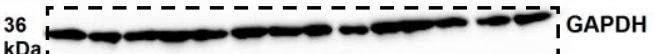

$\mathrm{kDa}_{\mathrm{L}}$ - - - - - - - - - - - - - - - 1

Abbildung 32: BMPR1A- (A) und GAPDH-Expression (B) in HK-2-Zellen nach pharmakologischer Präkonditionierung. Gele korrespondieren zu Abbildung 9 (A).
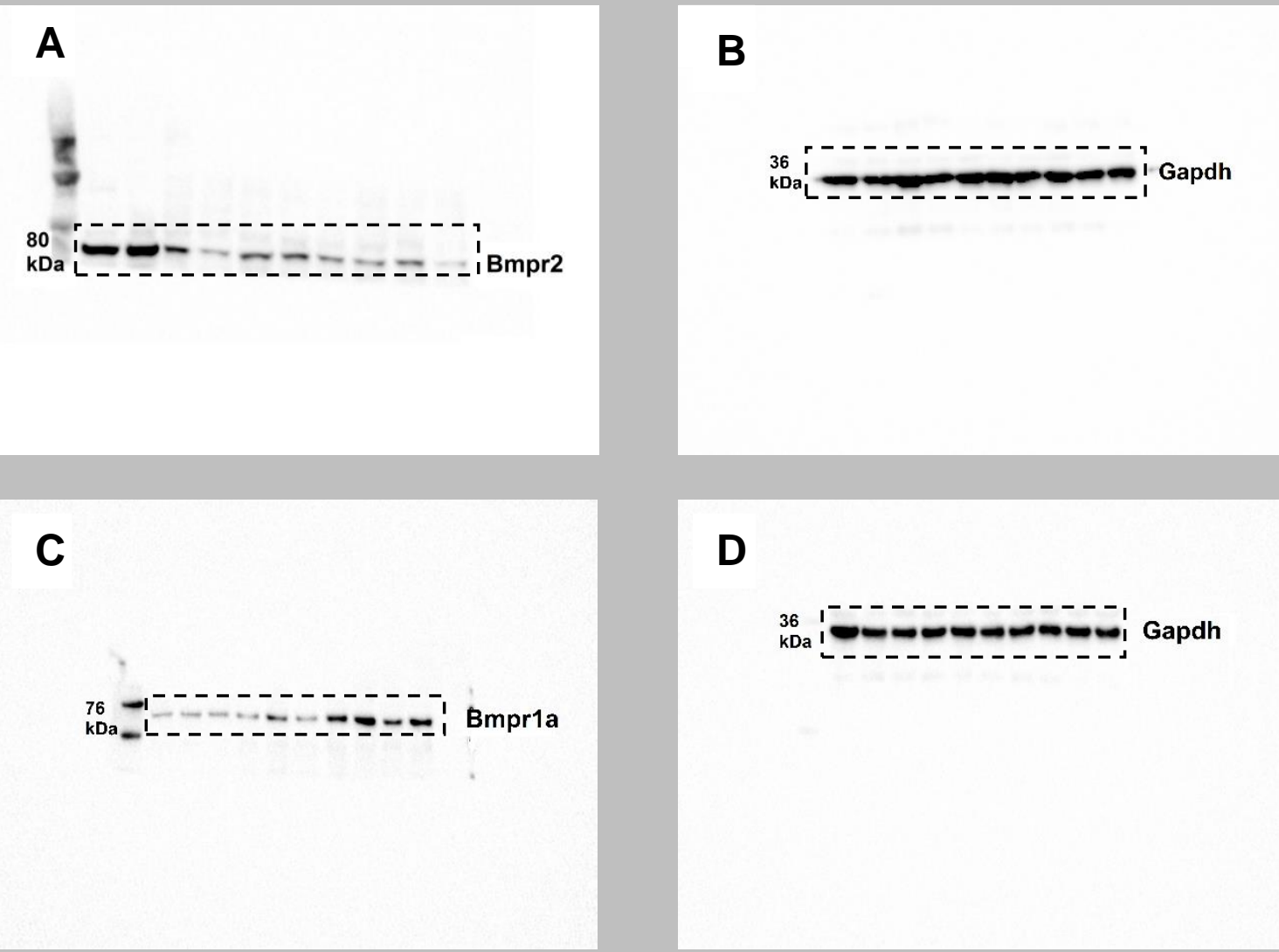

D

kDa I6 
$\mathbf{E}$

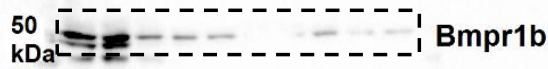

$-$
$\mathbf{F}$

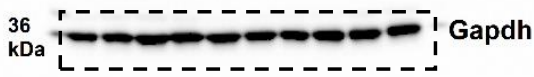

Abbildung 33: Expression der Bmp-Rezeptoren $(A, C, E)$ und Haushaltsgene $(B, D, F)$ in vivo. Gele korrespondieren zu Abbildung 11 (D).

A

kDa 60 (1)
B

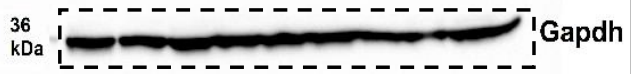

Abbildung 34: pSmad1/5/8- (A) und Gapdh-Expression (B) in vivo. Gele korrespondieren zu Abbildung 12 (D).

A

kDa

\section{B}

36

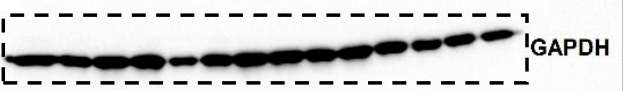

Abbildung 35: BMPR1A- (A) und GAPDH-Expression (B) in HK-2-Zellen nach Cycloheximid-Präinkubation. Gele korrespondieren zu Abbildung 18 (B). 


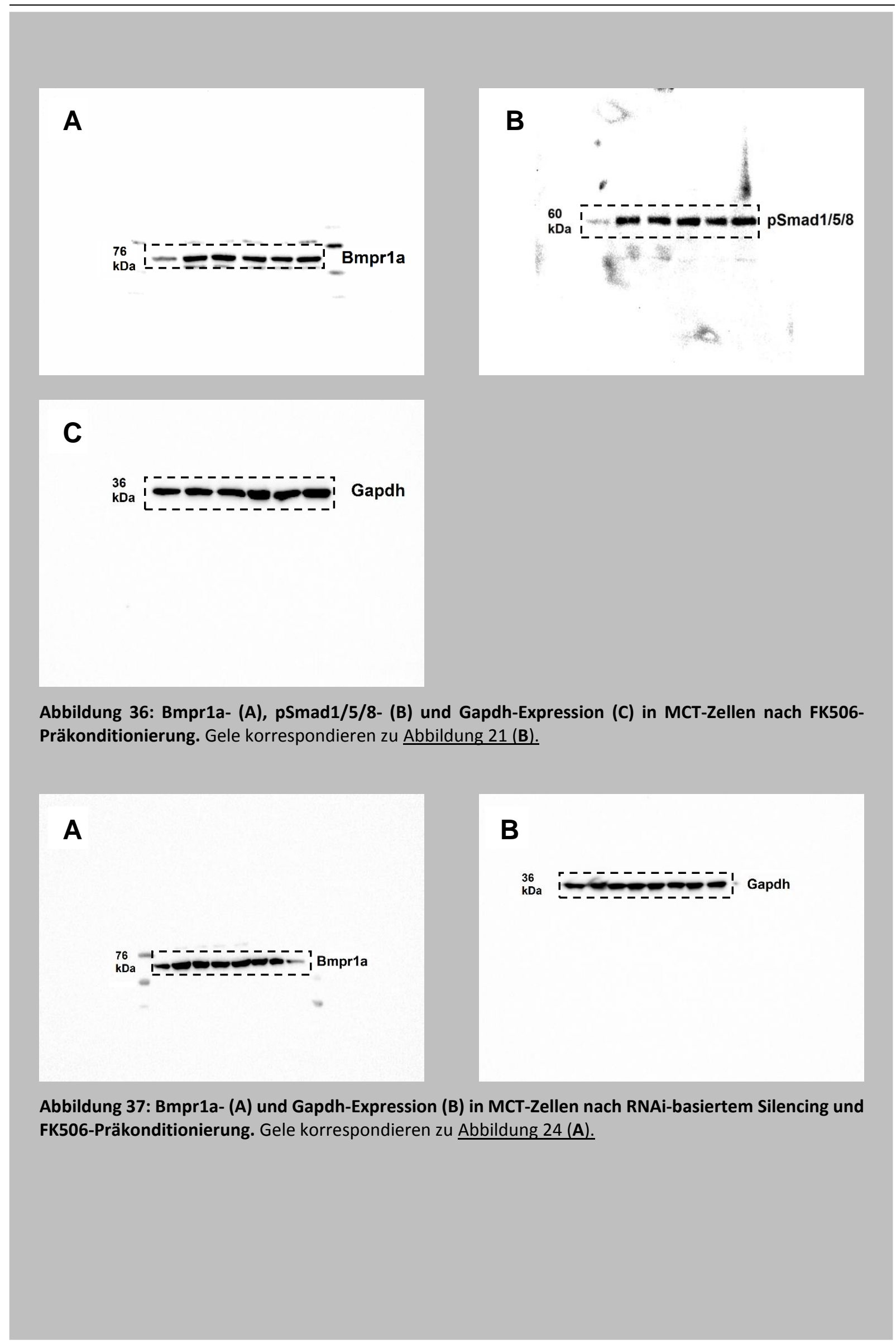


A

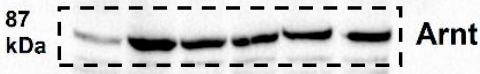

B

kDa I I Gapdh

Abbildung 38: Arnt- (A) und Gapdh-Expression (B) in MCT-Zellen nach FK506-Präkonditionierung. Gele korrespondieren zu Abbildung 25 (A).

A

$87 \mathrm{kDa}$

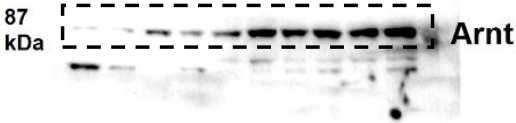

B

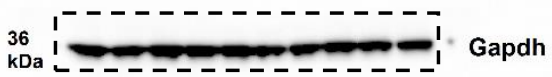

Abbildung 39: Arnt- (A) und Gapdh-Expression (B) in vivo. Gele korrespondieren zu Abbildung 26 (A). 


\section{LITERATURVERZEICHNIS}

Aksöyek S, Cinel I, Avlan D, Cinel L, Oztürk C, Gürbüz P, Nayci A, Oral U (2002): Intestinal ischemic preconditioning protects the intestine and reduces bacterial translocation. Shock $\underline{18}, 476-480$

Arrhenius S: Immunochemie. Akademische Verlagsgesellschaft, Leipzig 1907

Attisano L, Wrana JL (2002): Signal transduction by the TGF-beta superfamily. Science 296, 1646-1647

Bakris GL, Ritz E; World Kidney Day Steering Committee (2009): The message for World Kidney Day 2009: hypertension and kidney disease, a marriage that should be prevented. Iran J Kidney Dis $\underline{3}$, 7-10

Barbarino JM, Staatz CE, Venkataramanan R, Klein TE, Altman RB (2013): PharmGKB summary: cyclosporine and tacrolimus pathways. Pharmacogenet Genomics $\underline{10}$, 563-585

Barker CF, Markmann JF (2013): Historical overview of transplantation. Cold Spring Harb Perspect Med $\underline{3}$, a014977

Barreiro C, Prieto C, Sola-Landa A, Solera E, Martínez-Castro M, Pérez-Redondo R, García-Estrada C, Aparicio JF, Fernández-Martínez LT, Santos-Aberturas J (2012): Draft Genome of Streptomyces tsukubaensis NRRL 18488, the Producer of the Clinically Important Immunosuppressant Tacrolimus (FK506). J Bacteriol 194, 3756-3757

Bechtel W, Zeisberg M (2009): Bone Morphogenic Protein-7 (BMP7) and the kidneys: insights into the future management of chronic kidney diseases. Dtsch Med Wochenschr 134, 1688-1691

Becknell B, Greenbaum LA, Smoyer WE (2012): A new 'tac' for childhood nephrotic syndrome. Kidney Int $\underline{82}$, 1049-1051

Benet LZ, Izumi T, Zhang Y, Silverman JA, Wacher VJ (1999): Intestinal MDR transport proteins and P-450 enzymes as barriers to oral drug delivery. J Control Release $\underline{62}, 25-31$

Bernstein E, Caudy AA, Hammond SM, Hannon GJ (2001): Role for a bidentate ribonuclease in the initiation step of RNA interference. Nature $\underline{409}, 363-366$

Bishop T, Ratcliffe PJ (2015): HIF hydroxylase pathways in cardiovascular physiology and medicine. Circ Res $\underline{117}$, 65-79

Böttinger EP, Bitzer M (2002). TGF- $\beta$ signaling in renal disease. J Am Soc Nephrol $\underline{13}$, 2600-2610

Bohle A, Grund KE, Mackensen S, Tolon M (1977): Correlations between renal interstitium and level of serum creatinine. Morphometric investigations of biopsies in perimembranous glomerulonephritis. Virchows Arch $A$ Pathol Anat Histol 373, 15-22

Bohle A, Mackensen-Haen S, von Gise H (1987): Significance of tubulointerstitial changes in the renal cortex for the excretory function and concentration ability of the kidney: a morphometric contribution. Am J Nephrol $\underline{7}$, 421-433

Bohle A, Wehrmann M, Bogenschutz O, Batz C, Vogl W, Schmitt H, Müller CA, Müller GA (1992): The long-term prognosis of the primary glomerulonephritides. A morphological and clinical analysis of 1747 cases. Pathol Res Pract 188, 908-924

Boor P, Ostendorf T, Floege J (2010): Renal fibrosis: novel insights into mechanisms and therapeutic targets. Nat Rev Nephrol $\underline{6}$, 643-656

Border WA, Noble NA (1994): Transforming growth factor beta in tissue fibrosis. New Engl J Med $\underline{331}, 1286-1292$

Border WA, Okuda S, Languino LR, Ruoslahti E (1990): Transforming growth factor-beta regulates production of proteoglycans by mesangial cells. Kidney Int $\underline{37}, 689-695$ 
Bramlage CP, Tampe B, Koziolek M, Maatouk I, Bevanda J, Bramlage P, Ahrens K, Lange K, Schmid H, Cohen CD (2010): Bone Morphogenetic Protein (BMP)-7 expression is decreased in human hypertensive nephrosclerosis. BMC Nephrol 11, 31

Bramlage CP, Müller GA, Tampe B, Bevanda J, Maatouk I, Koziolek M, Lange K, Ahrens K, Schmid H, Cohen CD (2011): The role of bone morphogenetic protein-5 (BMP-5) in human nephrosclerosis. J Nephrol 24, 647-655

Bröcker V, Kreipe H, Haller H (2010): Tubulointerstitielle Fibrose. Endstrecke aller Nierenerkrankungen, prognostischer Faktor oder Pathomechanismus? Nephrologe $\underline{5}, 284-292$

Calne R (2004): Cyclosporine as a milestone in immunosuppression. Transplant Proc $\underline{36}, 13 S-15 S$

Celeste AJ, Iannazzi JA, Taylor RC, Hewick RM, Rosen V, Wang EA, Wozney JM (1990): Identification of transforming growth factor beta family members present in bone-inductive protein purified from bovine bone. Proc Natl Acad Sci U S A 87, 9843-9847

Chang H, Brown CW, Matzuk MM (2002): Genetic analysis of the mammalian transforming growth factor-beta superfamily. Endocr Rev 23, 787-823

Chang MM, Lovett J (2011): A laboratory exercise illustrating the sensitivity and specificity of Western blot analysis. Biochem Mol Biol Educ 39, 291-297

Charng MJ, Kinnunen P, Hawker J, Brand T, Schneider MD (1996): FKBP-12 recognition is dispensable for signal generation by type I transforming growth factor-beta receptors. J Biol Chem 271, 22941-22944

Chen D, Ji X, Harris MA, Feng JQ, Karsenty G, Celeste AJ, Rosen V, Mundy GR, Harris SE (1998): Differential roles for bone morphogenetic protein (BMP) receptor type IB and IA in differentiation and specification of mesenchymal precursor cells to osteoblast and adipocyte lineages. J Cell Biol 142, 295-305

Chen YG, Liu F, Massagué J (1997): Mechanism of TGFbeta receptor inhibition by FKBP12. EMBO J 16, 3866-3876

Chevalier RL, Forbes MS, Thornhill BA (2009): Ureteral obstruction as a model of renal interstitial fibrosis and nephropathy. Kidney Int $\underline{75}, 1145-1152$

Cho SG, Du Q, Huang S, Dong Z (2010): Drp1 dephosphorylation in ATP depletion induced mitochondrial injury and tubular cell apoptosis. Am J Physiol Renal Physiol 299, F199-206

Chomczynski P, Sacchi N (1987): Single-step method of RNA isolation by acid guanidinium thiocyanate-phenolchloroform extraction. Anal Biochem 162, 156-159

Christians U, Jacobsen W, Benet LZ, Lampen A (2002): Mechanisms of clinically relevant drug interactions associated with tacrolimus. Clin Pharmacokinet $\underline{41}, 813-851$

Cicora F, Roberti J, Vasquez D, Guerrieri D, Lausada N, Cicora P, Palti G, Chuluyan E, Gonzalez P, Stringa P (2012): Preconditioning donor with a combination of tacrolimus and rapamacyn to decrease ischaemia-reperfusion injury in a rat syngenic kidney transplantation model. Clin Exp Immunol 167, 169-177

Clavien PA, Yadav S, Sindram D, Bentley RC (2000): Protective effects of ischemic preconditioning for liver resection performed under inflow occlusion in humans. Ann Surg 232, 155-162

ClinicalTrials.gov, National Institutes of Health (NIH), Bethesda, MD, USA. Kennung: NCT01830920. A Study of THR-184 in Patients at Risk of Developing Cardiac Surgery Associated-Acute Kidney Injury (CSA-AKI). https://clinicaltrials.gov/ct2/show/NCT01830920?term=NCT01830920\&rank=1 (Zugriff im April 2016)

ClinicalTrials.gov, National Institutes of Health (NIH), Bethesda, MD, USA. Kennung: NCT01564095. TOP-Study (Tacrolimus Organ Perfusion): Treatment of Ischemia Reperfusion Injury in Marginal Organs With an ex Vivo Tacrolimus Perfusion (TOP).

https://clinicaltrials.gov/ct2/show/NCT01564095?term=NCT01564095\&rank=1 (Zugriff im April 2016)

Crabtree GR, Olson EN (2002): NFAT signaling: choreographing the social lives of cells. Cell 109 Suppl, S67-79

Danesh SM, Villasenor A, Chong D, Soukup C, Cleaver O (2009): BMP and BMP receptor expression during murine organogenesis. Gene Expr Patterns $\underline{9}$, 255-265 
Deepak S, Kottapalli K, Rakwal R, Oros G, Rangappa K, Iwahashi H, Masuo Y, Agrawal G (2007): Real-Time PCR: Revolutionizing Detection and Expression Analysis of Genes. Curr Genomics $\underline{8}$, 234-251

Denton MD, Magee CC, Sayvegh MH (1999): Immunsuppressive strategies in transplantation. Lancet $\underline{353}$, 10831091

Déry MA, Michaud MD, Richard DE( 2005): Hypoxia-inducible factor 1: regulation by hypoxic and non-hypoxic activators. Int J Biochem Cell Biol $\underline{37}, 535-540$

Derynck R, Zhang YE (2003): Smad-dependent and Smad-independent pathways in TGF-beta family signalling. Nature $\underline{425}, 577-584$.

Derynck R, Zhang Y, Feng XH (1998): Smads: transcriptional activators of TGF-beta responses. Cell $\underline{95}$, 737-740

Dewulf N, Verschueren K, Lonnoy O, Morén A, Grimsby S, Vande Spiegle K, Miyazono K, Huylebroeck D, Ten Dijke $P$ (1995): Distinct spatial and temporal expression patterns of two type I receptors for bone morphogenetic proteins during mouse embryogenesis. Endocrinology 136, 2652-2663

DGfN, Deutsche Gesellschaft für Nephrologie (2014): Daten und Fakten zur Nephrologie. http://www.dgfn.eu/presse/downloadbereich.html (Zugriff im September 2015)

DGfN und DTG (2012): Stellungnahme der Deutschen Gesellschaft für Nephrologie und der Deutschen TransplantationsGesellschaft zur Erstattungsfähigkeit der immunsuppressiven Kombination von Tacrolimus mit Mycophenolat Mofetil oder Mycophenolsäure nach Nierentransplantation.

http://www.dgfn.eu/presse/aktuelles/meldungen/artikel/erstattungsfaehigkeit-der-immunsuppressivenkombination-von-tacrolimus-mit-mycophenolat-mofetil-oder.html (Zugriff im September 2015)

Di Giovanni V, Alday A, Chi L, Mishina Y, Rosenblum ND (2011): Alk3 controls nephron number and androgen production via lineage-specific effects in intermediate mesoderm. Development $\underline{138}$, 2717-3727

Dooley S, Hamzavi J, Ciuclan L, Godoy P, Ilkavets I, Ehnert S, Ueberham E, Gebhardt R, Kanzler S, Geier A (2008): Hepatocyte-specific Smad7 expression attenuates TGF-beta-mediated fibrogenesis and protects against liver damage. Gastroenterology $\underline{135}$, 642-659

DSO, Deutsche Stiftung Organtransplantation: Organspende und Transplantation in Deutschland - Jahresbericht 2014. Frankfurt/Main 2015.

http://www.dso.de/uploads/tx_dsodl/JB_2014_Web_1.pdf (Zugriff im September 2015)

Ducy P, Karsenty G (2000): The family of bone morphogenetic proteins. Kidney Int 57, 2207-2214

Dudley AT, Robertson EJ (1997): Overlapping expression domains of bone morphogenetic protein family members potentially account for limited tissue defects in BMP7 deficient embryos. Dev Dyn 208, 349-362

Dudley AT, Lyons KM, Robertson EJ (1995): A requirement for bone morphogenetic protein-7 during development of the mammalian kidney and eye. Genes Dev $\underline{9}, 2795-2807$

Duplay P, Thome M, Hervé F, Acuto O (1994): p56lck interacts via its src homology 2 domain with the ZAP-70 kinase. J Exp Med 179, 1163-1172

Dykxhoorn DM, Novina CD, Sharp PA (2003): Killing the messenger: short RNAs that silence gene expression. Nat Rev Mol Cell Biol 4, 457-67

Eddy AA (1996): Molecular insights into renal interstitial fibrosis. J Am Soc Nephrol $\underline{7}, 2495-2508$

Eddy AA, López-Guisa JM, Okamura DM, Yamaguchi I (2012): Investigating mechanisms of chronic kidney disease in mouse models. Pediatr Nephrol 27, 1233-1247

Eguchi H, Ikuta T, Tachibana T, Yoneda Y, Kawajiri K (1997): A nuclear localization signal of human aryl hydrocarbon receptor nuclear translocator/hypoxia-inducible factor 1beta is a novel bipartite type recognized by the two components of nuclear pore-targeting complex. J Biol Chem $\underline{272}, 17640-17647$

Ekberg H, Tedesco-Silva H, Demirbas A, Vítko S, Nashan B, Gürkan A, Margreiter R, Hugo C, Grinyó JM, Frei U (2007): Reduced exposure to calcineurin inhibitors in renal transplantation. N Engl J Med 357, 2562-2575 
Elbashir SM, Lendeckel W, Tuschl T (2001): RNA interference is mediated by 21- and 22-nucleotide RNAs. Genes Dev $\underline{15}, 188-200$

Engvall E, Perlmann P (1971): Enzyme-linked immunosorbent assay (ELISA). Quantitative assay of immunoglobulin G. Immunochemistry $\underline{8}, 871-874$

ERA-EDTA Registry: ERA-EDTA Registry Annual Report 2013. Academic Medical Center, Department of Medical Informatics, Amsterdam 2015.

http://www.era-edta-reg.org/files/annualreports/pdf/AnnRep2013.pdf (Zugriff im September 2015)

Felgner PL, Gadek TR, Holm M, Roman R, Chan HW, Wenz M, Northrop JP, Ringold GM, Danielsen M (1987): Lipofection: a highly efficient, lipid-mediated DNA-transfection procedure. Proc Natl Acad Sci U S A $\underline{84}$, 74137417

Feng X, Li J, Liu J, Jin M, Liu X, Du H, Zhang L, Sun Z, Li X (2011): Protective effect of FK506 on myocardial ischemia/reperfusion injury by suppression of CaN and ASK1 signaling circuitry. Cardiovasc Toxicol 11, 18-27

Feng XH, Derynck R (1997): A kinase subdomain of transforming growth factor-beta (TGF-beta) type I receptor determines the TGF-beta intracellular signaling specificity. EMBO J $\underline{16}$, 3912-3923

Fire A, Xu S, Montgomery MK, Kostas SA, Driver SE, Mello CC (1998) Potent and specific genetic interference by double-stranded RNA in Caenorhabditis elegans. Nature $\underline{391}, 806-811$

Flechner SM, Kurian SM, Head SR, Sharp SM, Whisenant TC, Zhang J, Chismar JD, Horvath S, Mondala T, Gilmartin $T$ (2004): Kidney transplant rejection and tissue injury by gene profiling of biopsies and peripheral blood lymphocytes. Am J Transplant 4, 1475-1489

Flicek P, Amode MR, Barrell D, Beal K, Billis K, Brent S, Carvalho-Silva D, Clapham P, Coates G, Fitzgerald S (2014): Ensembl 2014. Nucleic Acids Res 42, D749-755

Floege J, Gröne HJ (1995): Progression of renal failure: what is the role of cytokines? Nephrol Dial Transplant $\underline{10}$, 1575-1586

Frei U, Schober-Halstenberg HJ: Nierenersatztherapie in Deutschland: Bericht über die Dialysebehandlung und Nierentransplantation in Deutschland 2006/2007. QuaSi-Niere gGmbH, Berlin 2008.

http://www.bundesverband-niere.de/fileadmin/user_upload/QuaSi-Niere-Bericht_2006-2007.pdf (Zugriff im September 2015)

Furic-Cunko V, Kes P, Coric M, Hudolin T, Kastelan Z, Basic-Jukic N (2015): Expression of bone morphogenetic proteins 4, 6 and 7 is downregulated in kidney allografts with interstitial fibrosis and tubular atrophy. Int Urol Nephrol 47, 1219-1229

Galat A (2013): Functional diversity and pharmacological profiles of the FKBPs and their complexes with small natural ligands. Cell Mol Life Sci $\underline{70}, 3243-3275$

Gassmann M, Grenacher B, Rohde B, Vogel J (2009): Quantifying Western blots: pitfalls of densitometry. Electrophoresis $\underline{30}, 1845-1855$

Godin RE, Robertson EJ, Dudley AT (1998): Role of BMP family members during kidney development. Int J Dev Biol $\underline{43}, 405-411$

Gordon KJ, Blobe GC (2008): Role of transforming growth factor-beta superfamily signaling pathways in human disease. Biochim Biophys Acta 1782, 197-228

Gould SE, Day M, Jones SS, Dorai H. (2002): BMP-7 regulates chemokine, cytokine, and hemodynamic gene expression in proximal tubule cells. Kidney Int $\underline{61}, 51-60$

Grande MT, Sánchez-Laorden B, López-Blau C, De Frutos CA, Boutet A, Arévalo M, Rowe RG, Weiss SJ, López-Novoa JM, Nieto MA (2015): Snail1-induced partial epithelial-to-mesenchymal transition drives renal fibrosis in mice and can be targeted to reverse established disease. Nat Med 21, 989-997

Greenbaum D, Colangelo C, Williams K, Gerstein M (2003): Comparing protein abundance and mRNA expression levels on a genomic scale. Genome Biol $\underline{4}, 117$ 
Greenburg G, Hay ED (1982): Epithelia suspended in collagen gels can lose polarity and express characteristics of migrating mesenchymal cells. J Cell Biol 95, 333-339

Griffith DL, Keck PC, Sampath TK, Rueger DC, Carlson WD (1996):Three-dimensional structure of recombinant human osteogenic protein 1: structural paradigm for the transforming growth factor beta superfamily. Proc Natl Acad Sci U S A $\underline{93}, 878-883$

Griffith JP, Kim JL, Kim EE, Sintchak MD, Thomson JA, Fitzgibbon MJ, Fleming MA, Caron PR, Hsiao K, Navia MA (1995): X-ray structure of calcineurin inhibited by the immunophilin-immunosuppressant FKBP12-FK506 complex. Cell $\underline{82}, 507-522$

Grimm M, Rinaldi M, Yonan NA, Arpesella G, Arizón Del Prado JM, Pulpón LA, Villemot JP, Frigerio M, Rodriguez Lambert JL, Crespo-Leiro MG (2006): Superior prevention of acute rejection by tacrolimus vs. cyclosporine in heart transplant recipients - a large European trial. Am J Transplant $\underline{6}$, 1387-1397

Guo Y, Feng L, Zhou Y, Sheng J, Long D, Li S, Li Y (2015): Systematic review with meta-analysis: HIF-1 $\alpha$ attenuates liver ischemia-reperfusion injury. Transplant Rev (Orlando) 29, 127-134

Haaijman A, Burger EH, Goei SW, Nelles L, ten Dijke P, Huylebroeck D, Bronckers AL (2000): Correlation between ALK-6 (BMPR-IB) distribution and responsiveness to osteogenic protein-1 (BMP-7) in embryonic mouse bone rudiments. Growth Factors $\underline{17}$, 177-192

Hadjipanayi E, Schilling AF (2013): Hypoxia-based strategies for angiogenic induction: the dawn of a new era for ischemia therapy and tissue regeneration. Organogenesis $\underline{9}$, 261-272

Hartwig S, Bridgewater D, Di Giovanni V, Cain J, Mishina Y, Rosenblum ND (2008): BMP receptor ALK3 controls collecting system development. J Am Soc Nephrol 19, 117-124

Hata A, Lagna G, Massagué J, Hemmati-Brivanlou A (1998): Smad6 inhibits BMP/Smad1 signaling by specifically competing with the Smad4 tumor suppressor. Genes Dev 12, 186-197

Haverty TP, Kelly CJ, Hines WH, Amenta PS, Watanabe M, Harper RA, Kefalides NA, Neilson EG (1988): Characterization of a renal tubular epithelial cell line which secretes the autologous target antigen of autoimmune experimental interstitial nephritis. J Cell Biol. 107, 1359-1368

Hayashi H, Abdollah S, Qiu Y, Cai J, Xu YY, Grinnell BW, Richardson MA, Topper JN, Gimbrone MA Jr, Wrana JL (1997): The MAD-related protein Smad7 associates with the TGFbeta receptor and functions as an antagonist of TGFbeta signaling. Cell $\underline{89}, 1165-1173$

Hazen VM, Phan KD, Hudiburgh S, Butler SJ (2001): Inhibitory Smads differentially regulate cell fate specification and axon dynamics in the dorsal spinal cord. Dev Biol $\underline{356}, 566-575$

Hebert MF (1997): Contributions of hepatic and intestinal metabolism and P-glycoprotein to cyclosporine and tacrolimus oral drug delivery. Adv Drug Deliv Rev 27, 201-214

Heinemeyer T, Wingender E, Reuter I, Hermjakob H, Kel AE, Kel OV, Ignatieva EV, Ananko EA, Podkolodnaya OA, Kolpakov FA (1998): Databases on transcriptional regulation: TRANSFAC, TRRD and COMPEL. Nucleic Acids Res 26, 362-367

Heldin CH, Miyazono K, ten Dijke P (1997): TGF-beta signalling from cell membrane to nucleus through SMAD proteins. Nature $\underline{390}, 465-471$

Herpin A, Lelong C, Favrel P (2004): Transforming growth factor-beta-related proteins: an ancestral and widespread superfamily of cytokines in metazoans. Dev Comp Immunol 28, 461-485

Hieronymus H, Lamb J, Ross KN, Peng XP, Clement C, Rodina A, Nieto M, Du J, Stegmaier K, Raj SM (2006): Gene expression signature-based chemical genomic prediction identifies a novel class of HSP90 pathway modulators. Cancer Cell $\underline{10}$, 321-330

Higuchi R, Dollinger G, Walsh PS, Griffith R (1992): Simultaneous amplification and detection of specific DNA sequences. Biotechnology $\underline{10}$, 413-417 
Higuchi R, Fockler C, Dollinger G, Watson R (1993): Kinetic PCR analysis: real-time monitoring of DNA amplification reactions. Biotechnology (N Y) 11, 1026-1030

Hirose K, Morita M, Ema M, Mimura J, Hamada H, Fujii H, Saijo Y, Gotoh O, Sogawa K, Fujii-Kuriyama Y (1996): cDNA cloning and tissue-specific expression of a novel basic helix-loop-helix/PAS factor (Arnt2) with close sequence similarity to the aryl hydrocarbon receptor nuclear translocator (Arnt). Mol Cell Biol 16, 1706-1713

Holdsworth SR, Summers SA (2008): Role of mast cells in progressive renal diseases. J Am Soc Nephrol 19, 22542261

Hruska KA, Guo G, Wozniak M, Martin D, Miller S, Liapis H, Loveday K, Klahr S, Sampath TK, Morrissey J (2000): Osteogenic protein-1 prevents renal fibrogenesis associated with ureteral obstruction. Am J Physiol Renal Physiol $\underline{279}$, F130-143

Humphreys BD, Lin SL, Kobayashi A, Hudson TE, Nowlin BT, Bonventre JV, Valerius MT, McMahon AP, Duffield JS (2010): Fate tracing reveals the pericyte and not epithelial origin of myofibroblasts in kidney fibrosis. Am J Pathol 176, 85-97

Huse M, Chen YG, Massagué J, Kuriyan J (1999): Crystal structure of the cytoplasmic domain of the type I TGF beta receptor in complex with FKBP12. Cell $\underline{96}$, 425-436

Hüser N, Doll D, Altomonte J, Werner M, Kriner M, Preissel A, Thorban S, Matevossian E (2009): Graft preconditioning with low-dose tacrolimus (FK506) and nitric oxide inhibitor aminoguanidine (AGH) reduces ischemia/ reperfusion injury after liver transplantation in the rat. Arch Pharm Res $\underline{32}$, 215-220

Iliodromitis EK, Lazou A, Kremastinos DT (2007): Ischemic preconditioning: protection against myocardial necrosis and apoptosis. Vasc Health Risk Manag $\underline{3}$, 629-637

Imamura T, Takase M, Nishihara A, Oeda E, Hanai J, Kawabata M, Miyazono K (1997): Smad6 inhibits signalling by the TGF-beta superfamily. Nature $\underline{389}, 622-626$

Ishida W, Hamamoto T, Kusanagi K, Yagi K, Kawabata M, Takehara K, Sampath TK, Kato M, Miyazono K. (2000): Smad6 is a Smad1/5-induced smad inhibitor. Characterization of bone morphogenetic protein-responsive element in the mouse Smad6 promoter. J Biol Chem 275, 6075-6079

Ivanac-Janković R, Ćorić M, Furić-Čunko V, Lovičić V, Bašić-Jukić N, Kes P (2015): BMP-7 protrein expression is downregulated in human diabetic nephropathy. Acta Clin Croat 54, 164-168

Iwano M, Plieth D, Danoff TM, Xue C, Okada H, Neilson EG (2002): Evidence that fibroblasts derive from epithelium during tissue fibrosis. J Clin Invest $\underline{110}$, 341-345

Iwasaki K (2007): Metabolism of tacrolimus (FK 506) and recent topics in clinical pharmacokinetics. Drug Metab Pharmacokinet 22, 328-335.

Izumi N, Mizuguchi S, Inagaki Y, Saika S, Kawada N, Nakajima Y, Inoue K, Suehiro S, Friedman SL, Ikeda K (2006): BMP-7 opposes TGF-beta1-mediated collagen induction in mouse pulmonary myofibroblasts through Id2. Am J Physiol Lung Cell Mol Physiol 290, L120-126

Jensen HA, Loukogeorgakis S, Yannopoulos F, Rimpiläinen E, Petzold A, Tuominen H, Lepola P, Macallister RJ, Deanfield JE, Mäkelä T (2011): Remote ischemic preconditioning protects the brain against injury after hypothermic circulatory arrest. Circulation $\underline{123}, 714-721$

Jha V, Garcia-Garcia G, Iseki K, Li Z, Naicker S, Plattner B, Saran R, Wang AY, Yang CW (2013): Chronic kidney disease: global dimension and perspectives. Lancet $\underline{382}, 260-272$

Jia Z, Johnson AC, Wang X, Guo Z, Dreisbach AW, Lewin JR, Kyle PB, Garrett MR (2015): Allelic Variants in Arhgef11 via the Rho-Rock Pathway Are Linked to Epithelial-Mesenchymal Transition and Contributes to Kidney Injury in the Dahl Salt-Sensitive Rat. PLoS One 10, e0132553

John R, Nelson PJ (2007): Dendritic cells in the kidney. J Am Soc Nephrol 18, 2628-2635

Jones CL, Buch S, Post M, McCulloch L, Liu E, Eddy AA (1992): Renal extracellular matrix accumulation in acute puromycin aminonucleoside nephrosis in rats. Am J Pathol 141, 1381-1396 
Ju W, Nair V, Smith S, Zhu L, Shedden K, Song PX, Mariani LH, Eichinger FH, Berthier CC, Randolph A (2015): Tissue transcriptome-driven identification of epidermal growth factor as a chronic kidney disease biomarker. Sci Transl Med 7, 316ra193

Kalluri R, Weinberg RA (2009): The basics of epithelial-mesenchymal transition. J Clin Invest 119, 1420-1428

Kang HM, Ahn SH, Choi P, Ko YA, Han SH, Chinga F, Park AS, Tao J, Sharma K, Pullman J (2015): Defective fatty acid oxidation in renal tubular epithelial cells has a key role in kidney fibrosis development. Nat Med $\underline{21}, 37-46$

Kang Y, Chen CR, Massagué J (2003): A self-enabling TGFbeta response coupled to stress signaling: Smad engages stress response factor ATF3 for Id1 repression in epithelial cells. Mol Cell 11, 915-926

Kapitsinou PP, Haase VH (2015): Molecular mechanisms of ischemic preconditioning in the kidney. Am J Physiol Renal Physiol 309, F821-834

Kaplan B, Meier-Kriesche HU (2004): Renal transplantation: a half century of success and the long road ahead. J Am Soc Nephrol 15, 3270-3271

Kawabata M, Imamura T, Miyazono K (1998): Signal transduction by bone morphogenetic proteins. Cytokine Growth Factor Rev $\underline{9}$, 49-61

KDIGO (Kidney Disease: Improving Global Outcomes) CKD Work Group (2013): KDIGO 2012 Clinical Practice Guideline for the Evaluation and Management of Chronic Kidney Disease. Kidney inter Suppl $\underline{3}$, 1-150

KDIGO (Kidney Disease: Improving Global Outcomes) Transplant Work Group (2009): KDIGO clinical practice guideline for the care of kidney transplant recipients. Am J Transplant 9 Suppl 3, S1-155

Keller CK, Geberth SK: Praxis der Nephrologie. 3. Auflage; Springer Medizin Verlag, Heidelberg 2010

Kershner RP, Fitzsimmons WE (1996): Relationship of FK506 whole blood concentrations and efficacy and toxicity after liver and kidney transplantation. Transplantation $\underline{62}, 920-926$

Kino T, Hatanaka H, Hashimoto M, Nishiyama M, Goto T, Okuhara M, Kohsaka M, Aoki H, Imanaka H (1987): FK506, a novel immunosuppressant isolated from a Streptomyces. I. Fermentation, isolation, and physico-chemical and biological characteristics. J Antibiot (Tokyo) 40 , 1249-1255

Kinoshita K, limuro Y, Otogawa K, Saika S, Inagaki Y, Nakajima Y, Kawada N, Fujimoto J, Friedman SL, Ikeda K (2007): Adenovirus-mediated expression of BMP-7 suppresses the development of liver fibrosis in rats. Gut $\underline{56}$, 706-714

Klahr S, Morrissey J (2002): Obstructive nephropathy and renal fibrosis. Am J Physiol Renal Physiol 283, F861-875

Klee CB, Ren H, Wang X (1998): Regulation of the calmodulin-stimulated protein phosphatase, calcineurin. J Biol Chem 273, 13367-13370

Kleophas W, Reichel H (2007): International study of health care organization and financing: development of renal replacement therapy in Germany. Int J Health Care Finance Econ $\underline{7}$, 185-200

Kondo M, Cubillo E, Tobiume K, Shirakihara T, Fukuda N, Suzuki H, Shimizu K, Takehara K, Cano A, Saitoh M (2004): A role for Id in the regulation of TGF-beta-induced epithelial-mesenchymal transdifferentiation. Cell Death Differ $\underline{10}, 1092-1101$

Kopp JB, Factor VM, Mozes M, Nagy P, Sanderson N, Böttinger EP, Klotman PE, Thorgeirsson SS (1996): Transgenic mice with increased plasma levels of TGF-beta 1 develop progressive renal disease. Lab Invest $\underline{74}$, 991-1003

Korchynskyi O, ten Dijke P (2002): Identification and functional characterization of distinct critically important bone morphogenetic protein-specific response elements in the Id1 promoter. J Biol Chem 277, 4883-4891

Kozak KR, Abbott B, Hankinson O (1997): ARNT-deficient mice and placental differentiation. Dev Biol $\underline{191}, 297-$ 305

Kriz W, Kaissling B, Le Hir M (2011): Epithelial-mesenchymal transition (EMT) in kidney fibrosis: fact or fantasy? J Clin Invest $\underline{121}, 468-474$

Kuncio GS, Neilson EG, Haverty T (1991): Mechanisms of tubulointerstitial fibrosis. Kidney Int $\underline{39}, 550-556$ 
Labrande C, Velly L, Canolle B, Guillet B, Masmejean F, Nieoullon A, Pisano P (2006): Neuroprotective effects of tacrolimus (FK506) in a model of ischemic cortical cell cultures: role of glutamate uptake and FK506 binding protein 12 kDa. Neuroscience 137, 231-239

Laemmli UK (1970): Cleavage of structural proteins during the assembly of the head of bacteriophage T4. Nature $\underline{227}, 680-685$

Lamb J, Crawford ED, Peck D, Modell JW, Blat IC, Wrobel MJ, Lerner J, Brunet JP, Subramanian A, Ross KN (2006): The Connectivity Map: using gene-expression signatures to connect small molecules, genes, and disease. Science $\underline{313}, 1929-1935$

Laskow DA, Vincenti F, Neylan JF, Mendez R, Matas A (1996): An open-label, concentration-ranging trial of FK506 in primary kidney transplantation: a report of the United States Multicenter FK506 Kidney Transplant Group. Transplantation $\underline{62}, 900-905$

LeBleu VS, Taduri G, O'Connell J, Teng Y, Cooke VG, Woda C, Sugimoto H, Kalluri R (2013): Origin and function of myofibroblasts in kidney fibrosis. Nat Med $\underline{19}, 1047-1053$

Levin A (2003): Clinical epidemiology of cardiovascular disease in chronic kidney disease prior to dialysis. Semin Dial $\underline{16}, 101-105$

Li L, Zepeda-Orozco D, Black R, Lin F (2010): Autophagy is a component of epithelial cell fate in obstructive uropathy. Am J Pathol $\underline{176}, 1767-1778$

Li L, Wang ZV, Hill JA, Lin F (2014): New autophagy reporter mice reveal dynamics of proximal tubular autophagy. J Am Soc Nephrol 25, 305-315

Li MO, Wan YY, Sanjabi S, Robertson AL, Flavell RA (2006): Transforming growth factor- $\beta$ regulation of immune responses. Annu Rev Immunol 24, 99-146

Liang S, Cuevas G, Tizani S, Salas T, Liu H, Li B, Habib SL (2013): Novel mechanism of regulation of fibrosis in kidney tumor with tuberous sclerosis. Mol Cancer $\underline{12}, 49$

Lin J, Patel SR, Cheng X, Cho EA, Levitan I, Ullenbruch M, Phan SH, Park JM, Dressler GR (2005): Kielin/chordinlike protein, a novel enhancer of BMP signaling, attenuates renal fibrotic disease. Nat Med 11, 387-393

Lin S, Lin Y, Nery JR, Urich MA, Breschi A, Davis CA, Dobin A, Zaleski C, Beer MA, Chapman WC (2014): Comparison of the transcriptional landscapes between human and mouse tissues. Proc Natl Acad Sci U S A $\underline{111}$, 1722417229

Lin X, Sime PJ, Xu H, Williams MA, LaRussa L, Georas SN, Guo J (2011): Yin yang 1 is a novel regulator of pulmonary fibrosis. Am J Respir Crit Care Med $\underline{183}, 1689-1697$

Liu Y (2004): Epithelial to mesenchymal transition in renal fibrogenesis: pathologic significance, molecular mechanism, and therapeutic intervention. J Am Soc Nephrol 15, 1-12

Liu Y (2006): Renal fibrosis: new insights into the pathogenesis and therapeutics. Kidney Int $\underline{69}, 213-217$

Lo RS, Chen YG, Shi Y, Pavletich, NP, Massagué J (1998): The L3 loop: a structural motif determining specific interactions between SMAD proteins and TGF-beta receptors. EMBO J 17, 996-1005

López-Rovira T, Chalaux E, Massagué J, Rosa JL, Ventura F (2002): Direct binding of Smad1 and Smad4 to two distinct motifs mediates bone morphogenetic protein-specific transcriptional activation of Id1 gene. J Biol Chem $\underline{277}, 3176-3185$

Lovisa S, LeBleu VS, Tampe B, Sugimoto H, Vadnagara K, Carstens JL, Wu CC, Hagos Y, Burckhardt BC, PentchevaHoang T (2015): Epithelial-to-mesenchymal transition induces cell cycle arrest and parenchymal damage in renal fibrosis. Nat Med 21, 998-1009

Lu C, Bentley WE, Rao G (2004): A high-throughput approach to promoter study using green fluorescent protein. Biotechnol Prog $\underline{20}, 1634-1640$ 
Luo G, Hofmann C, Bronckers AL, Sohocki M, Bradley A, Karsenty G (1995): BMP-7 is an inducer of nephrogenesis, and is also required for eye development and skeletal patterning. Genes Dev $\underline{9}, 2808-2820$

Lysaght MJ (2002): Maintenance dialysis population dynamics: current trends and long-term implications. J Am Soc Nephrol 13 Suppl 1, S37-40

Ma D, Lim T, Xu J, Tang H, Wan Y, Zhao H, Hossain M, Maxwell PH, Maze M (2009): Xenon preconditioning protects against renal ischemic-reperfusion injury via HIF-1alpha activation. J Am Soc Nephrol 20, 713-720

Malek TR, Bayer AL (2004): Tolerance, not immunity, crucially depends on IL-2. Nat Rev Immunol $\underline{4}$, 665-674

Maltepe E, Schmidt JV, Baunoch D, Bradfield CA, Simon MC (1997): Abnormal angiogenesis and responses to glucose and oxygen deprivation in mice lacking the protein ARNT. Nature $\underline{386}, 403-407$

Maric I, Poljak L, Zoricic S, Bobinac D, Bosukonda D, Sampath KT, Vukicevic S (2003): Bone morphogenetic protein-7 reduces the severity of colon tissue damage and accelerates the healing of inflammatory bowel disease in rats. J Cell Physiol 196, 258-264

Massagué J (1990): The transforming growth factor-beta family. Annu Rev Cell Biol $\underline{6}$, 597-641

Massagué J (2000): How cells read TGF-beta signals. Nat Rev Mol Cell Biol $\underline{1}$, 169-178

Mayer B (2012): Disease platforms als Grundlage integrativer Analyse in der nephrologischen Forschung. NephroScript 1, 34-38.

http://www.niere-hochdruck.at/fileadmin/Dokumente/Wir_ueber_Uns/Nephro_1_2012_online.pdf (Zugriff im September 2015)

Merrill JP, Murray JE, Harrison JH, Guild WR (1956): Successful homotransplantation of the human kidney between identical twins. J Am Med Assoc 160, 277-282

Methven S, MacGregor MS (2009): Clinical management of chronic kidney disease. Clin Med (Lond) $\underline{9}, 269-272$

Mishina Y, Suzuki A, Ueno N, Behringer RR (1995): Bmpr encodes a type I bone morphogenetic protein receptor that is essential for gastrulation during mouse embryogenesis. Genes Dev $\underline{9}, 3027-3037$

Möller A, Iwasaki K, Kawamura A, Teramura Y, Shiraga T, Hata T, Schäfer A, Undre NA (1999): The disposition of $14 \mathrm{C}$-labeled tacrolimus after intravenous and oral administration in healthy human subjects. Drug Metab Dispos 27, 633-636

Morrissey J, Hruska K, Guo G, Wang S, Chen Q, Klahr S (2002): Bone morphogenetic protein-7 improves renal fibrosis and accelerates the return of renal function. J Am Soc Nephrol 13 Suppl 1, S14-21

Motazed R, Colville-Nash P, Kwan JT, Dockrell ME (2008): BMP-7 and proximal tubule epithelial cells: activation of multiple signaling pathways reveals a novel anti-fibrotic mechanism. Pharm Res $\underline{25}, 2440-2446$

Müller GA, Markovic-Lipkovski J, Frank J, Rodemann HP (1992): The role of interstitial cells in the progression of renal diseases. J Am Soc Nephrol 2, S198-205

Müller GA, Zeisberg M, Strutz F (2000): The importance of tubulointerstitial damage in progressive renal disease. Nephrol Dial Transplant 15 Suppl 6, 76-77

Mullis KB, Faloona FA (1987): Specific synthesis of DNA in vitro via a polymerase-catalyzed chain reaction. Methods Enzymol 155, 335-350

Murakami G, Watabe T, Takaoka K, Miyazono K, Imamura T (2003): Cooperative inhibition of bone morphogenetic protein signaling by Smurf1 and inhibitory Smads. Mol Biol Cell $\underline{14}, 2809-2817$

Murry CE, Jennings RB, Reimer KA (1986): Preconditioning with ischemia: a delay of lethal cell injury in ischemic myocardium. Circulation $\underline{74}, 1124-1136$

Naesens M, Kuypers DR, Sarwal M (2009): Calcineurin inhibitor nephrotoxicity. Clin J Am Soc Nephrol 4, 481-508

Nagase K, Iwasaki K, Nozaki K, Noda K (1994): Distribution and protein binding of FK506, a potent immunosuppressive macrolide lactone, in human blood and its uptake by erythrocytes. J Pharm Pharmacol 46, 113-117 
Nakagawa S, Nishihara K, Miyata H, Shinke H, Tomita E, Kajiwara M, Matsubara T, lehara N, Igarashi Y, Yamada H (2015): Molecular Markers of Tubulointerstitial Fibrosis and Tubular Cell Damage in Patients with Chronic Kidney Disease. PLoS One 10, e0136994

Nakao A, Afrakhte M, Morén A, Nakayama T, Christian JL, Heuchel R, Itoh S, Kawabata M, Heldin NE, Heldin CH (1997): Identification of Smad7, a TGFbeta-inducible antagonist of TGF-beta signalling. Nature $\underline{389}, 631-635$

Nebel M: Kosten der Nierenersatztherapie. In: Dialyseverfahren in Theorie und Praxis; hrsg. v. Hörl WH, Wanner C; 6. Auflage; Georg Thieme Verlag, Stuttgart 2003, 619-629

Neuwirt H, Perco P, Kainz A, Mühlberger I, Leierer J, Braniff SJ, Mayer B, Mayer G, Rudnicki M (2014): A 3-biomarker-panel predicts renal outcome in patients with proteinuric renal diseases. BMC Med Genomics $\underline{7}, 75$

Ng YY, Huang TP, Yang WC, Chen ZP, Yang AH, Mu W, Nikolic-Paterson DJ, Atkins RC, Lan HY (1998): Tubular epithelial-myofibroblast transdifferentiation in progressive tubulointerstitial fibrosis in $5 / 6$ nephrectomized rats. Kidney Int 54, 864-876

Norton JD (2000): ID helix-loop-helix proteins in cell growth, differentiation and tumorigenesis. J Cell Sci $\underline{113}$, 3897-3905

Nykänen A, Haley B, Zamore PD (2001): ATP requirements and small interfering RNA structure in the RNA interference pathway. Cell. 107, 309- 321

Oka T, Yoshimura N (1996): Immunosuppression in organ transplantation. Jpn J Pharmacol 71, 89-100

Olert J, Wiedorn KH, Goldmann T, Kühl H, Mehraein Y, Scherthan H, Niketeghad F, Vollmer E, Müller AM, MüllerNavia J (2001): HOPE fixation: a novel fixing method and paraffin-embedding technique for human soft tissues. Pathol Res Pract 197, 823-826.

Ozkaynak E, Rueger DC, Drier EA, Corbett C, Ridge RJ, Sampath TK, Oppermann H (1990): OP-1 cDNA encodes an osteogenic protein in the TGF-beta family. EMBO J $\underline{9}$, 2085-2093

Ozkaynak E, Schnegelsberg PN, Oppermann H. (1991): Murine osteogenic protein (OP-1): high levels of mRNA in kidney. Biochem Biophysical Res Commun 179, 116-123

Palkowitsch L, Marienfeld U, Brunner C, Eitelhuber A, Krappmann D, Marienfeld RB (2011): The Ca2+-dependent phosphatase calcineurin controls the formation of the Carma1-Bcl10-Malt1 complex during T cell receptor-induced NF-kappaB activation. J Biol Chem, 286, 7522-7534

Pascal LE, True LD, Campbell DS, Deutsch EW, Risk M, Coleman IM, Eichner L, Nelson PS, Liu AY (2008): Correlation of mRNA and protein levels: cell type-specific gene expression of cluster designation antigens in the prostate. BMC Genomics $\underline{9}, 246$

Peters H, Border WA, Noble NA (1998): Targeting TGF- $\beta$ overexpression in renal disease: maximizing the antifibrotic action of angiotensin II blockade. Kidney Int 54, 1570-1580

Pirsch JD, Miller J, Deierhoi MH, Vincenti F, Filo RS (1997): A comparison of tacrolimus (FK506) and cyclosporine for immunosuppression after cadaveric renal transplantation. FK506 Kidney Transplant Study Group. Transplantation $\underline{63}, 977-983$

Poland A, Knutson JC (1982): 2,3,7,8-tetrachlorodibenzo-p-dioxin and related halogenated aromatic hydrocarbons: examination of the mechanism of toxicity. Annu Rev Pharmacol Toxicol 22, 517-554

Potthoff F, Münscher C, Berendes A : Jahresbericht Datenanalyse Dialyse für den Gemeinsamen Bundesausschuss. Berichtsjahr: 2011. Medical Netcare GmbH, Münster 2012.

https://www.g-ba.de/downloads/17-98-3294/2012-08-16_QSD-RL_Datenanalyst-Jahresbericht_2011_Bericht.pdf (Zugriff im September 2015)

Pratschke S, Eder M, Heise M, Nadalin S, Pascher A, Schemmer P, Scherer MN, Ulrich F, Wolters H, Jauch KW (2013): Protocol TOP-Study (tacrolimus organ perfusion): a prospective randomized multicenter trial to reduce ischemia reperfusion injury in transplantation of marginal liver grafts with an ex vivo tacrolimus perfusion. Transplant Res $\underline{2}, 3$ 
PubChem Substance Database, National Center for Biotechnology Information (NCBI), Bethesda, MD, USA. https://pubchem.ncbi.nlm.nih.gov/substance/210280598\#section=2D-Structure (Zugriff im September 2015)

Radonić A, Thulke S, Mackay IM, Landt O, Siegert W, Nitsche A (2004): Guideline to reference gene selection for quantitative real-time PCR. Biochem Biophys Res Commun 313, 856-862

Rahimi AR, Leof EB (2007): TGF- $\beta$ Signaling: A tale of two responses. J Cell Biochem 102, 593-608

Reich HN, Tritchler D, Cattran DC, Herzenberg AM, Eichinger F, Boucherot A, Henger A, Berthier CC, Nair V, Cohen CD (2010): A molecular signature of proteinuria in glomerulonephritis. PLoS One $\underline{5}$, e13451

Reynolds A, Leake D, Boese Q, Scaringe S, Marshall WS, Khvorova A (2004): Rational siRNA design for RNA interference. Nat Biotechnol 22, 326-330

Roberts AB, Lamb LC, Newton DL, Sporn MB, De Larco JE, Todaro GJ (1980): Transforming growth factors: isolation of polypeptides from virally and chemically transformed cells by acid/ethanol extraction. Proc Natl Acad Sci U S A $\underline{77}, 3494-3498$

Roider HG, Kanhere A, Manke T, Vingron M (2007): Predicting transcription factor affinities to DNA from a biophysical model. Bioinformatics $\underline{23}, 134-141$

Rossant J, McKerlie C (2001): Mouse-based phenogenomics for modelling human disease. Trends Mol Med $\underline{7}$, 502-507

Roth RB, Hevezi P, Lee J, Willhite D, Lechner SM, Foster AC, Zlotnik A (2006): Gene expression analyses reveal molecular relationships among 20 regions of the human CNS. Neurogenetics $\underline{7}, 67-80$

Rowlands JC, Gustafsson JA (1997): Aryl hydrocarbon receptor-mediated signal transduction. Crit Rev Toxicol 27 , $109-134$

Rulten SL, Kinloch RA, Tateossian H, Robinson C, Gettins L, Kay JE (2006):The human FK506-binding proteins: characterization of human FKBP19. Mamm Genome 17, 322-331

Rung J, Brazma A (2013): Reuse of public genome-wide gene expression data. Nat Rev Genet 14, 89-99

Ruzinova MB, Benezra R (2003): Id proteins in development, cell cycle and cancer. Trends Cell Biol $\underline{13}$, 410-418

Ryan MJ, Johnson G, Kirk J, Fuerstenberg SM, Zager RA, Torok-Storb B (1994): HK-2: an immortalized proximal tubule epithelial cell line from normal adult human kidney. Kidney Int $\underline{45}$, 48-57

Saika S, Ikeda K, Yamanaka O, Sato M, Muragaki Y, Ohnishi Y, Ooshima A, Nakajima Y, Namikawa K, Kiyama H (2004): Transient adenoviral gene transfer of Smad7 prevents injury-induced epithelial-mesenchymal transition of lens epithelium in mice. Lab Invest $\underline{84}$, 1259-1270

Saiki RK, Gelfand DH, Stoffel S, Scharf SJ, Higuchi R, Horn GT, Mullis KB, Erlich HA (1988): Primer-directed enzymatic amplification of DNA with a thermostable DNA polymerase. Science $\underline{239}, 487-491$

Sampath TK, Maliakal JC, Hauschka PV, Jones WK, Sasak H, Tucker RF, White KH, Coughlin JE, Tucker MM, Pang $\mathrm{RH}$ (1992): Recombinant human osteogenic protein-1 (hOP-1) induces new bone formation in vivo with a specific activity comparable with natural bovine osteogenic protein and stimulates osteoblast proliferation and differentiation in vitro. J Biol Chem 267, 20352-20362

Sandy P, Ventura A, Jacks T (2005): Mammalian RNAi: a practical guide. Biotechniques $\underline{39}$, 215-224

Schenborn E, Groskreutz D (1999): Reporter gene vectors and assays. Mol Biotechnol $\underline{13}$, 29-44

Schmid H, Boucherot A, Yasuda Y, Henger A, Brunner B, Eichinger F, Nitsche A, Kiss E, Bleich M, Gröne HJ (2006): Modular activation of nuclear factor-kappaB transcriptional programs in human diabetic nephropathy. Diabetes 55, 2993-3003

Schwartz R, Stack J, Dameshek W (1958): Effect of 6-mercaptopurine on antibody production. Proc Soc Exp Biol Med $\underline{99}, 164-167$

Semenza GL, Agani F, Booth G, Forsythe J, Iyer N, Jiang BH, Leung S, Roe R, Wiener C, Yu A (1997): Structural and functional analysis of hypoxia-inducible factor 1 . Kidney Int $\underline{51}, 553-555$ 
Shi Y, Massagué J (2003): Mechanisms of TGF-beta signaling from cell membrane to the nucleus. Cell $\underline{113}, 685-$ 700

Shi Y, Seto E, Chang LS, Shenk T (1991): Transcriptional repression by YY1, a human GLI-Krüppel-related protein, and relief of repression by adenovirus E1A protein. Cell $\underline{67}, 377-388$

Sikder HA, Devlin MK, Dunlap S, Ryu B, Alani RM (2003): Id proteins in cell growth and tumorigenesis. Cancer Cell $\underline{3}, 525-530$

Sioud M (2005): Induction of inflammatory cytokines and interferon responses by double-stranded and singlestranded siRNAs is sequence-dependent and requires endosomal localization. J Mol Biol 348, 1079-1090

Sledz CA, Williams BR (2005): RNA interference in biology and disease. Blood 106, 787-794

Smith CL, Hager GL (1997): Transcriptional regulation of mammalian genes in vivo. A tale of two templates. J Biol Chem 272, 27493-27496

Smith PK, Krohn RI, Hermanson GT, Mallia AK, Gartner FH, Provenzano MD, Fujimoto EK, Goeke NM, Olson BJ, Klenk DC (1985): Measurement of protein using bicinchoninic acid. Anal Biochem 150, 76-85

Soboleski MR, Oaks J, Halford WP (2005): Green fluorescent protein is a quantitative reporter of gene expression in individual eukaryotic cells. FASEB J $\underline{19}, 440-442$

Sogawa K, Nakano R, Kobayashi A, Kikuchi Y, Ohe N, Matsushita N, Fujii-Kuriyama Y (1995): Possible function of Ah receptor nuclear translocator (Arnt) homodimer in transcriptional regulation. Proc Natl Acad Sci U S A $\underline{92}$, 1936-1940

Soncul H, Oz E, Kalaycioglu S (1999): Role of ischemic preconditioning on ischemia-reperfusion injury of the lung. Chest $\underline{115}, 1672-1677$

Spiekerkoetter E, Tian X, Cai J, Hopper RK, Sudheendra D, Li CG, El-Bizri N, Sawada H, Haghighat R, Chan R (2013): FK506 activates BMPR2, rescues endothelial dysfunction, and reverses pulmonary hypertension. J Clin Invest $\underline{123}, 3600-3613$

Starzl TE, Marchioro TL, Waddell WR (1963): The reversal of rejection in human renal homografts with subsequent development of homograft tolerance. Surg Gynecol Obstet $\underline{117}$, 385-395

Stockwell BR, Schreiber SL (1998): TGF-beta-signaling with small molecule FKBP12 antagonists that bind myristoylated FKBP12-TGF-beta type I receptor fusion proteins. Chem Biol $\underline{5}$, 385-395

St Peter WL (2007): Introduction: chronic kidney disease: a burgeoning health epidemic. J Manag Care Pharm $\underline{13}$, S2-5

Stringa P, Lausada N, Romanin D, Portiansky E, Zanuzzi C, Machuca M, Gondolesi G, Rumbo M (2016): Pretreatment Combination Reduces Remote Organ Damage Secondary to Intestinal Reperfusion Injury in Mice: Followup Study. Transplant Proc $\underline{48}, 210-216$

Strutz F (1995): Novel aspects of renal fibrogenesis. Nephrol Dial Transplant 10, 1526-1532

Strutz F, Neilson EG (1994): The role of lymphocytes in the progression of interstitial disease. Kidney Int Suppl $\underline{45}, \mathrm{~S} 106-110$

Strutz F, Neilson EG (2003): New insights into mechanisms of fibrosis in immune renal injury. Springer Semin Immunopathol 24, 459-476

Strutz F, Zeisberg M, Renziehausen A, Raschke B, Becker V, van Kooten C, Müller G (2001): TGF-beta1 induces proliferation in human renal fibroblasts via induction of basic fibroblast growth factor (FGF-2). Kidney Int $\underline{59}$, 579592

Sugimoto H, Grahovac G, Zeisberg M, Kalluri R (2007): Renal fibrosis and glomerulosclerosis in a new mouse model of diabetic nephropathy and its regression by bone morphogenic protein-7 and advanced glycation end product inhibitors. Diabetes 56, 1825-1833

Sugimoto H, LeBleu VS, Bosukonda D, Keck P, Taduri G, Bechtel W, Okada H, Carlson W Jr, Bey P, Rusckowski M (2012): Activin-like kinase 3 is important for kidney regeneration and reversal of fibrosis. Nat Med 18, 396-404 
Szklarczyk D, Franceschini A, Wyder S, Forslund K, Heller D, Huerta-Cepas J, Simonovic M, Roth A, Santos A, Tsafou KP (2015): STRING v10: protein-protein interaction networks, integrated over the tree of life. Nucleic Acids Res $\underline{43}$, D447-452

Tamaki K, Souchelnytskyi S, Itoh S, Nakao A, Sampath K, Heldin CH, ten Dijke P (1998): Intracellular signaling of osteogenic protein-1 through Smad5 activation. J Cell Physiol 177, 355-363

Tampe B, Tampe D, Müller CA, Sugimoto H, LeBleu V, Xu X, Müller GA, Zeisberg EM, Kalluri R, Zeisberg M (2014): Tet3-mediated hydroxymethylation of epigenetically silenced genes contributes to bone morphogenic protein 7induced reversal of kidney fibrosis. J Am Soc Nephrol 25, 905-912

Tampe D, Zeisberg M (2014): Potential approaches to reverse or repair renal fibrosis. Nat Rev Nephrol $\underline{10}, 226-$ 237

ten Dijke P, Yamashita H, Sampath TK, Reddi AH, Estevez M, Riddle DL, Ichijo H, Heldin CH, Miyazono K (1994): Identification of type I receptors for osteogenic protein-1 and bone morphogenetic protein-4. J Biol Chem 269, 16985-16988

Thrasos Therapeutics, Montreal QC, Kanada: http://www.thrasos.com (Zugriff im September 2015)

Towbin H, Staehelin T, Gordon J (1992): Electrophoretic transfer of proteins from polyacrylamide gels to nitrocellulose sheets: procedure and some applications. 1979. Biotechnology 24, 145-149

Tricot L, Lebbe C, Pillebout E, Martinez F, Legendre C, Thervet E (2005): Tacrolimus-induced alopecia in female kidney-pancreas transplant recipients. Transplantation 80, 1546-1549

Turgut F, Balogun RA, Abdel-Rahman EM (2010): Renin-angiotensin-aldosterone system blockade effects on the kidney in the elderly: benefits and limitations. Clin J Am Soc Nephrol $\underline{5}, 1330-1339$

Tuschl T, Borkhardt A (2002): Small interfering RNAs: a revolutionary tool for the analysis of gene function and gene therapy. Mol Interv $\underline{2}, 158-167$

Urist MR (1965): Bone: formation by autoinduction. Science $\underline{150}, 893-899$

USRDS (United States Renal Data System) 2013 Annual Data Report: Atlas of Chronic Kidney Disease and EndStage Renal Disease in the United States, National Institutes of Health, National Institute of Diabetes and Digestive and Kidney Diseases, Bethesda, MD, 2013.

http://www.usrds.org/atlas13.aspx (Zugriff im September 2015)

Vafadari R, Kraaijeveld R, Weimar W, Baan CC (2013): Tacrolimus inhibits NF-kB activation in peripheral human T cells. PLoS One $\underline{8}$, e60784

Van Duyne GD, Standaert RF, Karplus PA, Schreiber SL, Clardy J (1991): Atomic structure of FKBP-FK506, an immunophilin-immunosuppressant complex. Science 252, 839-842

Vanholder R, Van Laecke S, Glorieux G (2008): What is new in uremic toxicity? Pediatr Nephrol 23, 1211-1221

Van Weemen BK, Schuurs AH (1971): Immunoassay using antigen-enzyme conjugates. FEBS Lett 15, 232-236

Venkataramanan R, Swaminathan A, Prasad T, Jain A, Zuckerman S, Warty V, McMichael J, Lever J, Burckart G, Starzl T (1995): Clinical pharmacokinetics of tacrolimus. Clin Pharmacokinet $\underline{29}, 404-430$

Venkataramanan R, Shaw LM, Sarkozi L, Mullins R, Pirsch J, MacFarlane G, Scheller D, Ersfeld D, Frick M, Fitzsimmons WE (2001): Clinical utility of monitoring tacrolimus blood concentrations in liver transplant patients. J Clin Pharmacol $\underline{41}, 542-551$

Vukicevic S, Kopp JB, Luyten FP, Sampath TK (1996): Induction of nephrogenic mesenchyme by osteogenic protein 1 (bone morphogenetic protein 7). Proc Natl Acad Sci U S A 93, 9021-9026

Vukicevic S, Basic V, Rogic D, Basic N, Shih MS, Shepard A, Jin D, Dattatreyamurty B, Jones W, Dorai H (1998): Osteogenic protein-1 (bone morphogenetic protein-7) reduces severity of injury after ischemic acute renal failure in rat. J Clin Invest 102, 202-214

Wain HM, Bruford EA, Lovering RC, Lush MJ, Wright MW, Povey S (2002): Guidelines for human gene nomenclature. Genomics $\underline{79}$, 464-470. 
Wallemacq PE, Verbeeck RK (2001): Comparative clinical pharmacokinetics of tacrolimus in paediatric and adult patients. Clin Pharmacokinet $\underline{40}$, 283-295

Wallemacq P, Armstrong VW, Brunet M, Haufroid V, Holt DW, Johnston A, Kuypers D, Le Meur Y, Marquet $P$, Oellerich M (2009): Opportunities to optimize tacrolimus therapy in solid organ transplantation: report of the European consensus conference. Ther Drug Monit 31, 139-152

Wang F, Shi S, Zhang R, Hankinson O (2006): Identifying target genes of the aryl hydrocarbon receptor nuclear translocator (Arnt) using DNA microarray analysis. Biol Chem $\underline{387}, 1215-1218$

Wang L, Jirka G, Rosenberg PB, Buckley AF, Gomez JA, Fields TA, Winn MP, Spurney RF (2015): Gq signaling causes glomerular injury by activating TRPC6. J Clin Invest $\underline{125}, 1913-1926$

Wang S, Hirschberg R (2003): BMP7 antagonizes TGF-beta -dependent fibrogenesis in mesangial cells. Am J Physiol Renal Physiol 284, F1006-1013

Wang S, Chen Q, Simon TC, Strebeck F, Chaudhary L, Morrissey J, Liapis H, Klahr S, Hruska KA (2003): Bone morphogenic protein-7 (BMP-7), a novel therapy for diabetic nephropathy. Kidney Int $\underline{63}$, 2037-2049

Wang S, de Caestecker M, Kopp J, Mitu G, Lapage J, Hirschberg R (2006): Renal bone morphogenetic protein-7 protects against diabetic nephropathy. J Am Soc Nephrol 17, 2504-2512

Wang SN, Lapage J, Hirschberg R (2001): Loss of tubular bone morphogenetic protein-7 in diabetic nephropathy. J Am Soc Nephrol 12, 2392-2399

Wang T, Li BY, Danielson PD, Shah PC, Rockwell S, Lechleider RJ, Martin J, Manganaro T, Donahoe PK (1996): The immunophilin FKBP12 functions as a common inhibitor of the TGF beta family type I receptors. Cell $\underline{86}$, 435444

Wangsiripaisan A, Gengaro PE, Edelstein CL, Schrier RW (2001): Role of polymeric Tamm-Horsfall protein in cast formation: oligosaccharide and tubular fluid ions. Kidney Int 59, 932-940

Weiskirchen R, Meurer SK (2013): BMP-7 counteracting TGF-beta1 activities in organ fibrosis. Front Biosci (Landmark Ed) $\underline{18}, 1407-1434$

Wetzel P, Haag J, Câmpean V, Goldschmeding R, Atalla A, Amann K, Aigner T (2006): Bone morphogenetic protein-7 expression and activity in the human adult normal kidney is predominantly localized to the distal nephron. Kidney Int $\underline{70}$, 717-723

Whaley-Connell A, Sowers JR, McCullough PA, Roberts T, McFarlane SI, Chen SC, Li S, Wang C, Collins AJ, Bakris GL (2009): Diabetes mellitus and CKD awareness: the Kidney Early Evaluation Program (KEEP) and National Health and Nutrition Examination Survey (NHANES). Am J Kidney Dis $\underline{53}$, S11-21

Whitelaw ML, Gustafsson JA, Poellinger L (1994): Identification of transactivation and repression functions of the dioxin receptor and its basic helix-loop-helix/PASpartner factor Arnt: inducible versus constitutive modes of regulation. Mol Cell Biol 14, 8343-8355

Willis BC, Borok Z (2007): TGF-beta-induced EMT: mechanisms and implications for fibrotic lung disease. Am J Physiol Lung Cell Mol Physiol 293, L525-534

Wolf G, Mueller E, Stahl RA, Ziyadeh FN (1993): Angiotensin II-induced hypertrophy of cultured murine proximal tubular cells is mediated by endogenous transforming growth factor-beta. J Clin Invest 92, 1366-1372

Woods SL, Whitelaw ML (2002): Differential activities of murine single minded 1 (SIM1) and SIM2 on a hypoxic response element. Cross-talk between basic helix-loop-helix/per-Arnt-Sim homology transcription factors. J Biol Chem 277, 10236-10243

Woroniecka KI, Park AS, Mohtat D, Thomas DB, Pullman JM, Susztak K (2011): Transcriptome analysis of human diabetic kidney disease. Diabetes $\underline{60}, 2354-2369$

Wozney JM, Rosen V, Celeste AJ, Mitsock LM, Whitters MJ, Kriz RW, Hewick RM, Wang EA (1988): Novel regulators of bone formation: molecular clones and activities. Science 242, 1528-1534

Yalow RS, Berson SA (1960): Immunoassay of endogenous plasma insulin in man. J Clin Invest $\underline{39}, 1157-1175$ 
Yamashita H, ten Dijke P, Franzen P, Miyazono K, Heldin CH (1994): Formation of hetero-oligomeric complexes of type I and type II receptors for transforming growth factorbeta. J Biol Chem $\underline{269}$, 20172-20178

Yamashita H, ten Dijke P, Heldin CH, Miyazono K (1996): Bone morphogenetic protein receptors. Bone $\underline{19}, 569-$ 574

Yang CW, Ahn HJ, Han HJ, Kim WY, Li C, Shin MJ, Kim SK, Park JH, Kim YS, Moon IS (2001): Pharmacological preconditioning with low-dose cyclosporine or FK506 reduces subsequent ischemia/reperfusion injury in rat kidney. Transplantation $\underline{72}$, 1753-1759

Yang J, Liu Y (2001): Dissection of key events in tubular epithelial to myofibroblast transition and its implications in renal interstitial fibrosis. Am J Pathol $\underline{159}, 1465-1475$

Yang J, Shultz RW, Mars WM, Wegner RE, Li Y, Dai C, Nejak K, Liu Y (2002): Disruption of tissue-type plasminogen activator gene in mice reduces renal interstitial fibrosis in obstructive nephropathy. J Clin Invest 110, 1525-1538

Yang L, Besschetnova TY, Brooks CR, Shah JV, Bonventre JV (2010): Epithelial cell cycle arrest in G2/M mediates kidney fibrosis after injury. Nat Med $\underline{16}, 535-543,1 p$ following 143

Yang WM, Inouye CJ, Seto E (1995): Cyclophilin A and FKBP12 interact with YY1 and alter its transcriptional activity. J Biol Chem 270, 15187-15193

Yao YL, Liang YC, Huang HH, Yang WM (2011): FKBPs in chromatin modification and cancer. Curr Opin Pharmacol 11, 301-307

Yi SE, Daluiski A, Pederson R, Rosen V, Lyons KM (2000): The type I BMP receptor BMPRIB is required for chondrogenesis in the mouse limb. Development $127,621-630$

Yoon YE, Lee KS, Choi KH, Kim KH, Yang SC, Han WK (2015): Preconditioning strategies for kidney ischemia reperfusion injury: implications of the "time-window" in remote ischemic preconditioning. PLoS One 10, e0124130

Zahir KS, Syed SA, Zink JR, Restifo RJ, Thomson JG (1998): Ischemic preconditioning improves the survival of skin and myocutaneous flaps in a rat model. Plast Reconstr Surg 102, 140-150; discussion 151-152

Zambrowicz BP, Sands AT (2003): Knockouts model the 100 best-selling drugs--will they model the next 100? Nat Rev Drug Discov $\underline{2}, 38-51$

Zeisberg EM, Tarnavski O, Zeisberg M, Dorfman AL, McMullen JR, Gustafsson E, Chandraker A, Yuan X, Pu WT, Roberts AB (2007): Endothelial-to-mesenchymal-transition contributes to cardiac fibrosis. Nat Med 13, $952-961$

Zeisberg M (2006): Bone morphogenic protein-7 and the kidney: current concepts and open questions. Nephrol Dial Transplant 21, 568-573

Zeisberg M, Kalluri R (2004 a): Experimental strategies to reverse chronic renal disease. Blood Purif 22, 440-445

Zeisberg M, Kalluri R (2004 b): The role of epithelial-to-mesenchymal transition in renal fibrosis. J Mol Med (Berl) 82, $175-181$

Zeisberg M, Neilson EG (2009): Biomarkers for epithelial-mesenchymal transitions. J Clin Invest 119, 1429-1437

Zeisberg M, Duffield JS (2010): Resolved: EMT produces fibroblasts in the kidney. J Am Soc Nephrol 21, $1247-$ 1253

Zeisberg M, Bottiglio C, Kumar N, Maeshima Y, Strutz F, Müller GA, Kalluri R (2003 a): Bone morphogenic protein7 inhibits progression of chronic renal fibrosis associated with two genetic mouse models. Am J Physiol Renal Physiol 285, F1060-1067

Zeisberg M, Hanai J, Sugimoto H, Mammoto T, Charytan D, Strutz F, Kalluri R (2003 b): BMP-7 counteracts TGFbeta1-induced epithelial-to-mesenchymal transition and reverses chronic renal injury. Nat Med $\underline{9}, 964-968$

Zeisberg M, Shah AA, Kalluri R (2005): Bone morphogenic protein-7 induces mesenchymal to epithelial transition in adult renal fibroblasts and facilitates regeneration of injured kidney. J Biol Chem 280, 8094-8100

Zeisberg M, Yang C, Martino M, Duncan MB, Rieder F, Tanjore H, Kalluri R (2007): Fibroblasts derive from hepatocytes in liver fibrosis via epithelial to mesenchymal transition. J biol Chem 282, 23337-23347 
Zhao M, Harris SE, Horn D, Geng Z, Nishimura R, Mundy GR, Chen D (2002): Bone morphogenetic protein receptor signaling is necessary for normal murine postnatal bone formation. J Cell Biol 157, 1049-1060

Zuk A, Matlin KS, Hay ED (1989): Type I collagen gel induces Madin-Darby canine kidney cells to become fusiform in shape and lose apical-basal polarity. J Cell Biol 108, 903-919 
„So eine Arbeit wird eigentlich nie fertig, man muss sie für fertig erklären, wenn man nach Zeit und Umständen das Möglichste getan hat."

Johann Wolfgang von Goethe, „Italienische Reise“, 1787

\section{DANKSAGUNG}

Zunächst möchte ich Herrn Prof. Dr. med. Michael Zeisberg für die Überlassung des Dissertationsthemas, die Bereitstellung erforderlicher Materialien und Geräte, die konstruktiven Ratschläge sowie die konstante Betreuung danken.

Mein ausdrücklicher Dank gilt Frau Dr. med Désirée Tampe und Herrn Dr. med. Björn Tampe. Ohne ihr persönliches Engagement, die intensive Unterstützung bei der Planung, Umsetzung und Auswertung der Versuche wäre eine Arbeit in solchem Rahmen nicht möglich gewesen wäre. Weiterhin danke ich für die hervorragende Hilfestellung bei der Verfassung und Korrektur der Dissertation.

Insbesondere danke ich den medizinisch-technischen Assistentinnen Frau Anika Krüger und Frau Sarah Rinkleff für die kompetente Einarbeitung, ihren fachlichen und mentalen Beistand bei der Durchführung vieler Experimente auch außerhalb ihrer regulären Arbeitszeiten sowie den täglichen kollegialen Austausch. Ein weiterer Dank kommt Frau Annika Faust für die allseits reibungslose Organisation ungeliebter externer Modalitäten, vor allem für so manchen außerplanmäßigen Bestellungsauftrag zu. 